\title{
Cu- and Fe-mediated Atom-Transfer Radical Polymerization in Aqueous Solution
}

\author{
Dissertation \\ zur Erlangung des mathematisch-naturwissenschaftlichen Doktorgrades \\ "Doctor rerum naturalium" \\ der Georg-August-Universität Göttingen \\ im Promotionsprogramm GAUSS \\ der Georg-August University School of Science (GAUSS) \\ vorgelegt von \\ Sebastian Smolne \\ aus Ludwigslust
}

Göttingen, 2016 


\section{Betreuungsausschuss}

Prof. Dr. Michael Buback Institut für Physikalische Chemie Georg-August-Universität Göttingen

Prof. Dr. Philipp Vana, MBA Institut für Physikalische Chemie Georg-August-Universität Göttingen

\section{Mitglieder der Prüfungskommission}

\section{Referent}

Prof. Dr. Michael Buback Institut für Physikalische Chemie Georg-August-Universität Göttingen

\section{Korreferent}

Prof. Dr. Philipp Vana, MBA Institut für Physikalische Chemie Georg-August-Universität Göttingen

Weitere Mitglieder der Prüfungskommission

Prof. Dr. Franc Meyer

Prof. Dr. Burkhard Geil

PD Dr. Thomas Zeuch

Dr. Florian Ehlers
Institut für Anorganische Chemie Georg-August-Universität Göttingen

Institut für Physikalische Chemie Georg-August-Universität Göttingen

Institut für Physikalische Chemie Georg-August-Universität Göttingen

Institut für Physikalische Chemie Georg-August-Universität Göttingen

Tag der mündlichen Prüfung: 6. Juni 2016 


\section{Für meine Familie}

Wenn man ein 0:2 kassiert, dann ist das 1:1 nicht mehr möglich.

Satz des Pythagoras Marc-Uwe Kling, die Känguru Chroniken 



\section{Table of Contents}

\section{Introduction}

2 Theoretical Background

2.1 Propagation 9

2.1.1 Dependence on Monomer concentration 9

2.1.2 Size-Exclusion Chromatography 11

2.1.3 PLP-SEC Technique 12

2.2 Termination 13

2.2.1 Chain-length Dependent Termination ${ }^{[62,80]} 13$

2.2.2 SP-PLP-EPR technique 15

2.3 Atom Transfer Radical Polymerization 16

2.3.1 Mechanism of ATRP ${ }^{[6,20,81]} 16$

2.3.2 Kinetics of ATRP 19

2.3.3 The Persistent Radical Effect 20

2.4 Experimental Techniques 22

2.4.1 Fourier-Transform Near-Infrared Spectroscopy 22

2.4.2 Mössbauer spectroscopy 23

2.4.3 EPR spectroscopy 24

2.4.4 Stopped-Flow Injection 25

3 Kinetics of Poly(ethylene glycol) methyl ehter methacrylate

3.1 Propagation rate coefficient by PLP-SEC of Poly(ethylene glycol) methyl ether methacrylate 28

3.1.1 Structural analysis of PLP-SEC curves 28 
3.1.2 Temperature and concentration dependence of $k_{\mathrm{p}} \quad 33$

3.1.3 Dependence of $k_{\mathrm{p}}$ on $\mathrm{NaBr}$ concentration 43

3.2 Termination rate coefficient by SP-PLP-EPR of Poly(ethylene glycol) methyl ether methacrylate $\quad 45$

3.2.1 EPR spectrum of PEGMA 45

3.2.2 Composite-model parameters $\quad 47$

\section{Cu-mediated ATRP}

4.1 Monomer-Free Model System 56

4.1.1 Determination of Kmodel $\quad 57$

4.1.2 Determination of $k_{\text {act }} \quad 65$

4.1.3 Modeling 68

4.2 Kinetics of $\mathrm{Cu}$-mediated ATRP in aqueous solution $\quad 73$

4.2.1 Determination of $k_{\text {deact }} \quad 74$

4.2.2 Determination of KATRP $\quad 79$

4.2.3 Impact on polymerization $\quad 85$

\section{Fe-mediated ATRP}

5.1 Speciation Analysis 96

5.2 Rate coefficients from SP-PLP-EPR analysis 104

5.2.1 Measurement of $k_{\text {deact }}$ via SP-PLP-EPR 105

5.3 Rate coefficients via Stopped-Flow-UV/Vis spectroscopy 115

5.3.1 Determination of $K_{\text {model, }} k_{\text {deact }}$ and $k_{\text {add,Fe }} \quad 115$

$\begin{array}{ll}5.4 & \text { Impact on polymerization } \\ & 125\end{array}$

6 Closing Remarks

\section{Experimental}

$\begin{array}{lll}7.1 & \text { Chemicals } & 133\end{array}$

7.2 PLP-SEC measurements 134

7.2.1 Pulsed-Laser-Polymerization (PLP) 134

7.2.2 Size-Exclusion Chromatography (SEC) 135

7.2.3 Density measurements 135 
7.2.4 Viscosity measurements 136

7.3 Spectroscopic measurements 136

7.3.1 Online FT-Vis/NIR spectroscopy 136

7.3.2 UV/Vis measurements 137

$\begin{array}{lll}\text { 7.3.3 Mössbauer } & 138\end{array}$

7.4 SP-PLP-EPR measurements 138

7.4.1 Sample Preparation 138

$\begin{array}{lll}7.4 .2 & \text { SP-PLP-EPR setup } & 139\end{array}$

7.4.3 SP-PLP-EPR experiment and calibration 139

7.5 Stopped-Flow injected measurements 140

8 Appendix 145

$\begin{array}{ll}\text { Literature } & 171\end{array}$

Danksagung 182 


\section{Summary}

The mechanism and the kinetics of metal-catalyzed radical polymerization were investigated by spectroscopic methods and by PREDICI ${ }^{\circledR}$ simulation. A particular focus was on $\mathrm{Cu}$ - and $\mathrm{Fe}$-mediated atom-transfer radical polymerization (ATRP) in aqueous solution of poly(ethylene glycol)ether methacrylate (PEGMA) and on monomerfree model systems.

The propagation kinetics of PEGMA in aqueous solution were determined between 20 and $77^{\circ} \mathrm{C}$ via PLP-SEC. The significant dependence of $k_{\mathrm{p}}$ on monomer content is due to the difference in the degree by which internal rotations of the transition state for propagation are hindered.

Chain-length-dependent termination was analyzed in terms of the composite model for PEGMA in aqueous solution via SP-PLP-EPR. The termination rate coefficient for two radicals of chain-length unity, $\mathrm{kt}^{1,1}$, scales with the inverse viscosity of the solution prior to polymerization. The composite-model parameters for the short-chain and long-chain regime, $\alpha_{\mathrm{s}}$ and $\alpha_{\mathrm{l}}$, respectively, are independent of water content, whereas the crossover chain length, $i$, decreases toward higher dilution.

$\mathrm{Cu}$-mediated ATRP in aqueous solution of the monomer-free model systems and of PEGMA polymerizations with $\mathrm{CuBr} / 2,2^{\prime}$-bipyridine acting as the catalyst and 2-hydroxyethyl 2-bromoisobutyrate (HEMA-Br) as the initiator were studied via online Vis/NIR spectroscopy. In the monomer-free model system, PEGMA was replaced by poly(ethylene glycol) dimethylether (PEO) to mimic an ATRP situation. The SP-PLP-EPR technique was used for the first time to measure an ATRP deactivation rate coefficient, $k_{\text {deact, }}$ in aqueous solution. Excess $\mathrm{NaBr}$ has been added to the polymerization system to avoid water-assisted dissociation of the $\mathrm{Br}-\mathrm{Cu}$ species.

The activation-deactivation equilibrium constant, KATRP, was measured at different water concentrations. In both the model system and the PEGMA polymerization, KATRP increases by about three orders of magnitude in passing from the bulk monomer toward a water 
environment. Since $k_{\text {deact }}$ is independent of water content, the change in $K_{\text {ATRP }}$ is essential due to the effect of the aqueous environment on the activation rate coefficient, $k_{\text {act. }}$

Kinetic analysis of the model system in conjunction with PREDICI ${ }^{\circledR}$ simulation under variation of $\mathrm{NaBr}$ concentration shows that $\mathrm{NaBr}$ does not affect $k_{\text {act }}$ and $k_{\text {deact, }}$ and thus has no impact on $K_{\text {AtrP. PREDICI }}{ }^{\circledR}$ simulation of the ATRP systems however tells that the concentrations of water and $\mathrm{NaBr}$ influence dispersity and the degree of chain-end functionality. Addition of at least five equivalents salt with respect to the total catalyst concentration are essential for carrying out successful ATRP experiments in aqueous solution.

Fe-mediated RDRP studies were performed with the bio-inspired protoporphyrin IX containing a ferric ion catalyst with an additional axial bromide ligand, Fe/Br-mesohemin-(MPEG500)2. The catalyst was kindly provided by the Matyjaszewski group. ${ }^{[1]}$ The Fe-catalyst was studied by combined Mössbauer and online Vis/NIR spectroscopic analysis for the relevant Fe species. The interplay between ATRP and an organometallic reaction (OM), which includes the reaction of propagating radicals with FeII, may occur depending on the ratio of $\mathrm{Fe}^{\mathrm{II}} / \mathrm{Fe}^{\mathrm{III}}$ concentrations.

The SP-PLP-EPR method was also applied to measure $k_{\text {deact }}$ for the

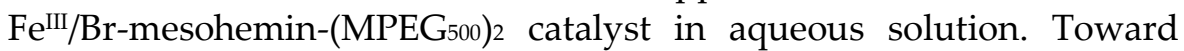
higher water content, $k_{\text {deact }}$ increases by about one order of magnitude from 30 to $90 \mathrm{wt} \% \mathrm{H}_{2} \mathrm{O}$, which is beneficial for ATRP control in diluted aqueous solution.

The activation-deactivation equilibrium and the addition of radicals to the Fe $\mathrm{Fe}^{\mathrm{II}}$ catalyst, $k_{\text {add,Fe, }}$ were measured for the Fe/Br-mesohemin(MPEG500)2 complex via UV/Vis spectroscopy in combination with stopped-flow injection. KATRP was found to be insensitive toward water content in the concentration range between 50 and $70 \mathrm{wt} \% \mathrm{H}_{2} \mathrm{O}$, whereas $k_{\text {add,Fe }}$ exhibits an increase by a factor of five. It could be shown that $k_{\text {deact }}$ exceeds $k_{\text {add,Fe }}$ by almost one order of magnitude, and that the control operates exclusively by ATRP.

The rate coefficients determined within this thesis allow for the prediction of dispersity, chain-end functionality and conversion vs time profiles for $\mathrm{Cu}$ - and Fe-mediated ATRP of PEGMA in bulk and aqueous solutions with the investigated catalysts and with catalysts of similar reactivity. 


\section{1}

\section{Introduction}

Polymeric products continue to replace many conventional materials such as iron, aluminum, glass and wood..$^{[2]}$ Especially in automotive, aviation and high-tech industries polymeric products are favored because of their low specific weight, high resistance to corrosion and mostly cheaper fabrication and processing. ${ }^{[2,3]}$ Aside the usage in the heavy industry, polymeric materials are also of growing importance for optical data chips, coatings, and medical applications. The majority of industrially produced polymers, e.g., polyethylene (PE) and polystyrene (PS), are prepared by conventional radical polymerization.

The so-obtained polymers exhibit no chain-end functionality and broad molar-mass distributions, which restricts the possibility to achieve polymeric materials with complex architecture and topology. Such precisely tailored polymers with targeted properties may, however, be synthesized via reversible deactivation radical polymerization (RDRP). ${ }^{[4-6]}$ Such methods are based on an activationdeactivation equilibrium, in which the growing radical is either in the deactivated "dormant" state or in the active state where chain growth may occur. RDRPs provide access to next-generation specialty polymers, additives and materials. The most known RDRP methods are atom-transfer radical polymerization (ATRP), ${ }^{[6-10]}$ reversible additionfragmentation chain-transfer (RAFT) polymerization, ${ }^{[11-16]}$ nitroxide- 
mediated polymerization (NMP), ${ }^{[17]}$ stable-radical-mediated polymerization (SRMP), ${ }^{[18]}$ and organometallic radical polymerization (OMRP). ${ }^{[19]}$

Several RDRPs are industrially licensed including applications as drug delivery systems, self-healing materials, coatings, adhesives, surfactants, dispersants, lubricants, gels, thermoplastic elastomers, nanocomposites, and electronic materials. ${ }^{66,18,20-24]}$ Enormous progress has been achieved in recycling and reducing the amount of metal catalysts, which promotes the industrial interest RDRPs.

The present thesis primarily focuses on the mechanism and kinetics of ATRP in aqueous solution. The ATRP technique has been developed independently by Matyjaszewski[ ${ }^{[25]}$ and Sawamoto ${ }^{[26]}$ in 1995. Mechanistically, ATRP is similar to the transition-metal-catalyzed atomtransfer radical addition (ATRA) or Kharasch-addition. ${ }^{[27-29]}$ In ATRP, an organic radical is released by halogen transfer from an alkylhalide under the action of transition-metal catalyst. Via reverse transfer of the halogen atom, the radical species is deactivated.

ATRP is a robust and versatile RDRP method, which has been used for polymerization of a wide range of monomers in bulk, in solution and in heterogeneous systems. ${ }^{[6,30]}$ ATRP in aqueous solution appears to be even more attractive, as water is non-toxic, cheap, and environmentally benign. Moreover, ATRP in aqueous solution should enable faster polymerization rate as compared to organic solvents. ${ }^{[20,31,32]}$ The enhanced rate is associated with a higher activation-deactivationequilibrium constant. Catalysts of high activity may be used in combination with special ATRP techniques, such as ARGET, ICAR, or eATRP, which allow for a significant lowering of the metal concentration. ${ }^{[33-35]}$ The associated low catalyst levels are also desirable because of toxicity concerns and cost reduction.

Cu-mediated ATRP has been extensively studied in organic solvents. ${ }^{[34-44]}$ A variety of ligands has been used for Cu-mediated ATRP. They allow for the effective tuning of catalytic activity and the application toward a wide range of monomers. ${ }^{[8,36]}$ Kinetic studies in aqueous solution are however rare and focus on electrochemical investigations or extrapolation of kinetic data measured in organic solvents toward the polarity of water. ${ }^{[43,45-47]}$ That there are so few kinetic studies in aqueous solution is due to the enhanced complexity of $\mathrm{Cu}$-mediated ATRP induced by side reactions of the catalyst with water 
and by the dependence of the propagation rate on the monomer concentration in aqueous solution.

An attractive alternative to the Cu-mediated ATRP is the Femediated ATRP because of the lower toxicity concerns and the broad availability of iron. ${ }^{[48,49]}$ Only very poor knowledge exists about Femediated ATRP in aqueous solution so far. ${ }^{[1,50-54]}$ The present thesis aims to providing accurate kinetic data on Fe-based ATRP in aqueous solution, which may allow for evaluation of the potential of this novel type of RDRP.

The reversible deactivation of radicals in Fe-based ATRP is mediated by an $\mathrm{Fe}^{\mathrm{III}}$ catalyst. The reaction of radicals with $\mathrm{Fe}^{\mathrm{II}}$ is relevant in Femediated organometallic radical polymerizations (OMRP), but may also contribute to the ATRP scheme. ${ }^{[5,19,49]}$ Experimental and computational studies into MMA polymerization showed that both ATRP and organometallic reactions may operate simultaneously. ${ }^{[19,48,55,56]}$ Investigations into $\alpha$-diimine iron complexes showed that the ligand may affect the dominating polymerization mechanism. With electrondonating groups ATRP is favored, whereas electron-withdrawing groups prefer the reaction via instable organometallic species resulting in $\beta$-hydrogen elimination. ${ }^{[48,57,58]}$ The interplay of ATRP and organometallic reactions of Fe-based catalyst in aqueous solution has not been investigated in literature before.

In the present study, spectroscopic techniques will be used to investigate the mechanism and kinetics of $\mathrm{Cu}$ - and Fe-based RDRP. For monomer-free model systems, as well as for actual polymerization systems of slow reaction rate, time-resolved UV/Vis/NIR spectroscopy is used. ${ }^{[57,59-61]}$ For very fast reactions, UV/Vis spectroscopy is carried out in conjunction with stopped-flow injection. Electron paramagnetic resonance (EPR) spectroscopy has turned out to be a valuable tool for the investigations into the kinetics of radical polymerization by which the type and concentration of radical species may be reliably measured. ${ }^{62-65]}$ In conjunction with single-pulse-pulsed laser polymerization (SP-PLP) highly time-resolved EPR spectroscopy has become a powerful technique for kinetic measurements of fast reaction steps such as radical-radical termination or ATRP deactivation. ${ }^{[62,66,67]}$ For Fe-based RDRP, ${ }^{57} \mathrm{Fe}$ Mössbauer spectroscopy is helpful to provide information on spin state and oxidation state and to distinguish between the participating iron species. ${ }^{[57,58,68]}$ All these techniques will be applied 
in the current study toward elucidating detailed ATRP kinetics in aqueous solution.

The kinetic studies will be extended up to high pressure to gain further mechanistic insight. For Fe-mediated ATRPs it has been reported that, depending on the ligand system, the activation-deactivationequilibrium constant, KATRP, changes with pressure. ${ }^{[57,69,70]}$ The reported high pressure data for $\mathrm{Cu}$ systems exhibit a significantly enhanced KATRP upon increasing pressure and thus a higher polymerization rate. ${ }^{60,61]}$ This rate acceleration is not accompanied by a higher dispersity of the polymer. ${ }^{[60,61]}$ The improved livingness of such high pressure ATRPs has been used to synthesize high molar-mass polymethacrylates and polystrenes.

The present study deals with the in-depth investigation of the mechanism and kinetics of metal-catalyzed RDRPs and focuses on $\mathrm{Cu}$ and Fe-mediated ATRP. Both catalyst systems will be examined in a monomer-free model system as well as during actual polymerizations. The study provides the first kinetic measurements of KATRP and the deactivation rate coefficient in aqueous solution for $\mathrm{Cu}$ - as well as for Fe-mediated ATRP. Wherever possible, the experiments will be accompanied by simulations with the program package PREDICI ${ }^{\circledR}$.

For the investigation of the ATRP system, the propagation rate coefficient, $k_{\mathrm{p}}$, and the composite-model parameters for termination of the monomer under investigation are required. Therefore, the propagation kinetics of the water-soluble monomer poly(ethylene glycol) methyl ether methacrylate (PEGMA) will be studied in section 3 in the absence of any metal catalyst. The dependence of $k_{\mathrm{p}}$ on monomer concentration will be determined with pulsed laser polymerization in combination with size-exclusion chromatography (PLP-SEC). The composite-model parameters for termination will be deduced via the SP-PLP-EPR technique.

Section 4 addresses the investigation of $\mathrm{Cu}$-mediated ATRP with the $\mathrm{CuBr} / 2,2$ '-bipyridine catalyst. The relevant reactions will be examined by FT-Vis/NIR spectroscopy and by SP-PLP-EPR spectroscopy within a wide range of monomer-solvent compositions. To obtain further mechanistic insight into KATRP via the reaction volumes, the $\mathrm{Cu}$ mediated ATRP is studied up to 2000 bar.

Section 5 deals with mechanistic and kinetic investigations into the 
porphyrin-based Fe catalysts recently developed by Simakova et $a .^{[1]}$ The relevant Fe species will be examined by ${ }^{57} \mathrm{Fe}$ Mössbauer as well as by UV/Vis spectroscopy. In addition, the relevant ATRP parameters, $k_{\text {act, }}$ $k_{\text {deact }}$ and KATRP will be determined via SP-PLP-EPR, and UV/Vis spectroscopy in conjunction with stopped-flow injection. The spectroscopic techniques will also be applied to capture the potential interplay of OM reactions and ATRP equilibria. 
Introduction 


\section{2}

Theoretical Background

\subsection{Propagation}

The propagation describes the reaction of monomer molecules, $\mathrm{M}$, with a radical, $\mathrm{R} \cdot{ }_{n}$, with $n$-numbers of monomer units resulting in new radical $\mathrm{R}_{n+1}$.

$$
\mathrm{R}_{n}^{\cdot}+\mathrm{M} \stackrel{k_{\mathrm{p}}}{\rightarrow} \mathrm{R}_{n+1}^{\cdot}
$$

The rate of consumption of monomer is described by:

$$
-\frac{\mathrm{d}[\mathrm{M}]}{\mathrm{d} t}=k_{\mathrm{p}} \cdot[\mathrm{M}] \cdot\left[\mathrm{R}^{\bullet}\right]
$$

\subsubsection{Dependence on Monomer concentration}

The propagation may be assumed to be a chemical controlled reaction. The absolute value of $k_{\mathrm{p}}$ is determined by the partition functions and the Gibbs energies of the reactants and of the activated 
complex. Detailed investigation of the propagation rate coefficient in polar solvents, especially water, revealed a dependency of $k_{\mathrm{p}}$ on the initial monomer concentration. ${ }^{[71-77]}$

The increase in $k_{\mathrm{p}}$ might be caused by a higher monomer concentration in the vicinity of the propagating radical, by a lower activation energy in water or by a higher pre-exponential Arrhenius factor.

In case of polymerizations in aqueous solution with good watersoluble monomers, a higher monomer concentration in the vicinity of the radical does not explain the increase in $k_{\mathrm{p}}$. This assumption requires an enormously large concentration gradient. Especially at highly diluted systems, all monomers would have been located in the direct vicinity of the propagation radical.

A variation of the activation energy of $k_{\mathrm{p}}$ has also been investigated for methacrylic acid (MAA) and acrylic acid (AA). ${ }^{[72,75,76]}$ It has been found that the activation energy is more or less insensitive to a variation of monomer concentration. However, slight changes of the activation energy cannot be ruled out.

The variation of $k_{\mathrm{p}}$ may be assigned to a change in the preexponential factor, which is composed by the partition function per volume for the reactants, $\tilde{q}_{M}$ and $\tilde{q}_{R}$, and for the activated complex, $\tilde{q}^{\ddagger}$ the Eyring-Equation:

$$
k_{\mathrm{p}}=\kappa \cdot \frac{k_{\mathrm{B}} \cdot T}{h_{\mathrm{p}}} \cdot \frac{\tilde{q}^{\ddagger}}{\tilde{q}_{\mathrm{M}} \cdot \tilde{q}_{\mathrm{R}}} \cdot \exp \left(-\frac{E_{0}}{k_{\mathrm{B}} \cdot T}\right)
$$

where $\kappa$ is the transmission coefficient, $h_{\mathrm{P}}$ the Planck constant and $E_{0}$ the difference of zero-point energies of the reactants of the transition state.

The pre-exponential factor is determined by the geometry of the rotating groups in the reactants and the activated complex as well as the rotational potentials of the relevant internal motions of the activated complex - the propagating center. ${ }^{[78]}$ Strong interactions of monomer molecules with the activated complex may result in a hindrance of the internal rotational and vibrational motions of the activated complex via intermolecular interactions. The lower internal rotational mobility leads to a reduced pre-exponential factor and thus a lower $k_{\mathrm{p}}$. 


\subsubsection{Size-Exclusion Chromatography}

Size-exclusion chromatography (SEC) is a technique to separate molecules mainly according to their hydrodynamic volume. In SEC a diluted polymer is passed through a column that contains a porous material. The separation is based on the diffusion of the polymer coils into the different sized pores of the stationary phase. Polymers with a low-molar-mass and small hydrodynamic volume will spend more time in the column than polymers with a high-molar-mass and high hydrodynamic volume as more pores are accessible. After separation, the relative concentration of the chains can be detected by different methods, e.g., absorption of UV-light or refractive index (RI).

The retention times depend on the experimental conditions such as polymer type, column type, flow rate, etc. Since the separation is by size and not by molar mass, the SEC setup has to be calibrated to obtain the molar mass of the polymer under investigation. Calibration standards are only available for a limited number of polymers. Without such standards, the molar-mass distribution can be estimated via a universal calibration.

To use a universal calibration, the SEC setup has to be calibrated with a standard. After calibration, the MMD of the polymer can calculated via the Kuhn-Mark-Houwink-Sakurada equation, which describes the correlation of the intrinsic viscosity, [ $\eta]$, and relative molecular mass, $\mathrm{K}$ and a are the Kuhn-Mark-Houwink-Sakurada parameters.

$$
[\eta]=K \cdot M_{\mathrm{r}}^{\mathrm{a}}
$$

Usually the intrinsic viscosity can be described by the following equation as the product of the hydrodynamic volume, $V_{\mathrm{h}}$, and the molar mass, $M$.

$$
[\eta]=\frac{2.5 \cdot N_{\mathrm{A}}}{V_{\mathrm{h}} \cdot M}
$$

The combination of the two Equations 2.4 and 2.5, and the 
knowledge of the Kuhn-Mark-Houwink-Sakurada parameters for the polymer used for calibration and for the polymer under investigation allow for the desired calculation of molar-mass via equation:

$$
\operatorname{lgM}_{\mathrm{r}, \mathrm{P}}=\frac{1}{1+a_{\mathrm{p}}} \cdot \lg \frac{K_{\mathrm{St}}}{K_{\mathrm{P}}}+\frac{1+a_{\mathrm{St}}}{1+a_{\mathrm{P}}} \cdot \operatorname{lgM}_{\mathrm{r}, \mathrm{St}}
$$

with the subscript $\mathrm{P}$ denoting the polymer under investigation and $\mathrm{St}$ the polymer used as the calibration standard.

\subsubsection{PLP-SEC Technique}

The PLP-SEC combines the pulsed-laser-polymerization with the size-exclusion chromatography. The PLP-SEC is the recommended technique by the IUPAC to determine propagation rate coefficients.

In PLP-SEC experiments, a mixture of monomer, photoinitiator and optionally of a solvent is irradiated by a sequence of very short laser pulses at a constant repetition rate, $v_{\text {rep}}$, and thus at a constant time interval, to. Each laser pulse generates almost instantaneously initiator radicals which start the chain growth by adding to the monomer. Because of the high radical concentration produced by each laser pulse, termination of the growing radicals occurs right after their formation by one of the subsequent laser pulses. In an ideal PLP-SEC experiment, multimodal molar-mass distributions (MMDs) are obtained with individual maxima resulting from the preferential termination of the macroradicals after multiples of $t$.

Between two laser pulses the polymer growths. The kinetic chain length, $L$, reached during a growth time, $t_{0}$, is usually best identified with the point of inflection (POI) on the low-molecular-mass side of the PLP-induced Peaks. ${ }^{[79]}$ For macroradicals which do not experience chain transfer or other side reactions, $L$ is given by the following equation:

$$
L=k_{\mathrm{p}} \cdot[\mathrm{M}] \cdot t_{0}
$$

The occurrence of additional POI's in the MMD at multiples of $L$ is 
an important internal consistency criterion for reliable $k_{\mathrm{p}}$ evaluation.

\subsection{Termination}

Termination is characterized by the reaction of two radicals. The radicals can react either by combination or disproportionation. The ratio of both termination modes is mainly monomer dependent. Highly substituted and bulky monomers favor the termination via disproportionation. In this case, the two radicals react to an unsaturated and saturated polymer species without change in chain length. In case of less steric monomers the termination occurs via combination of two radicals to one polymer species with the sum of chain length of each radical.

Combination:

$$
\mathrm{R}_{\mathrm{i}}^{\bullet}+\mathrm{R}_{\mathrm{j}} \stackrel{k_{\mathrm{t}, \text { combination }}}{\longrightarrow} \mathrm{P}_{\mathrm{i}+\mathrm{j}}
$$

Disproportionation:

$$
\mathrm{R}_{\mathrm{i}}^{\bullet}+\mathrm{R}_{\mathrm{j}} \stackrel{k_{\mathrm{t}, \text { disproportionation }}}{\longrightarrow} \mathrm{P}_{\mathrm{i}}^{=}+\mathrm{P}_{\mathrm{j}}^{\mathrm{H}}
$$

The termination rate is described by the following equation:

$$
\begin{gathered}
\frac{\mathrm{dc}_{\mathrm{R}}}{\mathrm{d} t}=-2 \cdot k_{\mathrm{t}} \cdot c_{\mathrm{R}}^{2} \\
k_{\mathrm{t}}=k_{\mathrm{t}, \text { combination }}+k_{\mathrm{t}, \text { disproportionation }}
\end{gathered}
$$

\subsubsection{Chain-length Dependent Termination ${ }^{[62,80]}$}

During a radical polymerization there are macroradicals with different chain lengths present. The longer the chain length, the higher is the hydrodynamic radius and thus the lower is the diffusion coefficient. 
This relationship can be expressed by the Stokes-Einstein equation:

$$
D_{i}=\frac{k_{\mathrm{B}} \cdot T}{6 \cdot \pi \cdot r_{i} \cdot \eta}
$$

where $D_{\mathrm{i}}$ is the diffusion coefficient for macromolecular species with a chain length $i, k_{\mathrm{B}}$ is the Boltzmann constant, $T$ the temperature, $r_{\mathrm{i}}$ the hydrodynamic radius for macromolecular species with a chain length $i$ and $\eta$ is the viscosity of the reaction mixture.

For small macroradicals, the termination rate coefficient for chainlength unity, $k_{\mathrm{t}^{1}, 1}$, is supposed to be controlled by center-of-mass diffusion. Thus the associated diffusion rate coefficient $k_{\text {diff }}$ may be expressed by the Smoluchowski equation:

$$
k_{\mathrm{t}}^{1,1}=k_{\mathrm{diff}}=4 \cdot \pi \cdot P_{\mathrm{Spin}} \cdot N_{\mathrm{A}} \cdot\left(D_{\mathrm{A}} \cdot D_{B}\right) \cdot R_{\mathrm{c}}
$$

where $P_{\text {spin }}$ is the probability of encounter involving a singlet electron pair, $N_{\mathrm{A}}$ the Avogadro constant, $D_{\mathrm{A}}$ and $D_{\mathrm{B}}$ are the diffusion coefficients of species $\mathrm{A}$ and $\mathrm{B}$, and $R_{\mathrm{c}}$ is the capture radius of the radicals.

Since the termination of short macroradicals is diffusion controlled, the termination rate coefficient depends on the chain length $i$ and $j$ of the associated radicals and may be described by $k^{\mathrm{i}, \mathrm{j},}$, the power-law exponent $\alpha$ and $k_{\mathrm{t}^{1,1}}$.

$$
k_{\mathrm{t}}^{\mathrm{i}, \mathrm{j}}=\frac{1}{2} \cdot k_{\mathrm{t}}^{1,1} \cdot\left(\frac{1}{i^{\alpha}}+\frac{1}{j^{\alpha}}\right)
$$

In case of laser-induced polymerization all radicals are generated simultaneously and have the same chain length at the same time. Therefore, Equation 2.12 is simplified to following expression:

$$
k_{\mathrm{t}}^{\mathrm{i}, \mathrm{i}}=k_{\mathrm{t}}^{1,1} \cdot\left(i^{-\alpha}\right)
$$

However, this simple equation does not consider that power-law 
exponent $\alpha$ change with the chain length. To overcome this problem, Smith et al. introduced the following equations for short-chain radicals $\mathrm{i} \leq i_{\text {c }}$ and long-chain radicals $i \geq i_{\text {c. }} i_{\text {c }}$ is the so-called crossover chainlength at which point the diffusion controlled polymerization transfers to the segmental diffusion controlled polymerization.

$$
\begin{gathered}
k_{\mathrm{t}}^{\mathrm{i}, \mathrm{i}}=k_{\mathrm{t}}^{1,1} \cdot\left(i^{-\alpha_{s}}\right), \quad i \leq i_{\mathrm{c}} \\
k_{\mathrm{t}}^{\mathrm{i}, \mathrm{i}}=k_{\mathrm{t}}^{1,1} \cdot\left(i_{c}\right)^{-\alpha_{s}+\alpha_{l}} \cdot i^{-\alpha_{l}}, \quad i \geq i_{\mathrm{c}}
\end{gathered}
$$

\subsubsection{SP-PLP-EPR technique}

The SP-PLP-EPR technique allows for high time-resolved and precise measurement of the radical concentration after single pulse laser initiation. The high time resolution of the EPR is well suited for the measurement of chain-length dependent termination, especially for short-chain radicals.

Because of the fast initiation and simultaneous propagation of the radicals, the length of propagation chains is proportional to the time $t$ after laser pulsing.

$$
i=k_{\mathrm{p}} \cdot[\mathrm{M}] \cdot t
$$

The combination of the Equations 2.8, 2.14 and 2.16 and subsequent integration leads to the following expression for the radical concentration for the chain-length dependent termination:

$$
\frac{c_{\mathrm{R}}^{0}}{c_{\mathrm{R}}(t)}-1=\frac{2 \cdot k_{\mathrm{t}}^{1,1} \cdot c_{\mathrm{R}}^{0} \cdot t_{p}^{\alpha}}{1-\alpha} t^{1-\alpha}
$$

Where $t_{\mathrm{p}}$ denotes the characteristic time for a propagation step $\left([\mathrm{M}] \cdot k_{\mathrm{p}}\right)^{-1}$. Via a double logarithmic plot of Equation 2.17, the measured radical concentration results in linear plot with two different slopes. The intersect of the two slopes denotes the crossover chain length $i_{\text {c. The }}$ 
slope yields 1- $\alpha$ and thus an access to composite-model exponents.

Equation 2.16 does not consider the right chain-length for very short radicals. Therefore, Russel et al. proposed a more precise analysis of the chain length:

$$
i=k_{\mathrm{p}} \cdot[\mathrm{M}] \cdot t+1
$$

Similar to Equation 2.17, the combination of Equation 2.8, 2.14 and 2.16 yields following more precise expression for the determination of the composite-model parameter:

$$
\frac{c_{\mathrm{R}}^{0}}{c_{\mathrm{R}}(t)}-1=\frac{2 \cdot k_{\mathrm{t}}^{1,1} \cdot c_{\mathrm{R}}^{0} \cdot\left(\left(k_{\mathrm{p}} \cdot[\mathrm{M}] \cdot t+1\right)^{1-\alpha_{s}}-1\right)}{k_{\mathrm{p}} \cdot[\mathrm{M}] \cdot\left(1-\alpha_{s}\right)}, \quad i \leq i_{\mathrm{c}}
$$

\subsection{Atom Transfer Radical Polymerization}

\subsubsection{Mechanism of ATRP ${ }^{[6,20,81]}$}

The kinetics of ATRP is superimposed on a conventional radical polymerization scheme. The ATRP mechanism is shown in Scheme Scheme 2.1. Even though ATRP has been performed with a series of transition metals, the study in hand focusses on $\mathrm{Fe}$ - and $\mathrm{Cu}$-mediated ATRP. In metal-catalyzed ATRP, the radical propagation occurs contemporaneously with a reversible deactivation of radicals. The deactivation is mediated by $\mathrm{Fe}^{\mathrm{III}}$ or $\mathrm{Cu}^{\mathrm{II}}\left(\mathrm{Mt}^{2+1} / \mathrm{L}_{n}-X\right)$ and the metal is reduced to one oxidation state to $\mathrm{Fe}^{\mathrm{II}}$ or $\mathrm{Cu}^{\mathrm{I}}\left(\mathrm{Mt}^{z} / \mathrm{L} n\right)$, respectively, with simultaneous formation of an alkyl halide. The activation rate coefficient, kact, describes the rate of formation of the transient radical, $\mathrm{R}^{\cdot}$, whereas the rate coefficient, $k_{\text {deact, }}$ quantifies the rate of formation of the alkyl halide, R-X. The ratio of these two rate coefficients describes the ATRP equilibrium constanst, $K_{\mathrm{ATRP}}=k_{\text {act }} / k_{\text {deact. }}$. 


$$
\mathrm{Mt}^{\mathrm{z} / \mathrm{L}_{n}}+\mathrm{R}-\mathrm{X} \underset{k_{\text {deact }}}{\stackrel{k_{\text {act }}}{=} \mathrm{Mt}^{\mathrm{z}+1} / \mathrm{L}_{n}-\mathrm{X}+\mathrm{R} \overbrace{}^{k_{\mathrm{p}}}}
$$

Scheme 2.1: Mechanism of Fe- or Cu-mediated ATRP; $\mathrm{Mt}^{\mathrm{z}} / \mathrm{L}_{n}$ represents the Fe or $\mathrm{Cu}$ catalyst in the lower oxidation state and $\mathrm{Mt}^{\mathrm{z}+1} / \mathrm{L}_{n}-\mathrm{X}$ the Fe or $\mathrm{Cu}$ catalyst in the higher oxidation state with the transferred halide, R-X refers to dormant alkyl halide species, $\mathrm{R} \cdot$ to the propagating radical, $\mathrm{M}$ to monomer, $k_{\mathrm{t}}$ the termination rate coefficient and $k_{\mathrm{p}}$ to the propagation rate coefficient. The activation and deactivation rate coefficients are described by $k_{\text {act }}$ and $k_{\text {deact, }}$ respectively.

In ATRP as well as in all radical polymerizations, radical-radical termination cannot be avoided. Each termination step yields to the accumulation of the deactivator $\mathrm{Fe}^{\mathrm{III}}$ - or $\mathrm{Cu}^{\mathrm{II}}$-species, the so-called Persistent Radical Effect (PRE). The accumulation of the deactivator species slows down the polymerization rate. Moreover, termination leads also to a lower degree of chain-end functionality.

By properly selecting the reaction conditions, the amount of terminated chains can be lowered, as well as a high degree of control and livingness can be achieved. To match the reaction conditions to the high number of potential ATRP catalyst and initiators, various ATRP procedures have been invented. These procedures can be described by different initiation methods or different methods to reduce or reverse the accumulation of the persistent radical. A few methodologies are explained in the following.

A "normal" ATRP is initiated by the reaction of lower oxidative catalyst, e.g., $\mathrm{Fe}^{\mathrm{II}}$ or $\mathrm{Cu}^{\mathrm{I}}$ with an alkyl halide which is usually of chain length unity and a monomeric unit. The structure of the alkyl halide may be close to the structure of the monomer. To ensure an efficient initiation, the formed radicals by the activation step should exhibit the same reactivity as the radicals generated from the growing chain. This method can be used for accessing more complex polymer architectures 
such as star polymers by using multifunctional chain initiators. However, this method is mainly suited for non-oxygen sensitive catalysts. Moreover, this technique is not suited for high active catalysts because of the accumulation of persistent radical.

In reverse ATRP (R-ATRP), the alkyl halide and the catalyst in the lower oxidation state are produced in equal amounts in situ via the decomposition of an radical initiator, for example an azo initiator. The initiator decomposition should be fast at the desired polymerization conditions to provide a fast reduction of the higher oxidative catalyst and to enable an immediate initiation of the chain-growth reaction. For fast initiation photoinitiators as well as thermal initiators may be used. This method is favored by the use of the stable oxidation state of the catalyst and is less sensitive to oxygen.

Simultaneous Revers \& Normal Initiation (SR\&NI) ATRP combines the advantages of normal and R-ATRP. The catalyst is reduced in situ by a thermal initiator. The majority of growing chains is then initiated analogue to the normal ATRP. SR\&NI ATRP may be operated with substoichiometric amounts of catalyst to alkyl halide.

In Activators Generated by Electron Transfer (AGET) ATRP, reducing agents are used to generate in situ the catalyst in the lower oxidation state. Because of the usage of a reducing agent, the formation of new growing chains as a byproduct of reduction process with a thermal radical initiator can be ruled out. As in SR\&NI ATRP the initiator type and amounts can be selected independently.

The techniques R-ATRP, SR\&NI, and ARGET ATRP are based on a rapid and single reduction of the catalyst in the higher oxidation state. This rapid reduction may result in a high radical concentration and subsequent radical-radical termination thus leads to the accumulation of the persistent radical and a simultaneous loss of the activator species. The accumulation of the persistent radical results also in a lower radical concentration and thus a slower polymerization rate. A continuous generation of the activator species may be desirable to increase the equilibrium concentration of growing radicals.

In Initiators for Continuous Activator Regeneration (ICAR) ATRP a thermal radical initiator is added to the polymerization solution which decomposes slowly during the polymerization and progressively reduces the catalyst in the higher oxidation state. The ATRP initiation occurs by an alkyl halide. The regenerative concept of the catalyst in the 
lower oxidation state allows for a reduction of the used catalyst concentration to a ppm level. However, the slow initiator decomposition results in the formation of a background polymer, which increases the dispersity of the polymer.

In Activators ReGenerated by Electron Transfer (ARGET) ATRP, the thermal radical initiator is replaced by reducing agent that constantly regenerates the lower oxidation state of the catalyst. This method strongly reduces the formation of background polymer.

The newest method is the $\boldsymbol{e A T R P}$ in which the reduction of the metal catalyst is realized by an electrochemical potential. This method allows a very precise reduction rate of the catalyst by change the electrical current.

The different initiation methods will be addressed throughout the present work. The normal and reverse ATRP are most suited for kinetic studies because of the absence of background initiation and unknown reduction mechanism during an ARGET ATRP. However, ICAR and ARGET ATRP are very attractive techniques for the polymer synthesis due to the lower catalyst concentration and high livingness. These key features may also important for cost reduction for industrial use.

\subsubsection{Kinetics of ATRP}

The polymerization rate in ATRP under equilibrium conditions depends on the size of $K_{\text {ATRP }}$ as well as on the concentration of the activator catalyst, $\mathrm{Mt}^{\mathrm{Z}} / \mathrm{L}$, the deactivator species $\mathrm{Mt}^{\mathrm{Z}+1} / \mathrm{L}-\mathrm{X}$, and the alkyl halide, $R-X$, as described in the following equation:

$$
R_{\mathrm{P}}=-\frac{\mathrm{d}[\mathrm{M}]}{\mathrm{d} t}=k_{\mathrm{p}} \cdot[\mathrm{M}] \cdot\left[\mathrm{R}^{\bullet}\right]=k_{\mathrm{p}} \cdot[\mathrm{M}] \cdot K_{\mathrm{ATRP}} \cdot \frac{\left[\mathrm{Mt}^{\mathrm{z}} / \mathrm{L}\right][\mathrm{R}-\mathrm{X}]}{\left[\mathrm{Mt}^{\mathrm{z}+1} / \mathrm{L}-\mathrm{X}\right]}
$$

Based on Equation 2.20 KatRP may be determined by measuring the polymerization rate, the concentrations of the associated catalyst, the alkyl halide species and the monomer concentration (for details see chapter 4.2.2). 
The degree of polymerization, $D P$, of the polymer synthesized via ATRP may be calculated by the ratio of consumed monomer, $[\mathrm{M}]_{0} \cdot$ conv, to the initial concentration of the alkyl halide. The number average molar mass of the polymer, $M n$, may be estimated by the product of $D P$ and the molar mass of the monomer.

$$
D P=\frac{[\mathrm{M}]_{0} \cdot \operatorname{conv}}{[\mathrm{R}-\mathrm{X}]_{0}}
$$

A well-controlled ATRP results in low dispersities, $Đ=M_{w} / M_{n}$, and needs sufficient concentration of the ATRP deactivator. The disperisity may be predicted with Equation 2.22. The dispersity decreases with conversion, towards smaller initiator concentration and with decreasing ratio of $k_{\mathrm{p}}$ and $k_{\text {deact. }}$

$$
\mathrm{Ð}=\frac{M_{w}}{M_{n}}=1+\frac{1}{D P}+\left(\frac{[\mathrm{R}-\mathrm{X}]_{0} \cdot k_{\mathrm{p}}}{k_{\text {deact }} \cdot\left[\mathrm{Mt}^{\mathrm{z}+1} / \mathrm{L}-\mathrm{X}\right]}\right) \cdot\left(\frac{2}{\operatorname{conv}}-1\right)
$$

Besides a narrow molar mass distribution of the polymer, it is also very important to obtain a polymer with a high degree of chain-end functionality (CEF). The chain-end functionality allows for a further ATRP polymerization to achieve more complex polymer architectures. Since, radical-radical termination cannot be avoided in ATRP, the degree of CEF decreases with higher conversion and higher termination rate. The loss of CEF can be described with the following equation where $[\mathrm{T}]$ is the concentration of dead chains without a halogen endgroup.

$$
[T]=2 k_{\mathrm{t}} \cdot\left[R^{\bullet}\right]^{2} \cdot t=\frac{2 k_{\mathrm{t}} \cdot \mathrm{d} \ln (1-\operatorname{conv})^{2}}{k_{\mathrm{p}}{ }^{2} \cdot \mathrm{d} t}
$$

\subsubsection{The Persistent Radical Effect}

In ATRPs without a regenerative concept of the catalyst, termination of radicals results in the accumulation of the persistent radical, i.e., the 
catalyst in the higher oxidation state capped with a halogen. This accumulation is called the Persistent Radical Effect (PRE). To describe the PRE for ATRP and to estimate the activation-deactivation equilibrium constant, Fischer introduced the so-called $F([Y])$-function (Equation $2.24)$. In order to remain consistent with previous works, $[\mathrm{I}]_{0}$ represents $[\mathrm{R}-\mathrm{X}]_{0},[\mathrm{C}]_{0}$ refers to $\left[\mathrm{Mt}^{\mathrm{z}} / \mathrm{L}\right]$, and $[\mathrm{Y}]$ to $\left[\mathrm{Mt}^{\mathrm{z}+1} / \mathrm{L}-\mathrm{X}\right]$.

$$
F([\mathrm{Y}])=\frac{\left([\mathrm{C}]_{0}\right)^{2}}{3\left([\mathrm{C}]_{0}-[\mathrm{Y}]\right)^{3}}-\frac{[\mathrm{C}]_{0}}{\left([\mathrm{C}]_{0}-[\mathrm{Y}]\right)^{2}}+\frac{1}{\left([\mathrm{C}]_{0}-[\mathrm{Y}]\right)}
$$

Equation 2.24 is only valid for equimolar concentration of [C]0 and $[\mathrm{I}] 0$, and less reactive catalysts. Therefore, Tang et al. introduced a modified $F([Y])$-function, which also holds for the non-equimolar case and for highly reactive catalyst.

$$
\begin{gathered}
F([\mathrm{Y}])=\left(\frac{[\mathrm{I}]_{0}[\mathrm{C}]_{0}}{[\mathrm{C}]_{0}-[\mathrm{I}]_{0}}\right)^{2}\left(\frac{1}{[\mathrm{C}]_{0}^{2}\left([\mathrm{I}]_{0}-[\mathrm{Y}]\right)}+\frac{2}{[\mathrm{I}]_{0}[\mathrm{C}]_{0}\left([\mathrm{C}]_{0}-[\mathrm{I}]_{0}\right)}\right. \\
\left.\cdot \ln \left(\frac{[\mathrm{I}]_{0}-[\mathrm{Y}]}{[\mathrm{C}]_{0}-[\mathrm{Y}]}\right)+\frac{1}{[\mathrm{I}]_{0}^{2}\left([\mathrm{C}]_{0}-[\mathrm{Y}]\right)}\right) \\
F([\mathrm{Y}])=2 \cdot k_{\mathrm{t}} \cdot K_{\text {model }}^{2} \cdot t+c^{\prime}
\end{gathered}
$$

The $F([Y])$-function can only be applied in case of normal, reverse SR\&NI or AGET ATRP, in which the activation-deactivation equilibrium can be reached. This equation does not consider the continuous reduction of the persistent radical. Therefore, the $F([Y])$ function is typically determined from normal ATRP procedures. The time-dependent concentrations of the persistent radical species may be measured via online UV/Vis or Vis/NIR spectroscopy as detailed in chapter 4 and 5.3.

By plotting the $F([Y])$-function versus time, the equilibrium constant KatRP can be determined from the slope. The estimation of KATRP requires the knowledge of termination rate coefficient, $k_{\mathrm{t}}$. To avoid chain-length dependent variation of $k_{\mathrm{t}}$, it is favorable to estimate KATRP via a monomer-free model system.

The termination rate coefficient in a monomer-free model system may be estimated via the assumption that the termination is accessible 
by the diffusion controlled limit of the reaction $\left(k_{\mathrm{t}} \mathrm{D}\right)$. The detailed derivation of the following equation is described elsewhere. $k_{\mathrm{t}}^{\mathrm{D}}$ may be estimated from reciprocal viscosity of the solution.

$$
k_{\mathrm{t}}^{\mathrm{D}}=\frac{R \cdot T}{3 \cdot \eta(T, p)}
$$

\subsection{Experimental Techniques}

\subsubsection{Fourier-Transform Near-Infrared Spectroscopy}

The Fourier-transform near-infrared (FT-NIR) spectroscopy is a powerful technique to determine a near-infrared spectrum of chemical substances. A scanning interferometer splits a beam of light into at least two components and then recombines these with a variable phase difference. The most common interferometer is a continuous-wave Michelson interferometer. After determination of the temporal coherence of the resulting beam, the raw data in the time domain are converted into frequency-domain data by Fourier-transformation.

Like every optical spectroscopy, the signal intensity is directly proportional to the concentration of the investigated substance and can be described by the Lambert-Beer's law:

$$
A(\tilde{v})=\log \frac{I_{0}}{I}=\varepsilon(\tilde{v}) \cdot c \cdot d
$$

Where $\mathrm{A}(\tilde{v})$ is the absorbance at a specific wavenumber, $(\tilde{v})$. The concentration of the substance is denoted with $c$, the optical path length is $d$ and the extinction coefficient for a specific wavenumber is $\varepsilon(\tilde{v})$.

The linearity of the Lambert-Beer's law has been checked for all detectors within the spectral range of interest as detailed in refs. ${ }^{[82]}$ 


\subsubsection{Mössbauer spectroscopy}

Mössbauer spectroscopy is based on the recoilless nuclear resonance absorption of $\gamma$-radiation by atomic nuclei bound in a solid phase. The most common form is the Mössbauer absorption spectroscopy, where a solid sample is exposed to a beam of gamma radiation and a detector measures the intensity of the beam after passing through the sample. The gamma-ray source needs to be of the same element as the sample nuclei, e.g. ${ }^{57} \mathrm{Fe}$. The source for ${ }^{57} \mathrm{Fe} \gamma$-radiation consists of ${ }^{57} \mathrm{Co}$, which decays by electron capture to an excited state of ${ }^{57} \mathrm{Fe}$, which in turn decays to a ground state emitting a gamma-ray of the appropriate energy. Because of the difference in chemical environments, the nuclear energy levels of the sample are shifted in different ways. These energy shifts results in large changes in absorbance, and the sample is no longer in resonance with the $\gamma$-radiation of the source. To bring the two nuclei back into resonance, the energy of the gamma ray is slightly changed by using the Doppler effect.

Shown in Figure 2.1 is an exemplary Mössbauer absorbance spectrum with the characteristic parameters. The isomer shift, $\delta / \mathrm{mm} \mathrm{s}^{-1}$, provides direct information on the oxidation state and spin state and may provide information about the ligand sphere of the investigated nuclei. The quadrupole splitting, $\Delta E_{\mathrm{Q}}$, a doublet of the resonance line occurs in case of unsymmetrical charge distribution of $\mathrm{d}$ electrons. The peak area of the Mössbauer spectrum is proportional to the relative concentrations of the associated species in case that the relaxation rates and Lamb Mössbauer factors are identical - which they are in most cases. The line width, $\Gamma$, is determined at the half maximum. 


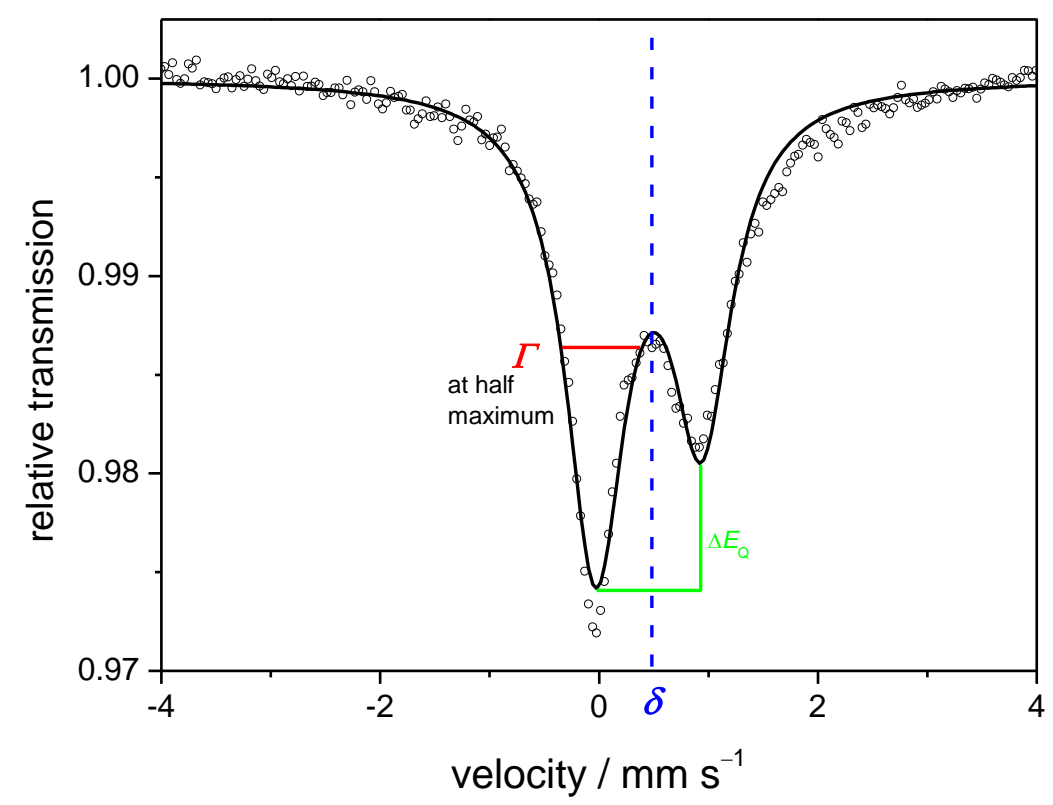

Figure 2.1: Mössbauer spectrum of $\mathrm{Fe}$ III/Cl-mesohemin-(MPEG500)2 in bulk solution recorded at $13 \mathrm{~K}$. The Mössbauer doublet is characterized by the isomer shift, $\delta / \mathrm{mm} \mathrm{s}^{-1}$, the quadrupole splitting, $\Delta E_{\mathrm{Q}}$, and the line width, $\Gamma$, at half maximum.

\subsubsection{EPR spectroscopy}

Electron paramagnetic resonance (EPR) spectroscopy is used for studying materials with unpaired electrons. The basic concepts of EPR are similar to those of NMR spectroscopy. Instead of exciting the spins of atomic nuclei, the electron spins are excited.

An EPR spectrum is typically presented as the first derivation of the absorbance spectrum. The hyperfine structure of the resonance lines provides information about the molecular structure. The EPR spectroscopy was applied in combination with single-pulse-pulsed laser polymerization (SP-PLP-EPR). This setup consists of an excimer laser $(351 \mathrm{~nm})$, which is placed in front of the EPR spectrometer. The cavity of the EPR spectrometer is equipped with a grid for irradiation with the laser light. A detailed description is found elsewhere. ${ }^{[62]}$ 


\subsubsection{Stopped-Flow Injection}

Stopped-Flow measurements are used to study the chemical kinetics of fast reactions in solution. A Stopped-Flow setup may combined with different spectroscopic and scattering of radiation methods, e.g. UV/Vis, NMR, IR, etc. The stopped-flow technique benefits from usage of small reactions volumes, very short mixing period and the kinetic equations for modeling are equivalent to those used in conventional methods.

In stopped-flow injection techniques, the sample solutions are forced from syringes into a mixing chamber. After a very short time of flow - a few $\mathrm{ms}$ - the flow is stopped suddenly when the observation cell is filled. The measurement is triggered by an opposing piston that is linked with the observation cell. 
Theoretical Background 


\section{3}

\section{Kinetics of Poly(ethylene glycol) methyl ether methacrylate}

Within the last years monomers with poly(ethylene glycol) (PEG) side chains have gained more and more attention. Depending on the length of the PEG units, these polymers are water soluble and show a tuneable lower critical solution temperature (LCST). ${ }^{[83-85]}$ PEG-based polymers and co-polymers are used in a wide field of applications such as biocompatible coatings for magnetic resonance tomography contrast agents, ${ }^{[86]}$ drug delivery systems, ${ }^{[21,87]}$ surfactants, ${ }^{[12]}$ co-monomers in emulsion copolymerization ${ }^{[88]}$ or in the synthesis of bioconjugates. ${ }^{[89]}$ Polymers with a short PEG side chain are applied as dental soft lining materials ${ }^{[0]}$ or as polymer gel electrolytes in lithium batteries. ${ }^{[91]}$

PEG monomers are also widely used for RDR polymerizations such as RAFT and ATRP. ${ }^{[1,33,92,93]}$ A key advantage is the good solubility in water. Moreover, these monomers offer a weakly interacting and unreactive side chain which is important for polymerization systems with sensitive control agents. PEG methacrylates also provide a less sophisticated kinetic scheme with no side reactions such as backbiting.

Despite the growing scientific attention and importance of this type of monomers, the knowledge of polymerization kinetics is not adequately developed. Optimization and control of tailored polymers largely benefit from the accurate knowledge of rate coefficients.

In this chapter the rate coefficients for propagation, $k_{\mathrm{p}}$, and the 
chain-length-dependent termination, $k_{\mathrm{t}}^{\mathrm{i}, \mathrm{i}}$, plus the associated compositemodel parameters of poly(ethylene glycol) methyl ether methacrylate (PEGMA) are investigated in aqueous solution via PLP-SEC and SPPLP-EPR, respectively.

\subsection{Propagation rate coefficient by PLP-SEC of Poly(ethylene glycol) methyl ether methacrylate $^{1}$}

Since the introduction of the PLP-SEC technique, which combines pulse-laser polymerization (PLP) with size-exclusion-chromatography (SEC) by Olaj et al. ${ }^{[94,95]}$, reliable propagation rate coefficients were determined for a large set of monomers. For several monomers in bulk, e.g., styrene, ${ }^{[96]}$ methacrylate-, ${ }^{[97-100]}$ and acrylate-type monomers, ${ }^{[101,102]}$ critically reviewed rate coefficients were reported. During recent years an enormous progress was made in the understanding of polymerization kinetics in aqueous solution by the investigation of acrylic acid,[74,76,103-105] methacrylic acid[75,106] and water-soluble amides. ${ }^{[71,107]}$

However, for PEG monomers only a few investigations of $k_{\mathrm{p}}$ were reported. These reports are limited to $k_{\mathrm{p}}$ of the monomer poly(ethylene glycol) ethyl ether methacrylate (PEGEEMA) in bulk or ionic liquids. ${ }^{[108,109]}$

This subchapter deals with the investigation of $k_{\mathrm{p}}$ via PLP-SEC in aqueous solution for poly(ethylene glycol) methyl ether methacrylate (PEGMA), which is considered with an average $M_{\mathrm{n}}$ of $500 \mathrm{~g} / \mathrm{mol}$ as one of most frequently used PEG monomers in literature. ${ }^{6,21,33,52,85,92,110,111]}$

\subsubsection{Structural analysis of PLP-SEC curves}

PLP-SEC experiments to determine $k_{\mathrm{p}}$ were conducted in the concentration range from $5 \mathrm{wt} \%$ PEGMA in water up to bulk PEGMA

${ }^{1}$ All PLP-SEC experiments were carried out by Stella Weber during her bachelor thesis. 

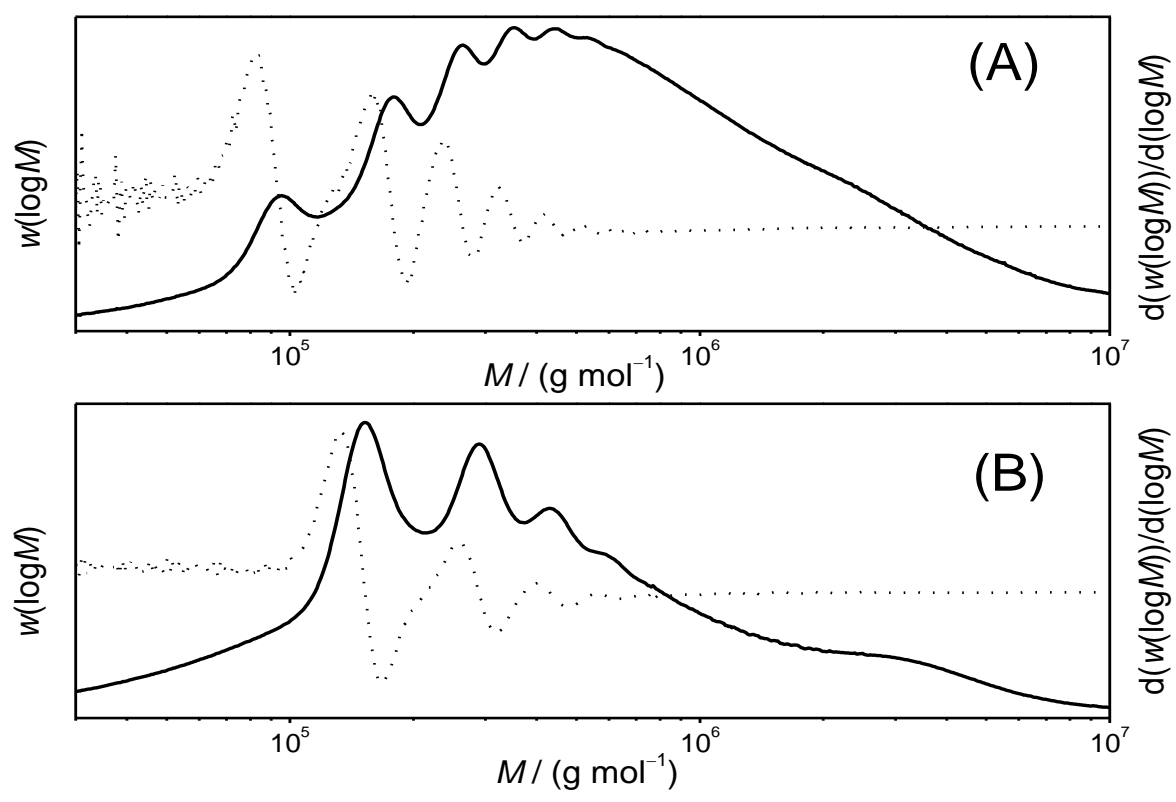

Figure 3.1: Molar mass distribution (solid lines) and associated first-derivate curves (dotted lines) for poly(PEGMA) samples from PLP experiments on aqueous solutions at $50 \mathrm{wt} \%$ PEGMA, Darocur acting as initiator $c_{\text {ini }}=5 \cdot 10^{-2} \mathrm{~mol} \mathrm{~L}^{-1}, v_{\text {rep }}=10 \mathrm{~Hz}, 30^{\circ} \mathrm{C}(\mathrm{A})$ and bulk at $c_{\text {ini }}=5 \cdot 10^{-2} \mathrm{~mol} \mathrm{~L}^{-1}$, $v_{\text {rep }}=15 \mathrm{~Hz}, 77^{\circ} \mathrm{C}(\mathrm{B})$.

polymerization at temperatures from 22 to $77{ }^{\circ} \mathrm{C}$. To match the PLP consistency criteria for reliable PLP-SEC experiments, initiator concentration and laser pulse repetition rate were varied. The number of applied laser pulses has been selected such as to keep monomer conversion below $10 \%$ in order to keep monomer concentration almost constant and, on the other side, provide a sufficient amount of polymer for SEC analysis.

Shown in Figure 3.1 are typical MMD curves (solid lines) and associated first-derivate curves (dotted lines) obtained for poly(PEGMA) samples in aqueous solution and bulk PLP experiments at different reaction conditions. Depicted in Figure 3.1A is a PLP structure which is 
typical for experiments carried out between 22 and $40{ }^{\circ} \mathrm{C}$ in bulk and aqueous solution, and is close to the low-termination-rate-limit (LTRL). ${ }^{[12]}$ Above $40{ }^{\circ} \mathrm{C}$, the PLP structure changes to the one presented in Figure $3.1 \mathrm{~B}$ which corresponds to the intermediate-termination case. ${ }^{[112]}$ In both cases the resulting first-derivative curves show several pronounced maxima, whose positions correspond to the inflection points (POI) of the MMD.

The high-molar-mass material between $10^{6}$ and $10^{7} \mathrm{~g} \cdot \mathrm{mol}^{-1}$ without PLP structure results from continuous polymerization during and after the PLP experiment. However, the determination of $k_{\mathrm{p}}$ is not affected by this high-molar-mass material as $k_{\mathrm{p}}$ has been deduced according to Equation 2.7 from POIs at significantly lower molar masses.

A selection of arithmetic mean $k_{\mathrm{p}}$ values (complete Table see Appendix Table A2 to Table A5) deduced from the position of the POIs is listed in Table 3.1 together with all relevant experimental conditions, which are initiator concentration, $c_{\text {ini, }}$ laser repetition rate, $v_{\text {rep}}$, and monomer concentration in $\mathrm{wt} \%$ and $\mathrm{mol} \cdot \mathrm{L}^{-1}$. The ratio of the molecular masses at the first and second POI plus the ratio of the second and third POIs, $M_{1} / M_{2}$ and $M_{2} / M_{3}$, respectively, is added to proof consistency and reproducibility of the measurement.

The occurrence of at least two POIs, with a multiple molecular mass of the first POI, is an important consistency criterion for reliable $k_{\mathrm{p}}$ determination via PLP-SEC. ${ }^{[94,95]}$ As can be seen from Table 3.1, the ratio of $M_{1} / M_{2}$ lies always above the expected value of 0.5 whereas the ratio of $M_{2} / M_{3}$ fulfills the expectations of 0.66 . This behavior may be explained by the PLP structure. For the PLP structure close to the LTRL case, the molar mass of the first POI is estimated to be too high due to broadening and overlapping of each single signal in the MMD. ${ }^{[7,113]}$ In case of intermediate termination, the overlapping and broadening effects have only a minor influence on the POIs because of a better signal separation. ${ }^{[113]}$ The higher deviation at 10 and $5 \mathrm{wt} \%$ PEGMA may be caused by a low $\mathrm{S} / \mathrm{N}$ ratio and monomer conversion up to $15 \%$.

Despite the inaccuracy of the first POI, the PLP structures provide up to six POIs. This high number of POIs allows for a particularly precise determination of $k_{\mathrm{p}}$. Shown in Figure 3.2 are the experimental $k_{\mathrm{p}}$ values reduced by the arithmetic mean $k_{\mathrm{p}}$ values plotted against the $i$-th inflection point from which $k_{\mathrm{p}}$ has been calculated. The $k_{\mathrm{p}}$ values 
Table 3.1: Selection of measured $k_{\mathrm{p}}$ data in dependence on $v_{\mathrm{rep}}$, initiator and monomer concentrations at $22{ }^{\circ} \mathrm{C}$. $M_{1} / M_{2}$ and $M_{2} / M_{3}$ represents the ratio of molecular weight at particular POIs (see Table A2 to Table A5 for complete table). The $k_{\mathrm{p}}$ values are the arithmetic mean values of the second and higher POIs.

\begin{tabular}{|c|c|c|c|c|c|c|}
\hline CPEGMA & CPEGMA & CInitiator & $\begin{array}{l}\nu_{\mathrm{re}} \\
\mathrm{p}\end{array}$ & $M_{1} / M_{2}$ & $M_{2} / \mathrm{M}_{3}$ & $k_{\mathrm{p}}$ \\
\hline$w t \%$ & $\mathrm{~mol} \cdot \mathrm{L}^{-1}$ & $\mathrm{~mol} \cdot \mathrm{L}^{-1}$ & $\mathrm{~Hz}$ & & & $\begin{array}{l}\mathrm{L} \cdot \mathrm{mol}^{-1} \\
\mathrm{~s}^{-1}\end{array}$ \\
\hline \multirow[t]{4}{*}{100} & 2.07 & $5 \cdot 10^{-2}$ & 20 & 0.54 & 0.67 & 521 \\
\hline & & & 40 & 0.57 & 0.68 & 583 \\
\hline & & & 70 & 0.60 & 0.72 & 715 \\
\hline & & $5 \cdot 10^{-3}$ & 20 & 0.55 & 0.67 & 494 \\
\hline \multirow[t]{5}{*}{70} & 1.40 & $5 \cdot 10^{-2}$ & 10 & 0.52 & 0.67 & 960 \\
\hline & & & 15 & 0.55 & 0.66 & 978 \\
\hline & & & 20 & 0.55 & 0.67 & 980 \\
\hline & & & 40 & 0.58 & 0.68 & 1100 \\
\hline & & $5 \cdot 10^{-3}$ & 20 & 0.56 & 0.64 & 907 \\
\hline \multirow[t]{3}{*}{50} & 0.96 & $5 \cdot 10^{-2}$ & 20 & 0.55 & 0.67 & 1397 \\
\hline & & & 40 & 0.57 & 0.67 & 1570 \\
\hline & & $5 \cdot 10^{-3}$ & 20 & 0.54 & 0.68 & 1414 \\
\hline \multirow[t]{2}{*}{30} & 0.58 & $5 \cdot 10^{-2}$ & 15 & 0.56 & 0.66 & 1579 \\
\hline & & & 20 & 0.56 & 0.68 & 1703 \\
\hline \multirow[t]{2}{*}{10} & 0.19 & $5 \cdot 10^{-2}$ & 15 & 0.58 & 0.72 & 2323 \\
\hline & & & 20 & 0.58 & 0.71 & 2700 \\
\hline \multirow[t]{2}{*}{5} & 0.10 & $5 \cdot 10^{-2}$ & 10 & 0.61 & 0.73 & 2890 \\
\hline & & & 15 & 0.62 & 0.71 & 3512 \\
\hline
\end{tabular}


Kinetics of Poly(ethylene glycol) methyl ether methacrylate
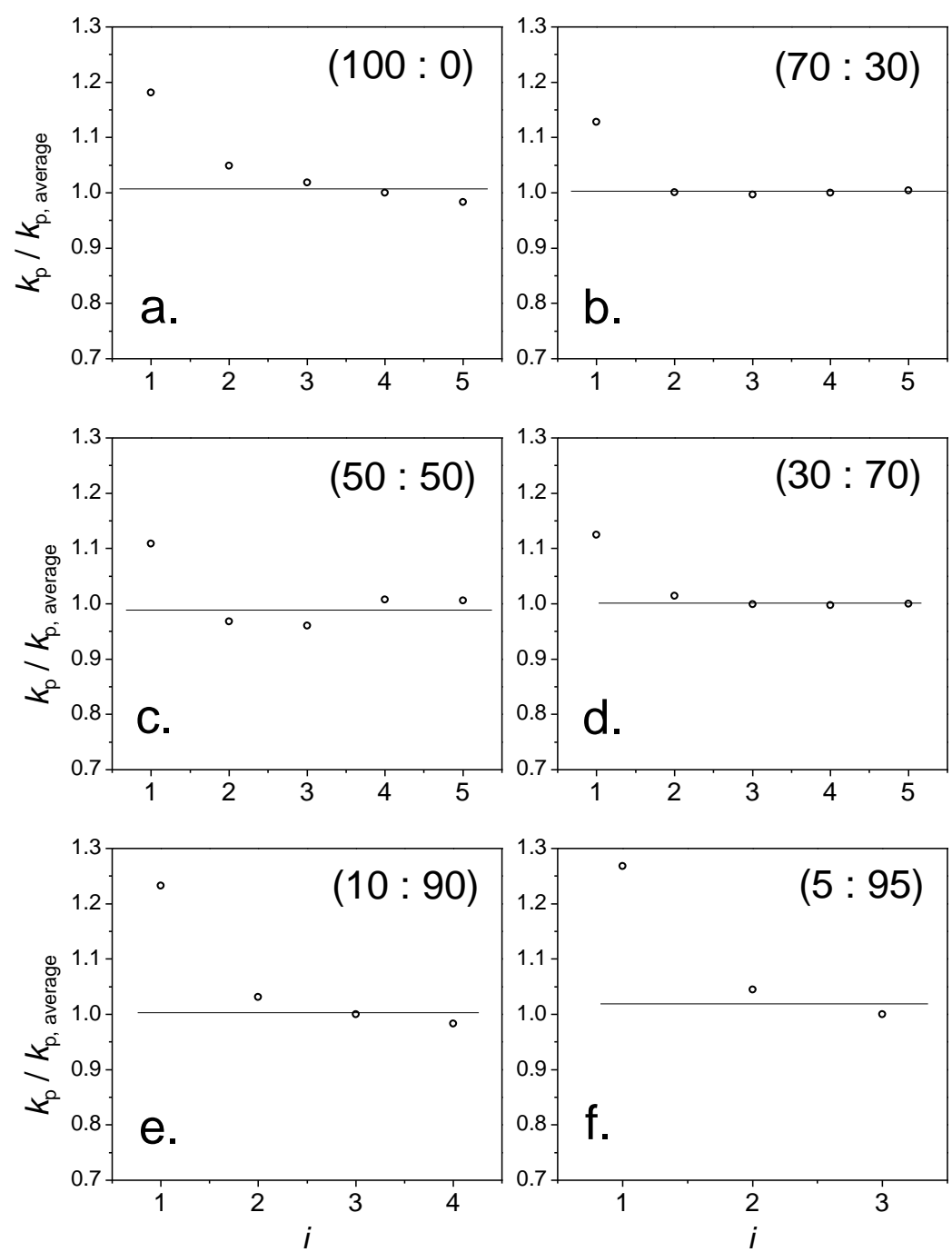

Figure 3.2: Normalized $k_{\mathrm{p}}$ values deterimined from the $\mathrm{i}^{\text {th }} \mathrm{POI}, i$, of various PEGMA- $\mathrm{H}_{2} \mathrm{O}-$-compositions (PEGMA : $\mathrm{H}_{2} \mathrm{O}$ ) at $22{ }^{\circ} \mathrm{C}$. a.-c.: $\quad c_{\text {ini }}=2 \cdot 10^{-2}$ mol L-1, $v_{\text {rep }}=20 \mathrm{~Hz}$. d.-e.: $c_{\text {ini }}=2 \cdot 10^{-2} \mathrm{~mol} \mathrm{~L}^{-1}, v_{\text {rep }}=15 \mathrm{~Hz}$. f.: $\quad c_{\text {ini }}=2 \cdot 10^{-2}$ mol L-1, v rep $=10 \mathrm{~Hz}$. The solid represent the arithmetic mean value of $k_{\mathrm{p}}$ from the second and higher POIs. 
obtained from the first POI is always 10 to $20 \%$ above the $k_{\mathrm{p}}$ values derived from the higher POIs. The deduced $k_{\mathrm{p}}$ values from the second and higher POIs are relatively constant and yield precise $k_{\mathrm{p}}$ values with a uncertainty of $5 \%$.

A further inaccuracy of $k_{\mathrm{p}}$ has been reported for high $v_{\text {rep. }}$ With higher $v_{\mathrm{rep}}, k_{\mathrm{p}}$ increases because of the change in PLP structure toward the LTRL case and thus stronger overlap. To check for a dependency on

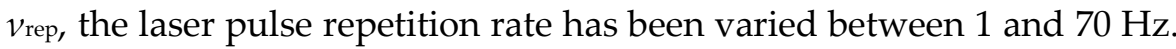
As seen in Table 3.1 and Figure A3, $k_{\mathrm{p}}$ increases with $v_{\text {rep }}$ higher than $20 \mathrm{~Hz}$. This behavior is in agreement with findings by Beuermann, ${ }^{\text {[9] }}$ and can be explained by the change of the PLP structure toward the LTRL.

The determined $k_{\mathrm{p}}$ values have also been checked for independency of the initiator concentration to prove the consistency criterion, which is fulfilled in the investigated concentration range between $5 \cdot 10^{-1}$ and $5 \cdot 10^{-2} \mathrm{~mol} \cdot \mathrm{L}^{-1}$ (Figure A4).

Because of the above-described effects, arithmetic mean $k_{\mathrm{p}}$-values have been determined from the second and higher inflection points with low $v_{\text {rep }}$ between 5 and $15 \mathrm{~Hz}$, and initiator concentrations between $2 \cdot 10^{-2}$ and $5 \cdot 10^{-2} \mathrm{~mol} \cdot \mathrm{L}^{-1}$.

\subsubsection{Temperature and concentration dependence of $k_{\mathrm{p}}$}

As is known from other water-soluble monomers such as acrylic acid (AA) ${ }^{[104]}$, methacrylic acid (MAA) ${ }^{[114]}$, prop-2-enamides ${ }^{[71]}, N$-vinyl pyrrolidone ${ }^{[73]}$ and $N$-vinyl formamide ${ }^{[107]}$, the solvent water has an significant influence on the propagation rate coefficient, $k_{\mathrm{p}}$, the Arrhenius parameter $A_{0}$, the pre-exponential factor, and a weaker effect on $E_{\mathrm{A}}$, the activation energy. These studies showed that $k_{\mathrm{p}}$ and $A_{0}$ increase toward lower monomer concentration.

To quantify the influence of the water concentration and the temperature on PEGMA polymerization, the $k_{\mathrm{p}}$ data were determined ranging from PEGMA bulk toward $90 \mathrm{wt} \% \mathrm{H}_{2} \mathrm{O}$ at 22, 30, 40, 60 and $80^{\circ} \mathrm{C}$. The water dependency will also be correlated to the structural aspects of PEGMA. 
The first part of this subchapter deals with the estimate of $A_{0}$ and $E_{\mathrm{A}}$ for PEGMA in bulk. $A_{0}$ and $E_{\mathrm{A}}$ are obtained via the Arrheniusrelationship of $k_{\mathrm{p}}$. The absolute $k_{\mathrm{p}}$ values and their dependency on water content will be discussed in the second part of this section.

The Arrhenius plots for different monomer concentrations are shown in Figure 3.3. Although these Arrhenius plots in Figure 3.3 show some scattering and indicate that the activation energy is slightly higher at lower temperatures, the $k_{\mathrm{p}}$ data have been fitted with a single straight line for each solvent composition. All data points exhibit a linear dependency and may therefore be represented by linear fits. The following discussion focuses on the Arrhenius parameter for bulk PEGMA, which is represented by the black line.

For PEGMA in bulk an $E_{\mathrm{A}}$ of $22 \mathrm{~kJ} \mathrm{~mol}^{-1}$ has been estimated. This value is in a good agreement with other methacrylate type monomers, e.g., methyl methacrylate (MMA), butyl methacrylate (BMA) and dodecyl methacrylate (DMA), and indicates a certain family behavior. ${ }^{[97,100]}$

Depicted in Table 3.2 are $E_{\mathrm{A}}, A_{0}$ and $k_{\mathrm{p}}$ values at $25^{\circ} \mathrm{C}$ for different water-soluble methacrylic monomers, such as MAA, 2-hydroxyethyl methacrylate (HEMA) and PEGEEMA. Except for MAA, each monomer exhibits an $E_{\mathrm{A}}$ in the range of $22 \mathrm{~kJ} \mathrm{~mol}^{-1}$ in bulk which agrees with the obtained value for PEGMA. The slightly higher $E_{\mathrm{A}}=24 \mathrm{~kJ} \mathrm{~mol}^{-1}$ for PEEGEMA may be caused by the structural difference through an additional $\mathrm{CH}_{2}$-group at the end as well as the shorter poly(ethylene glycol) ether group.

The small $E_{\mathrm{A}}$ value of MAA, $16 \mathrm{~kJ} \mathrm{~mol}^{-1}$, demonstrates that MAA does not behave like a typical methacrylate. The difference with MAA may be explained by a special behavior of the carboxylic end group which affects the reaction barrier of the propagation process by hydrogen-bonded interactions. ${ }^{[72,114]}$ All other examples of water-soluble monomers have an ester functionality which may interact only to a weaker extent with the radical functionality of the propagating radical.

The fact that the monomer interacts with the radical functionality may also influence the vibrational and rotational motion in the transition state for propagation. For this reason it seems worthwhile to compare the second Arrhenius parameter, $A_{0}$, which is linked to the mobility of the radical, for PEGMA with the other monomers in Table 3.2. 


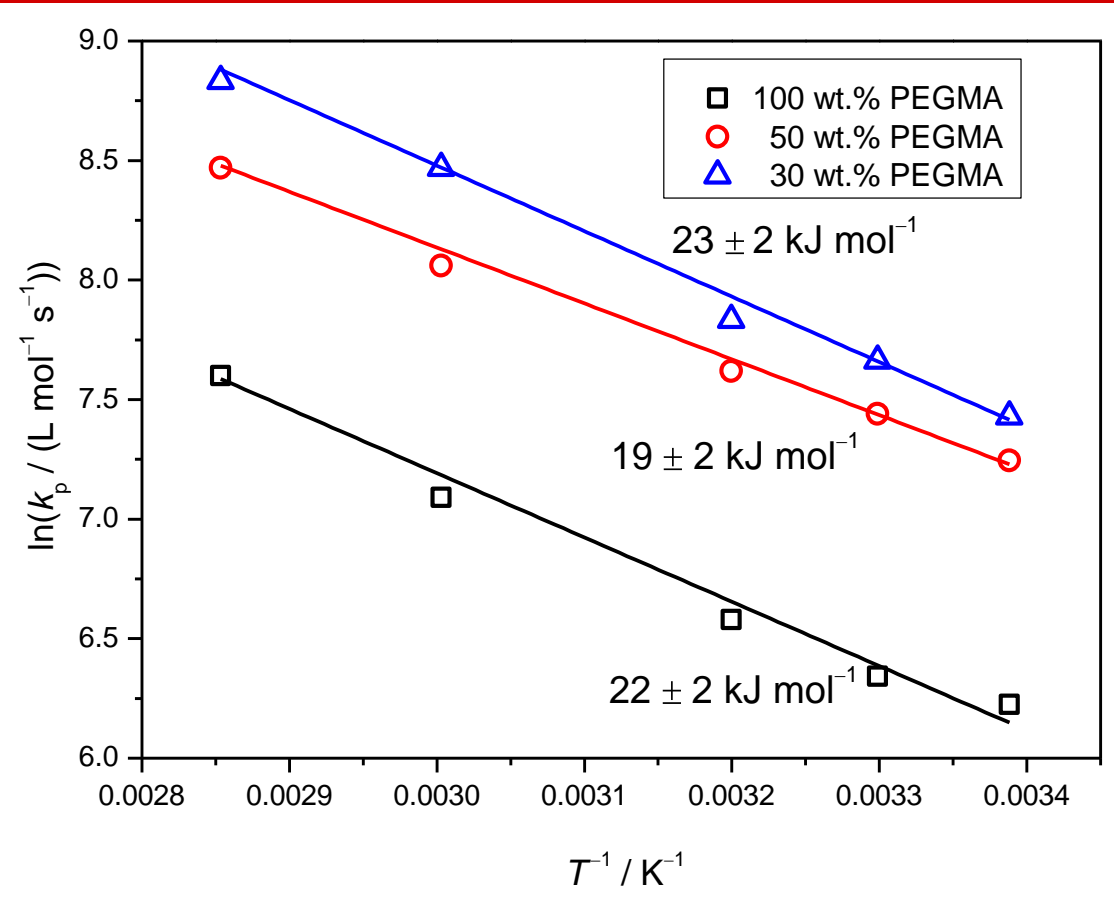

Figure 3.3: Variation of $k_{\mathrm{p}}$ for PEGMA with temperature and three different monomer mass fractions in aqueous solution. The straight lines represent an Arrhenius fit.

The $A_{0}$ values in Table 3.2 are varying by one order of magnitude from $A_{0}=0.4 \cdot 10^{6} \mathrm{~L} \mathrm{~mol}^{-1} \mathrm{~s}^{-1}$ for MAA to $A_{0}=8.9 \cdot 10^{6} \mathrm{~L} \mathrm{~mol}^{-1} \mathrm{~s}^{-1}$ for HEMA. $A_{0}$ for PEGMA lies in the middle of these values at $3.5 \cdot 10^{6} \mathrm{~L} \mathrm{~mol}^{-1} \mathrm{~s}^{-1}$ which is not surprising, as MAA and HEMA are monomers with special properties.

The very small $A_{0}$ for MAA might be explained by the carboxylic acid group of MAA. The carboxylic acid group is known to strongly interact with other MAA molecules, as is shown by the spectroscopic detection of cyclic MAA dimers. ${ }^{[115]}$ For this reason, it is expected that MAA in bulk exhibits a high barrier for internal rotational motion of the transition state and thus $A_{0}$ is strongly reduced. ${ }^{[75]}$

On the contrary, HEMA is a carboxylate ester with a hydroxyethyl group. The ester group and the short side chain may weakly interact 
Kinetics of Poly(ethylene glycol) methyl ether methacrylate

Table 3.2: Activation energies, Arrhenius pre-exponential factors and $k_{\mathrm{p}}-$ values at $25{ }^{\circ} \mathrm{C}$ for different methacrylic monomers in bulk.

\begin{tabular}{lccc}
\hline & $\begin{array}{c}E_{\mathrm{A}} / \mathrm{kJ} \\
\mathrm{mol}^{-1}\end{array}$ & $\begin{array}{c}A_{0} /\left(10^{6} \mathrm{~L} \mathrm{~mol}^{-1}\right. \\
\left.\mathrm{s}^{-1}\right)\end{array}$ & $k_{\mathrm{p}} / \mathrm{L} \mathrm{mol}^{-1} \mathrm{~s}^{-1}$ \\
\hline \hline $\begin{array}{l}\text { Methacrylic acid[75,106] } \\
\text { 2-Hydroxyethyl }\end{array}$ & 16 & 0.4 & 600 \\
methacrylate $^{[99]}$ & 22 & 8.9 & 1200 \\
PEGEEMA $^{[109]}$ & 24 & 9.3 & 489 \\
PEGMA & 22 & 3.5 & 500 \\
\hline \hline
\end{tabular}

with the propagation center of HEMA. The weak interaction yields a higher internal rotational freedom, which is reflected by a high $A_{0}=8.9 \cdot 10^{6} \mathrm{~L} \mathrm{~mol}^{-1} \mathrm{~s}^{-1}$.

Besides the almost identical poly(ethylene glycol) side chain, PEGMA and PEEGEMA are distinguished by a shorter poly(ethylene glycol) side chain for PEGEEMA. Because of the shorter side chain, it is expected that the rotational mobility of the radical functionality is increased, and thus results in a higher $A_{0}$. It should be noted that $E_{\mathrm{A}}$ and $A_{0}$ are correlated with each other and a higher estimated $E_{\mathrm{A}}$ for PEGEEMA may yield accordingly a higher A0.

Since the vibrational and rotational motions of the transition state are linked to $A_{0}$, it seems necessary to check the impact of the water concentration on the activation energy, $E_{\mathrm{A}}$, and the pre-exponential Arrhenius factor, $A_{0}$. Shown in Figure 3.3 are the Arrhenius plots for bulk, 30 and $50 \mathrm{wt} \%$ PEGMA water mixtures. The fits of bulk and 30 wt $\%$ PEGMA feature a similar slope, whereas the linear increase of $50 \mathrm{wt} \%$ PEGMA is lower. The activation energy for bulk, $50 \mathrm{wt} \%$ and $30 \mathrm{wt} \%$ PEGMA has been determined to be $22 \mathrm{~kJ} \mathrm{~mol}^{-1}, 19 \mathrm{~kJ} \mathrm{~mol}^{-1}$, $23 \mathrm{~kJ} \mathrm{~mol}^{-1}$, respectively (see also Table 3.3). As shown in Figure 3.3, $k_{\mathrm{p}}$ increases additionally with the water content.

To check the quality of the Arrhenius plots, 95\% joint confidence intervals (JCIs) were estimated for the measured concentration range. Depicted in Figure 3.4 are JCIs corresponding to the Arrhenius plots in 


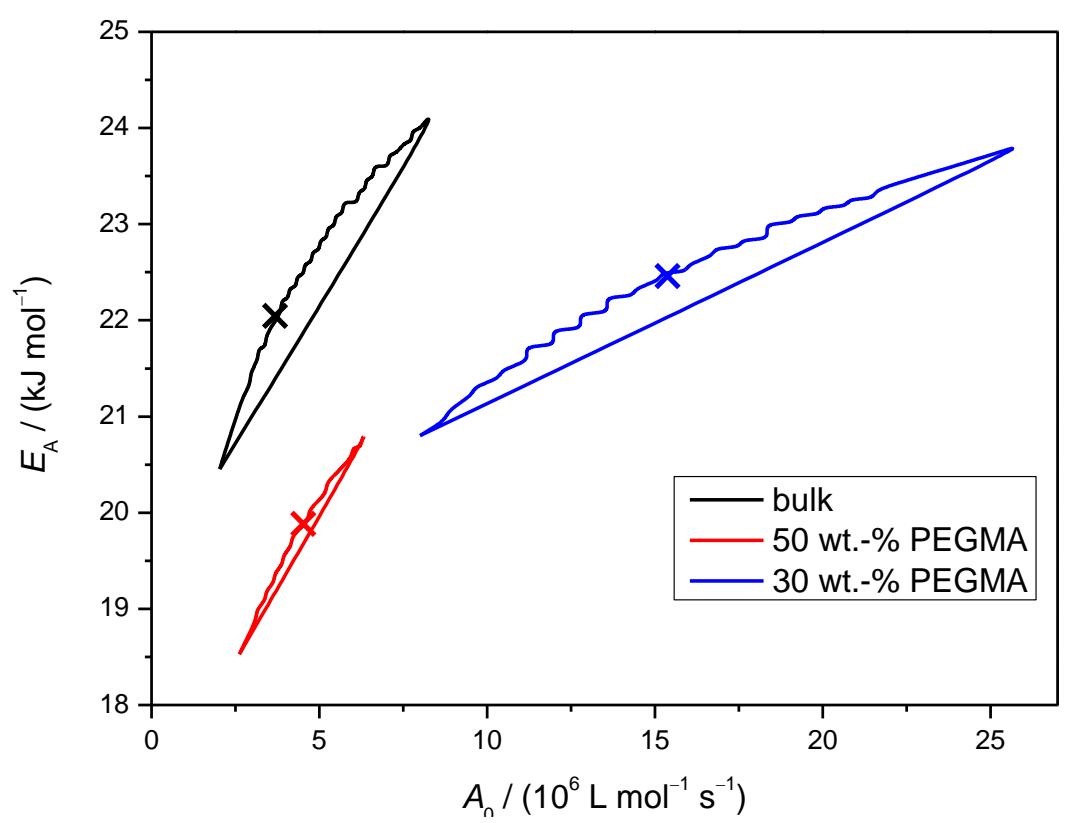

Figure 3.4: $95 \%$ joint confidence region for the Arrhenius parameters of $k_{\mathrm{p}}$ for PEGMA for various monomer mass fractions in aqueous solution. The symbols $(X)$ indicate the best estimates of Arrhenius activation energy and pre-exponential factor.

Figure 3.3. These JCIs were obtained by a nonlinear least-squares fit assuming a constant error of $k_{\mathrm{p}}$ as suggested by van Herk. ${ }^{[16]}$ The JCIs are not overlapping, however regarding the experimental uncertainty of $\Delta E_{\mathrm{A}}= \pm 2 \mathrm{~kJ} \mathrm{~mol}^{-1}$ it may be justified to assume that the activation energy is independent of monomer concentration, and $E_{\mathrm{A}}=21 \mathrm{~kJ} \mathrm{~mol}^{-1}$. This behavior has also been observed for MAA, various acrylamides and AA at high monomer concentrations, those activation energies are also independent of monomer concentration. ${ }^{71,104,114]}$

$E_{A}$ being independent of the water concentration indicates that $\mathrm{H}_{2} \mathrm{O}$ has no effect on the reaction barrier of the propagating radicals of PEGMA and thus the increase in $k_{\mathrm{p}}$ is not induced by lowering the reaction barrier. Considering the absence of hydrogen-bonded interactions of PEGMA with itself and with the aqueous environment it 
could be expected that water has no effect on the reaction barrier. For MAA is has been reported that hydrogen-bonded interactions with water molecules appear to have an almost identical effect on the reaction barrier as MAA molecules. ${ }^{[114]}$

Since an increase in $k_{\mathrm{p}}$ may not be induced by a change of $E_{\mathrm{A}}$, another fact that needs to be discussed is the impact of water content on $A_{0}$. Shown in Figure 3.5 are the estimated $A_{0}$ values for bulk, 50 and $30 \mathrm{wt} \%$ under the assumption that $E_{\mathrm{A}}$ is constant at $21 \mathrm{~kJ} \mathrm{~mol}^{-1}$. From bulk to 50 and $30 \mathrm{wt} \%$ PEGMA/ $\mathrm{H}_{2} \mathrm{O} A_{0}$ increases in a linear fashion by a factor 4 from 3.5 to 9.3 and $14.4 \cdot 10^{6} \mathrm{~L} \mathrm{~mol}^{-1} \mathrm{~s}^{-1}$, respectively.

Listed in Table 3.3 are the estimated $A_{0}$ and associated $k_{\mathrm{p}}$ values at $25{ }^{\circ} \mathrm{C}$ for bulk, 50 and $30 \mathrm{wt} \%$ PEGMA in water. Although an increase in $A_{0}$ with the water concentration is associated with an increased $k_{\mathrm{p}}$, the $k_{\mathrm{p}}$ values exhibit an increase only by a factor of 3 instead of a factor 4 as it was found for $A_{0}$. However, this increase is still consistent with the previously discussed theory of a better rotational motion and thus a higher $k_{\mathrm{p}}$.

The same behavior has been observed for MAA in water. In contrast to PEGMA, A0 for MAA exhibits a stronger increase, by one order of magnitude, from bulk $A_{0}=4.0 \cdot 10^{5} \mathrm{~L} \mathrm{~mol}^{-1} \mathrm{~s}^{-1}$ toward $A_{0}=3.64 \cdot 10^{6} \mathrm{~L} \mathrm{~mol}^{-1} \mathrm{~s}^{-1}$ at $5 \mathrm{wt} \%$ MAA. ${ }^{[75,114]}$ It should be noted that due to the high molar mass of PEGMA the concentration of $30 \mathrm{wt} \%$ PEGMA correspond to $0.57 \mathrm{~mol} \cdot \mathrm{L}^{-1}$, whereas $5 \mathrm{wt} \%$ MAA in water compares to $0.59 \mathrm{~mol} \cdot \mathrm{L}^{-1}$ which is almost the same molar monomer concentration.

Shown in Figure 3.6 is a semi-logarithmic plot for the $A_{0}$-values of PEGMA and MAA versus monomer concentration at $20{ }^{\circ} \mathrm{C}$. A0 was calculated from the $k_{\mathrm{p}}$ values extracted from Figure 3.7 below with the approximation of $E_{\mathrm{A}}$ being independent of monomer concentration. The $A_{0}$ values for PEGMA are by one order of magnitude above the ones for MAA bulk. At infinite dilution, the difference is reduced to a factor of 4 .

$A_{0}$ for PEGMA increases in a linear fashion from bulk toward highly diluted aqueous solutions. On the contrary, the water dependence of $A_{0}$ for MAA may follow an exponential course. Between $50 \mathrm{wt} \%$ and bulk MAA the increase in $A_{0}$ is almost identical to the one for PEGMA. At higher water concentration above $50 \mathrm{wt} \%$ the increase in $A_{0}$ for MAA is more pronounced. 


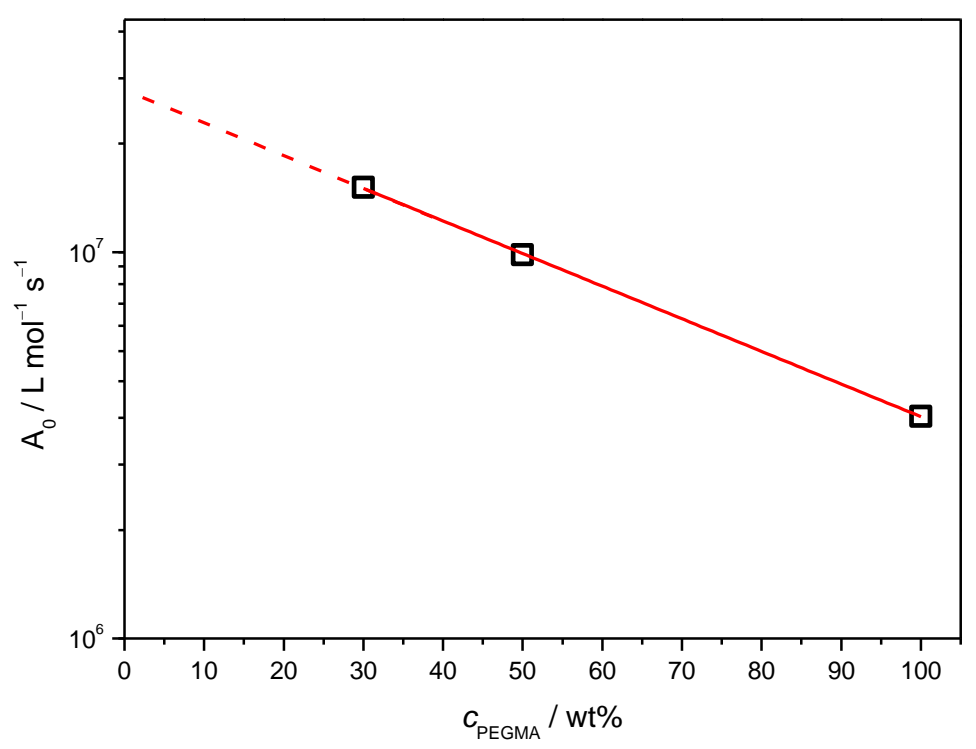

Figure 3.5: Variation of $A_{0}$ for PEGMA with the water content. The $A_{0}$ are obtained from the Arrhenius plot of Figure 3.3 under the assumption that $E_{\mathrm{A}}$ is constant at $21 \mathrm{~kJ} \mathrm{~mol}^{-1}$. The straight lines represent the best fit (the results are replicated in Table 3.3).

Table 3.3: Arrhenius parameter and $k_{\mathrm{p}}$ for PEGMA at $25^{\circ} \mathrm{C}$ for various PEGMA/ $\mathrm{H}_{2} \mathrm{O}$ mixtures.

\begin{tabular}{cccc}
\hline $\mathrm{wt} \%$ PEGMA & 100 & 50 & 30 \\
\hline \hline$E_{\mathrm{A}} / \mathrm{kJ} \mathrm{mol}^{-1}$ & $21 \pm 2$ & $21 \pm 2$ & $21 \pm 2$ \\
$A_{0} /\left(10^{6} \mathrm{~L} \mathrm{~mol}^{-1} \mathrm{~s}^{-1}\right)$ & $2.1 \leq 3.5 \leq 8.0$ & $5.9 \leq 9.3 \leq 10.7$ & $6.2 \leq 14.4 \leq 23.0$ \\
$k_{\mathrm{p}}\left(25^{\circ} \mathrm{C}\right) / \mathrm{L} \mathrm{mol}^{-1} \mathrm{~s}^{-1}$ & 500 & 1400 & 1700 \\
\hline \hline
\end{tabular}

The stronger water dependency of $A_{0}$ for MAA might be explained by the carboxylic moiety which allows for stronger intermolecular interactions through hydrogen bonds and dipole-dipole interactions. 


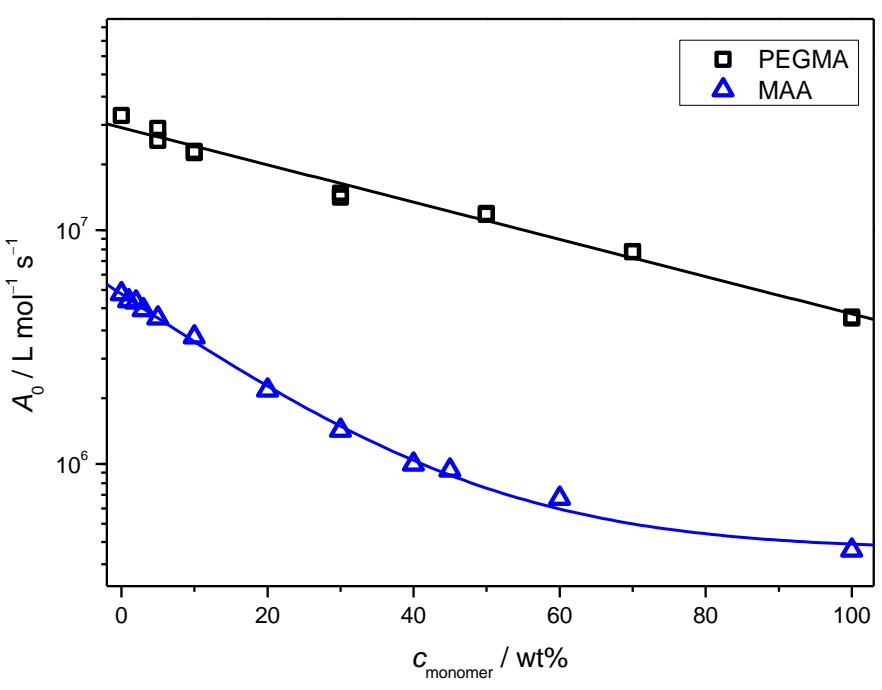

Figure 3.6: Variation of $A_{0}$ with monomer concentration in aqueous solution for MAA and PEGMA at $20^{\circ} \mathrm{C}$. A constant EA for MAA and PEGMA were used with $16 \mathrm{~kJ} \mathrm{~mol}^{-1}$ for MAA and $21 \mathrm{~kJ} \mathrm{~mol}^{-1}$ for PEGMA.

For bulk polymerization, the interactions of MAA may be stronger with the propagating center. This leads to a more pronounced retardation of $k_{\text {p. }}$ Upon replacing MAA by $\mathrm{H}_{2} \mathrm{O}$ molecules in the direct vicinity of the propagating center at high dilution, the interaction of water molecules weakens the influence of MAA molecules on the propagating center and result in a better internal rotational freedom of the radical functionality. ${ }^{[106]}$

PEGMA, on the contrary, bears a very weak proton acceptor side chain with weak dipole-dipole interactions. This leads to a small hindrance of the internal rotational mobility. The fluidizing effect of water is less pronounced for monomers with a high mobility even in bulk.

As described above, $A_{0}$ increases with the water content and that $E_{\mathrm{A}}$ is independent of the $\mathrm{H}_{2} \mathrm{O}$ concentration. The next part focusses on the water dependency of $k_{\mathrm{p}}$ in correlation with the obtained Arrhenius parameters.

The $k_{\mathrm{p}}$ values in bulk of various water-soluble methacrylates show a 
correlation between $A_{0}$ and $k_{\mathrm{p}}$. The $k_{\mathrm{p}}$ values for different water-soluble methacrylates such as MAA, HEMA and PEGEEMA in bulk at $25^{\circ} \mathrm{C}$ are listed in Table 3.2. The structure of PEGEEMA and PEGMA is almost identical, therefore the $k_{\mathrm{p}}$ values are very similar with $490 \mathrm{~L} \mathrm{~mol}^{-1} \mathrm{~s}^{-1}$ for PEGEEMA and $500 \mathrm{~L} \mathrm{~mol}^{-1} \mathrm{~s}^{-1}$ for PEGMA.[109]

For HEMA, a much higher $k_{\mathrm{p}}$ value of $1200 \mathrm{~L} \mathrm{~mol}^{-1} \mathrm{~s}^{-1}$ was obtained than for PEGMA. ${ }^{[9]}$ The relatively high $k_{\mathrm{p}}$ in bulk may be explained by the short alcoholic side chain, which provides a small dipole-dipole moment and thus a weak hindrance to internal rotational mobility. This is also reflected in the high $A_{0}$ value.

Although MAA exhibits the smallest $A_{0}$ from the listed monomers the $k_{\mathrm{p}}$ value is slightly higher than for PEGMA due to the lower activation energy.

After discussing the differences of $k_{\mathrm{p}}$ in bulk, the change of $k_{\mathrm{p}}$ with monomer concentration is of interest, since the evolution of $k_{\mathrm{p}}$ with monomer concentration varies with the type of monomer. ${ }^{[71,76,114]}$ The comparison focus on MAA and PEGMA. The already investigated water-soluble amides are not considered here because they represent a completely different monomer family.

From the right column of Table 3.1 the following conclusion can be drawn: $k_{\mathrm{p}}$ is strongly decreasing from highly diluted solutions of PEGMA, $k_{\mathrm{p}}=3200 \mathrm{~L} \mathrm{~mol}^{-1} \mathrm{~s}^{-1}$, toward bulk polymerization, $k_{\mathrm{p}}=500 \mathrm{~L} \mathrm{~mol}^{-1} \mathrm{~s}^{-1}$. Shown in Figure 3.7 is the variation of $k_{\mathrm{p}}$ over the entire concentration range for PEGMA and MAA in aqueous solution at $20{ }^{\circ} \mathrm{C}$.

The data for PEGMA plotted in Figure 3.7 were fitted with the following expression:

$$
k_{P} /\left(\mathrm{L} \mathrm{mol}^{-1} \mathrm{~s}^{-1}\right)=5643-1086 \cdot \ln \left(c_{\mathrm{PEGMA}} /(\mathrm{wt} \%)+5.989\right)
$$

As seen in Figure 3.7, $k_{\mathrm{p}}$ increases toward lower monomer concentration. The propagation rate coefficient of PEGMA increases by a factor of 7 from bulk, $k_{\mathrm{p}}=500 \mathrm{~L} \mathrm{~mol}^{-1} \mathrm{~s}^{-1}$, toward infinite dilution, $k_{\mathrm{p}} \approx 3700 \mathrm{~L} \mathrm{~mol}^{-1} \mathrm{~s}^{-1}$. For methacrylic acid (MAA) a stronger increase by a factor 13 of $k_{\mathrm{p}}$ has been observed from bulk, $k_{\mathrm{p}}=600 \mathrm{~L} \mathrm{~mol}^{-1} \mathrm{~s}^{-1}$, toward 
Kinetics of Poly(ethylene glycol) methyl ether methacrylate

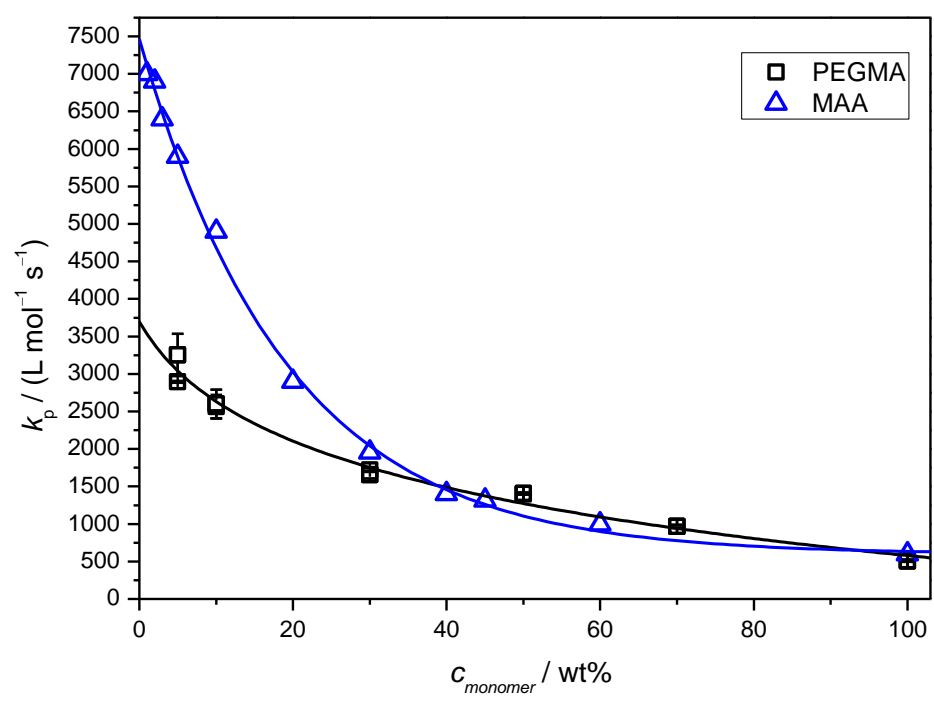

Figure 3.7: Variation of $k_{\mathrm{p}}$ with monomer concentration for polymerizations of PEGMA in water with different initiator concentration at $22^{\circ} \mathrm{C}$.

infinite dilution, $k_{\mathrm{p}} \approx 7500 \mathrm{~L} \mathrm{~mol}^{-1} \mathrm{~s}^{-1}$. This increase in $k_{\mathrm{p}}$ becomes more pronounced in highly diluted solutions of PEGMA and MAA. PEGMA shows an almost linear increase in $k_{\mathrm{p}}$ from bulk toward 30wt $\%$ PEGMA, whereas MAA shows a very weak increase in $k_{\mathrm{p}}$ above $60 \mathrm{wt} \%$. For higher dilutions, the increase in $k_{\mathrm{p}}$ is more pronounced for both monomers. The increase in $k_{\mathrm{p}}$ for MAA is however significantly stronger than for PEGMA. The stronger water influence at higher dilution is consistent with the findings for $A_{0}$, shown in Figure 3.6. Through the connection of $A_{0}$ and $k_{\mathrm{p}}$, the strong increase in $k_{\mathrm{p}}$ may be explained by the higher internal rotational freedom of the transition state for propagation.

The influence of the ethylene glycol side chain of PEGMA may explain the difference between the absolute values of $k_{\mathrm{p}}$ at infinite dilution with $k_{\mathrm{p}}=3700 \mathrm{~L} \mathrm{~mol}^{-1} \mathrm{~s}^{-1}$ for PEGMA compared to $k_{\mathrm{p}} \approx 7500$ $\mathrm{L} \mathrm{mol}^{-1} \mathrm{~s}^{-1}$ for MAA. The tenfold higher $A_{0}$ value in combination with a smaller $k_{\mathrm{p}}$ for PEGMA suggests that the internal rotational freedom of the transition state for propagating radical is less hindered and that the 
fluidizing effect of water is less pronounced for monomers with high $A_{0}$ values in bulk.

\subsubsection{Dependence of $k_{\mathrm{p}}$ on $\mathrm{NaBr}$ concentration}

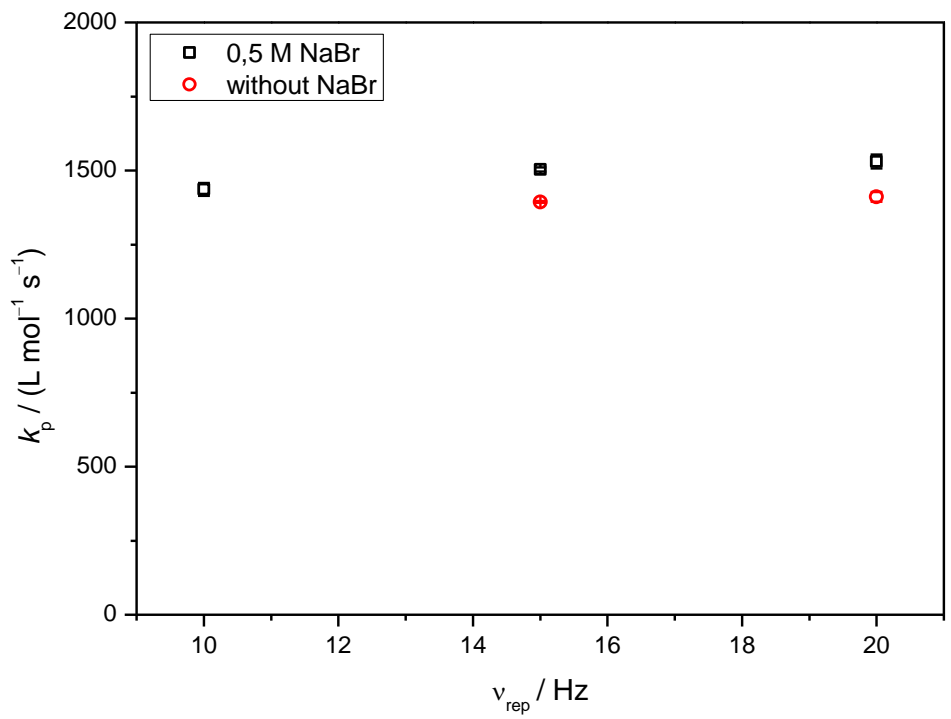

Figure 3.8: Variation of $k_{\mathrm{p}}$ with sodium bromide and laser repetition rate at $50 \mathrm{wt} \%$ PEGMA and $22^{\circ} \mathrm{C}$.

In later chapters the mechanism, equilibrium constant, deactivation rate coefficient of ATRP will be investigated under polymerization conditions. As described in chapter 4, ATRP in water requires a high excess of sodium bromide $(\mathrm{NaBr})$ to the solution to prevent halide dissociation. Therefore it seems necessary to check for potential variations of $k_{\mathrm{p}}$ with sodium bromide concentration.

Depicted in Figure 3.8 is the variation of $k_{\mathrm{p}}$ for $50 \mathrm{wt} \%$ PEGMA in $\mathrm{H}_{2} \mathrm{O}$ with and without $\mathrm{NaBr}\left(0.5 \mathrm{~mol} \mathrm{~L}^{-1}\right)$ at $22{ }^{\circ} \mathrm{C}$. Within the calculations of $k_{\mathrm{p}}$ with $\mathrm{NaBr}$ the change of density and viscosity due to the addition of $\mathrm{NaBr}$ has been ignored. 
Kinetics of Poly(ethylene glycol) methyl ether methacrylate

The $k_{\mathrm{p}}$ values exhibit a small variation with laser repetition rate. As described in chapter 3.1.1, a lower $k_{\mathrm{t}}$ may shift the PLP structure to the LTRL, which yields a slightly higher $k_{\mathrm{p}}$.

At $v_{\text {rep }}=10 \mathrm{~Hz}$ and $0.5 \mathrm{~mol} \mathrm{~L}^{-1} \mathrm{NaBr} k_{\mathrm{p}}$ is $1435 \mathrm{~L} \mathrm{~mol}^{-1} \mathrm{~s}^{-1}$ and thus agrees within experimental error with $k_{\mathrm{p}}=1400 \mathrm{~L} \mathrm{~mol}^{-1} \mathrm{~s}^{-1}$ measured without added $\mathrm{NaBr}$. Consequently, $k_{\mathrm{p}}$ appears to be independent of $\mathrm{NaBr}$ concentration. This behavior is in agreement with the assumption that PEGMA has no ionized form which may interact with bromide or sodium ions. The same behavior has already been observed for nonionized MAA and AA in aqueous solution. ${ }^{[72,76]}$ 


\subsection{Termination rate coefficient by SP-PLP- EPR of Poly(ethylene glycol) methyl ether methacrylate}

Information about the termination kinetics is important for conventional radical polymerization and for predictions of these polymerizations. In contrast, RDRP reactions experience only small or even insignificant termination in the equilibrium state. However, for determination of individual reaction rate coefficients of RDRP, e.g., the rate of deactivation, $k_{\text {deact, }}$ in ATRP, the knowledge of the termination rate, especially of chain-length-dependent termination rate coefficients, $k^{\mathrm{i}, \mathrm{i}}$, is crucial.

For the direct measurement of the radical concentration, the combination of single-pulse (SP) pulsed laser polymerization (PLP) with electron paramagnetic resonance (EPR) spectroscopy has evolved as a reliable tool for the determination of chain-length-dependent termination rate coefficients.

In this section, the termination rate coefficient and the compositemodel parameters were determined for 30, 50 and $70 \mathrm{wt} \%$ PEGMA in aqueous solution at $20^{\circ} \mathrm{C}$ via SP-PLP-EPR.

\subsubsection{EPR spectrum of PEGMA}

The EPR spectrum of methacrylates may be distinguished by a characteristic splitting pattern which mainly results from interactions of the unpaired electron with hydrogen atoms and the presence of different conformers in solution. Depicted in Figure 3.9 is the EPR spectrum measured during a polymerization of PEGMA in $50 \mathrm{wt} \%$ water. The spectrum was recorded with a $3 \mathrm{G}$ modulation amplitude in conjunction with a modulation frequency of $100 \mathrm{kHz}$, a receiver gain of 84 and an attenuation of $13 \mathrm{~dB}$ under continuous laser irradiation at $20 \mathrm{~Hz}$ and $20^{\circ} \mathrm{C}$. A typical methacrylate spectrum consists of 13 lines, 5 more intense lines at a distance of ca. $20-25 \mathrm{G}$ and 8 inner lines.[117-120] The intensity of the 8 inner lines is strongly temperature dependent and decreases toward lower temperature. ${ }^{[120]}$ Because of the hindrance of the rotation around the $\mathrm{C}_{\alpha}-\mathrm{C}_{\beta}$ backbone axis, two conformers with different 
coupling constants of methylene hydrogen atoms coexist and contribute to the overall EPR spectrum. This effect has also been observed for monomers with a sterically demanding side group like tert-butyl methacrylate and generally at high monomer conversions. ${ }^{[117,120,121]}$ Figure 3.9 shows a spectrum with 5 intense lines, in which the 8 inner lines cannot be distinguished anymore due to the steric demands of the poly(ethylene glycol) side chain.

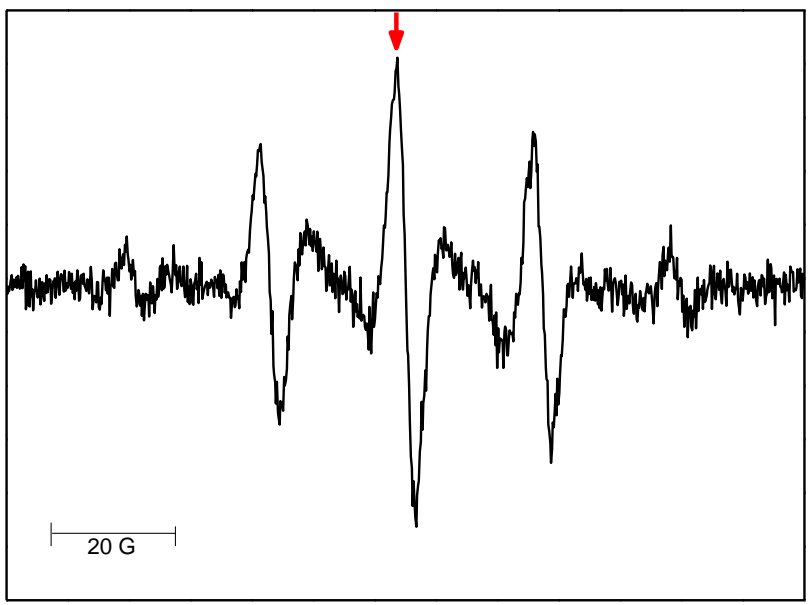

Figure 3.9: EPR spectrum of PEGMA $50 \mathrm{wt} \%$ in aqueous solution at $20^{\circ} \mathrm{C}$ with a $3 \mathrm{G}$ modulation amplitude, a modulation frequency of $100 \mathrm{kHz}$, a receiver gain of 84 and an attenuation of $13 \mathrm{~dB}$ under laser irradiation at $20 \mathrm{~Hz}$. The red arrow indicates the field position for the measurement of concentration vs time profiles. 


\subsubsection{Composite-model parameters}

Single laser pulse experiments for the determination of the composite-model parameter $k_{\mathrm{t}^{1,1}}, \alpha_{\mathrm{s}}, \alpha_{1}$ and $i_{c}$ were carried out at a constant field of $3332 \mathrm{G}$ (indicated by the arrow in Figure 3.9) for various PEGMA-water mixtures at $20^{\circ} \mathrm{C}$.

Darocur has been chosen as the photoinitiator due to its good solubility and the good initiation behavior for methacrylates. ${ }^{[122]}$ The concentration was set to $0.02 \mathrm{~mol} \cdot \mathrm{L}^{-1}$, which yields an initial radical concentration, $\mathrm{cr}_{\mathrm{r}}^{0}$, of around $1 \cdot 10^{-5} \mathrm{~mol} \cdot \mathrm{L}^{-1}$ per laser pulse. A monomer conversion up to $15 \%$ may be reached, which was substantiated by FTNIR spectroscopy. Because of the fast initiation and the fast first propagation step, no interference of the signals derived from initiator on propagating radicals were observed. The monomer concentration has been kept low and was determined from the arithmetic mean of the conversion measured before and after laser pulsing.

Shown in Figure 3.10 are the normalized time-resolved EPR spectra for 30, 50 and $70 \mathrm{wt} \%$ PEGMA that have been recorded at the signal maximum of $3332 \mathrm{G}$ and $20^{\circ} \mathrm{C}$. For a better signal-to-noise ratio at least 20 individual concentration vs time traces were co-added. After laser irradiation at $t=0$, the radical concentration increases instantaneously by initiator decomposition plus the subsequent addition to the monomer and decreases by radical-radical termination. Because of enhanced termination at lower PEGMA and higher $\mathrm{H}_{2} \mathrm{O}$ content, the radical decay becomes faster from 70 to $30 \mathrm{wt} \%$ PEGMA. From the SPPLP-EPR spectra, the composite-model parameters were deduced by a two-step procedure.

In the first evaluation step, the composite-model parameters $i_{\mathrm{c}}$ and $\alpha_{\mathrm{l}}$ were determined by plotting $\log \left(c_{\mathrm{r}} 0 / c_{\mathrm{r}}-1\right)$ vs $\log (t)$ according to Equation 2.17. Depicted in Figure 3.11 is an example of the corresponding plot for $70 \mathrm{wt} \%$ PEGMA in water at $20^{\circ} \mathrm{C}$. Two straight lines may be fitted to the double-log plots, one for short-chain radicals at $t \leq i_{c}$ and the other for long-chain radicals $t \geq i$ c. The slope of each fit corresponds to $1-\alpha$. The intersection of the straight lines indicates the crossover time $t_{c}$, which yields the crossover chain length $i_{c}$ by multiplying with $k_{\mathrm{p}}$ and monomer concentration. The data of $k_{\mathrm{p}}$ required for the composite-model parameter were previously determined in chapter 3.1. 
Kinetics of Poly(ethylene glycol) methyl ether methacrylate

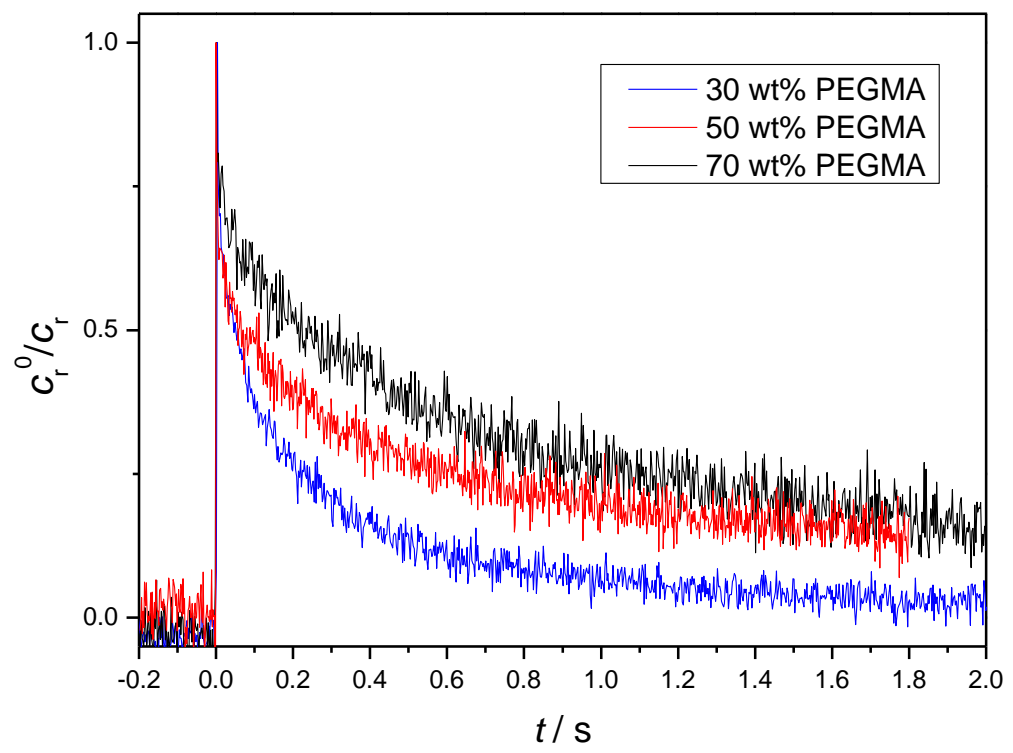

Figure 3.10: Normalized radical concentration vs time profiles for PEGMA in aqueous solution with 30, 50 and $70 \mathrm{wt} \%$ PEGMA at a constant magnetic field of $3332 \mathrm{G}$ and $20^{\circ} \mathrm{C}$.

In Table 3.4 the composite-model parameters are listed, as determined by the double-log plot for 30, 50 and $70 \mathrm{wt} \%$ PEGMA in aqueous solution at $20^{\circ} \mathrm{C}$. For the long-chain radicals at 30,50 and $70 \mathrm{wt} \%$ PEGMA, $\alpha_{1}$ has been determined to be $0.28,0.30$ and 0.25 , respectively. For 30 and $50 \mathrm{wt} \%$ PEGMA, the uncertainty is higher as for $70 \mathrm{wt} \%$ and lies around $\Delta \alpha_{1}=0.10$. The $\alpha_{1}$ values for all concentrations are in agreement with theoretical $\alpha_{1}$ values around 0.10 to 0.25 for the long-chain radicals. ${ }^{[123-125]}$ Moreover, various methacrylates provide an $\alpha_{1}$ value around 0.20 . No dependence on the size and structure of the side chain has been found for the methacrylates. ${ }^{[63,117,118]}$

The $\alpha_{\mathrm{s}}$ values deduced from the short-chain region are similar for all PEGMA mixtures: $\alpha_{\mathrm{s}} \approx 0.65$. The double-log procedure, however, does not adequately represent termination kinetics at very short chain lengths. Consequently, $k_{\mathrm{t}}{ }^{1,1}$ and $\alpha_{\mathrm{s}}$ values were determined according to Equation 2.19. 


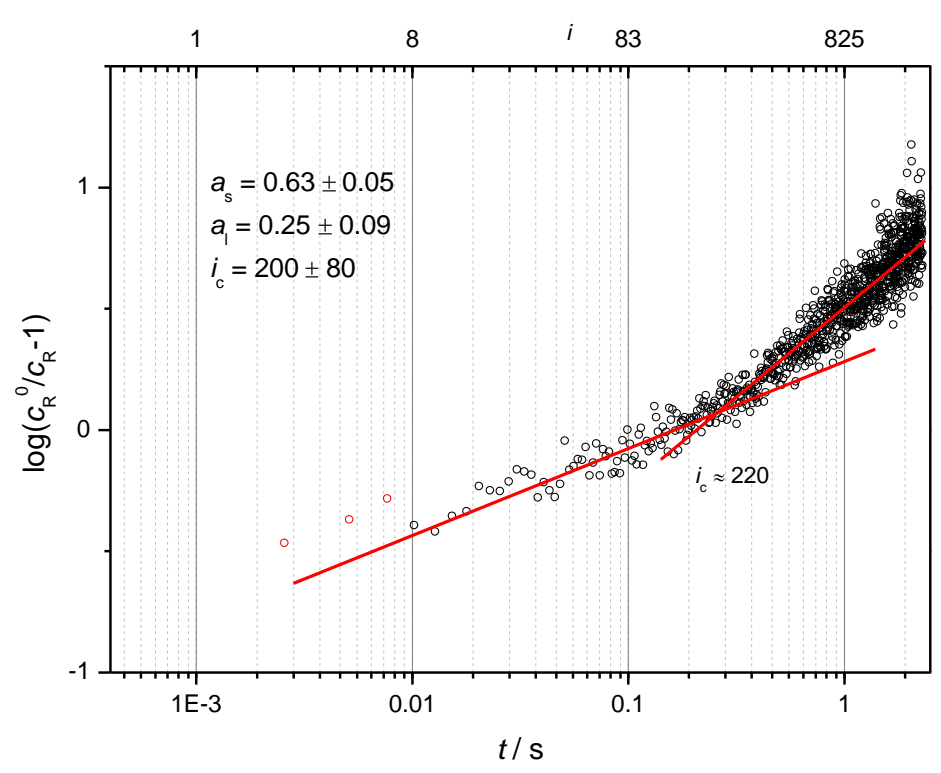

Figure 3.11: Double-log plot of the SP-PLP-EPR data for PEGMA/ $\mathrm{H}_{2} \mathrm{O}$ in $70 \mathrm{wt} \%$ PEGMA at $20^{\circ} \mathrm{C}$. Analysis of the long-chain regime yields $\alpha$; the crossover chain length $i_{c}$ is obtained by the intersection of the two straight lines. An accurate number for $\alpha_{s}$ is obtained by the procedure illustrated in Figure 3.12.

Table 3.4: Composite-model parameters $\alpha_{\mathrm{s}}, \alpha_{\mathrm{l}}$ and crossover chain length $i_{\mathrm{c}}$ for various PEGMA compositions in aq. solution estimated by the double$\log$ procedure.

\begin{tabular}{cccc}
\hline system at $20{ }^{\circ} \mathrm{C}$ & $\alpha_{\mathrm{s}}$ & $\alpha_{\mathrm{l}}$ & $i_{\mathrm{c}}$ \\
\hline \hline $70 \mathrm{wt} \%$ PEGMA & $0.63 \pm 0.05$ & $0.25 \pm 0.09$ & $200 \pm 80$ \\
$50 \mathrm{wt} \%$ PEGMA & $0.63 \pm 0.04$ & $0.30 \pm 0.11$ & $150 \pm 70$ \\
$30 \mathrm{wt} \%$ PEGMA & $0.69 \pm 0.07$ & $0.25 \pm 0.09$ & $70 \pm 20$ \\
DMA bulk ${ }^{[126]}$ & $0.65 \pm 0.08$ & $0.17 \pm 0.04$ & 150 \\
\hline
\end{tabular}


In this second evaluation step, the measured EPR data for $i \leq i_{c}$ are plotted as $c_{r}{ }^{0} / c_{r}-1$ vs. time. They were fitted by a least-squares procedure, as illustrated in Figure 3.12 . $i_{c}$ is again obtained by the intersection of the straight lines from the double-log plot (Figure 3.11) and will be discussed in detail later. The fit in Figure 3.12 yields $\alpha_{\mathrm{s}}$ as a single composite-model parameter and $k_{\mathrm{t}}^{1,1} \cdot c_{\mathrm{r}^{0}}$ as a combined value. From calibration with TEMPOL, as described in chapter 7.4.3, the initial radical concentration ${C_{r}}^{0}$ is available and thus are $k_{\mathrm{t}}^{1,1}$ values.

The obtained $\alpha_{\mathrm{s}}$ and $k_{\mathrm{t}}{ }^{1,1}$ values are listed in Table 3.5 together with the measured viscosity $(\eta)$ of the mixture prior to polymerization and the product of $k_{t^{1,1}} \cdot \eta$. As mentioned above, the $\alpha_{\mathrm{s}}$ values are little higher than the ones obtained by the procedure shown in Figure 3.11 due to the correct consideration of short chains. The $\alpha_{\mathrm{s}}$ values vary around 0.69 with no obvious concentration dependence. The values fit also very well to results obtained with various other methacrylates, whose $\alpha_{\text {s }}$ were determined to be around $0.65 .{ }^{[117,118,127]}$ In contrast, for acrylates $\alpha_{\mathrm{s}}$ values of 0.80 have been found. ${ }^{[63,128]}$

The deduced $k_{\mathrm{t}^{1,1}}$ values are summarized in Table 3.5. For PEGMA in water, $k_{\mathrm{t}}^{1,1}$ increase from $k_{\mathrm{t}}^{1,1}=4.3 \cdot 10^{6} \mathrm{~L} \mathrm{~mol}^{-1} \mathrm{~s}^{-1}$ at $70 \mathrm{wt} \%$ PEGMA to $k_{\mathrm{t}^{1,1}}=27.4 \cdot 10^{6} \mathrm{~L} \mathrm{~mol}^{-1} \mathrm{~s}^{-1}$ at $30 \mathrm{wt} \%$ PEGMA. Since the termination kinetics of radicals with hypothetical chain length unity is strongly diffusion controlled, $k_{\mathrm{t}^{1}, 1}$ should be proportional to solution fluidity, i.e. the inverse viscosity $\eta^{-1}$. As a consequence, $k_{\mathrm{t}^{1,1}}$ is described by the two Equations 2.10 and 2.11. An upper limit for $k_{\mathrm{t}}^{1,1}$ may be expressed by $k_{\mathrm{t}}^{\max }=1 R T / 3 \eta$, which is the so-called diffusion limit. The values for the diffusion limit lie above the measured data due to the neglection of a shielding of the radical site in Equation 2.11.

Illustrated in Figure 3.13 are experimental $k_{\mathrm{t}^{1,1}}$ data and the calculated $k_{t}{ }^{\max }$ values. Both coefficients show a similar slope with increasing water content and thus $k_{\mathrm{t}^{1,1}}$ behaves as expected. In the same context the product of $k_{t}^{1,1} \cdot \eta$ should yield a constant value for each solvent mixture. This is indeed the case as the values in Table 3.5 are all close to $1.3 \cdot 10^{8} \mathrm{~L} \mathrm{~mol}^{-1} \mathrm{mPa}$. The product $k_{\mathrm{t}^{1,1}} \cdot \eta$ relates to the 


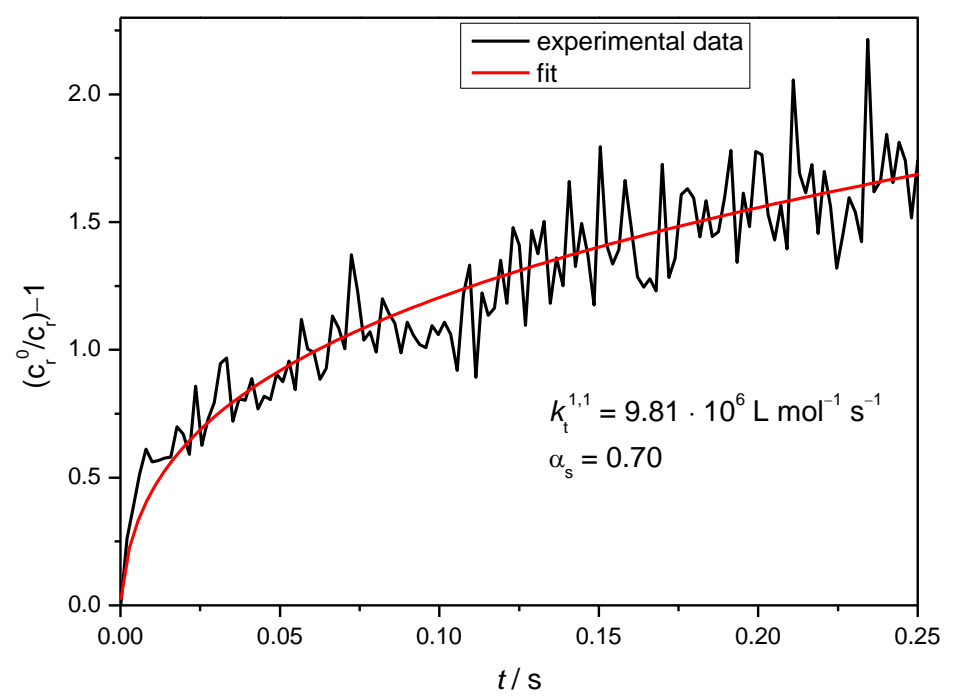

Figure 3.12: Least-squares fit for the determination of $\alpha_{\mathrm{s}}$ and $k_{\mathrm{t}}^{1,1}$ for $50 \mathrm{wt} \%$ PEGMA $/ \mathrm{H}_{2} \mathrm{O}$ at $20^{\circ} \mathrm{C}$. The solid line corresponds to the best fit.

Table 3.5: Termination rate coefficient $k_{\mathrm{t}}{ }^{1,1}$ and $\alpha_{\mathrm{s}}$ for various PEGMA/ $\mathrm{H}_{2} \mathrm{O}$ mixtures at $20^{\circ} \mathrm{C}$ estimated by a least-square fit. Additional values for $k^{1,1} \cdot \eta$ and viscosity are given for the particular system.

\begin{tabular}{ccccc}
\hline $\begin{array}{c}\text { system at } \\
20{ }^{\circ} \mathrm{C}\end{array}$ & $\alpha_{\mathrm{s}}$ & $\begin{array}{c}k_{\mathrm{t}}^{1,1} / \\
\left(10^{6} \mathrm{~L} \mathrm{~mol}^{-1} \mathrm{~s}^{-1}\right)\end{array}$ & $\begin{array}{c}\eta / \\
(\mathrm{mPa} \cdot \mathrm{s})\end{array}$ & $\begin{array}{c}k_{\mathrm{t}}^{1,1} \cdot \eta / \\
\left(10^{8} \mathrm{~L} \mathrm{~mol}^{-1} \mathrm{mPa}\right)\end{array}$ \\
\hline \hline $\begin{array}{c}70 \mathrm{wt} \% \\
\text { PEGMA }\end{array}$ & 0.67 & $4.3 \pm 1.2$ & 29.4 & 1.3 \\
$\begin{array}{c}50 \mathrm{wt} \% \\
\text { PEGMA }\end{array}$ & 0.70 & $9.8 \pm 1.2$ & 12.3 & 1.2 \\
$\begin{array}{c}30 \mathrm{wt} \% \\
\text { PEGMA }\end{array}$ & 0.69 & $27.4 \pm 3.5$ & 4.68 & 1.3 \\
$\begin{array}{c}\text { DMA } \\
\text { bulk }\end{array}$ & 0.65 & $28.5 \pm 1.5$ & 4.63 & 1.3 \\
\hline
\end{tabular}




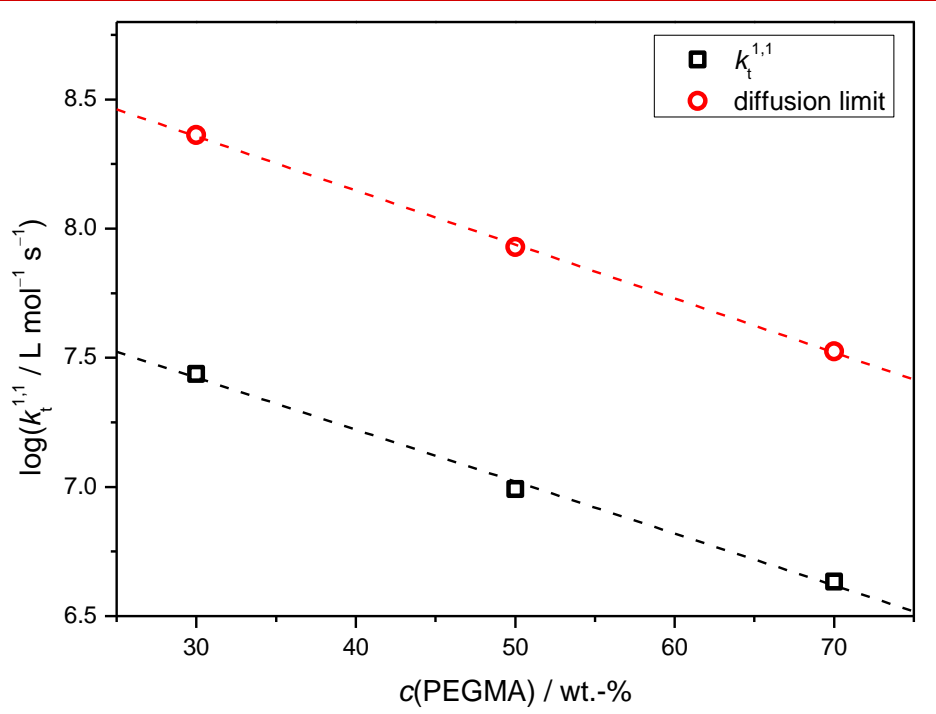

Figure 3.13: Solvent dependence of $k_{\mathrm{t}^{1,1}}$ and diffusion limit for various PEGMA/ $\mathrm{H}_{2} \mathrm{O}$ compositions at $20{ }^{\circ} \mathrm{C}$.

hydrodynamic radius, $r_{\mathrm{h}}$, and shielding of the radical site. ${ }^{[129]}$

PEGMA as a sterically demanding monomer is structurally similar to DMA. Both monomers possess a long side chain and an $\alpha$-methyl group. They exhibit a similar viscosity at $20^{\circ} \mathrm{C}$. In Table 3.5 are listed the $k^{1,1}, \alpha_{s}, \eta$ and $k_{\mathrm{t}^{1,1}} \cdot \eta$ values for DMA in bulk at $20^{\circ} \mathrm{C}$. For $30 \mathrm{wt} \%$ PEGMA in $\mathrm{H}_{2} \mathrm{O} \quad k^{1,1}$ is $27.4 \cdot 10^{6} \mathrm{~L} \mathrm{~mol}^{-1} \mathrm{~s}^{-1}$ and DMA bulk $k \mathrm{t}^{1,1}$ is $28.5 \cdot 10^{6} \mathrm{~L} \mathrm{~mol}^{-1} \mathrm{~s}^{-1}$. Both values of $k_{\mathrm{t}^{1,1}}$ lie in the same range and are in good agreement with theoretical expectations due to similar viscosities of $30 \mathrm{wt} \%$ PEGMA and DMA bulk being 4.68 and $4.63 \mathrm{mPa} \cdot \mathrm{s}$, respectively. Yet, it should be considered that the knowledge of the viscosity does not provide $k \mathrm{t}^{1,1}$, as $R_{\mathrm{c}}$ and the hydrodynamic radius may vary with the type of monomer. As PEGMA and DMA are structurally similar, it seems reasonable to assume that both monomers provide a similar $R_{\mathrm{c}} / r_{\mathrm{h}}$.

Since $k^{1,1}$ is closely connected to viscosity, it seems plausible to extrapolate $k_{\mathrm{t}^{1,1}}$ values at given temperatures via the viscosity of the actual mixture. It has also been shown that $k \mathrm{t}^{1,1}$ has a more or less comparable temperature dependence as the inverse 
viscosity. ${ }^{[62,122,128,130,131]}$ Therefore it is not necessary to measure $k_{\mathrm{t}}{ }^{1,1}$ values for every temperature. In favorable cases, only a single $k_{t^{1}}{ }^{1,1}$ value in combination with viscosity measurements may allow to estimate $k_{\mathrm{t}^{1}, 1}$ values. ${ }^{[126,130,131]}$ The same appears to be true for $\alpha_{\mathrm{s}}$ being independent of temperature and solvent mixture composition. ${ }^{[62,122,128]}$

However, the characteristic composite-model parameter $i_{c}$ is not necessarily independent of temperature and solvent composition. $i_{\mathrm{c}}$ is estimated by the intersection of the straight lines in Figure 3.11, which were used to determine the power-law exponents in Figure 3.11 and Figure 3.14.

As seen in Figure 3.11 and Figure 3.14, the $i_{c}$ values exhibit a solvent dependency and $i_{c}$ is decreasing from 200 toward 70 for 70 and $30 \mathrm{wt} \%$ PEGMA in aqueous solution. In Table 3.4 are listed the $i_{c}$ values for various PEGMA/ $\mathrm{H}_{2} \mathrm{O}$ mixtures at $20{ }^{\circ} \mathrm{C}$. Similar high $i_{\mathrm{c}}$ values between 200 and 100 were also found for sterically demanding monomers such as DMA, tert-butylmetharcylate, EHMA and dodecylacrylate (DA). ${ }^{126,128]}$

The difference in $i_{c}$ might be caused by chain-length-dependent propagation, which would result in a lower $\alpha_{\mathrm{s}}$ value. This theory can be discarded in this case as $\alpha_{\mathrm{s}}$ is independent of water concentration. This is in agreement with other observations for $\alpha_{\mathrm{s}}$ being independent of temperature and solvent type. ${ }^{[62,128]}$

The influence on $i_{\text {c }}$ of a too high $k_{\mathrm{p}}$ can be excluded. To achieve a constant $i_{\text {c, }} k_{\mathrm{p}}$ would have to be by a factor 2 lower to $900 \mathrm{~L} \mathrm{~mol}^{-1} \mathrm{~s}^{-1}$ for the experiments with higher water content. Such low $k_{\mathrm{p}}$ value would not be not consistent with the findings in chapter 3.1.

A final explanation for a changing $i_{c}$ with the solvent environment and monomer cannot be given at this point. An increasing $i_{c}$ with longer side chain has been reported for vinyl acetate and vinyl pivalate as well as for acrylates. ${ }^{[128,131]}$ This effect is explained by the assumption that $i_{\mathrm{c}}$ is related to chain flexibility and that chains with more spherical pendant groups exhibit a higher $i_{c}$ due to higher stiffness. ${ }^{[117]}$ For acrylates it has been found that $i_{c}$ decreases from bulk to solutions in toluene. ${ }^{[128]}$

For DMA and EHMA it has been observed that $i_{c}$ is temperature dependent which has been assigned to a better chain flexibility at elevated temperatures.[126] This observation suggests enhanced segmental mobility at higher temperature which allows for easier entanglement of macroradicals already at smaller size of the growing radicals. This explanation is corrobareted by the assumption that the 
Kinetics of Poly(ethylene glycol) methyl ether methacrylate

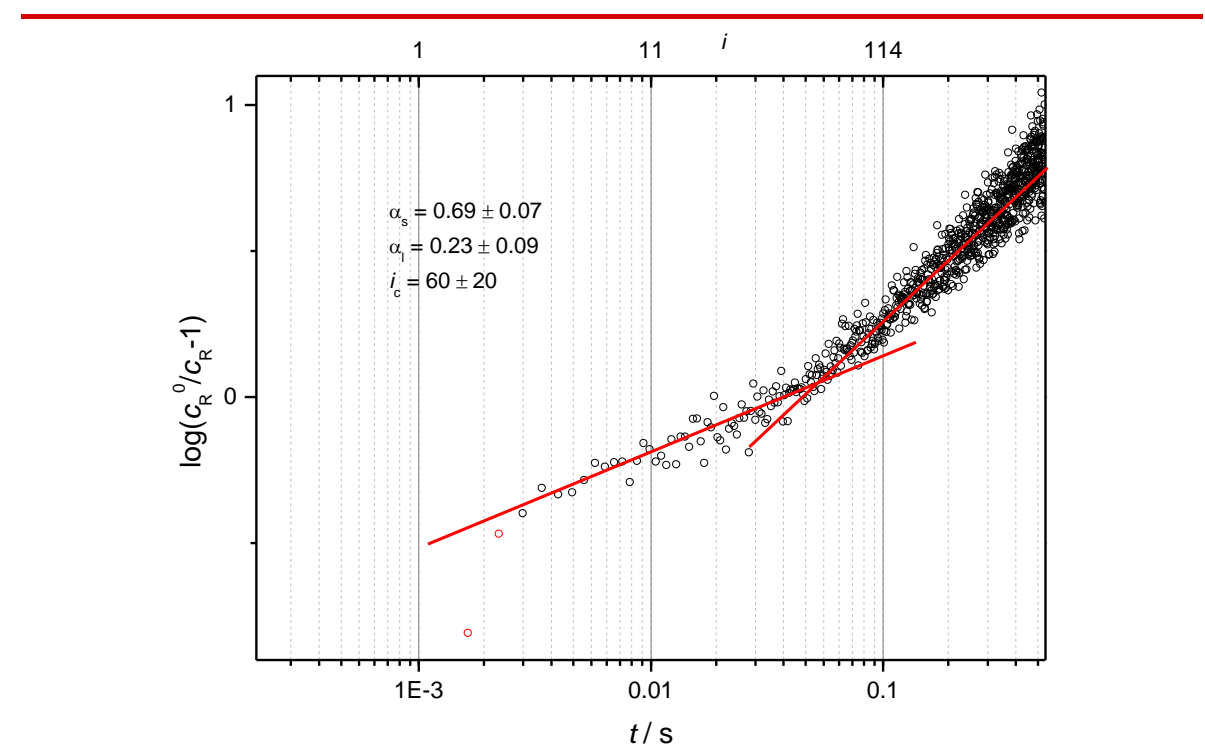

Figure 3.14: Double-log plot of the SP-PLP-EPR data for PEGMA/ $\mathrm{H}_{2} \mathrm{O}$ in $30 \mathrm{wt} \%$ PEGMA at $20^{\circ} \mathrm{C}$. Analysis of the long-chain regime yields $\alpha \mathrm{l}$, the crossover chain length $i_{c}$ is obtained by the intersection of the two straight lines.

crossover-chain length is associated with a transition from translational diffusion control to segmental diffusion control toward larger $i$. According to this argument, the lowering of $i_{c}$ toward higher water content indicates increasing mobility. This interpretation is consistent with the observed enhancement of PEGMA $k_{\mathrm{p}}$ upon passing to higher water content.

Apart from the correlation of $i_{c}$ with chain flexibility within a monomer family, $i_{c}$ should be considered as an empirical parameter, which describes the transition from translational diffusion control of short-chain radicals toward the segmental diffusion control of longchain radicals. 


\section{4}

\section{Cu-mediated ATRP in aqueous solution}

This chapter deals with the measurement of ATRP-relevant rate coefficients and equilibrium constants for the $\mathrm{CuBr} / 2,2^{\prime}$-bipyridine catalyst in aqueous solution. The ATRP parameters will be investigated for the monomer-free model system and an actual polymerization with PEGMA via both online FT-Vis/NIR spectroscopy and the highly timeresolved SP-PLP-EPR technique. The deactivation rate coefficient, $k_{\text {deact, }}$ is directly measured in aqueous solution for the first time. The precise knowledge of ATRP rate coefficients allows for the prediction of polymerization rate, monomer conversion vs time, dispersity and chainend functionality. Therefore, the measurements are accompanied with PREDICI $^{\circledR}$ simulations to provide further guidance for suitable reaction conditions.

With the exception of electro-chemical studies by the Matyjaszewski group, ${ }^{[43,47]}$ in which ATRP equilibrium constants and rate coefficients have been measured via cyclovoltametry in aqueous solution, such ATRP data have so far been only obtained either by extrapolation via linear solvation energy correlations, by analysis in terms of Kamlet-Taft parameters or by scaling against solvent polarity and dielectric constant of the organic solvents. ${ }^{[46]}$ Extrapolation of KATRP values measured in organic solvents on a polarity scale suggests that KATRP in an aqueous environment should be by one to four orders of magnitude above KATRP in typical organic solvents. ${ }^{[42]}$ This enhancement of KATRP may probably 
be due to an increase of $k_{\text {act }}$ because of the higher charge of $\mathrm{Cu}^{\mathrm{II}}$ and because of $\mathrm{Cu}^{\mathrm{I}}$ complexes potentially occurring as non-charged species. ${ }^{[132]}$ The preference for $\left[\mathrm{Cu}^{\mathrm{II}} \mathrm{LnX}\right]^{+}[\mathrm{X}]^{-}$over $\left[\mathrm{Cu}{ }^{\mathrm{I}} \mathrm{Ln}\right]^{+}[\mathrm{X}]^{-}$in highly polar solvents has also been predicted by quantum-chemical calculations. ${ }^{[41]}$ The direct measurement of $k_{\text {act, }} k_{\text {deact }}$ and KATRP in aqueous solution in the present study aims at understanding the increase in KATRP.

However, the kinetics of ATRP in aqueous solution are complicated due to potential halide dissociation of the penta-coordinated $\left[\mathrm{Cu}^{\mathrm{II}} \mathrm{LnX}\right]^{+}[\mathrm{X}]^{-}$complex and formation of a hydrated halide ion, which as shown in the lower part of Scheme 4.1 below. ${ }^{[38]}$ Polar solvent molecules, such as $\mathrm{H}_{2} \mathrm{O}$, also occupy coordination sites and substitute the halide ligand to the inactive $\left[\mathrm{Cu}^{\mathrm{II}} \mathrm{Ln}\left(\mathrm{H}_{2} \mathrm{O}\right)\right]^{2+}$ deactivator complex due to the absence of halide.

Matyjaszewski et al. showed that the unfavorable transformation to the hydrated species occurs up to $92 \%$ for $\left[\mathrm{Cu}^{\mathrm{II}}(\mathrm{bpy}){ }_{2} \mathrm{Br}\right]^{+}[\mathrm{Br}]^{-}$in pure water. ${ }^{[38]}$ The associated reduction in deactivator concentration results in poor control of the ATRP. By adding halide ions, e.g., sodium salts or organic halide salts, the dissociation equilibrium may be shifted to the side of the active ATRP species $\mathrm{Cu}^{\mathrm{II}} \mathrm{Ln} X .{ }^{[38]}$

\subsection{Monomer-Free Model System ${ }^{2}$}

Due to the absence of monomer, the reaction scheme for the monomer-free ATRP model system consists of three reaction steps: ATRP activation, ATRP deactivation and termination of two small radicals. This simplified model system is perfectly suited for the direct investigation of the effect of water on the activation-deactivation equilibrium without the interference PEGMA propagation kinetics which depends on water concentration.

The measurements of the equilibrium constants for a monomer-free model system, $K_{\text {model, }}$ and of the activation rate coefficients, $k_{\text {act, }}$ were

2 Reproduced with permission from Smolne, S.; Buback M. Macromolecular Chemistry and Physics 2015, 216, 894-902, Copyright 2015 John Wiley and Sons. 
carried out in a solvent mixture of $\mathrm{H}_{2} \mathrm{O}$ and poly(ethylene glycol)dimethyl ether (PEO). PEO has been selected as co-solvent to mimic the polymerization of poly(ethylene glycol) methyl ether methacrylate (PEGMA). Solvent compositions between 20 and $80 \mathrm{wt} \% \mathrm{H}_{2} \mathrm{O}$ were chosen. A large body of ATRPs with PEGMA in the presence of 50 to $70 \mathrm{wt} \%$ water have already been reported. ${ }^{[33,108,133]}$

To estimate $K_{\text {model }}$ and $k_{\text {act, }}$ online FT-Vis/NIR spectroscopy has been applied for the quantitative analysis of the persistent radical concentration, $\quad\left[\mathrm{Cu}^{\mathrm{II}}\left(2,2^{\prime} \text {-bipyridine }\right){ }_{2} \mathrm{Br}\right]^{+}[\mathrm{Br}]^{-}$. To gain further mechanistic insights, $K$ model has been measured at pressures up to 2000 bar for deducing reaction volumes, $\Delta V_{\mathrm{R}}$. Via PREDICI ${ }^{\circledR}$ modeling it was checked, whether the obtained rate coefficients may be used for estimates of $\left[\mathrm{Cu}^{\mathrm{II}}(\mathrm{bpy})_{2} \mathrm{Br}\right]^{+}[\mathrm{Br}]^{-}$concentration at widely varying contents of the sodium salt, e.g., of $\mathrm{NaBr}$.

\subsubsection{Determination of $K_{\text {model }}$}

As shown in the upper part of Scheme 4.1, the copper-mediated ATRP mechanism consists of reversible oxidation of a tetra-coordinated copper(I)-ligand complex, $\left.\left[\mathrm{Cu}^{\mathrm{L}}\right]_{n}\right]^{+}[\mathrm{X}]^{-}$, with an alkyl halide, $\mathrm{R}-\mathrm{X}$, to produce a penta-coordinated $\left[\mathrm{Cu}^{\mathrm{II}} \mathrm{LnX}\right]^{+}[\mathrm{X}]^{-}$species and an alkyl radical, $R \cdot\left[{ }^{[6,39]}\right.$ The activation rate coefficient is denoted by $k_{\text {act, }}$ whereas the back reaction occurs with the deactivation rate coefficient, $k_{\text {deact. }}$ The radical produced by the activation step may add to a monomer molecule, $M$, with the propagation rate coefficient $k_{\mathrm{p}}$ and may terminate with another radical, with the rate coefficient $k_{\mathrm{t}}$. Both $k_{\mathrm{p}}$ and $k_{\mathrm{t}}$ should be identical to the associated rate coefficients of conventional radical polymerization of M. The ratio $k_{\text {act }}$ to $k_{\text {deact }}$ represents the ATRP equilibrium constant, $K_{\text {ATRP }}=k_{\text {act }} / k_{\text {deact. }}$. Higher $K_{\text {ATRP }}$ is associated with faster ATRP.

The measurement of $K_{\text {model }}$ in aqueous solution is especially challenging because of various side reactions. The most important side reaction is the potential dissociation of the penta-coordinated $\left[\mathrm{Cu}^{\mathrm{II}} \mathrm{LnX}\right]^{+}[\mathrm{X}]^{-}$complex and formation of a hydrated halide ion, as shown in the lower part of Scheme 4.1. ${ }^{[38]}$ The equilibrium constant for the halide dissociation is denoted by $K x$, which provides a measure for the strength of the halide complex. $\mathrm{H}_{2} \mathrm{O}$ molecules may occupy coordination 


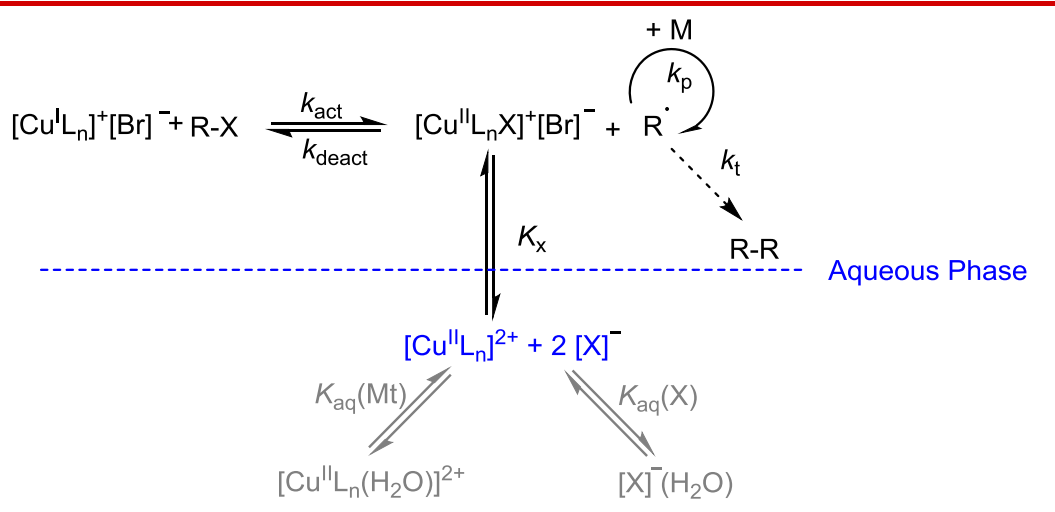

Scheme 4.1: Suggested mechanism of $\mathrm{Cu}$-mediated ATRP in aqueous solution; Ln ligand with $\mathrm{n}$ complexing sites, $\mathrm{R}-\mathrm{X}$ initiator, $\mathrm{M}$ monomer, $\mathrm{R} \cdot$ propagating radical, $k_{\mathrm{p}}$ propagation rate coefficient, $k_{\mathrm{t}}$ termination rate coefficient, $K_{x}$ halide dissociation equilibrium constant, $K_{a q}(\mathrm{Mt})$ equilibrium constant of water complexation, $K_{a q}(X)$ equilibrium constant for hydration of the halide ion.

sites and substitute the halide ligand. This dissociation side reaction may lead to hydration of both the $\left[\mathrm{Cu}^{\mathrm{II}} \mathrm{Ln}\right]^{2+}$ and $[\mathrm{X}]^{-}$species. These processes are quantified by the equilibrium constants $K_{a q}(\mathrm{Mt})$ and $K_{a q}(X)$, respectively. Due to the absence of halide the produced $\left[\mathrm{Cu}^{\mathrm{II}} \mathrm{Ln}\left(\mathrm{H}_{2} \mathrm{O}\right)\right]^{2+}$ is unable to deactivate radicals. The equilibria represented by $K_{a q}(\mathrm{X})$ and $K_{\mathrm{aq}}(\mathrm{Mt})$ are established almost immediately. It appears justified to include these side equilibria into a single equilibrium constant, $K x$.

To measure $K_{\text {model }}$ and in order to avoid hydration and dissociation of the $\mathrm{Cu}^{\mathrm{II}}$-complex, up to 1000 equivalents $\mathrm{NaBr}$ relative to copper concentration have been added to the solution. Previous studies indicated that such high quantities of $\mathrm{NaBr}$ are required for shifting the equilibrium more or less quantitatively towards the ATRP-active halide complex. ${ }^{[38]}$

Kmodel was determined from the $\left[\mathrm{Cu}^{\mathrm{II}}(\mathrm{bpy})_{2} \mathrm{Br}\right]^{+}[\mathrm{Br}]^{-}$complex concentration vs time traces for the monomer-free model system in water-PEO solutions. The $\left[\mathrm{Cu}^{\mathrm{II}}(\mathrm{bpy})_{2} \mathrm{Br}\right]^{+}[\mathrm{Br}]^{-}$concentration was measured via the Vis/NIR absorption of the copper d-d-transition. 
Figure 4.1 shows a so-obtained spectral series for $7 \mathrm{mmol} \cdot \mathrm{L}^{-1}$ $\left[\mathrm{Cu}^{\mathrm{II}}(\mathrm{bpy})_{2} \mathrm{Br}\right]^{+}[\mathrm{Br}]^{-}, 500$ equivalents of $\mathrm{NaBr}$ and $91 \mathrm{mmol} \cdot \mathrm{L}^{-1} \mathrm{HEMA}-$ $-\mathrm{Br}$ in a $50 \mathrm{wt} . \%$ water-PEO mixture at $22{ }^{\circ} \mathrm{C}$. The increase of $\left[\mathrm{Cu}^{\mathrm{II}}(\mathrm{bpy})_{2} \mathrm{Br}\right]^{+}[\mathrm{Br}]^{-}$concentration with time, indicated by the direction of the arrow in Figure 4.1, was quantitatively monitored via the absorbance between 13300 and $11400 \mathrm{~cm}^{-1}$. The absorbance between 15500 and $8500 \mathrm{~cm}^{-1}$ is assigned to the $\left[\mathrm{Cu}^{\mathrm{II}}(\mathrm{bpy})_{2} \mathrm{Br}\right]^{+}[\mathrm{Br}]^{-}$-species. The absorption between 10500 and $9500 \mathrm{~cm}^{-1}$ at $t=0$ may not be assigned to the $\mathrm{d}-\mathrm{d}$ absorption of the $\left[\mathrm{Cu}^{\mathrm{II}^{*}}(\mathrm{bpy})_{2} \mathrm{Br}\right]^{+}[\mathrm{Br}]^{-}$complex, therefore the integration is limited to $11400 \mathrm{~cm}^{-1}$. The increase in $\mathrm{Cu}^{\mathrm{II}}$-concentration results from termination of radicals according to Scheme 4.1.

It has been reported that some $\mathrm{Cu}^{\mathrm{I}} /$ ligand systems may disproportionate in aqueous solution. ${ }^{[134]}$ This is obviously not the case with the $\mathrm{Cu}^{\mathrm{I}}$-complex under investigation, at least not on the time scale of the experiments. Measurements over several hours, in the absence of the initiator $\mathrm{R}-\mathrm{X}$, showed no $\mathrm{Cu}^{\mathrm{II}}$ evolution and no $\mathrm{Cu}^{0}$ was produced, which would indicate $\mathrm{Cu}^{\mathrm{I}}$ species undergoing disproportion. There is also no indication of $\mathrm{Cu}^{\mathrm{II}}$ comproportionation, which would require trace amounts of $\mathrm{Cu}^{0}$. In contrast to the stable $\mathrm{Cu} / \mathrm{bpy}$ system the $\mathrm{Cu} / \mathrm{Me} 6$ TREN complex disproportionates in a few minutes. ${ }^{[135]}$ The reason for the difference is not yet clear. Perhaps the conjugated $\pi$ system of bpy contributes to stabilization against disproportionation.

The equilibrium constant for the model system, Kmodel, was estimated from the Fischer-Fukuda-equation modified by Matyjaszewski et al. for systems with large equilibrium constants and non-equimolar initial concentrations, i.e., via the so-called F[Y]-function, ${ }^{[45]}$ :

$$
\begin{gathered}
F([\mathrm{Y}])=\left(\frac{[\mathrm{I}]_{0}[\mathrm{C}]_{0}}{[\mathrm{C}]_{0}-[\mathrm{I}]_{0}}\right)^{2}\left(\frac{1}{[\mathrm{C}]_{0}^{2}\left([\mathrm{I}]_{0}-[\mathrm{Y}]\right)}+\frac{2}{[\mathrm{I}]_{0}[\mathrm{C}]_{0}\left([\mathrm{C}]_{0}-[\mathrm{I}]_{0}\right)}\right. \\
\left.\cdot \ln \left(\frac{[\mathrm{I}]_{0}-[\mathrm{Y}]}{[\mathrm{C}]_{0}-[\mathrm{Y}]}\right)+\frac{1}{[\mathrm{I}]_{0}^{2}\left([\mathrm{C}]_{0}-[\mathrm{Y}]\right)}\right) \\
F([\mathrm{Y}])=2 \cdot k_{\mathrm{t}} \cdot K_{\text {model }}^{2} \cdot t+c^{\prime}
\end{gathered}
$$




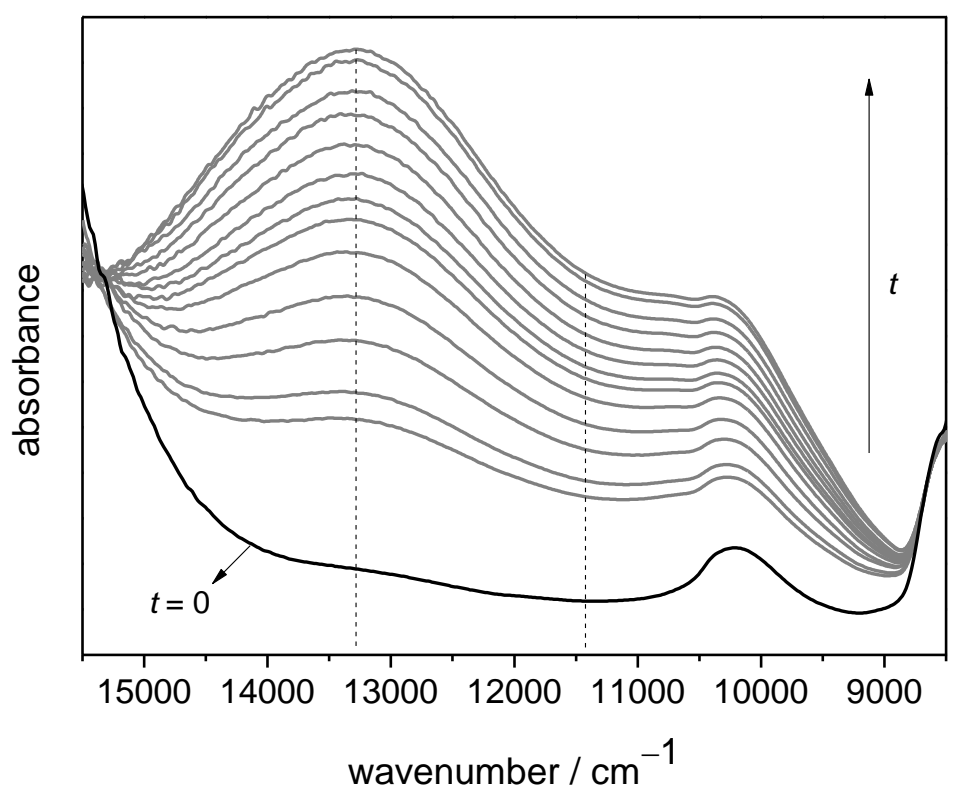

Figure 4.1: FT-Vis/NIR spectral series recorded during the reaction of $7 \mathrm{mmol} \cdot \mathrm{L}^{-1} \mathrm{Cu}^{\mathrm{I}}(\mathrm{Bpy})_{2} \mathrm{Br}, 91 \mathrm{mmol} \cdot \mathrm{L}^{-1}$ HEMA-Br and 500 equivalents of $\mathrm{NaBr}$ in a $50 \mathrm{wt} . \%$ water-PEO mixture at $22{ }^{\circ} \mathrm{C}$ and ambient pressure. The absorbance of the $\mathrm{Cu}^{\mathrm{II}}$ complex increases with time $t$. The dashed lines denote the upper and lower limiting wavenumbers for integration. Integrated absorbance due to the $\mathrm{Cu}^{\mathrm{II}}$ complex was determined from the absorbance difference to the spectrum recorded at $t=0$.

The initial concentrations of initiator and of the $\mathrm{Cu}^{\mathrm{I}}$-complex are represented by $[\mathrm{I}]_{0}$ and $[\mathrm{C}]_{0}$, respectively. The time-dependent concentration of the $\mathrm{Cu}^{\mathrm{II}}$ complex is denoted by [Y]. Equation 4.1 holds for situations where only a single $\mathrm{Cu}^{\mathrm{II}}$-complex is present, i.e., without taking the dissociation of the $\left[\mathrm{Cu}^{\mathrm{II}} \mathrm{LnX}\right]^{+}[\mathrm{Br}]^{-}$complex and subsequent halide hydration into account. Analysis of Kmodel via Equation 4.2 should however be valid at large excess concentration of $\mathrm{NaBr}$. 


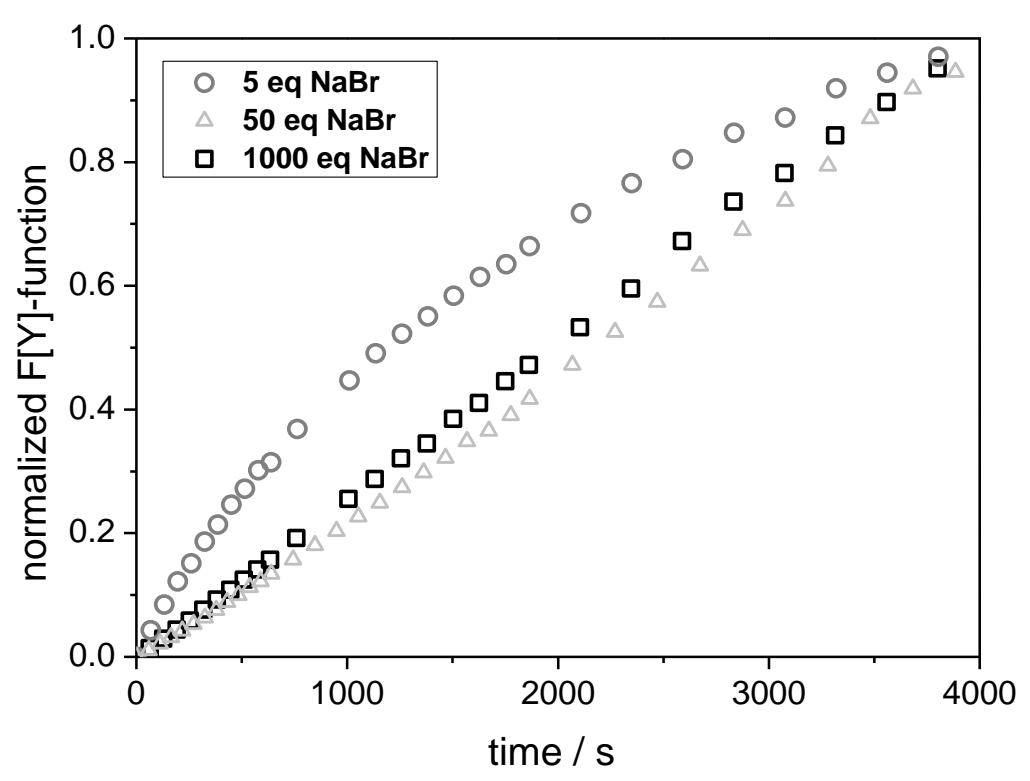

Figure 4.2: Plot of the normalized $F[Y]$-function vs. time for a reacting system containing $70 \mathrm{wt} \%$ water, $7 \mathrm{mmol} \cdot \mathrm{L}^{-1} \mathrm{Cu}^{\mathrm{I}}(\mathrm{Bpy}){ }_{2} \mathrm{Br}$, as well as 5, 50, and 1000 equivalents of $\mathrm{NaBr}$ at $22{ }^{\circ} \mathrm{C}$ with HEMA-Br acting as the initiator.

Shown in Figure 4.2 are three normalized $F[Y]-$ functions plotted vs. time $t$, measured with 5,50 and 1000 equivalents of $\mathrm{NaBr}$ being added to a reacting mixture composed of $70 \mathrm{wt} \%$ water in $\mathrm{PEO}$ with $7 \mathrm{mmol} \cdot \mathrm{L}^{-1}$ $\left[\mathrm{Cu}^{\mathrm{I}}(\mathrm{bpy})_{2}\right]^{+}[\mathrm{Br}]^{-}$and with HEMA-Br acting as the initiator. Straight-line behavior, as predicted by Equation 4.2, is only seen for the data measured upon the addition of 1000 equivalents of $\mathrm{NaBr}$. The strong curvature of the $F[Y]$-function for 5 equivalents of $\mathrm{NaBr}$ and the weak curvature for 50 equivalents of $\mathrm{NaBr}$ indicate the presence of additional copper species at these lower $\mathrm{NaBr}$ levels. Straight-line behavior probably occurs from 300 to 500 equivalents $\mathrm{NaBr}$ on. Thus the analyses for $K_{\text {model }}$ have been carried out with $\mathrm{NaBr}$ being present in large excess.

With the termination rate coefficient, $k_{\mathrm{t}}$, being known, the slope of the linear $F[Y]$-plot yields the ATRP equilibrium constant $K_{\text {model. }}$ For the low-molar-mass model system, $k_{\mathrm{t}}$ may be identified with $k_{\mathrm{t}^{1,1}}$, the rate coefficient for termination of two radicals of chain length unity, which is 
accessible from literature in conjunction with viscosity being measured for the particular solvent system. ${ }^{[69]}$ The viscosity of the solution depends on the water-PEO ratio as well as on the concentration of $\mathrm{NaBr}$ and has been measured by means of a falling ball viscometer for the pure solvents and for three solvent mixtures with and without excess $\mathrm{NaBr}$. Alternatively, $k_{\mathrm{t}^{1,1}}$ may be determined via pulsed-laser experiments in conjunction with highly time-resolved EPR spectroscopy. ${ }^{[62]}$ The two approaches result in $k_{t^{1,1}}$ values which differ by a factor of 4 . As $k_{t}$ exhibits a square-root dependence, the associated uncertainty of the $K$ model reduces to a factor of 2.[69]

$K_{\text {model }}$ has been determined for a wide range of $\mathrm{PEO}-\mathrm{H}_{2} \mathrm{O}$ compositions. Due to the insolubility of the copper complex in $\mathrm{H}_{2} \mathrm{O}$, $K_{\text {model }}$ for pure water has been deduced by linear extrapolation of the Kmodel data in Figure 4.3 for the model system $\mathrm{Cu}^{\mathrm{I}} \mathrm{Br}\left(2,2^{\prime}-\right.$ bipyridine)/HEMA-Br obtained in solvent mixtures of different PEOwater content at $22{ }^{\circ} \mathrm{C}$. The solvent compositions include situations which mimic polymerization conditions. Most of the reported ATRPs with PEGMA were obtained at about $70 \mathrm{wt} \%$ water. ${ }^{[33,108,133]}$

Figure 4.3 shows the steep increase of Kmodel towards higher water content. At $22{ }^{\circ} \mathrm{C}$, Kmodel increases by about a factor of 100 , from $4.7 \cdot 10^{-8}$ to $4.6 \cdot 10^{-6}$, in passing from 20 to $80 \mathrm{wt} \% \mathrm{H}_{2} \mathrm{O}$. Linear extrapolation on the semi-log scale, $\ln K_{\text {model }}$ vs $\mathrm{wt}_{\mathrm{O}} \mathrm{H} \mathrm{H}_{2} \mathrm{O}$ toward pure water yields $K_{\text {model }}=2.5 \cdot 10^{-5}$ and $K_{\text {model }}=1.5 \cdot 10^{-8}$ results for pure PEO. Thus $K_{\text {model }}$ varies within the entire $\mathrm{H}_{2} \mathrm{O}-\mathrm{PEO}$ range by a factor 1500 . A change of this size is also predicted by the correlation via the Kamlet-Taft relationship for the difference between $K_{\text {model }}$ for $\mathrm{H}_{2} \mathrm{O}$ and polar solvents such as dimethyl formamide. ${ }^{[42]}$

On the basis of linear solvation energy correlations and of electrochemical measurements, the Kamlet-Taft parameters predict Kmodel in a water environment to be by a factor of $10^{3}$ to $10^{4}$ above $K_{\text {model }}$ in a purely organic environment, ${ }^{[42]}$ which is in agreement with the data in Figure 4.3. It was also reported that $K_{\text {model }}$ of the $\mathrm{CuBr} / \mathrm{Me} 6 \mathrm{TREN}$ system increases by a factor of 100 from an organic solvent toward pure water. ${ }^{[47]}$ Matyjaszewski et al. predicted Kmodel for CuBr/HMTETA in aqueous solution to be $5.9 \cdot 10^{-5}$, which is close to our estimated value for the bipyridine system to be $2.5 \cdot 10^{-5}$. Such difference in KatRP has also been observed for Kmodel with HMTETA and bipyridine in acetonitrile solution. For the initiator methyl 2-bromo-iso-butyrate 


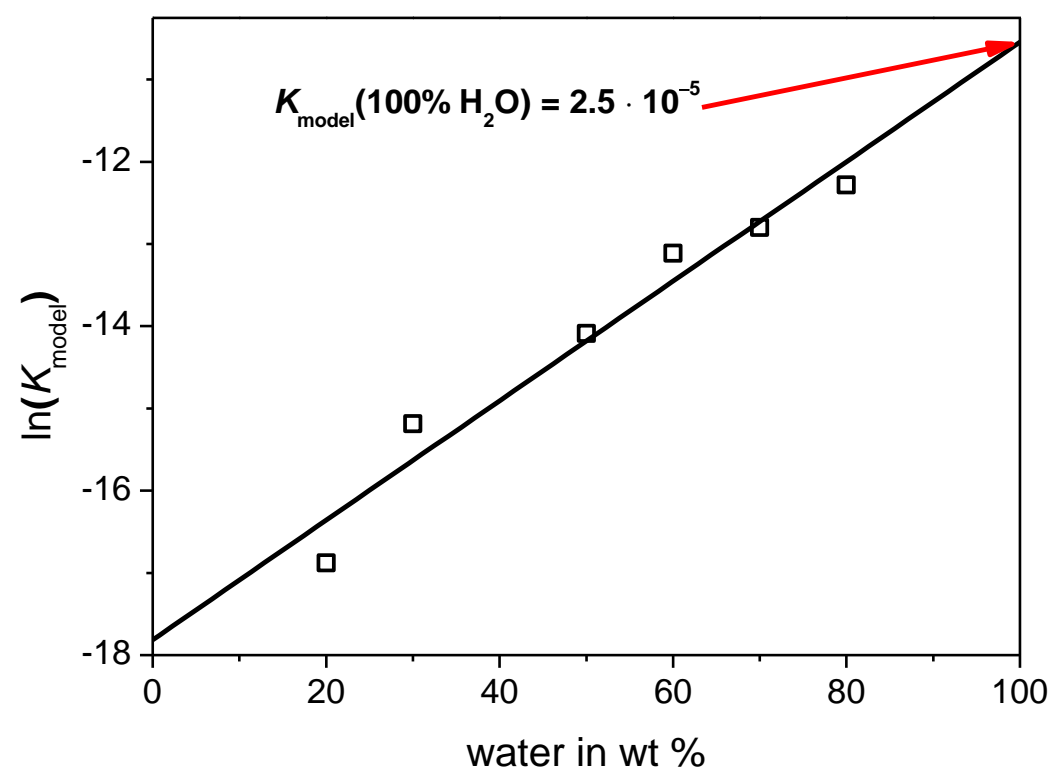

Figure 4.3: Plot of $\ln K_{\text {model }}$ vs. the weight fraction of water in $\mathrm{H}_{2} \mathrm{O}-\mathrm{PEO}$ mixtures for the monomer-free model system $\mathrm{CuBr} / 2,2^{\prime}$-bipyrdine at $22{ }^{\circ} \mathrm{C}$. The open squares are measured data to which the straight line has been fitted.

(MBriB), the resulting value for $\mathrm{CuBr} / \mathrm{HMTETA} / \mathrm{MBriB}$ is $K_{\text {model }}=2.8 \cdot 10^{-8}$ which is about four times above the value for $\mathrm{CuBr} / \mathrm{Bpy} / \mathrm{MBriB}, K_{\text {model }}=7.3 \cdot 10^{-9} .{ }^{[59,60]}$

$K$ model has additionally been measured as a function of pressure. The experiments were carried out from 500 to 2000 bar for $5 \mathrm{mmol} \cdot \mathrm{L}^{-1}$ $\mathrm{Cu}^{\mathrm{I}}(\mathrm{bpy})_{2} \mathrm{Br}$, at HEMA-Br concentrations between 40 and $70 \mathrm{mmol} \cdot \mathrm{L}^{-1}$, and in $\mathrm{H}_{2} \mathrm{O}-\mathrm{PEO}$ mixtures containing 30,50 or $70 \mathrm{wt}$. \% water at $22{ }^{\circ} \mathrm{C}$. Plotted in Figure 4.4 are the obtained Kmodel data. Absolute Kmodel increases with water concentration as shown for ambient pressure in Figure 4.3. The data in Figure 4.4 demonstrates that the relative increase in $K_{\text {model }}$ with pressure is not affected by the water content. The slope to the straight lines in Figure 4.4 yields the reaction volume, $\Delta V_{\mathrm{R}}$, according to the relation: ${ }^{[59]}$ 


$$
\left[\frac{\delta \ln \left(K_{\text {model }}\right)}{\delta p}\right]=-\frac{\Delta V_{\mathrm{R}}}{R \cdot T}
$$

$\Delta V_{\mathrm{R}}$ is close to $-14 \mathrm{~cm}^{3} \mathrm{~mol}^{-1}$ irrespective of the concentration of water contained in the $\mathrm{H}_{2} \mathrm{O}-\mathrm{PEO}$ mixture. The negative $\Delta V_{\mathrm{R}}$ value indicates that the pressure effect results from the stronger contraction of the ligand sphere with the $\mathrm{Cu}^{\mathrm{II}}$-complex being a stronger Lewis acid than the $\mathrm{Cu}^{\mathrm{I}}$ species, as has been suggested for polar organic solvents. ${ }^{[59]}$ That $\Delta V_{\mathrm{R}}$ does not significantly vary with solvent environment indicates that the pressure dependence reflects an intrinsic effect of the copperligand system under investigation. Toward higher pressure, the pentacoordinated $\mathrm{Cu}^{\mathrm{II}}$-complex is favored over the tetra-coordinated $\mathrm{Cu}^{\mathrm{I}-}$ complex because of reduced molar volume resulting from the higher oxidation state and the higher coordination.

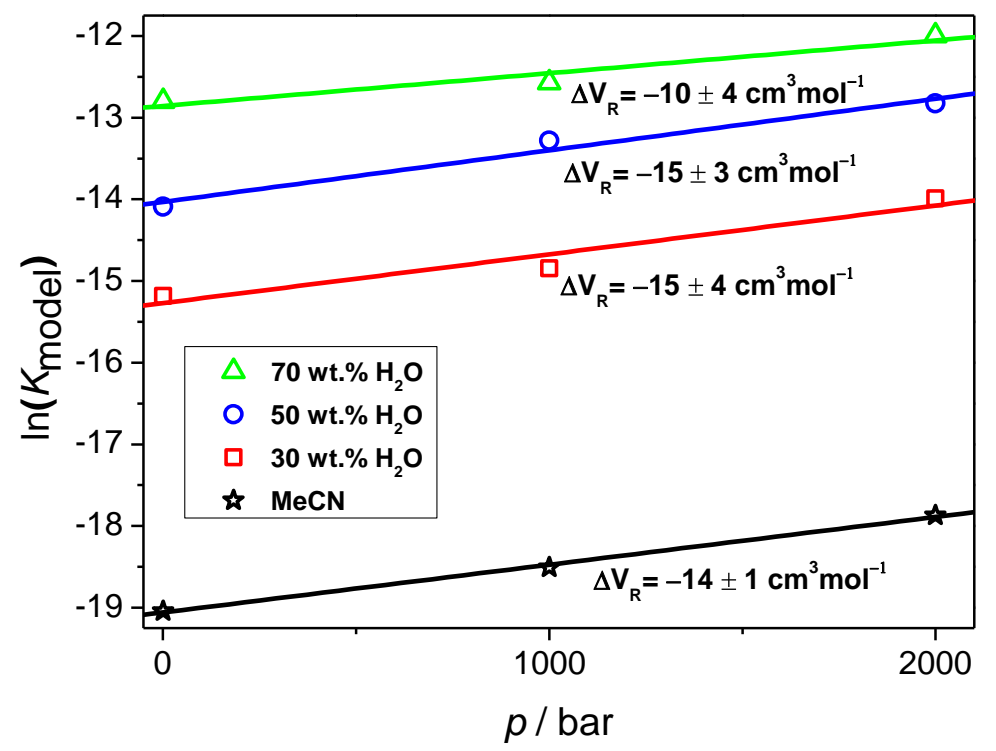

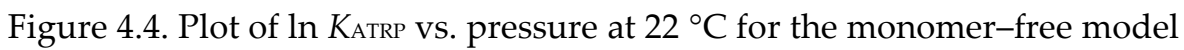
system with $7 \mathrm{mmol} \cdot \mathrm{L}^{-1} \mathrm{Cu}^{\mathrm{l} b p y}{ }_{2} \mathrm{Br}$ in acetonitrile as well as in different $\mathrm{H}_{2} \mathrm{O}-\mathrm{PEO}$ solvent mixtures. The slope of the straight lines yields the reaction volume, $\Delta V_{\mathrm{R}}$, for each mixture. 


\subsubsection{Determination of $k_{\text {act }}$}

In order to elucidate, to which extent the observed changes in $K_{\text {model }}=k_{\text {act }} / k_{\text {deact }}$ are due to effects on the activation rate coefficient, $k_{\text {act }}$, the deactivation rate coefficient, $k_{\text {deact, }}$ or on both coefficients, trapping experiments with TEMPOL have been performed. The strategy is the same as described by Fischer et al. using TEMPO. ${ }^{[136]}$ To allow for firstorder kinetics, both TEMPOL and the $\mathrm{Cu}^{\mathrm{I}}$-complex were used in a tenfold to twenty-fold excess relative to initiator concentration, [R-X].

$$
\begin{aligned}
& -\frac{\mathrm{d}[\mathrm{RX}]}{\mathrm{d} t}=k_{\mathrm{act}} \cdot[\mathrm{RX}] \cdot\left[\mathrm{Cu}^{\mathrm{I} L}\right] \\
& \rightarrow-\frac{\mathrm{d} \ln ([\mathrm{RX}])}{\mathrm{d} t} \approx k_{\mathrm{act}} \cdot\left[\mathrm{Cu}^{\mathrm{I}} \mathrm{L}\right]_{0}
\end{aligned}
$$

Illustrated in Figure 4.5A is the pseudo-first-order plot according to Equation 4.5 for the system $\left[\mathrm{Cu}^{\mathrm{I}}(\mathrm{bpy})_{2}\right]^{+}[\mathrm{Br}]^{-}$with $\mathrm{HEMA}-\mathrm{Br}$ as the initiator reacting at $22{ }^{\circ} \mathrm{C}$ in a water-PEO mixture containing $50 \mathrm{wt} \%$ $\mathrm{H}_{2} \mathrm{O}$. The $\mathrm{Cu}^{\mathrm{I}}$-complex concentration was obtained from the difference between the selected initial $\mathrm{Cu}^{\mathrm{I}}$ concentration and the measured $\mathrm{Cu}^{\mathrm{II}}$ complex concentration. The slope of the straight line fit yields $k_{\text {act }}=2.3 \cdot \mathrm{L} \mathrm{mol}^{-1} \cdot \mathrm{s}^{-1}$.

Figure $4.5 \mathrm{~B}$ illustrates the dependence of $k_{\text {act }}$ and $k_{\text {deact }}$ on water content for the system $\mathrm{Cu}^{\mathrm{I}}(\mathrm{bpy})_{2} \mathrm{Br} / \mathrm{HEMA}-\mathrm{Br}$ in $\mathrm{H}_{2} \mathrm{O}-\mathrm{PEO}$ mixtures at $22{ }^{\circ} \mathrm{C}$. The activation rate coefficient increases with the water content of the solvent mixture as does $K_{\text {model, }}$ which is evidenced from $k_{\text {deact }}=$ $K_{\text {model }} / k_{\text {act }}$ being insensitive towards water content (Figure $5 \mathrm{~B}$ ). The extrapolated limiting value of $k_{\text {act }}$ is enhanced by a factor of 1500 in passing from a PEO to a hypothetical pure water environment, i.e., from $4.8 \cdot 10^{-2} \mathrm{~L} \mathrm{~mol}^{-1} \cdot \mathrm{s}^{-1}$ to $66 \mathrm{~L} \mathrm{~mol}^{-1} \cdot \mathrm{s}^{-1}$, respectively. Matyjaszewski et al. already demonstrated that the better stabilization of the $\mathrm{Cu}^{\mathrm{II}}$-complex in more polar organic solvents enhances $k_{\text {act. }}{ }^{[1]}$ As a highly polar solvent, water follows this trend. For $22{ }^{\circ} \mathrm{C}$, $k_{\text {act }}$ in acetonitrile was found to be $4 \cdot 10^{-2} \mathrm{~L} \mathrm{~mol}^{-1} \cdot \mathrm{s}^{-1}$ which is close to the associated value for PEO. ${ }^{[36]}$

It should be mentioned that $k_{\text {act }}$ strongly increases toward higher 

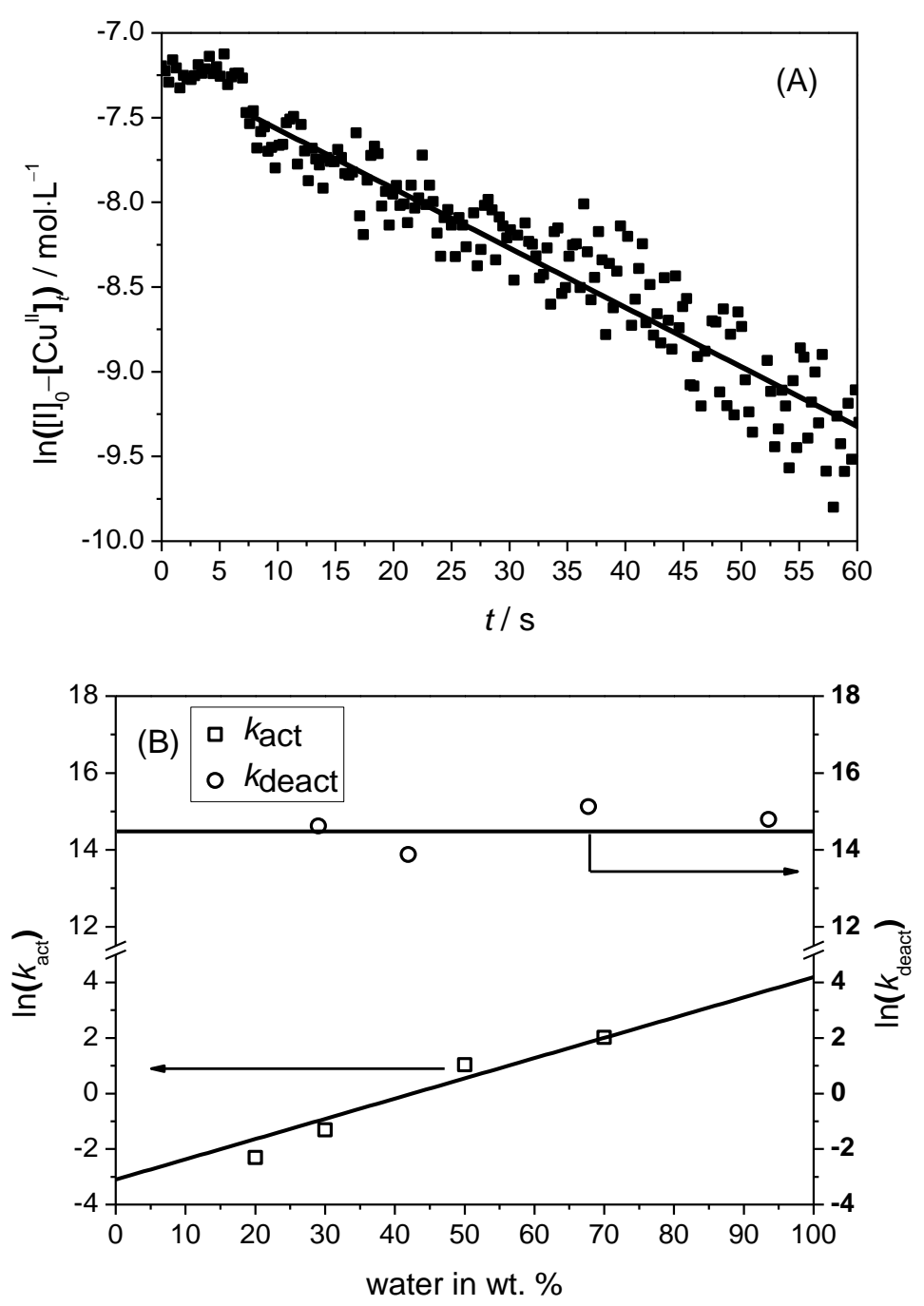

Figure 4.5: (A) Determination of $k_{\text {act }}$ by a pseudo-first-order plot for the reaction of $1.5 \cdot 10^{-2} \mathrm{~mol} \cdot \mathrm{L}^{-1} \mathrm{Cu}^{\mathrm{I}}(\mathrm{bpy})_{2} \mathrm{Br}, 8 \cdot 10^{-4} \mathrm{~mol} \cdot \mathrm{L}^{-1} \mathrm{HEMA}-\mathrm{Br}$, and $3.0 \cdot 10^{-2} \mathrm{~mol} \cdot \mathrm{L}^{-1}$ TEMPOL at $22{ }^{\circ} \mathrm{C}$ in a water-PEO mixture containing 50 wt. $\% \mathrm{H}_{2} \mathrm{O}$. (B) Dependence of $k_{\text {act }}$ and $k_{\text {deact }}$ on $\mathrm{H}_{2} \mathrm{O}$ content for the reaction of $\mathrm{Cu}^{\mathrm{l} b p y}{ }_{2} \mathrm{Br}$ with $\mathrm{HEMA}-\mathrm{Br}$ in water-PEO solutions at $22{ }^{\circ} \mathrm{C}$. 
water concentration, from $70 \mathrm{wt} \%$ water to pure water by about one order of magnitude. Matyjaszewski et al. reported that $k_{\text {act }}$ of the more active system $\mathrm{Cu} / \mathrm{Me}_{\mathrm{TREN}}$ increases by a factor of ten from a water (82 wt\%) mitxture with oligo(ethylene oxide) monomethyl ether acrylate (OEOA) to pure water with 2-hydroxyethyl $\alpha$-bromoisobutyrate (HEBiB) being the initiator. ${ }^{[47]}$

The deactivation rate coefficient, $k_{\text {deact, }}$ which is obtained from $k_{\text {act }}$ and $K_{\text {model }}$ to be $2.5 \cdot 10^{6} \mathrm{~L} \mathrm{~mol}^{-1} \cdot \mathrm{s}^{-1}$ at $22{ }^{\circ} \mathrm{C}$ and ambient pressure is by no more than a factor of three below the number reported for solution in acetonitrile: $k_{\text {deact }}=8.5 \cdot 10^{6} \mathrm{~L} \mathrm{~mol}^{-1} \cdot \mathrm{s}^{-1}{ }^{[36]}$ It has been suggested that $k_{\text {deact }}$ decreases towards more polar solvents. ${ }^{[41]}$ Thus $k_{\text {deact }}$ in aqueous solution should be lower than in acetonitrile. Figure 4.5B reveals no such trend. Within experimental accuracy, $k_{\text {deact }}$ is insensitive towards water content. The observed high $k_{\text {deact }}$ in an aqueous environment explains, why narrow molar mass distributions are obtained in aqueous-solution ATRPs irrespective of water content.[33,108,137]

The results in Figure 4.5B demonstrate that the strong variations of $K$ model are essentially due to changes of $k_{\text {act. }}$. The poor sensitivity of $k_{\text {deact }}$ suggests that small amounts of $\mathrm{NaBr}$ are sufficient to guarantee good control during ATRP even at low $\mathrm{Cu}^{\mathrm{II}}$ deactivator levels. 


\subsubsection{Modeling}

The rate coefficients $k_{\text {act }}$ and $k_{\text {deact }}$ have been deduced from experiments carried out under high loads of $\mathrm{NaBr}$. As it is desirable to run ATRP experiments at significantly smaller amounts of added salt, it appears interesting to find out, whether the $K_{\text {model }}$ and $k_{\text {act }}$ values from studies at high $\mathrm{NaBr}$ content are also valid at far lower $\mathrm{NaBr}$ concentration and thus may be used to identify optimum ATRP conditions at reduced levels of added $\mathrm{NaBr}$.

Plotted in Figure 4.6 is a spectral series measured for $3 \mathrm{~mm}$ $\left[\mathrm{Cu}^{\mathrm{II}}(\mathrm{bpy})_{2}\right]^{2+}(\mathrm{TfO})^{-} 2$ dissolved in an $\mathrm{H}_{2} \mathrm{O}-\mathrm{PEO}$ mixture initially containing $70 \mathrm{wt} \%$ water to which $\mathrm{NaBr}$ has been successively added. The spectrum with lowest absorbance in the $13000 \mathrm{~cm}^{-1}$ region refers to a solution without added $\mathrm{NaBr}$. Because of the weak bonding between copper and the triflate moiety, $\left[\mathrm{Cu}^{\mathrm{II}}(\mathrm{bpy})_{2}\left(\mathrm{H}_{2} \mathrm{O}\right)\right]^{2+}$ should be the dominant species when $\mathrm{NaBr}$ is absent. Upon the addition of $\mathrm{NaBr}$, the spectrum first changes strongly, but finally added $\mathrm{NaBr}$ results in no further absorbance increase. At these higher $\mathrm{NaBr}$ contents, the equilibrium seems to be almost completely shifted to the side of $\left[\mathrm{Cu}^{\mathrm{II}}(\mathrm{bpy})_{2} \mathrm{Br}\right]^{+}[\mathrm{Br}]^{-}$. Under the assumption of $\left[\mathrm{Cu}^{\mathrm{II}}(\mathrm{bpy})_{2}\right]^{2+}(\mathrm{TfO})_{2}$ not being present and of $\left[\mathrm{Cu}^{\mathrm{II}}(\mathrm{bpy})_{2}\left(\mathrm{H}_{2} \mathrm{O}\right)\right]^{2+}$ concentration being given by the difference between the measured $\left[\mathrm{Cu}^{\mathrm{II}}(\mathrm{bpy})_{2} \mathrm{Br}\right]^{+}[\mathrm{Br}]^{-}$concentration and the initial $\left[\mathrm{Cu}^{\mathrm{II}}(\mathrm{bpy})_{2}\right]^{2+}(\mathrm{TfO})^{-}{ }_{2}$ concentration, the equilibrium constant Kx may be calculated from Equation 4.6.

$$
K_{X}=\frac{\left[\mathrm{Cu}^{\mathrm{II}} \mathrm{bpy}_{2} \mathrm{Br}_{2}\right]\left[\mathrm{H}_{2} \mathrm{O}\right]}{\left([\mathrm{Cu}]_{\text {tot }}-\left[\mathrm{Cu}^{\mathrm{II}} \mathrm{bpy}_{2} \mathrm{Br}_{2}\right]\right)\left[\mathrm{Br}^{-}\right]}
$$

For $70 \mathrm{wt} \%$ water $K x$ is determined to $4.3 \cdot 10^{3}$ and the Matyjaszewski group estimated $K x$ for $\mathrm{Cu}^{\mathrm{II}} \mathrm{Br} / \mathrm{Me} 6 \mathrm{TREN}$ in $82 \mathrm{wt} \%$ water to be $6.2 \cdot 10^{2}$. Due to the different definitions of $K_{x}$ the latter value has been multiplied by the water concentration for better comparison.

The $K x$ values differ by a factor of seven. Taking into account that the $K x$ value of the present study would decrease by the addition water, the difference is not large. It should be noted that $K x$ exhibits a strong dependence on solvent-composition. Perhaps the ligand may also affect Kx. 


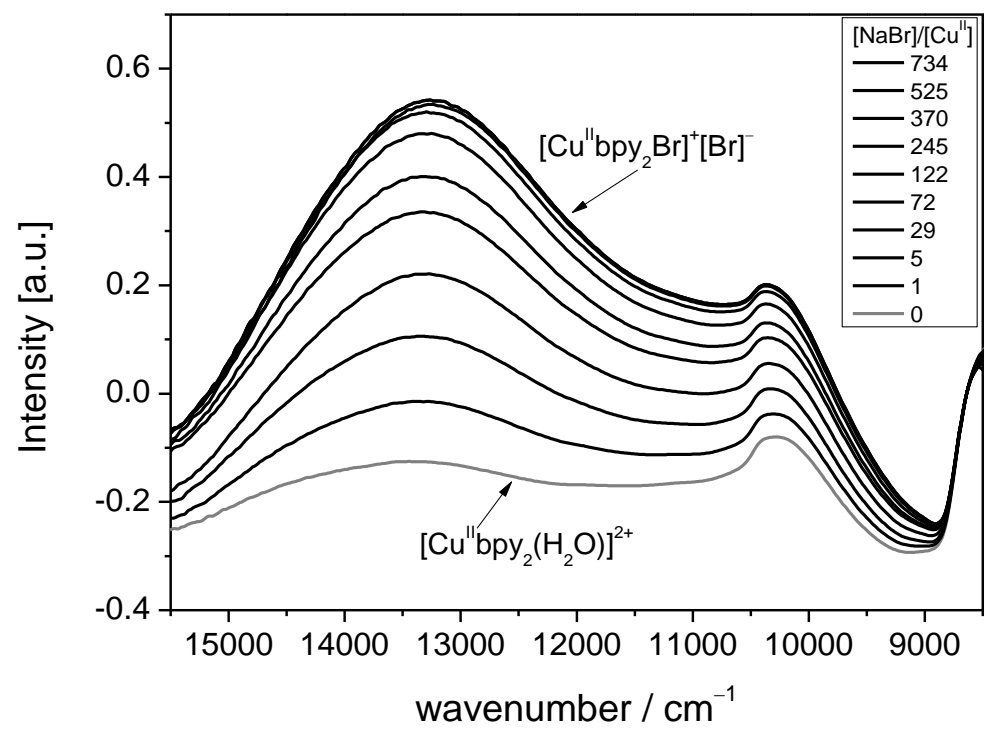

Figure 4.6. Spectral series measured on $3 \mathrm{mmol} \cdot \mathrm{L}^{-1}\left[\mathrm{Cu}^{\mathrm{II} b p y}\right]^{2+}(\mathrm{TfO})_{2}$ dissolved in a solution of $70 \mathrm{wt} . \%$ water and $30 \mathrm{wt} . \%$ PEO at $22^{\circ} \mathrm{C}$ upon successive addition of $\mathrm{NaBr}$. The spectrum with lowest absorbance refers to the solution without added $\mathrm{NaBr}$.

The data in Figure 4.6 demonstrate that relatively small amounts of $\mathrm{NaBr}$ are capable of stabilizing a considerable fraction of $\left[\mathrm{Cu}^{\mathrm{II}}(\mathrm{bpy})_{2} \mathrm{Br}\right]^{+}[\mathrm{Br}]^{-}$species. Thus ATRP in aqueous solution should be feasible at modest amounts of added $\mathrm{NaBr} .{ }^{[33]}$

A PREDICI ${ }^{\circledR}$ model was developed which takes the independently measured rate coefficients $k_{\mathrm{t}}$ and $k_{\text {act }}$ as well as the equilibrium constants $K_{\text {model }}$ and $K_{x}$ into account. Shown in Table 4.1 are the reaction steps implemented into the PREDICI ${ }^{\circledR}$ simulation of the monomer-free model system $\mathrm{CuBr}$, 2,2'-bipyridine and HEMA-Br in $\mathrm{PEO}-\mathrm{H}_{2} \mathrm{O}$ solution. The rate coefficients $k_{\text {act, }} k_{\text {deact }}$ and $k_{\mathrm{t}}$ have been introduced as a function of $\mathrm{PEO}-\mathrm{H}_{2} \mathrm{O}$ mixture composition and of measured viscosity. The dissociation and association of bromide is described by the rate coefficients $k_{\text {diss }}$ and $k_{\text {ass, }}$ respectively. $k_{\text {diss }}$ has been adopted to be $1 \cdot 10^{4} \mathrm{~mol} \cdot \mathrm{L}^{-1} \cdot \mathrm{s}^{-1}$ which value ensures immediate equilibration of the dissociation and association processes. $k_{\text {ass }}$ is estimated from the product 
Table 4.1. Reaction scheme for PREDICI ${ }^{\circledR}$ modeling of the monomer-free model system $\mathrm{CuBr}$, 2,2'-bipyridine, and HEMA-Br in $\mathrm{PEO}-\mathrm{H}_{2} \mathrm{O}$ solution.

$$
\begin{gathered}
{\left[\mathrm{Cu}^{\mathrm{I} L n}\right]^{+}[\mathrm{Br}]^{-}+\mathrm{R}-\mathrm{Br} \stackrel{k_{\text {act }}}{\longrightarrow}\left[\mathrm{Cu}^{\mathrm{II}} \mathrm{LnBr}\right]^{+}[\mathrm{Br}]^{-}+\mathrm{R} \bullet} \\
{\left[\mathrm{Cu}{ }^{\mathrm{II} L n B r}\right]^{+}[\mathrm{Br}]^{-}+\mathrm{R} \bullet \stackrel{k_{\text {deact }}}{\longrightarrow}\left[\mathrm{Cu}^{\mathrm{I} L n}\right]^{+}[\mathrm{Br}]^{-}+\mathrm{R}-\mathrm{Br}} \\
\mathrm{R} \bullet+\mathrm{R} \bullet \stackrel{k_{\mathrm{t}}}{\longrightarrow} \mathrm{R}-\mathrm{R} \\
{\left[\mathrm{Cu}^{\mathrm{II} L n}\left(\mathrm{H}_{2} \mathrm{O}\right)\right]^{2+}+[\mathrm{Br}]^{-} \stackrel{k_{\text {ass }}}{\longrightarrow}\left[\mathrm{Cu}^{\mathrm{II} L n B r}\right]^{+}+\mathrm{H}_{2} \mathrm{O}} \\
{\left[\mathrm{Cu}^{\mathrm{II}} \mathrm{LnBr}^{+}+\mathrm{H}_{2} \mathrm{O} \stackrel{k_{\text {diss }}}{\longrightarrow}\left[\mathrm{Cu}^{\mathrm{II}} \mathrm{Ln}\left(\mathrm{H}_{2} \mathrm{O}\right)\right]^{2+}+[\mathrm{Br}]^{-}\right.}
\end{gathered}
$$

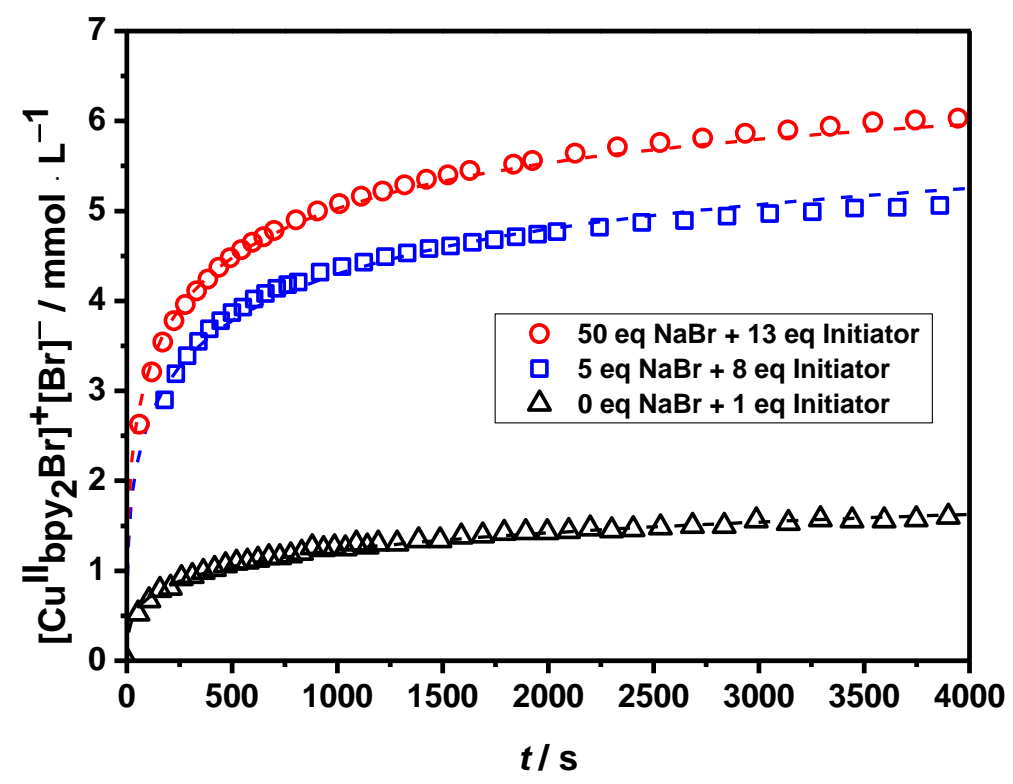

Figure 4.7. $\left[\mathrm{Cu}{ }^{\mathrm{II}}(\mathrm{bpy})_{2} \mathrm{Br}\right]^{+}[\mathrm{Br}]^{-}$concentration of the monomer-free model system plotted vs. time for the reaction of $\mathrm{CuBr}, 2,2$ '-bipyridine, and HEMA-Br in $\mathrm{PEO}-\mathrm{H}_{2} \mathrm{O}$ solutions containing different amounts of $\mathrm{NaBr}$. The dashed lines represent the associated PREDICI ${ }^{\circledR}$ simulations. 
of $k_{\text {diss }}$ and $K x$.

Plotted in Figure 4.7 are the measured $\mathrm{Cu}^{\mathrm{II}}$ data (symbols) together with the associated PREDICI ${ }^{\circledR}$-modelled curves (dashed lines). The open symbols refer to $\left[\mathrm{Cu}^{\mathrm{II}}(\mathrm{bpy})_{2} \mathrm{Br}\right]^{+}[\mathrm{Br}]^{-}$measured for an $\mathrm{H}_{2} \mathrm{O}-\mathrm{PEO}$ mixture with $70 \mathrm{wt} \%$ water initially containing $7 \mathrm{mmol} \cdot \mathrm{L}^{-1}\left[\mathrm{Cu}^{\mathrm{I}}(\mathrm{bpy})_{2}\right]^{+}[\mathrm{Br}]^{-}$, different amounts of initiator and of $\mathrm{NaBr}$ at $22{ }^{\circ} \mathrm{C}$; $\mathrm{O}: 90 \mathrm{mmol} \cdot \mathrm{L}^{-1}$ HEMA-Br, $350 \mathrm{mmol} \cdot \mathrm{L}^{-1} \mathrm{NaBr} ; \quad \square: 53 \mathrm{mmol} \cdot \mathrm{L}^{-1} \quad \mathrm{HEMA}-\mathrm{Br}$, $35 \mathrm{mmol} \cdot \mathrm{L}^{-1} \mathrm{NaBr} ; \Delta: \quad 7 \mathrm{mmol} \cdot \mathrm{L}^{-1}$ HEMA-Br, $0 \mathrm{mmol} \cdot \mathrm{L}^{-1} \mathrm{NaBr}$. Toward lower $\mathrm{NaBr}$ content, the $\left[\mathrm{Cu}^{\mathrm{II}}(\mathrm{bpy})_{2} \mathrm{Br}\right]^{+}[\mathrm{Br}]^{-}$absorbance is low and is overlapped by the one of the $\left[\mathrm{Cu}^{\mathrm{II}}(\mathrm{bpy})_{2}\left(\mathrm{H}_{2} \mathrm{O}\right)\right]^{2+}$ complex. The individual concentrations of $\left[\mathrm{Cu}^{\mathrm{II}}(\mathrm{bpy})_{2} \mathrm{Br}\right]^{+}[\mathrm{Br}]^{-}$(and of $\left.\left[\mathrm{Cu}^{\mathrm{II}}(\mathrm{bpy})_{2}\left(\mathrm{H}_{2} \mathrm{O}\right)\right]^{2+}\right)$ have been deduced from the overlapping absorbance bands by means of the known molar extinction coefficients, $\varepsilon$, of the $\left[\mathrm{Cu}^{\mathrm{II}}(\mathrm{bpy})_{2} \mathrm{Br}\right]^{+}[\mathrm{Br}]^{-}$and $\left[\mathrm{Cu}^{\mathrm{II}}(\mathrm{bpy})_{2}\left(\mathrm{H}_{2} \mathrm{O}\right)\right]^{2+}$ complexes and the measured equilibrium constant, $K x$, for these two species according to Equation 4.7, in which $l$ denotes the optical path length.

$$
\begin{aligned}
\mathrm{Cu}_{\text {absorbance }}=c & \left(\left[\mathrm{Cu}^{\mathrm{II}} \operatorname{bpy}_{2}\left(\mathrm{H}_{2} \mathrm{O}\right)\right]^{2+}\right) \cdot \varepsilon_{\left[\mathrm{Cu}^{\mathrm{II}} \mathrm{bpy}_{2}\left(\mathrm{H}_{2} \mathrm{O}\right)\right]^{2+} \cdot l} \\
& +c\left(\left[\mathrm{Cu}^{\mathrm{II}} \mathrm{bpy}_{2} \mathrm{Br}\right]^{+}[\mathrm{Br}]^{-}\right) \cdot \varepsilon_{\left[\mathrm{Cu}^{\mathrm{II}} \mathrm{bpy}_{2} \mathrm{Br}\right]^{+}[\mathrm{Br}]^{-}} \cdot l
\end{aligned}
$$

Figure 4.7 illustrates the close agreement of measured and PREDICI ${ }^{\circledR}$ modelled data at widely differing $\mathrm{NaBr}$ concentrations. Listed in Table 4.2 are the values used for PREDICI ${ }^{\circledR}$ modeling. The initial initiator concentration, $[\mathrm{I}] \mathrm{0}$, and the $\mathrm{NaBr}$ concentration listed in Table 4.2 are the ones selected for the experiments. The termination rate coefficient, $k_{t}$, has been modified according to the viscosity change which accompanies the addition of $\mathrm{NaBr}$. The only one quantity which was adjusted, however only within the limits of experimental accuracy of \pm 30 per cent, was $k_{\text {act. }}$ The close agreement of simulated and measured $\left[\mathrm{Cu}^{\mathrm{II}}(\mathrm{bpy})_{2} \mathrm{Br}\right]^{+}[\mathrm{Br}]^{-}$vs. $t$ traces achieved by the minor adjustment of $k_{\text {act }}$ (see Table 4.2) is strongly indicative of the measured equilibrium constant and rate coefficients being independent of $\mathrm{NaBr}$ concentration. 
Table 4.2: Rate coefficients and equilibrium constants used for modeling the measured $\left[\mathrm{Cu}^{\mathrm{II}}(\mathrm{bpy})_{2} \mathrm{Br}\right]^{+}[\mathrm{Br}]^{-}$vs. $t$ traces for $7 \mathrm{mmol} \cdot \mathrm{L}^{-1}\left[\mathrm{Cu}^{\mathrm{I}}(\mathrm{bpy})_{2}\right]^{+}[\mathrm{Br}]^{-}$ and $\mathrm{HEMABr}$ reacting in an $\mathrm{H}_{2} \mathrm{O}-\mathrm{PEO}$ solution containing $70 \mathrm{wt}$.\% water. The termination rate coefficient, $k$, has been corrected for the measured viscosity change upon the addition of $\mathrm{NaBr}$.

\begin{tabular}{|c|c|c|c|c|}
\hline & $\begin{array}{c}{[\mathrm{I}]_{0} /} \\
\mathrm{mol} \cdot \mathrm{L}^{-1}\end{array}$ & $\begin{array}{l}{[\mathrm{NaBr}] /} \\
\mathrm{mol} \cdot \mathrm{L}^{-1}\end{array}$ & $\begin{array}{c}k_{\text {deact }} / \\
\mathrm{L} \mathrm{mol}^{-1} \cdot \mathrm{s}^{-1}\end{array}$ & $\begin{array}{c}k_{\text {act }} / \\
\mathrm{L} \mathrm{mol}^{-1} \cdot \mathrm{s}^{-1}\end{array}$ \\
\hline$\Delta$ & $7.4 \cdot 10^{-3}$ & 0 & $2.6 \cdot 10^{6}$ & 7.6 \\
\hline$\square$ & $9.3 \cdot 10^{-2}$ & $3.5 \cdot 10^{-2}$ & $2.6 \cdot 10^{6}$ & 6.4 \\
\hline \multirow[t]{3}{*}{$\mathrm{O}$} & $5.3 \cdot 10^{-2}$ & $3.5 \cdot 10^{-1}$ & $2.6 \cdot 10^{6}$ & 7.1 \\
\hline & Kmodel & $k_{\mathrm{t}} /$ & $K x$ & \\
\hline & & $\mathrm{L} \mathrm{mol}^{-1} \cdot \mathrm{s}^{-1}$ & & \\
\hline$\Delta$ & $2.9 \cdot 10^{-6}$ & $1.4 \cdot 10^{-8}$ & $4.3 \cdot 10^{3}$ & \\
\hline$\square$ & $2.5 \cdot 10^{-6}$ & $1.0 \cdot 10^{-8}$ & $4.3 \cdot 10^{3}$ & \\
\hline $\mathrm{O}$ & $2.7 \cdot 10^{-6}$ & $1.2 \cdot 10^{-8}$ & $4.3 \cdot 10^{3}$ & \\
\hline
\end{tabular}




\subsection{Kinetics of Cu-mediated ATRP in aqueous solution}

A deeper understanding of the impact of a water environment on ATRP has been achieved by studying Cu-meditated ATRP model systems. It has been shown that the strong increase of the activationdeactivation equilibrium is mainly due to the enhancement of the activation step, whereas the deactivation is not significantly dependent on water concentration.

Because of the difficulties associated with the fast deactivation step, $k_{\text {deact }}$ in the monomer-free model systems was only indirectly determined via the equilibrium constant and $k_{\text {act. }}$ To measure $k_{\text {deact }}$ during Cu-mediated ATRP, the SP-PLP-EPR technique has been applied. ${ }^{[66]}$ Such direct measurement should also be carried out, as the activation-deactivation equilibrium constant for the actual polymerization may differ from the one obtained for the model system. Moreover, the data for the model system consider only radicals of chain length unity and may not fully reflect by the polymerizing system. ${ }^{[60,126]}$ Furthermore, during actual ATRP the solvent is initially a mixture of solvent and monomer, which gradually changes due to the replacement of monomer by polymer. For this reason, it seems mandatory to investigate the influence of the solvent/monomer/polymer mixture on KATRP.

The online spectroscopic measurement of the PEGMA concentration in combination with the accumulation of $\mathrm{Cu}^{\mathrm{II}}$ allows for the direct measurement of KATRP during polymerization. ${ }^{[60,138]}$ The challenges of the procedure are due to the copper catalyst possibly undergoing several side reactions in aqueous solution and to the conversion-dependence of propagation kinetics in aqueous solution. The direct measurement of the activation-deactivation equilibrium constant during a polymerization will help to better understand ATRP and may allow for PREDICI ${ }^{\circledR}$ simulations of monomer conversion vs time traces, of dispersity and of chain-end functionality in actual ATRPs. 


\subsubsection{Determination of $\boldsymbol{k}_{\text {deact }}$}

This section deals with the SP-PLP-EPR measurement of the ATRP deactivation rate coefficient, $k_{\text {deact, }}$, for the $\left[\mathrm{Cu}^{\mathrm{II}}(\mathrm{bpy}){ }_{2} \mathrm{Br}\right]^{+}[\mathrm{Br}]^{-}$complex within a wide range of $\mathrm{PEGMA}-\mathrm{H}_{2} \mathrm{O}$ mixtures. The $k_{\text {deact }}$ values are estimated via PREDICI ${ }^{\circledR}$ modeling. ${ }^{[66]}$ Because of the excess of halide salts used in these polymerizations, the notation of $\left[\mathrm{Cu}^{\mathrm{II}}(\mathrm{bpy}){ }_{2} \mathrm{Br}\right]^{+}[\mathrm{Br}]^{-}$and $\left[\mathrm{Cu}^{\mathrm{I} L n}\right]^{+}[\mathrm{Br}]^{-}$are simplified to $\mathrm{Cu}{ }^{\mathrm{II}} / \mathrm{L}-\mathrm{Br}$ and $\mathrm{Cu} / \mathrm{L}$ within what follows.

Illustrated in Scheme 4.2 is the scenario for the measurement of the ATRP deactivation rate coefficient, $k_{\text {deact. }}$ The experiment is started in a reversed fashion with the catalyst in the higher oxidation state, e.g., $\mathrm{Cu}^{\mathrm{II}}(\mathrm{bpy})_{2} \mathrm{Br}$. The starting reagents are marked red. Darocur 1173 (Darocur) acts as the photoinitiator to produce primary radicals, which add to monomer molecules, $\mathrm{M}$. The propagating radical, $\mathrm{R} \cdot$, reacts with the $\mathrm{Cu}$ II/L-Br deactivator complex to generate the alkyl halide, $\mathrm{R}-\mathrm{Br}$, and the $\mathrm{Cu} / \mathrm{L}$ complex. In addition to ATRP deactivation, the radicals may also undergo conventional radical-radical termination.

In Cu-mediated ATRP, at least two types of paramagnetic species are present: the $\mathrm{Cu} / \mathrm{II} / \mathrm{L}-\mathrm{Br}$ species and the propagation radical. The EPR spectra for quantification of the $\mathrm{Cu} \mathrm{u}^{\mathrm{II}} / \mathrm{L}-\mathrm{Br}$ species have been measured before and after SP application. The SP-PLP-EPR technique has been used to the measure the PEGMA radical concentration vs time traces.

Shown in Figure 4.8 are the EPR spectra of the two paramagnetic species. Figure 4.8A shows the pseudo-stationary EPR spectrum of PEGMA radicals recorded in the presence of $\mathrm{Cu}^{\mathrm{II}}$. The spectrum was recorded between 3285 and $3385 \mathrm{G}$ with a pulse repetition rate of $20 \mathrm{~Hz}$ at $20^{\circ} \mathrm{C}$ to identify the appropriate field position for time-resolved detection of PEGMA radical at a constant magnetic field, which is indicated by the arrow in Figure 4.8A. The EPR spectrum of PEGMA radicals is identical to the one in solvent mixtures without $\mathrm{Cu}$ (cf. Figure 3.9 , p. 46). 


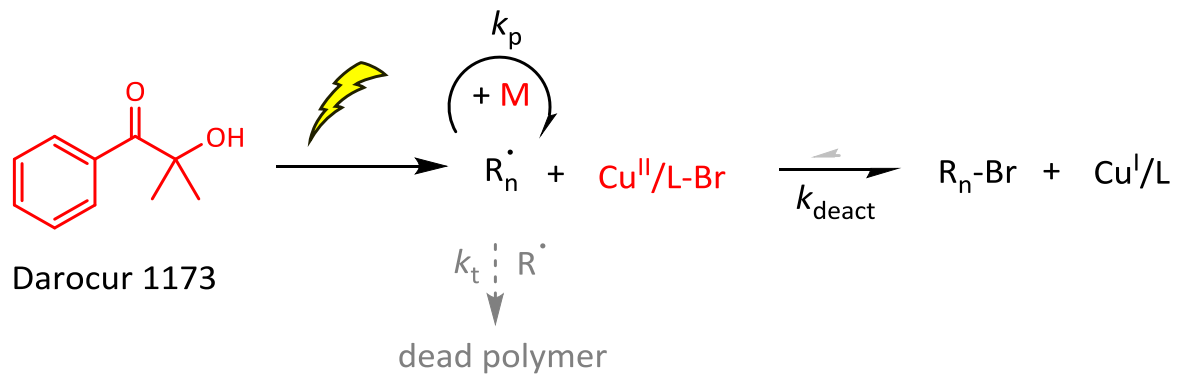

Scheme 4.2: SP-PLP-EPR measurement of $k_{\text {deact. }}$ The starting components, i.e., the photoinitiator Darocur 1173 , the monomer $\mathrm{M}$, and the $\mathrm{Cu}$ complex are marked red. The primary radicals are generated by a laser pulse which produces primary propagation radicals $\mathrm{R}_{1}$ which grow to propagating radicals, $\mathrm{R}_{n}$, of chain length $n . \mathrm{Cu}^{\mathrm{I}} / \mathrm{L}$ and $\mathrm{R}_{n}-\mathrm{Br}$ are produced by the deactivation step.
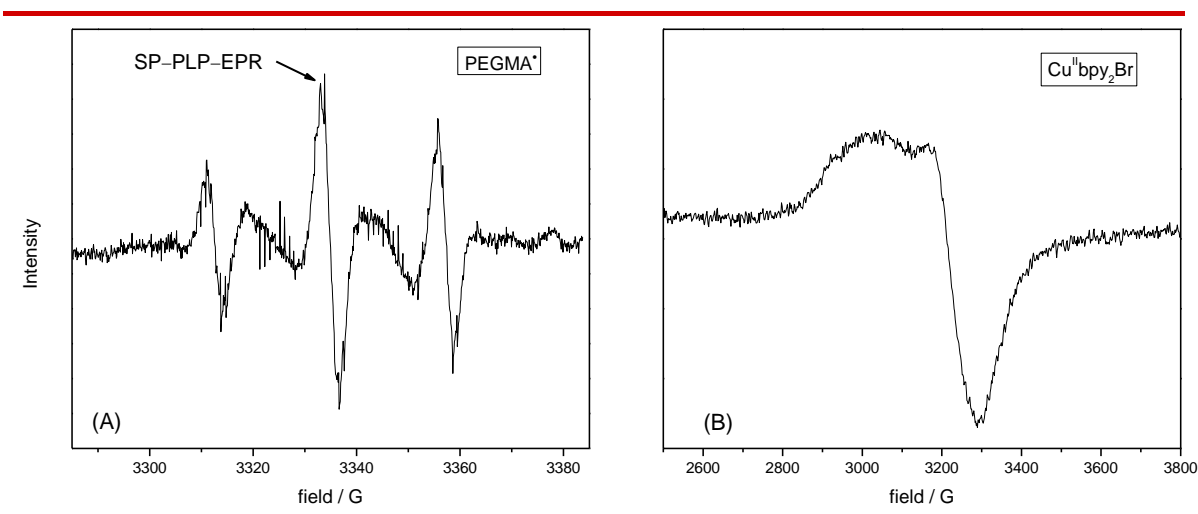

Figure 4.8: (A) Pseudo-stationary spectrum of PEGMA radicals recorded in $50 \mathrm{wt} \% \mathrm{H}_{2} \mathrm{O}$ with a laser repetition rate of $20 \mathrm{~Hz}$ at $20{ }^{\circ} \mathrm{C}$. The arrow indicates the magnetic field position for the SP-PLP-EPR experiment. (B) EPR spectrum of $\mathrm{Cu}^{\mathrm{II} b p y}{ }_{2} \mathrm{Br}$ for a stationary ATRP in $50 \mathrm{wt} \% \mathrm{H}_{2} \mathrm{O}$ at $20{ }^{\circ} \mathrm{C}$. 
Illustrated in Figure 4.8B is the EPR spectrum of a $3 \mathrm{mM}$ solution of the $\mathrm{Cu}^{\mathrm{II}} / \mathrm{L}-\mathrm{Br}$ species recorded between 2500 and $3800 \mathrm{G}$. The broad unsymmetrical singlet spectrum is characteristic of $\mathrm{Cu}^{\mathrm{II}}$-complexes. ${ }^{[39,66]}$ The $\mathrm{Cu}^{\mathrm{II}}$ spectrum is used to monitor the conversion of the $\mathrm{Cu} / \mathrm{L}-\mathrm{Br}$ catalyst during SP-PLP-EPR experiment.

For the time-resolved SP-PLP-EPR experiments, the system under investigation contains $1 \mathrm{mM}$ of $\mathrm{Cu}^{\mathrm{II}}(\mathrm{bpy})_{2} \mathrm{Br}$ and $20 \mathrm{mM}$ of Darocur in different solution mixtures of PEGMA, containing between 30 and $70 \mathrm{wt} \% \mathrm{H}_{2} \mathrm{O}$. Darocur was chosen as the photoinitiator because of the good solubility in water and the strong absorption at the laser wavelength of $351 \mathrm{~nm}$. An excess of 500 equivalents of $\mathrm{NaBr}$ with respect to $\mathrm{Cu}^{\mathrm{II}}(\mathrm{bpy})_{2} \mathrm{Br}$ has been added to the solution in order to prevent halide dissociation.

Shown in Figure 4.9A are the [PEGMA ${ }^{\circ}$ ] vs time traces recorded at $20{ }^{\circ} \mathrm{C}$ in solution of $50 \mathrm{wt} \% \mathrm{H}_{2} \mathrm{O}$. The black line refers to the concentration vs time trace without $\mathrm{Cu}$ II/L-Br being present. The blue concentration vs time profile shows the experimental SP-PLP-EPR data for $1 \mathrm{mM} \mathrm{Cu}^{\mathrm{II}}(\mathrm{bpy})_{2} \mathrm{Br}$ in solution of $50 \mathrm{wt} \% \mathrm{H}_{2} \mathrm{O}$. The red line represents the associated PREDICI ${ }^{\circledR}$ modeling. An intense burst of PEGMA ${ }^{*}$ is produced at $t=0$, when the laser pulse is applied to the sample. The decay in [PEGMA ${ }^{*}$ ] is significantly accelerated by $\mathrm{Cu}^{\mathrm{II}} / \mathrm{L}-\mathrm{Br}$ due to the ATRP deactivation. In the absence of $\mathrm{Cu}^{\mathrm{II}} / \mathrm{L}-\mathrm{Br}$ the decay in radical concentration occurs entirely by conventional radical-radical termination. Shown in Figure 4.9B are the corresponding spectra of

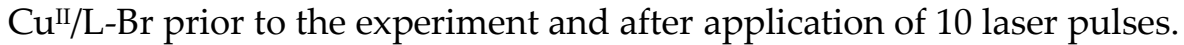
The conversion of $\mathrm{Cu}^{\mathrm{II}} / \mathrm{L}-\mathrm{Br}$ is well below $10 \%$ as deduced from the associated double integrals of the $\mathrm{Cu}$ II $/ \mathrm{L}-\mathrm{Br}$ EPR spectra. Thus, only minor amounts of $\mathrm{Cu}^{\mathrm{I}} / \mathrm{L}$ are formed, which ensures that the activation reaction does not occur to any significant amount and may be neglected.

Therefore the reaction is adequately represented by the three reaction steps listed in Table 4.3: propagation (4.8), ATRP deactivation (4.9) and conventional radical-radical termination (4.10). These reaction steps are implemented into the PREDICI $^{\circledR}$ model along with the propagation rate coefficient as well as the composite-model parameters for chain-length-dependent termination as detailed in chapter 3 . The knowledge of these parameters in combination with the 

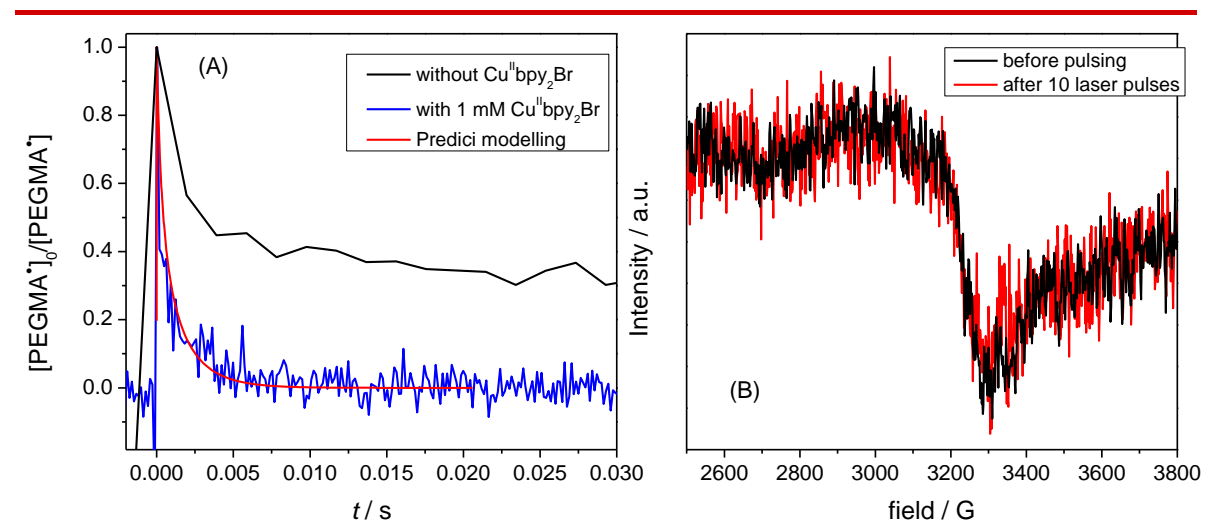

Figure 4.9: (A) PEGMA radical concentration vs time recorded via the timeresolved SP-PLP-EPR spectroscopy. The black line represents the SP-PLPEPR experiment without $\mathrm{Cu}^{\mathrm{II} b p y}{ }_{2} \mathrm{Br}$ being present. The blue line refers to the experiment with $1 \mathrm{~mm} \mathrm{Cu} \mathrm{Cu}^{\mathrm{II} b p y}{ }_{2} \mathrm{Br}$. Both concentration vs time profiles were measured in solution of $50 \mathrm{wt} \% \mathrm{H}_{2} \mathrm{O}$ at $20{ }^{\circ} \mathrm{C}$ and at a constant magnetic field position of 3332 G. (B) EPR spectra of $\mathrm{Cu}^{\mathrm{II}} / \mathrm{L}-\mathrm{Br}$ for before (black line) and after laser pulse application (red line).

Table 4.3: Reaction scheme used for PREDICI ${ }^{\circledR}$ modeling of the PEGMA radical concentration vs time traces.

\begin{tabular}{|l|c|}
\hline $\mathrm{R} \cdot+\mathrm{M} \stackrel{k_{p}}{\longrightarrow} \mathrm{R}_{\mathrm{n}+1}$ & $(4.8)$ \\
\hline $\mathrm{Cu}{ }^{\mathrm{II}} \mathrm{bpy}_{2} \mathrm{Br}+\mathrm{R} \cdot \stackrel{k_{\text {deact }}}{\longrightarrow} \mathrm{Cu}^{\mathrm{I} b p y 2}+\mathrm{R}-\mathrm{Br}$ & $(4.9)$ \\
\hline $\mathrm{R} \cdot+\mathrm{R} \cdot \stackrel{k_{\mathrm{t}}}{\longrightarrow} \mathrm{R}-\mathrm{R}$ & $(4.10)$ \\
\hline
\end{tabular}

measured $\mathrm{Cu} / \mathrm{II} / \mathrm{L}-\mathrm{Br}$ concentration and the absolute radical concentration allows for estimating $k_{\text {deact }}$ via PREDICI ${ }^{\circledR}$ modeling.

The radical concentration vs time trace in Figure 4.9A was modeled via PREDICI ${ }^{\circledR}$, which results in a close agreement with the experimental 
data, as seen in Figure $4.9 \mathrm{~A}$. The $k_{\text {deact }}$ value was estimated from the fit to be $k_{\text {deact }}=6.3 \cdot 10^{5} \mathrm{~L} \mathrm{~mol}^{-1} \mathrm{~s}^{-1}$. The absolute $k_{\text {deact }}$ value thus is of the same order of magnitude as found for other $\mathrm{Cu}$-mediated ATRP systems in organic solvents. For DMA with $\mathrm{CuBr} / \mathrm{HMTETA}$, $k_{\text {deact }}=8 \cdot 10^{5} \mathrm{~L} \mathrm{~mol}^{-1} \mathrm{~s}^{-1}$ has been reported. [66] For PMDETA being the ligand, $k_{\text {deact }}$ amounts to $2 \cdot 10^{6} \mathrm{~L} \mathrm{~mol}^{-1} \mathrm{~s}^{-1} \cdot{ }^{[66]}$

Analogous to the $k_{\text {deact }}$ measurement in solution with $50 \mathrm{wt} \% \mathrm{H}_{2} \mathrm{O}$, further experiments with 30 and $70 \mathrm{wt} \% \mathrm{H}_{2} \mathrm{O}$ were conducted to check for a potential water dependency of $k_{\text {deact. }}$ The resulting $k_{\text {deact }}$ values in 30,50 and $70 \mathrm{wt} \% \mathrm{H}_{2} \mathrm{O}$ at $20^{\circ} \mathrm{C}$ are listed in Table 4.4 . The $k_{\text {deact }}$ values exhibit a slight decrease, by a factor of 1.5 , in passing from 30 to $70 \mathrm{wt} \%$ $\mathrm{H}_{2} \mathrm{O}$. In view of the experimental accuracy, it may be concluded that $k_{\text {deact }}$ is independent of water concentration, which is consistent with what has been found for the model system in chapter 4.1 .

The $k_{\text {deact }}$ values estimated via SP-PLP-EPR are by a factor of 4 below the ones obtained for the monomer-free model system, where $k_{\text {deact }}$ is $2.6 \cdot 10^{6} \mathrm{~L} \mathrm{~mol}^{-1} \mathrm{~s}^{-1}$. The lower $k_{\text {deact }}$ values for the polymerization system are a consequence of the back-strain effect for methacrylate type monomers.[139] As a consequence of the $\alpha$-methyl group of the penultimate methacrylate unit in the polymeric chain, a steric strain is induced that hinders the addition of the bromide to the radical, and thus reduces $k_{\text {deact. }}$ In the model system, the methacrylate ATRP initiator has no penultimate unit to induce such a steric strain. A difference of this magnitude between model system and polymerization system is known from Cu-mediated ATRP. ${ }^{[126]}$

Even if $k_{\text {deact }}$ for the polymerization system is smaller than for the model system, the polymerization is expected to be well controlled. Such high $k_{\text {deact }}$ values in the order of magnitude between $5 \cdot 10^{5}$ and $10^{6}$ are associated with fast deactivation providing efficient control over a polymerization. This is especially true, if additional $\mathrm{Cu}^{\mathrm{II}} / \mathrm{L}-\mathrm{Br}$ is added to the solution to ensure the presence of a sufficient amount of the deactivator complex from the beginning of the polymerization. 
Table 4.4: $k_{\text {deact }}$ values for $\mathrm{Cu}$-mediated ATRP with $\mathrm{CuBr} / \mathrm{bpy}$ deduced via SP-PLP-EPR at $20^{\circ} \mathrm{C}$.

\begin{tabular}{|c|c|}
\hline $\mathrm{wt} \% \mathrm{H}_{2} \mathrm{O}$ & $k_{\text {deact }} / 10^{5} \mathrm{~L} \mathrm{~mol}^{-1} \mathrm{~s}^{-1}$ \\
\hline 30 & $7.8 \pm 1.5$ \\
\hline 50 & $6.3 \pm 1.7$ \\
\hline 70 & $5.5 \pm 2.0$ \\
\hline
\end{tabular}

\subsubsection{Determination of $K_{\text {ATRP }}$}

The increase of $K_{\text {model }}$ with increasing water content (see chapter 4.1.1) should also be studied for KATRP of actual ATRP, in particular to check for the effect of changes in solvent composition due to monomerto-polymer conversion.

This section deals with the measurement of KATRP for the ATRP of PEGMA in aqueous solution using $\mathrm{Cu} \mathrm{u}^{\mathrm{B}} / \mathrm{bpy} 2$ as the catalyst and HEMA-Br as the initiator. KATRP is estimated via the simultaneous measurement of monomer conversion and of $\mathrm{Cu}^{\mathrm{II}} / \mathrm{L}-\mathrm{Br}$ concentration by online time resolved FT-Vis/NIR spectroscopy.

According to Equation 4.11 the overall polymerization rate, $R_{P}$, is proportional to the equilibrium constant, KATRP, and the ratio of the $\mathrm{Cu}^{\mathrm{I}} / \mathrm{L}$ and $\mathrm{Cu}{ }^{\mathrm{II}} / \mathrm{L}-\mathrm{Br}$ concentration: ${ }^{[140]}$

$$
\begin{gathered}
R_{\mathrm{P}}=k_{\mathrm{p}} \cdot[\mathrm{R}] \cdot[\mathrm{M}]=k_{\mathrm{p}} \cdot K_{\mathrm{ATRP}} \cdot \frac{\left[\mathrm{Cu}^{\mathrm{I}}\right] \cdot[\mathrm{RX}]}{\left[\mathrm{Cu}^{\mathrm{II}}\right]} \cdot[\mathrm{M}] \\
K_{A T R P}=-\frac{\left[\mathrm{Cu}^{\mathrm{II}}\right]}{k_{\mathrm{p}} \cdot\left[\mathrm{Cu}^{\mathrm{I}}\right] \cdot[\mathrm{RX}]} \frac{\mathrm{d} \ln [\mathrm{M}]}{\mathrm{d} t}
\end{gathered}
$$

where $k_{\mathrm{p}}$ is the propagation rate coefficient, and $[\mathrm{RX}]$ and $[\mathrm{M}]$ represent 
the concentration of the ATRP initiator and of the monomer, respectively. The $\mathrm{Cu}^{\mathrm{I}}$ concentration was deduced from the difference of the initial $\mathrm{Cu}^{\mathrm{I}}$ concentration and the measured time-dependent $\mathrm{Cu}^{\mathrm{II}}$ concentration, $\left[\mathrm{Cu}^{\mathrm{I}}\right]=\left[\mathrm{Cu}^{\mathrm{I}}\right]_{0}+\left(\left[\mathrm{Cu}^{\mathrm{II}}\right]-\left[\mathrm{Cu}^{\mathrm{II}}\right]_{0}\right)$. Similarly, the $R X$ concentration was estimated via the difference of the initial $R X$ concentration and the measured $\mathrm{Cu}^{\mathrm{II}}$ concentration.

Shown in Figure 4.10 is a series of Vis/NIR absorbance spectra measured during an ATRP of PEGMA in $50 \mathrm{wt} \% \mathrm{H}_{2} \mathrm{O}$ starting with $8 \mathrm{mM} \mathrm{Cu}^{\mathrm{I}} / \mathrm{L}, 1.8 \mathrm{mM} \mathrm{Cu}{ }^{\mathrm{II}} / \mathrm{L}-\mathrm{Br}$ and $5 \mathrm{mM} \mathrm{HEMA}-\mathrm{Br}$ at $20^{\circ} \mathrm{C}$. Additional $\mathrm{Cu}^{\mathrm{II}} / \mathrm{L}-\mathrm{Br}$ was added to obtain better control to reduce polymerization rate, thus making concentration measurements easier. Figure 4.10A shows the evolution of $\mathrm{Cu}$ II/L-Br concentration with time. To deduce $\mathrm{Cu}^{\mathrm{II}} / \mathrm{L}-\mathrm{Br}$ concentration, the absorbance band was integrated between 13500 and $11000 \mathrm{~cm}^{-1}$, as is indicated by the dashed lines, and calibrated against three known concentrations of $\mathrm{Cu}$ conversion was measured via the first overtone of the unsaturated $\mathrm{C}-\mathrm{H}$ stretching vibration of PEGMA as shown in Figure 4.10B. The absorbance band was integrated between 6212 and $6120 \mathrm{~cm}^{-1}$ as indicated by the dashed lines. The arrows in Figure 4.10 indicate the direction of change with time $t$.

Illustrated in Figure $4.11 \mathrm{~A}$ are the associated $\ln \left([\mathrm{M}]_{0} /[\mathrm{M}]\right.$ ) (black curve) and monomer conversion (blue curve) vs time traces for the measurements shown in Figure 4.10. The associated $\mathrm{Cu}^{\mathrm{II}} / \mathrm{L}-\mathrm{Br}$ concentration vs time plot of Figure 4.10 is shown in Figure 4.11B. The concentration vs time traces yield a lower polymerization rate below 200 seconds, as will be discussed below.

After 300 seconds, the slope of the $\ln \left([\mathrm{M}]_{0} /[\mathrm{M}]\right)$ vs time plot is almost constant and a monomer conversion close to $90 \%$ is reached. Referring to Equation 4.12, it is interesting to note that the slope of $\ln \left([\mathrm{M}]_{0} /[\mathrm{M}]\right)$ vs time is constant over a wide range although the $\mathrm{Cu}$ $\mathrm{Br}$ concentration (see Figure 4.11B) increases significantly. This behavior may be assigned to the increase in $k_{\mathrm{p}}$ toward lower monomer concentration, which compensates the accumulation of $\mathrm{Cu}^{\mathrm{II}} / \mathrm{L}-\mathrm{Br}$. In contrast to ATRPs in organic solvents, $k_{\mathrm{p}}$ of ATRPs in aqueous solution exhibits a strong dependency on water content, which has to be taken into account in the determination of KATRP. To estimate $K_{\text {ATRP, }}$ the $k_{\mathrm{p}}$ values (see chapter 3.1) have to be selected according to the actual monomer concentration. 

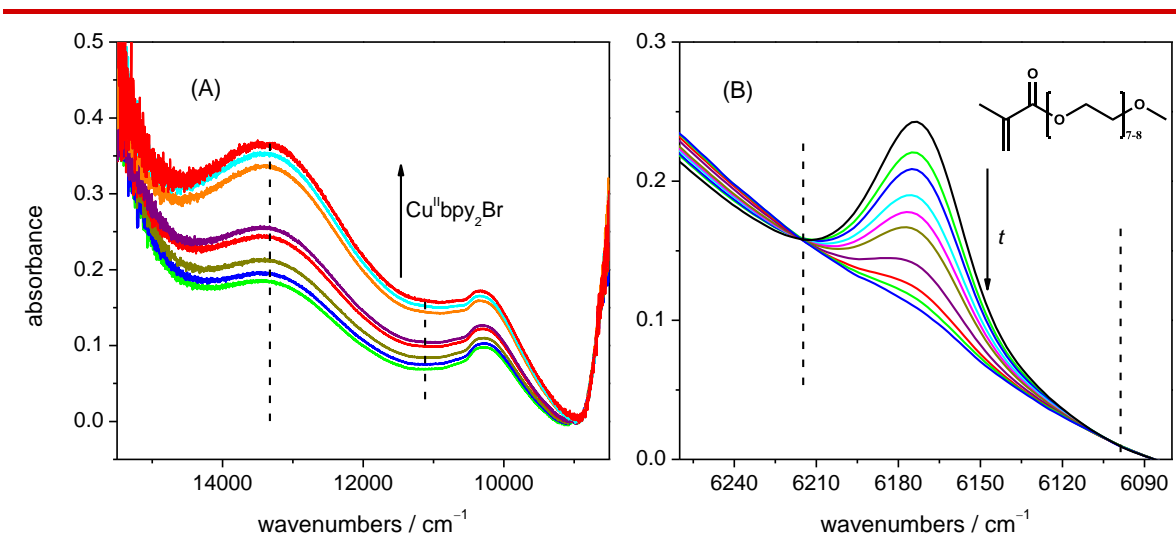

Figure 4.10: Vis-NIR spectral series recorded during ATRP of PEGMA with starting concentrations of $8 \mathrm{mM} \mathrm{Cu}^{\mathrm{I}} / \mathrm{L}, 1.8 \mathrm{mM} \mathrm{Cu} \mathrm{Cu}^{\mathrm{I}} / \mathrm{L}-\mathrm{Br}$ and $5 \mathrm{mM}$ HEMA-Br in solution of $50 \mathrm{wt} \% \mathrm{H}_{2} \mathrm{O}$ at $20^{\circ} \mathrm{C}$. The dashed lines denote the upper and lower limiting wavenumbers for integration. (A) The absorbance of the $\mathrm{Cu}^{\mathrm{II}}(\mathrm{bpy})_{2} \mathrm{Br}$ complex increases with time $t$. The absolute $\mathrm{Cu}$ concentration was estimated via a calibration with $\mathrm{Cu} \mathrm{u}^{\mathrm{II}} / \mathrm{L}-\mathrm{Br}(1,3$ and $7 \mathrm{mM})$ without R-X being present. (B) Spectral series of PEGMA with time. The arrow indicates the direction for the absorbance change with time.

With the monomer concentration vs time traces, the $k_{\mathrm{p}}$ values and the $\mathrm{Cu}^{\mathrm{II}} / \mathrm{L}-\mathrm{Br}$ concentration are known, the KATRP values were estimated from the first derivative of the $\ln ([\mathrm{M}] \mathrm{o} /[\mathrm{M}])$ vs time plots.

Depicted in Figure 4.12 are KATRP data obtained during the course of the ATRP described above. The data is from the analysis of the measured conversion vs time behavior. Within the first 200 seconds, a strong increase in KATRP by almost two orders of magnitude, from $3 \cdot 10^{-7}$ to $4 \cdot 10^{-5}$, is observed. The low KATRP value in the initial period may be caused by the lower ATRP equilibrium of HEMA-Br which acts as the initiator. Since HEMA-Br was also used as R-X species for the monomerfree model system, this pre-equilibrium should be similar to the activation-deactivation equilibrium for the monomer-free model system: $K_{\text {model }}=7 \cdot 10^{-7}$. The subsequent increase up to 300 seconds is associated with the transition from the pre-equilibrium to the actual 

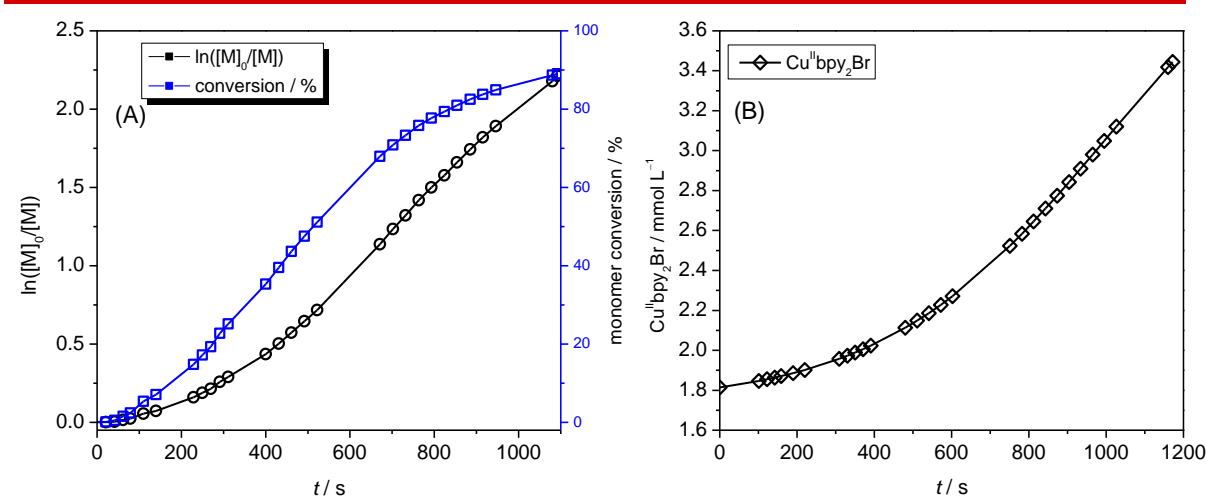

Figure 4.11: (A) $\operatorname{Ln}\left([\mathrm{M}]_{0} /[\mathrm{M}]\right)$ (black) and conversion (blue) vs time curves for ATRP of PEGMA with initial concentrations of $8 \mathrm{~mm} \mathrm{Cu} / \mathrm{L}, 1.8 \mathrm{~mm}$ $\mathrm{Cu}^{\mathrm{II}} / \mathrm{L}-\mathrm{Br}$ and $5 \mathrm{~mm}$ HEMA-Br in $50 \mathrm{wt}^{\mathrm{O}} \% \mathrm{H}_{2} \mathrm{O}$ at $20^{\circ} \mathrm{C}$. (B) $\mathrm{The} \mathrm{Cu}^{\mathrm{II}} / \mathrm{L}-\mathrm{Br}$ concentration versus time curve for the same experiment as in (A).

polymerization equilibrium of PEGMA-Br. After the initiator equilibrium period, KATRP increases slightly by a factor of about 2 toward high conversion. It may be assumed that $K_{\text {ATRP }}$ for the ATRP equilibrium is constant at a value of $8 \cdot 10^{-5}$. As indicated in Figure 4.12 , KATRP is almost independent of the monomer conversion and thus of polymer content.

To check for a potential dependency on water content as it was found for $K_{\text {model, }} K_{\text {ATRP }}$ was measured for different water concentrations between 30 and $80 \mathrm{wt} \% \mathrm{H}_{2} \mathrm{O}$. The analysis of $K_{\text {ATRP }}$ was performed analogous to the procedure described above. Depicted in Figure 4.13 are the estimated average values of $K_{\text {ATRP }}$ (black squares) from at least two independent $K_{\text {ATRP }}$ measurements for various water concentrations and $\mathrm{Cu}$ concentrations. KATRP increases by more than order of magnitude, from $1 \cdot 10^{-5}$ at $30 \mathrm{wt} \% \mathrm{H}_{2} \mathrm{O}$ toward $4 \cdot 10^{-4}$ at $80 \mathrm{wt} \% \mathrm{H}_{2} \mathrm{O}$. This finding also indicates that the increase in KATRP is primarily influenced by the absolute water content.

Similarly high KAtRP values as the one at $80 \mathrm{wt} \% \mathrm{H}_{2} \mathrm{O}$ have been reported for the very active $\mathrm{CuBr} / \mathrm{Me}$ TREN and $\mathrm{CuBr} / \mathrm{TPMA}$ catalysts systems in MMA in bulk ATRPs where KATRP amounts to $7.8 \cdot 10^{-4}$ and 


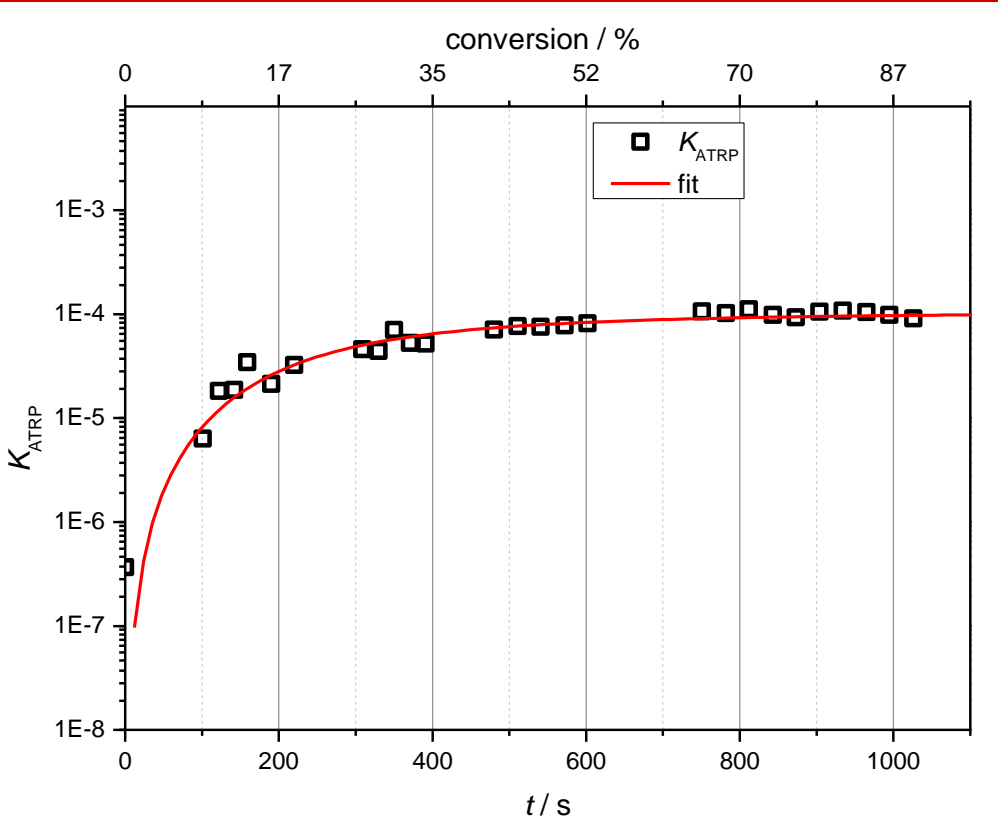

Figure 4.12: KATRP values estimated via 4.12 versus time and monomer conversion for ATRP of PEGMA with starting concentrations of $8 \mathrm{~mm}$ $\mathrm{Cu}^{\mathrm{I}} / \mathrm{L}, 1.8 \mathrm{~mm} \mathrm{Cu} \mathrm{ul}^{\mathrm{II}} / \mathrm{L}-\mathrm{Br}$ and $5 \mathrm{~mm}$ HEMA-Br in $50 \mathrm{wt} \% \mathrm{H}_{2} \mathrm{O}$ at $20^{\circ} \mathrm{C}$. KATRP is initially lower due to the lower equilibrium constant associated with the initiator fragments (grey box), but reaches a constant value of $8 \cdot 10^{-5}$.

9.4 $\cdot 10^{-5}$, respectively. ${ }^{[60]}$ The strong increase of KATRP with the water content is a key feature of ATRP in aqueous solution. The increase of KATRP by an aqueous environment may allow for a fast ATRP rate which is otherwise, in organic solvents, only achieved by using very active catalysts such as MerTREN and TPMA. Moreover, such high KATRP values are suitable for ATRP techniques according to the regenerative concept for the $\mathrm{Cu}^{\mathrm{II}}$-catalyst thereby reducing the $\mathrm{Cu}$ concentration to a ppm level.

Included in Figure 4.13 are the $K_{\text {model }}$ values from chapter 4.1.1. Interestingly the KatRP values exceed $K_{\text {model }}$ by almost two orders of magnitude. This finding is consistent with measurements of MMA in organic solvents using PMDETA and HMTETA as the ligands to $\mathrm{Cu} .{ }^{[60]}$ 


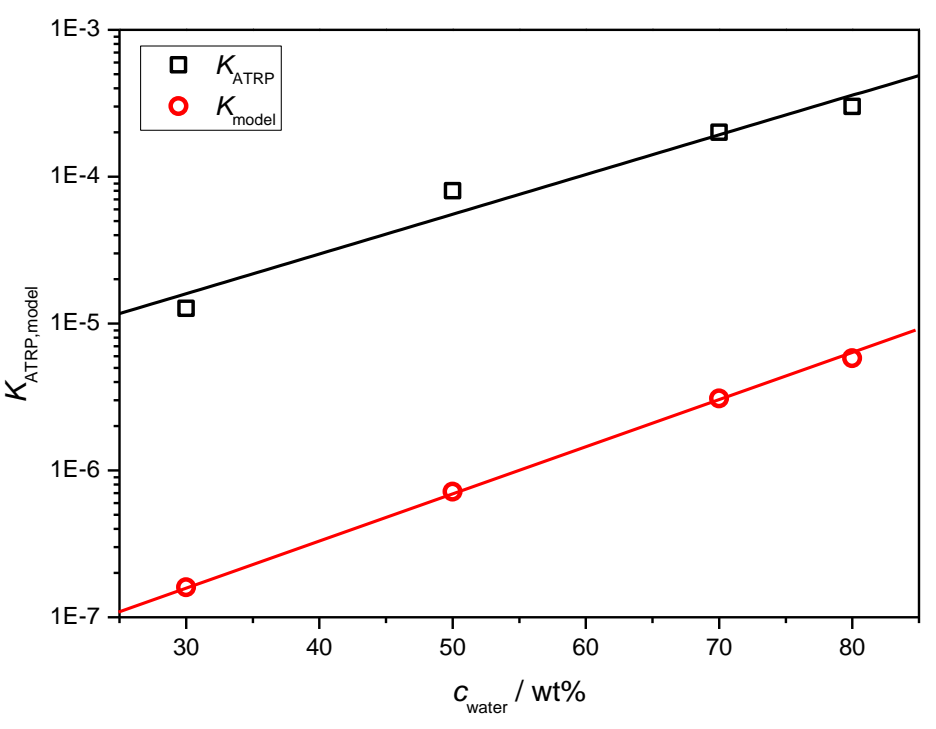

Figure 4.13: KATRP (black squares) and $K_{\text {model }}$ (red circles) versus the water concentration in $\mathrm{wt} \%$ at $20^{\circ} \mathrm{C}$.

For the $\mathrm{Cu}$ /HMTETA complexes, $K_{\text {ATRP }}$ is by a factor 120 above $K_{\text {model. }}$. For $\mathrm{Cu} / \mathrm{PMDETA}$ the difference is even slightly higher with the factor being 160 . The difference in $K_{\text {ATRP }}$ and $K_{\text {model }}$ is most likely caused by the back-strain effect. ${ }^{[60,126]}$ In case of low Kmodel values, the ATRP rate may be controlled by the bond dissociation energy of R-X. In this case, the back-strain effect contributes to the dissociation of $\mathrm{R}-\mathrm{X}$ and results in a high KATRP.

Despite the difference in absolute values, the results of this work demonstrate that the increase of KATRP with the water content is almost identical to the one for $K_{\text {model. }}$. The difference between $K_{\text {model }}$ and $K_{\text {ATRP }}$ reduces from a factor of 100 at $30 \mathrm{wt} \% \mathrm{H}_{2} \mathrm{O}$ towards a factor of 60 at $80 \mathrm{wt} \% \mathrm{H}_{2} \mathrm{O}$. Via $K_{\mathrm{ATRP}}=k_{\text {act }} / k_{\text {deact}}$, $k_{\text {act }}$ may be calculated from the $K_{\mathrm{ATRP}}$ values of this chapter and the $k_{\text {deact }}$ values deduced from the SP-PLPEPR experiment. As the $k_{\text {deact }}$ values are more or less independent of water content, $k_{\text {act }}$ is essentially responsible for the increase in KATRP. The $k_{\text {act }}$ values are almost 20 times higher than in the model system. Such high $k_{\text {act }}$ in combination with constant $k_{\text {deact }}$ suggest that polymerization 
rate may be tunable by the water content without compromising the ATRP control. This effect will be addressed in more detail in the next section.

\subsubsection{Impact on polymerization}

The purpose of measuring the activation-deactivation equilibrium for a monomer-free model system and polymerization system with monomer is the perspective to predict polymer relevant properties such as dispersity, molecular mass and chain-end functionality. Additionally, the kinetic data allow for the prediction of conversion vs time profiles. Moreover, modeling a polymerization may also provide guidance how much halide salts may be necessary to achieve an efficient control over the polymerization.

To predict the dispersity, conversion and the influence on halide salts, a PREDICI ${ }^{\circledR}$ model has been used for a PEGMA ATRP in water with HEMA-Br acting as an initiator. The reaction scheme for the PREDICI ${ }^{\circledR}$ model is shown in Table 4.5 and is divided in four different parts: the conventional kinetics without $\mathrm{Cu}$, the ATRP pre-equilibrium of HEMA-Br, the ATRP equilibrium for PEGMA and the halide dissociation equilibrium.

The water dependency of $k_{\mathrm{p}}$ (chapter 3.1) is included to the model as well as the chain-length dependency of $k_{\mathrm{t}}^{\mathrm{i}, \mathrm{i}}$ (chapter 3.2) and the dependence of $k_{\mathrm{t}}^{\mathrm{i}, \mathrm{i}}$ with fluidity. The activation and deactivation rate coefficients are based on the values for the monomer-free model ATRP with HEMA-Br (cf. chapter 4.1). The $k_{\text {act }}$ and $k_{\text {deact }}$ values for the PEGMA ATRP are known from chapter 4.2. The equilibrium for the halide dissociation should be equal to the one discussed for the model system in chapter 4.1.3.

For ATRP in aqueous solution it is particular interesting to check for the effects of variation of halide salt concentration. Shown in Figure 4.14 are the simulated dispersities (black curve) and the chain-end functionality (blue curve) of a PEGMA polymerization versus the $\mathrm{NaBr}$ equivalents with respect to the total $\mathrm{Cu}$ concentration, $[\mathrm{Cu}]_{\text {tot. The }}$ PREDICI $^{\circledR}$ simulations were performed with a constant initial 
Table 4.5: PREDICI $^{\circledR}$ model for the Cu-mediated ATRP of PEGMA in aqueous solution.

conventional kinetics

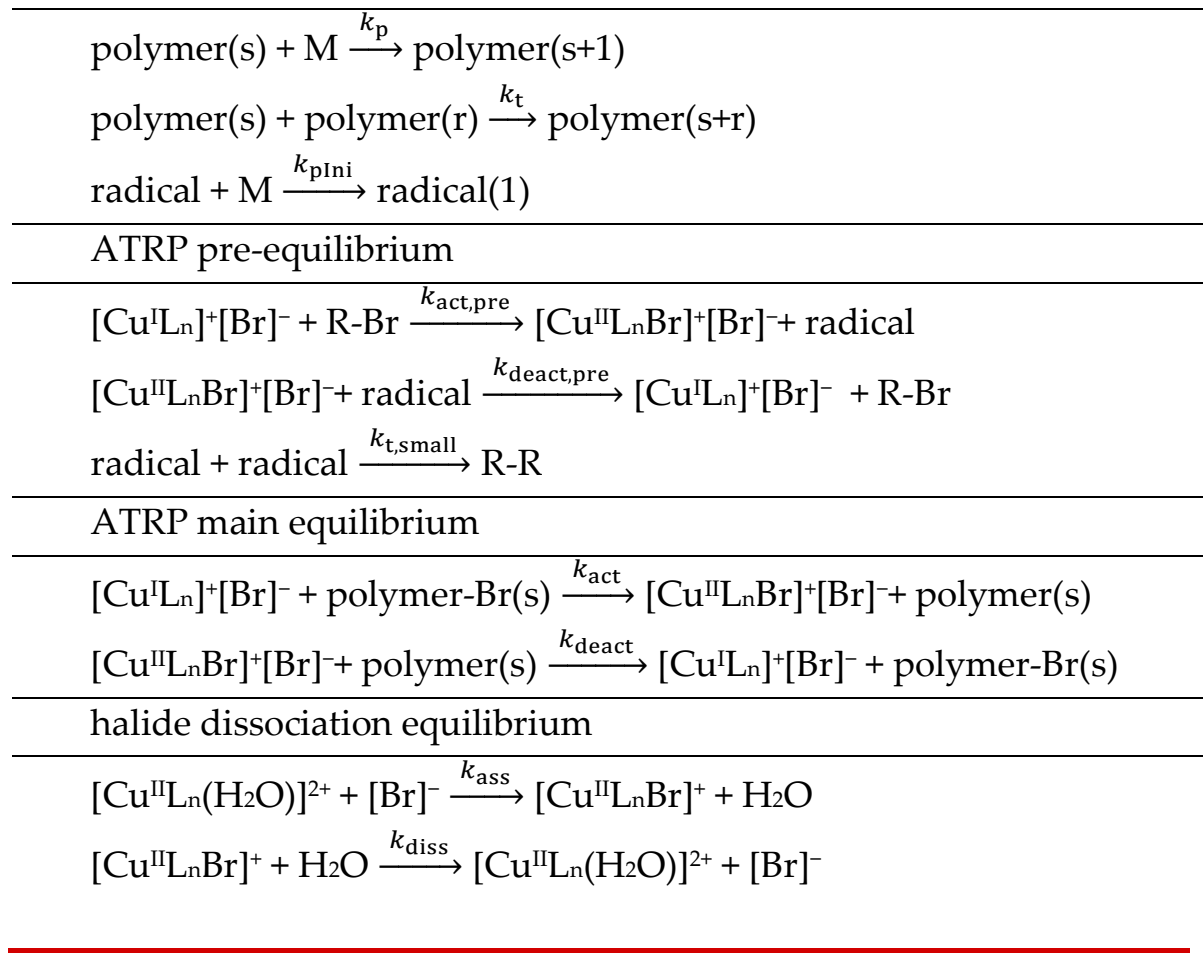

composition of $50 \mathrm{wt} \%$ PEGMA, $3 \mathrm{mM} \mathrm{Cu}{ }^{\mathrm{I}}(\mathrm{bpy}) 2,1 \mathrm{mM} \mathrm{Cu}{ }^{\mathrm{II}}(\mathrm{bpy}){ }_{2} \mathrm{Br}$ and $3 \mathrm{mM}$ HEMA-Br up to a monomer conversion of $75 \%$.

The data in Figure 4.14 show that the addition of up to 5 equivalents of $\mathrm{NaBr}$ relative to the total copper concentration results in a significant reduction of dispersity for the produced polymer. Upon further addition of $\mathrm{NaBr}$ only minor improvements of dispersity are achieved.

As seen in Figure 4.14, additional 5 to 50 equivalents of $\mathrm{NaBr}$ further improve the chain-end functionality drastically from $30 \%$ to almost $90 \%$. Furthermore, the reaction time is influenced by $\mathrm{NaBr}$ concentration (not shown in Figure 4.14). In the case of no $\mathrm{NaBr}$ addition, the simulation yields a reaction time of ca. 40 minutes for 


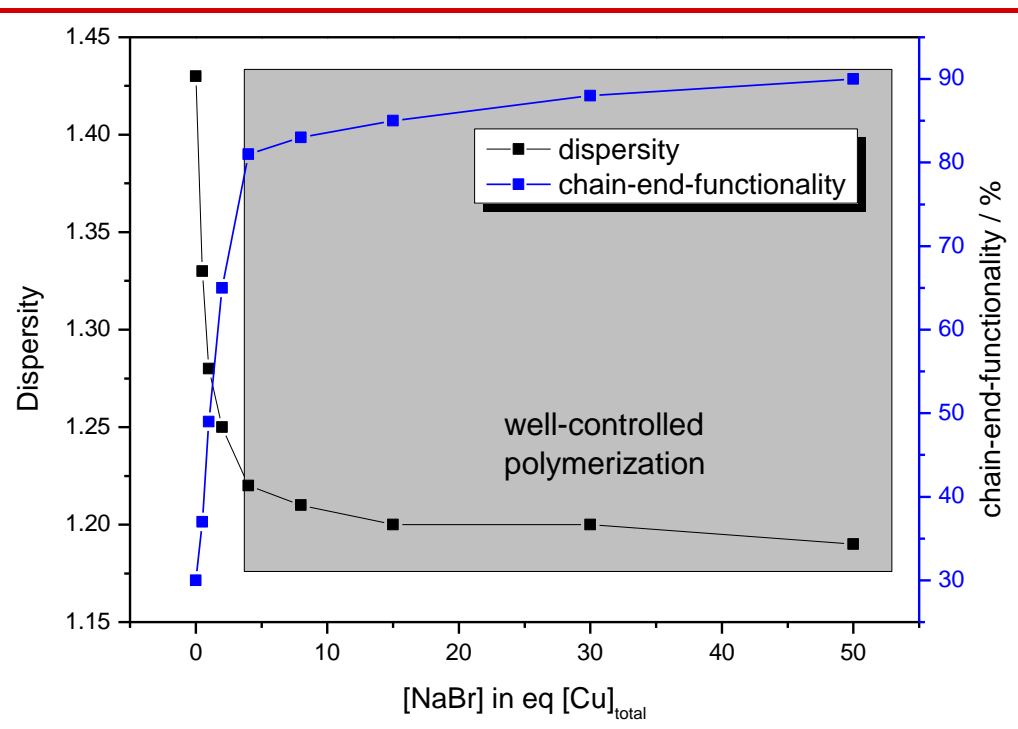

Figure 4.14: PREDICI $^{\circledR}$ simulations for a PEGMA polymerization and the influence of the $\mathrm{NaBr}$ concentration on the dispersity (black curve) and chain-end functionality (blue curve). The $\mathrm{NaBr}$ concentration is given in equivalents in respect with the total $\mathrm{Cu}$ concentration, $[\mathrm{Cu}]_{\text {tot. The PREDICI }}{ }^{\circledR}$ model consists of the reactions in Table 4.5 and was simulated with $3 \mathrm{mM}$ $\mathrm{Cu}^{\mathrm{l} b p y}$ 2, $1 \mathrm{mM} \mathrm{Cu} \mathrm{Cu}^{\mathrm{II} b p y}{ }_{2} \mathrm{Br}$ and $3 \mathrm{mM}$ HEMA-Br in $50 \mathrm{wt} \% \mathrm{H}_{2} \mathrm{O}$. The grey box shows the sodium bromide concentration range for a well-controlled polymerization.

reaching a monomer conversion of $75 \%$. The reaction time for $75 \%$ conversion reduces to 33 minutes upon the addition of 50 equivalents $\mathrm{NaBr}$. The added $\mathrm{NaBr}$ stabilizes the $\mathrm{Cu}$ II/ $\mathrm{L}-\mathrm{Br}$ complex, which reduces radical termination and enhances the polymerization rate.

Although the dispersity is around 1.20 with 15 equivalents and may not significantly further lowered with higher $\mathrm{NaBr}$ content, even lower dispersities would be desirable for a better control over the polymerization. The dispersity may be further reduced by the selection of an initiator with higher pre-equilibrium constant and thus larger $k_{\text {act. }}$. The $k_{\text {act }}$ for the alkyl initiator, HEMA-Br, which was used for the simulations in Figure 4.14, is about 20 times below the one for PEGMA. Simulations with an identical $k_{\text {act }}$ for the pre-equilibrium and 
equilibrium in combination with 50 equivalents of $\mathrm{NaBr}$ at otherwise identical ATRP parameters as applied in Figure 4.14, showed that the dispersity is reduced to 1.10. This improvement in dispersity is achieved by a shorter initiation phase and thus a concerted start of the chaingrowth.

However, a 10 times higher activation rate coefficient for the preequilibrium than for the polymerization equilibrium would result in an enormously high radical concentration and thus in high amounts of termination of initiator-derived radicals would occur. Because of the high termination rate of initiator radicals, the chain-end functionality would be strongly reduced below $60 \%$.

These findings are especially important for polymerizations with methacrylates, since $K_{\text {ATRP }}$ is by almost two orders of magnitude above the associated $K_{\text {model }}$ and the corresponding initiation pre-equilibrium. As a consequence, the used ATRP initiator should be almost as active as the polymeric R-X species for polymerizations with methacrylates. HEMA-Br may not be perfectly suited, but has been used because of the very good solubility in solutions containing high fractions of water. Moreover, dispersities as low as 1.20 may be considered as an indication of well-controlled polymerization.

In addition to the impact of $\mathrm{NaBr}$ on the control over polymerization, the influence of water concentration on dispersity and polymerization rate is of particular interest. The PREDICI ${ }^{\circledR}$ model was used to simulate reaction time and dispersity for different water concentrations. The concentrations used for the PREDICI ${ }^{\circledR}$ simulations were identical to the ones presented before, with $3 \mathrm{mM} \mathrm{Cu}(\mathrm{bpy}) 2,1 \mathrm{mM}$ $\mathrm{Cu}^{\mathrm{II}}(\mathrm{bpy})_{2} \mathrm{Br}$ and $3 \mathrm{mM}$ HEMA-Br. The sodium bromide concentration was kept constant at 50 equivalents of total copper content.

Shown in Figure 4.15 are the results of the PREDICI ${ }^{\circledR}$ simulations for the effect of water on dispersity and reaction time. The dispersity of the polymerization vs the water concentration is depicted in black, whereas the reaction time up to $75 \%$ monomer conversion vs water concentration is depicted in blue. Toward higher water content, the dispersity increases from 1.05 to 1.40 at $80 \mathrm{wt} \% \mathrm{H}_{2} \mathrm{O}$. This increase in dispersity is induced by the high KATRP at high water content. For such high KATRP's normal ATRP is not effective any more. This unfavorable effect may be counterbalanced by using of a higher initial $\mathrm{NaBr}$ addition, a higher initial $\mathrm{Cu}^{\mathrm{II}} / \mathrm{L}-\mathrm{Br}$ concentration or by the introduction 


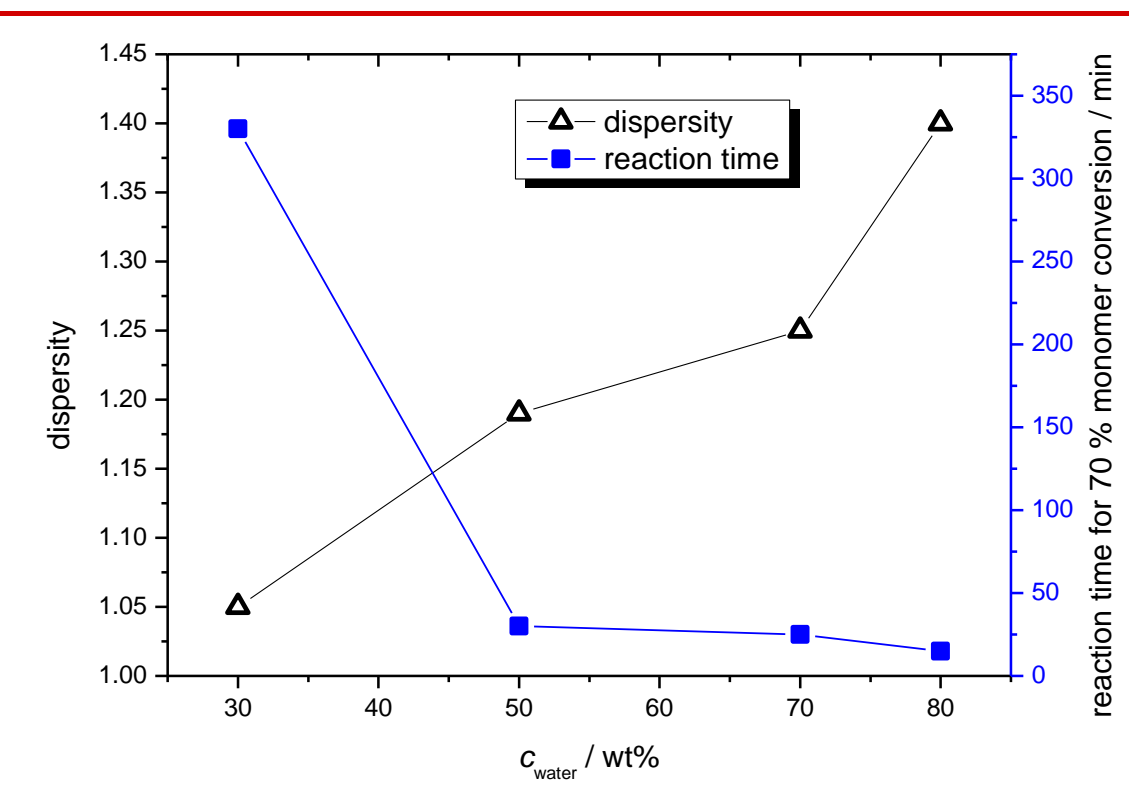

Figure 4.15: PREDICI ${ }^{\circledR}$ simulations for the variation of dispersity (black triangles) and reaction time (blue squares) with water concentration. The PREDICI $^{\circledR}$ simulations for a PEGMA polymerization were calculated for 3 mM Cu${ }^{\mathrm{I}}(\mathrm{bpy})_{2}, 1 \mathrm{mM} \mathrm{Cu}{ }^{\mathrm{II}}(\mathrm{bpy})_{2} \mathrm{Br}$ and $3 \mathrm{mM}$ HEMA-Br.

of an ARGET or ICAR ATRP protocol.

Even though higher water contents may result in a loss of control, the reaction is highly accelerated by water and the time to reach $75 \%$ conversion reduces from 330 minutes at $30 \mathrm{wt} \%$ water to 15 minutes at $80 \mathrm{wt} \% \mathrm{H}_{2} \mathrm{O}$. This acceleration toward higher water content is the most important feature of $\mathrm{Cu}$-mediated ATRP in aqueous phase. This effect allows for a reduction of the $\mathrm{Cu}$ concentration without compromising reaction time. Moreover, such highly active catalysts systems are favorable for ATRPs in which regenerative concepts such as ICAR or ARGET ATRP are used.

To check the accuracy of the PREDICI ${ }^{\circledR}$ simulations, a set of PEGMA polymerization with various $\mathrm{Cu}$ catalyst concentrations and different amounts of water were carried out. The resulting polymer was analyzed by SEC with dimethylacetamide (DMAc) as the eluent, because of a 
better solubility of the high conversion polymer. However, the molecular mass of the polymer could not be determined, due to the missing Kuhn-Mark-Houwink-Sakurada coefficients for this eluent.

Nevertheless, the measured dispersity of the polymer was compared to calculated dispersity of the PREDICI ${ }^{\circledR}$ simulations. In Table 4.6 are listed the measured dispersities for various PEGMA ATRPs with the associated initial $\mathrm{Cu} / \mathrm{L}$ and $\mathrm{Cu} / \mathrm{II} / \mathrm{L}-\mathrm{Br}$ concentrations, the monomer conversion, and the measured and simulated dispersity of the polymer. The HEMA-Br initiator concentration is equal to the $\mathrm{Cu} / \mathrm{L}$ concentration for each experiment and all polymerizations were carried out with an excess of $\mathrm{NaBr}$.

As seen in Table 4.6, the experimental dispersity is in close agreement with the theoretical predictions. The slight deviation is caused by the experimental uncertainty and the disregard of SEC broadening during the simulation. The dispersity for all experiments is between 1.15 and 1.30. The small dispersities of around 1.2 even at high diluted solutions were realized by adding more $\mathrm{Cu} \mathrm{u}^{\mathrm{II}} / \mathrm{L}-\mathrm{Br}$ to the solution. These findings show that the PREDICI ${ }^{\circledR}$ simulations allow for a precise prediction of the dispersity for each polymerization.

The simulations in the present section were focused on the impact of $\mathrm{NaBr}$ content and water content on dispersity, chain-end functionality and reaction time. The simulations were carried out for a normal ATRP, however, the kinetic data may also be used for reverse, SR\&NI or ICAR ATRP by implementing the literature known decomposition rates of various thermal initiators. It may further be possible to simulate an ARGET and AGET ATRP once the kinetics and mechanism of the reduction process is known.

The kinetic data were exclusively determined for $\mathrm{Cu}$-meditated ATRP of PEGMA with $\mathrm{CuBr} / 2,2$ '-bipyridine. It may however possible to use the data to predict quantitatively the impact on dispersity, chainend functionality for similar reactive ATRP catalyst, e.g., HMTETA or 4,4'-Di(5-nonyl)-2,2'-bipyridine (dNbpy). 
Table 4.6: Comparison of experimental measured dispersity and simulated dispersity for different polymerization conditions with HEMA-Br acting as the initiator. All experiments were carried out in an excess of 50 equivalents $\mathrm{NaBr}$. The measured SEC-spectra are depicted in Figure A5.

\begin{tabular}{cccccc}
\hline $\begin{array}{c}\text { PEGMA / } \\
\text { wt } \%\end{array}$ & $\begin{array}{c}{\left[\mathrm{Cu}^{\mathrm{I} / \mathrm{L}]} /\right.} \\
\mathrm{mM}\end{array}$ & $\begin{array}{c}{\left[\mathrm{Cu}^{\mathrm{II}} / \mathrm{L}-\mathrm{Br}\right]} \\
/ \mathrm{mM}\end{array}$ & $\begin{array}{c}\text { conv. / } \\
\%\end{array}$ & exp. $Ð$ & theo. $Ð$ \\
\hline \hline 20 & 1.56 & 1.27 & 90 & 1.13 & 1.17 \\
30 & 2.36 & 0.75 & 92 & 1.29 & 1.27 \\
50 & 3.00 & 1.51 & 74 & 1.16 & 1.12 \\
70 & 2.56 & 1.28 & 53 & 1.21 & 1.22 \\
\hline
\end{tabular}




\section{5}

\section{Iron-mediated ATRP in aqueous phase}

Fe-mediated ATRP is an attractive alternative to the extensively used Cu-mediated ATRP due to low toxicity, good biocompatibility and good accessibility of iron. ${ }^{[141]}$ Fe-based ATRP in organic solvents has mostly been applied to ATRP of styrene ${ }^{[55,142,143]}$ and methacrylates, ${ }^{[144-148]}$ but also to nitriles ${ }^{[49,149]}$ and, with some complications, also to acrylates. ${ }^{[55,57,150,151]}$

The iron catalysts reported to date are mostly based on halides, phosphines, amines, and imines as ligands for the formation of iron complexes. ${ }^{[5,8,10,49,152]}$ In contrast to Cu-catalysis, iron-halide-mediated ATRP may also be performed in polar solvents without additional specific ligands. ${ }^{[146]}$ However, Fe-ATRP with these types of ligands is limited to the above-mentioned types of monomers. Even though NMP may be used as a solvent for Fe-based ATRP, attempts in this work to polymerize the structurally similar N-vinylpyrrolidone (NVP) were unsuccessful, most likely due to dimerization of NVP as reported for xanthate-mediated polymerization. ${ }^{[153]}$ It has been was suggested that alkyl halides with some metal complexes may also catalyze NVP dimerization. ${ }^{[153]}$

To achieve Fe-based ATRP in aqueous solution, stable and welldefined Fe-ligand systems are required, similar to $\mathrm{Cu}$-mediated ATRP.

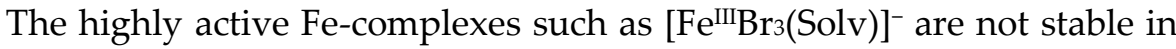
water. Stable amine ligands, that have been used in Cu-mediated ATRP, 
often showed unsatisfying activity, low polymerization rates and a lack of control.[5] A few reports suggest that the amine tris(3,6dioxaheptyl)amine (TDA) may be used in an AGET ATRP. ${ }^{[52,154]}$ However, experiments with Fe and TDA in this work evidenced a limited solubility and stability of the catalyst in aqueous solution.

Recently, a growing interest in the development of water-soluble porphyrin based ligands has emerged. These bio-inspired Fe-ATRP ligands promise polymerization under bio-relevant conditions, i.e., at low temperature and high water content. Protein-based ATRP ligands with iron-heme centers, such as horseradish peroxidase (HRP), ${ }^{[155]}$ catalase $^{[54]}$ and hemoglobin $(\mathrm{Hb})^{[53]}$ act as ATRP catalysts and may be used to produce high-molecular-mass polymers with narrow MMD. ${ }^{[5,49]}$

Matyjaszewski et al. reported a modified water-soluble protoporphyrin IX containing a ferric ion with an additional axial bromide ligand (see Figure 5.1), without however performing kinetic studies. ${ }^{[1]}$ The protoporpyhrin-type catalysts has been used within the present study and were kindly provided by the Matyjaszewski group. These complexes have a poly(ethylene glycol) (MPEG) side arm for better solubility. The vinyl moieties from the initial protoporphyrin IX have been removed to prevent polymerization of the ligand itself. Further modifications of the catalyst, which have been tested in this work, involve the replacement of one MPEG side arm with an imidazole or thioether end group to potentially improve the protection against coordinating monomers and solvents. The recently developed mesohemin-(MPEG500)2 catalyst provides a good polymerization control and relatively fast polymerization even at low temperatures in aqueous solution. ${ }^{[1]}$

The reversible deactivation of radicals in Fe-based ATRP is mediated by an $\mathrm{Fe}^{\mathrm{III}}$ catalyst. The reaction of $\mathrm{Fe}^{\mathrm{II}}$ with radicals is also relevant in Fe-mediated organometallic radical polymerization (OMRP) (see Scheme 5.1 below). Experimental and computational analysis suggest that ATRP as well as organometallic reactions may operate simultaneously. ${ }^{[5,152]}$ Iron porphyrin complexes are also known to form stable organometallic species in organic solvents by the reaction of alkyl radicals with $\mathrm{Fe}^{\mathrm{II}}$ or by various other reactions. ${ }^{[156-160]}$ Thereby, organometallic reactions may not be limited to organic solvents. Organometallic reactions and Fe-mediated ATRP in aqueous solution have not yet been investigated. The relative importance of either 


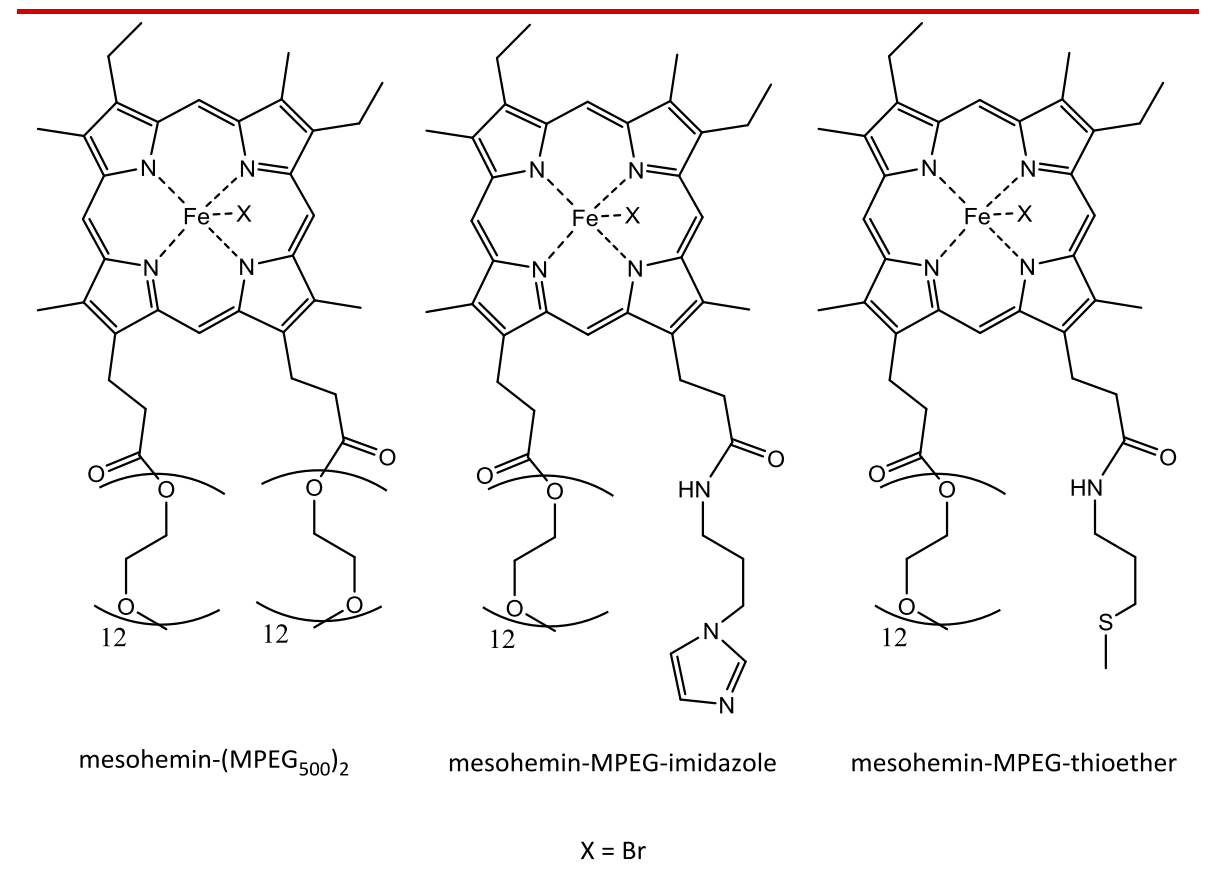

Figure 5.1: Structural formulae for the iron-porphyrin-catalysts investigated in this chapter. The mesohemin-(MPEG500) 2 was available as the bromide and chloride derivative. The catalysts were kindly provided by A. Simakova from the Matyjaszewski group. ${ }^{[1]}$

pathway has also not been discussed for Fe-porphyrin mediated reactions in aqueous solution.

To gain a better understanding of Fe-mediated RDRP in aqueous solution this chapter deals with the spectroscopic analysis via UV/Vis and Moessbauer spectroscopy of the Fe species occuring during polymerization. Besides the ATRP-relevant $\mathrm{Fe}^{\mathrm{II}} / \mathrm{L}$ and $\mathrm{Fe} \mathrm{III}_{\mathrm{II}} \mathrm{L}-\mathrm{Br}$ species, it will be checked for organometallic species, Fe ${ }^{\mathrm{III}} / \mathrm{L}-\mathrm{R}$. Moreover, highly time-resolved EPR, and UV/Vis spectroscopy in combination with Stopped-Flow injection will be used to measure ATRP- and OMRPrelevant parameters, i.e., $k_{\text {deact, }} K_{\text {ATRP }}$ and $k_{\text {add,Fe, the addition of radicals }}$ to $\mathrm{Fe}^{\mathrm{II}}$, in various monomer-water mixtures and in monomer-free model systems. Additionally, the experiments are accompanied by sizeexclusion chromatography to provide guidance for a suitable selection 
of reaction conditions for polymerization.

\subsection{Speciation Analysis}

This subchapter deals with a detailed investigation into the involved species via online monitoring of the mesohemin-(MPEG500)2 catalyst concentration (Figure 5.1) in PEGMA/ $\mathrm{H}_{2} \mathrm{O}$ mixtures and in monomerfree model systems via UV/Vis spectroscopy combined with Moessbauer spectroscopy.

Illustrated in Scheme 5.1 are the equilibria involved in Fe-mediated RDRP. The blue box represents the ATRP mechanism without the water-induced halide dissociation as described in chapter 4 . To prevent halide dissociation in aqueous solution, the reactions were performed in the presence of an excess of the corresponding sodium halides. According to the ATRP equilibrium, activation of an alkyl halide initiator, $\mathrm{R}-\mathrm{Br}$, by $\mathrm{Fe}^{\mathrm{II}} / \mathrm{L}$ generates radicals, $\mathrm{R}^{\bullet}$, and the deactivator complex FeII/L-Br.

The OMRP equilibrium depicted in the red box describes the reaction of $\mathrm{Fe}$ II/L with $\mathrm{R} \cdot$ to the organometallic species, $\mathrm{Fe}$ III/L-R. This organometallic species may react in different subsequent reactions, the most important ones are the reverse reaction to $\mathrm{Fe}^{\mathrm{II}} / \mathrm{L}$, i.e., the reversible termination (RT), and the catalytic radical termination (CRT) of two

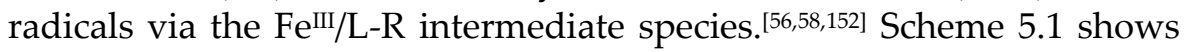
that the $\mathrm{Fe}^{\mathrm{II}} / \mathrm{L}$ species participates in both reaction pathways and may be crucial for the selection of the pathway for the subsequent reaction. The focus of the spectroscopic studies centers around the question whether ATRP and OMRP equilibria are both operating with the Fe catalyst under investigation.

To distinguish between the iron species occurring during a polymerization and in a model system, UV/Vis spectroscopy has been applied. Iron porphyrin complexes exhibits a characteristic strong Soretabsorption band at around $400 \mathrm{~nm}$ and usually up to four additional, but less intense $Q$ bands between 400 and $800 \mathrm{~nm} .{ }^{[159,161]}$ The intense Soret bands are strongly overlapping which poses problems for 


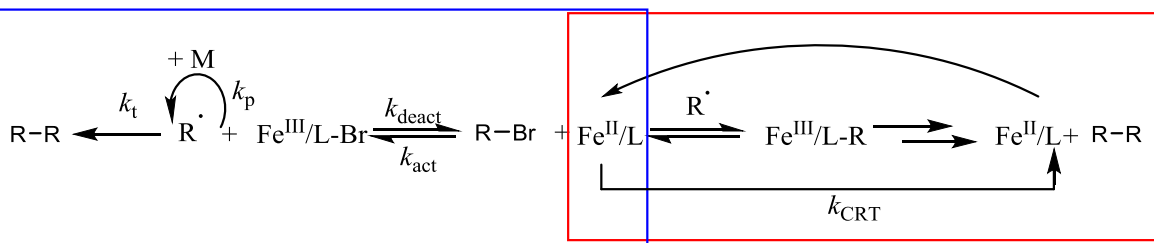

ATRP

OMRP

Scheme 5.1: Iron-mediated radical polymerization with a simultaneous ATRP and OMRP equilibrium. Both reaction pathways involve the Fe $\mathrm{II}_{-}$ hemin activator complex and growing radicals, $R \cdot$. The potential subsequent reaction of the catalytic radical termination (CRT) is also included.

distinguishing the iron species. However, the iron species provide distinctly different $Q$ band absorption spectra. Shown in Figure 5.2 are the UV/Vis spectra between 400 and $700 \mathrm{~nm}$ for $\mathrm{Fe} / \mathrm{L}$ species in $50 \mathrm{wt} \% \mathrm{H}_{2} \mathrm{O} / \mathrm{PEGMA}$ at $22^{\circ} \mathrm{C}$. The black line represents the initial $\mathrm{Fe}^{\mathrm{III}} / \mathrm{L}-\mathrm{Br}$ species, which exhibits a characteristic absorption centered around $577 \mathrm{~nm}$. Upon the addition of HEMA-Br which acts as an ATRP initiator, no change of the absorption spectrum is observed. As the original spectrum was retained after addition of $\mathrm{HEMA}-\mathrm{Br}$, the $\mathrm{Fe}^{\mathrm{III}}$ state of the metal was confirmed.

Reported polymerizations of mesohemin-(MPEG500)2 were carried out in a reverse fashion, starting with $\mathrm{Fe}{ }^{\mathrm{III}} / \mathrm{L}-\mathrm{Br}$ and ascorbic acid as a reducing agent (AGET ATRP, activators generated by electron transfer, see chapter 2.3). ${ }^{[1]}$ The recorded Fe/L spectrum in the presence of a tenfold excess of ascorbic acid is almost identical to the initial Fe $\mathrm{FII} / \mathrm{L}-\mathrm{Br}$ species (black line) indicating that ascorbic acid provides only an inefficient reduction power. The very slow decay in absorption band suggests that less than one percent of the $\mathrm{Fe}^{\mathrm{III}} / \mathrm{L}-\mathrm{Br}$ is reduced to $\mathrm{Fe}^{\mathrm{II}} / \mathrm{L}$. This finding is important to understand the reported AGET polymerization. The fact that the polymerization rate with this catalyst species was very high, despite the slow reduction rate with ascorbic acid, indicates a high catalytic activity even at ppm levels of Fe $\mathrm{F}^{\mathrm{II}} / \mathrm{L}$. Moreover, the finding suggests that the type of ATRP may be better 


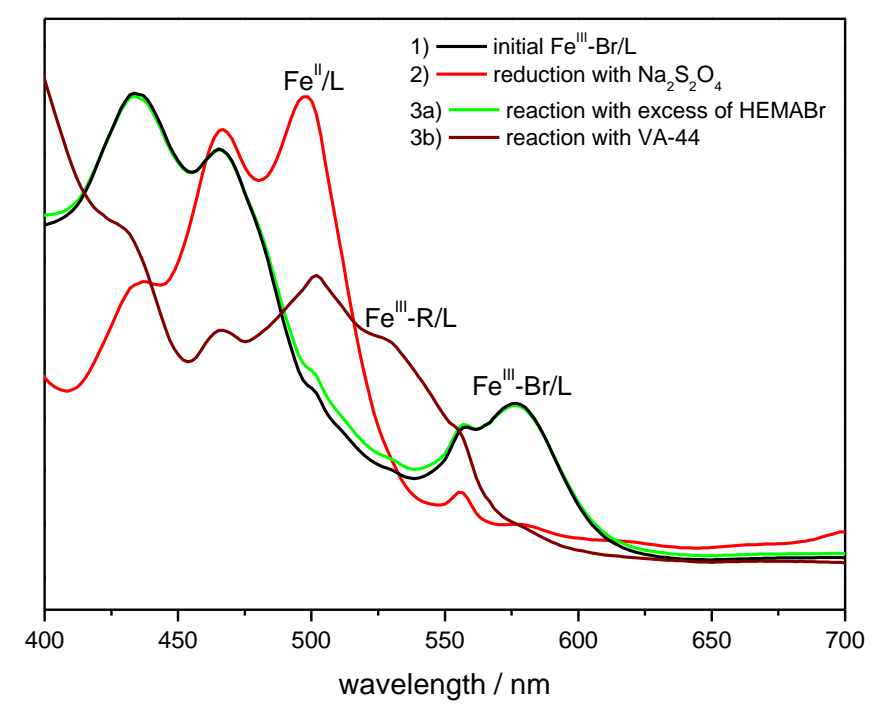

Figure 5.2: UV/Vis spectra of the participating mesohemin-(MPEG500)2 species in PEGMA/ $\mathrm{H}_{2} \mathrm{O}$ mixtures with $50 \mathrm{wt} \%$ water at $22{ }^{\circ} \mathrm{C}$. The black line indicates the initial Fe ${ }^{\mathrm{III}}-\mathrm{Br} / \mathrm{L}$ species which was reduced with $\mathrm{Na}_{2} \mathrm{~S}_{2} \mathrm{O}_{4}$ to yield the $\mathrm{Fe} \mathrm{I}^{\mathrm{I}} / \mathrm{L}$ spectrum (red line). The reaction of $\mathrm{Fe}$ initiator VA-44 at $65^{\circ} \mathrm{C}$ lead to the Fe $\mathrm{III} / \mathrm{L}-\mathrm{R}$ species (brown line). The green line spectrum results from the reversible reaction with HEMA-Br and may associated with the almost pure Fe ${ }^{\mathrm{II}} / \mathrm{L}-\mathrm{Br}$. The small variation may be due to traces of $\mathrm{Fe}$ III/L-R.

described by an ARGET ATRP, in which the $\mathrm{Fe}^{\mathrm{II}} / \mathrm{L}$ complex is slowly and constantly regenerated.

To obtain an $\mathrm{Fe}^{\mathrm{II}}$ spectrum, the stronger water soluble reducing agent sodium dithionite $\left(\mathrm{Na}_{2} \mathrm{~S}_{2} \mathrm{O}_{4}\right)$ was chosen. The reaction with $\mathrm{Na}_{2} \mathrm{~S}_{2} \mathrm{O}_{4}$ yields a different absorption spectrum (red line), which is assigned to the formation of the anticipated $\mathrm{Fe}^{\mathrm{II}} / \mathrm{L}$ complex. The absorption band at $577 \mathrm{~nm}$, associated with the $\mathrm{Fe}$ III/L-Br complex, completely disappears and the characteristic double band for $\mathrm{Fe}^{\mathrm{II}}$ porphyrin complexes at around 466 and $500 \mathrm{~nm}$ shows up. ${ }^{[162,163]}$ The solution with the produced $\mathrm{Fe}^{\mathrm{II}} / \mathrm{L}$ complex was used to check whether and to which extent $\mathrm{Fe}^{\mathrm{II}} / \mathrm{L}$ undergoes either of the two reaction pathways proposed in Scheme 5.1 $\mathrm{Fe} / \mathrm{II}$ may react via two pathways: 
one option is the reaction with an alkyl halide the other one is the reaction with a radical. The reaction with HEMA-Br yields the green line spectrum which is close to the spectrum of $\mathrm{Fe}^{\mathrm{III}} / \mathrm{L}-\mathrm{Br}$. The small difference between the black and green spectra at ca. $540 \mathrm{~nm}$ in the absorption may be due to the potential reaction pathway of the Fe $\mathrm{FI} / \mathrm{L}-\mathrm{R}$ species. The reaction with HEMA-Br is also reversible, since the formed $\mathrm{Fe}^{\mathrm{III}} / \mathrm{L}-\mathrm{Br}$ can again be reduced with $\mathrm{Na}_{2} \mathrm{~S}_{2} \mathrm{O}_{4}$ to $\mathrm{Fe}^{\mathrm{II}} / \mathrm{L}$ (not shown).

The second option is the formation of $\mathrm{Fe}$ III/L-R species. The absorption due to the Fe $\mathrm{F}^{\mathrm{II}} / \mathrm{L}-\mathrm{R}$ species is shown in Figure 5.2 as the third iron species (brown line). This species is obtained by the reaction of $\mathrm{Fe} / \mathrm{L}$ with the thermal initiator $\mathrm{VA}-44$ at $65^{\circ} \mathrm{C}$, where initiation decomposition is fast, yielding a high radical concentration of PEGMA radicals that may react via the OMRP pathway to the stable Fe $\mathrm{Fe}^{\mathrm{III}} / \mathrm{L}-\mathrm{R}$ species. The formation of the $\mathrm{Fe}^{\mathrm{III}} / \mathrm{L}-\mathrm{R}$ signal can be monitored via the decrease of the absorption at around $500 \mathrm{~nm}$ on a timescale of $10 \mathrm{~min}$ (see Figure A6A). Further experiments indicate that the Fe ${ }^{I I I} / \mathrm{L}-\mathrm{R}$ species is stable for at least $15 \mathrm{~min}$ at $65^{\circ} \mathrm{C}$ and, of course significantly longer at $20{ }^{\circ} \mathrm{C}$ (see Figure A6B). Stable OM species were also reported for Fe ${ }^{\mathrm{II}}$ porphyrins reacting with alkyl radicals. $[156,157,159,160,164]$

To obtain further mechanistic insights, UV/Vis measurements were carried out with monomer-free model systems using PEO as solvent, which may be regarded as the saturated analogue of PEGMA. In addition to the strong solvatochromic shift by $70 \mathrm{~nm}$ to higher wavelengths, the changes in the UV/Vis absorbance are otherwise identical to the ones observed with the polymeric system (see Figure A7).

Solutions as subjected to UV/Vis spectroscopy were also investigated via ${ }^{57} \mathrm{Fe}$ zerofield Moessbauer spectroscopy to provide direct information on the oxidation and spin states of the Fe species. This information is also used to confirm the assignment from UV/Vis spectroscopy. The experimental procedures to yield the polymer samples subjected to Moessbauer analysis were similar to the ones used for preparing the samples for UV/Vis spectroscopy, except that higher concentrations of each component were used to achieve a sufficiently good signal-to-noise ratio. All Moessbauer spectra were recorded at $80 \mathrm{~K}$ and were flash-frozen in liquid nitrogen, and should represent the $\mathrm{Fe} / \mathrm{L}$ composition at ambient temperature.

Due to the unfavorably large $\gamma$-capture cross-section of bromide, the 
chloride derivative of the complex was used for the measurements. Previous investigations suggest that the chloride catalyst behaves as does the bromide species. The characteristic absorption of Fe $\mathrm{FI}^{\mathrm{II}} / \mathrm{L}-\mathrm{Br}$ at $577 \mathrm{~nm}$ shows a small blue shift of ca. $15 \mathrm{~nm}$ due to the stronger $\mathrm{Fe}-\mathrm{Cl}$ bond with an otherwise almost identical absorption spectrum.

Because of the non-optimum $\gamma$-capture cross-section of chloride, all experiments were carried out with no more than 50 eq. of $\mathrm{NaCl}$ with respect to the Fe complex in a $50 \mathrm{wt} \% \mathrm{H}_{2} \mathrm{O} / \mathrm{PEGMA}$ mixture. Illustrated in Figure 5.3 are the recorded Moessbauer spectra of $\mathrm{Fe}^{\mathrm{II}} / \mathrm{L}$ obtained by the reaction with 0.5 equivalents of $\mathrm{Na}_{2} \mathrm{~S}_{2} \mathrm{O}_{4}(\mathrm{~A})$, the $\mathrm{Fe}{ }^{\mathrm{II}} / \mathrm{L}$ reduced by an excess of $\mathrm{Na}_{2} \mathrm{~S}_{2} \mathrm{O}_{4}$ (B) and the Fe $\mathrm{B}^{\mathrm{III}} / \mathrm{L}-\mathrm{R}$ species through the reaction of $\mathrm{Fe}^{\mathrm{II} / \mathrm{L}}$ with VA-44 (C). The associated Moessbauer parameters of the isomeric shift, $\delta$, quadrupole splitting, $\Delta E_{\mathrm{Q}}$, line width, $\Gamma$, and relative intensity are listed in Table 5.1.

The spectrum of $\mathrm{Fe}^{\mathrm{III}}-\mathrm{Cl} / \mathrm{L}$ in solution was also recorded as a reference. The porphyrin-complex in solution is Moessbauer-silent, which is assigned to intermediate spin relaxation. ${ }^{[165,166]}$ The Moessbauer spectrum of the $\mathrm{Fe} \mathrm{III}^{\mathrm{II}} \mathrm{L}-\mathrm{Cl}$ complex in bulk, however, shows asymmetric broadened lines (see Figure A8). The situation improves by lowering the temperature for the Moessbauer measurements. The onset of broadening occurs in a temperature range which is characteristic for Fe $\mathrm{FII}$ porphyrins and can only occur for iron species with an odd number of spin state. ${ }^{[165,166]}$

Shown in Figure 5.3A is the Moessbauer spectrum obtained by the reaction of $\mathrm{Fe}$ III/L-Cl with 0.5 equivalents of $\mathrm{Na}_{2} \mathrm{~S}_{2} \mathrm{O}_{4}$, since $\mathrm{Na}_{2} \mathrm{~S}_{2} \mathrm{O}_{4}$ decomposes into two anionic $\left[\mathrm{SO}_{2}\right]^{-}$radicals. The spectrum has been fitted with two subfunctions to fit the overall spectrum. The red spectrum was fitted with typical $\mathrm{Fe}^{\mathrm{II}}$ low spin parameter of $\delta=0.46 \mathrm{~mm} \mathrm{~s}^{-1}$ and $\Delta \mathrm{EQ}=0.29 \mathrm{~mm} \mathrm{~s}^{-1}$ (see Table 5.1). The blue spectrum was fitted with the parameter $\delta=0.01 \mathrm{~mm} \mathrm{~s}^{-1}$ and $\Delta \mathrm{EQ}=0.10 \mathrm{~mm} \mathrm{~s}^{-1}$. The broad signal with no quadrupole splitting indicates an $\mathrm{Fe}^{\mathrm{III}}$ species. It appears reasonable to assume that the absorption can be assigned to $\mathrm{Fe} \mathrm{III}^{\mathrm{II}} \mathrm{L}-\mathrm{Cl}$ and occurs as a consequence of incomplete reduction. The incomplete reduction may be due to the unstable nature of the formed $\left[\mathrm{SO}_{2}\right]^{-}$anionic radicals from $\mathrm{Na}_{2} \mathrm{~S}_{2} \mathrm{O}_{4}$ in water. $\mathrm{Na}_{2} \mathrm{~S}_{2} \mathrm{O}_{4}$ was dissolved in water prior to adding it to the solution. Under these circumstances a significant amount of $\left[\mathrm{SO}_{2}\right]^{-}$may have decomposed before the addition 


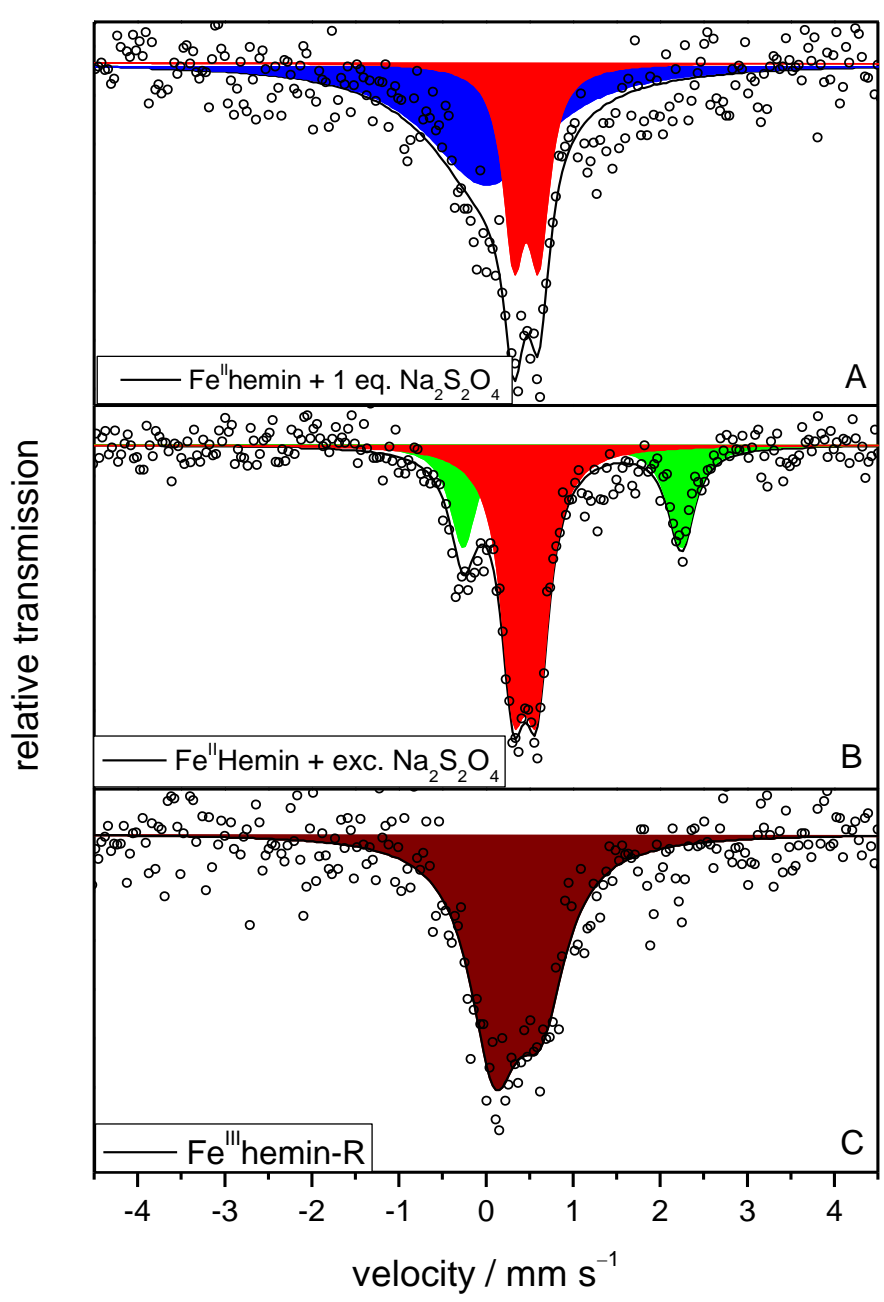

Figure 5.3: ${ }^{57} \mathrm{Fe}$ Mössbauer spectra recorded at $80 \mathrm{~K}$ on a flash-frozen solution of PEGMA $/ 50 \mathrm{wt}_{\mathrm{t}} \% \mathrm{H}_{2} \mathrm{O}$. (A) Spectrum of the $\mathrm{Fe}$ II/ $/ \mathrm{L}$ low spin

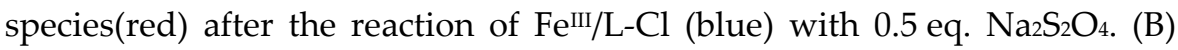
Spectrum of the $\mathrm{Fe}^{\mathrm{II}} / \mathrm{L}$ low spin species (red) and the $\mathrm{Fe}^{\mathrm{II}} / \mathrm{L}$ high spin species (green) after the reaction of $\mathrm{Fe} e^{\mathrm{III}} / \mathrm{L}-\mathrm{Cl}$ with 2 eq. $\mathrm{Na}_{2} \mathrm{~S}_{2} \mathrm{O}_{4}$. (C) Spectrum of the $\mathrm{Fe}^{\mathrm{II} / \mathrm{L}-\mathrm{R} \text { recorded after the reaction of } \mathrm{Fe}} \mathrm{e}^{\mathrm{II}} / \mathrm{L}$ with VA-44 for 20 min at $65^{\circ} \mathrm{C}$. The associated Mössbauer parameters are listed in Table 5.1. 
Table 5.1: Mössbauer parameters from Figure 5.3; $\delta, \Delta E_{\mathrm{Q}}$ and $\Gamma$ refer to isomeric shift, quadrupole splitting, and line width, respectively. The spectra were measured at $80 \mathrm{~K}$.

\begin{tabular}{|c|c|c|c|c|c|}
\hline & Iron species & $\delta / \mathrm{mm} \mathrm{s}^{-1}$ & $\begin{array}{c}\Delta E_{\mathrm{Q}} / \\
\mathrm{mm} \mathrm{s}^{-1}\end{array}$ & $\begin{array}{c}\Gamma / \\
\mathrm{mm} \mathrm{s}^{-1}\end{array}$ & $\begin{array}{c}\text { rel. conc. } \\
/ \%\end{array}$ \\
\hline$(\mathrm{A})$ & $\begin{array}{l}\mathrm{Fe}^{\mathrm{II}} / \mathrm{L} \\
S=1 / 2\end{array}$ & 0.46 & 0.29 & 0.29 & 35 \\
\hline$(\mathrm{A})$ & $\mathrm{Fe}^{\mathrm{III}} / \mathrm{L}-\mathrm{Br}$ & 0.01 & 0.10 & 1.64 & 65 \\
\hline (B) & $\begin{array}{c}\mathrm{Fe}^{\mathrm{II}} / \mathrm{L} \\
S=1 / 2\end{array}$ & 0.46 & 0.27 & 0.35 & 66 \\
\hline (B) & $\begin{array}{c}\mathrm{Fe}^{\mathrm{II}} / \mathrm{L} \\
S=2\end{array}$ & 0.99 & 2.5 & 0.37 & 34 \\
\hline (C) & $\mathrm{Fe}^{\mathrm{III} / \mathrm{L}-\mathrm{R}}$ & 0.36 & 0.53 & 0.69 & 100 \\
\hline
\end{tabular}

to the catalyst.

It is interesting to note that the $\mathrm{Fe}$ III/L-Cl species is observed in the presence of $\mathrm{Fe}^{\mathrm{II}}$, even though the same species is Moessbauer-silent in the absence of other Fe species (see Figure A9A). This situation may be due the interaction with $\mathrm{Fe}^{\mathrm{II}}$ that induces a change of the spin relaxation times.

To achieve a complete reduction, a second experiment with a twofold excess of $\mathrm{Na}_{2} \mathrm{~S}_{2} \mathrm{O}_{4}$ with respect to $\mathrm{Fe}$ "III/L-Cl was carried out. Moreover, $\mathrm{Na}_{2} \mathrm{~S}_{2} \mathrm{O}_{4}$ was added to the solution without prior solvation in water. The resulting Moessbauer spectrum is shown in Figure 5.3B. The overall spectrum has again been fitted with two subfunctions, which are assigned to one $\mathrm{Fe}$ II/L species with different spin state, high spin and low spin. The red fit has the identical Moessbauer parameters as the one in Figure 5.3A that indicates being the same $\mathrm{Fe} / \mathrm{II}$ low spin species. The second subfunction has been fitted with characteristic parameters for a $\mathrm{Fe}^{\mathrm{II}}$ high spin species with a strong isomeric shift of $\delta=0.99 \mathrm{~mm} \mathrm{~s}^{-1}$ and a high quadrupole splitting of $\Delta \mathrm{EQ}_{\mathrm{Q}}=2.50 \mathrm{~mm} \mathrm{~s}^{-1}$. It cannot be ruled out 
that the second $\mathrm{Fe}^{\mathrm{II}} / \mathrm{L}$ high spin species is also present in the mixture associated with Figure 5.3A, but it is not seen due to the low signal-tonoise ratio and being a minor species.

In contrast to the Moessbauer spectrum, the UV/Vis spectra showed no indications of a different spin state of the $\mathrm{Fe}^{\mathrm{II}} / \mathrm{L}$ species. The $\mathrm{Fe}^{\mathrm{II}} / \mathrm{L}$ high spin species may either a result of the coordination of some dithionite or since some iron porphyrins are known to exhibit a spin cross-over in the investigated temperature range at $80 \mathrm{~K}$, the Moessbauer spectrum of two species may be caused by spin-crossover phenomena. ${ }^{167,168]}$ As high spin complexes are favored at elevated temperature, it can be assumed that the $\mathrm{Fe} \mathrm{e}^{\mathrm{II}} / \mathrm{L}$ high spin species is the dominant species during UV/Vis experiments at $20^{\circ} \mathrm{C}$.

Shown in Figure 5.3C is the Moessbauer spectrum of Fe ${ }^{\mathrm{III}} / \mathrm{L}-\mathrm{R}$ which is obtained by the reaction of $\mathrm{Fe}^{\mathrm{II}} / \mathrm{L}$ with $\mathrm{VA}-44$, and thus PEGMA radicals $\left(\mathrm{R}^{\cdot}\right)$, at $65^{\circ} \mathrm{C}$ for $20 \mathrm{~min}$. The overall spectrum has been fitted by a single Fe species. The fitted parameters of $\delta=0.36 \mathrm{~mm} \mathrm{~s}^{-1}$ and $\Delta \mathrm{E}_{\mathrm{Q}}=0.53 \mathrm{~mm} \mathrm{~s}^{-1}$, and the asymmetric peak shape may be assigned to the spectrum of a Fe ${ }^{\mathrm{III}}$ species, which differs from the Moessbauer-silent $\mathrm{Fe} \mathrm{eII}^{\mathrm{II}} \mathrm{L}-\mathrm{Cl}$ species. It is reasonable to assume that the spectrum belongs to a Fe ${ }^{\mathrm{III}}$ low spin species, since $\mathrm{Fe}$ III/L-R species are known to be mostly stable as low spin complexes. ${ }^{[164]}$ Moreover, the Moessbauer spectrum shows no evidence that the two above described $\mathrm{Fe}^{\mathrm{II}} / \mathrm{L}$ species react in two different pathways. This underlines the assumption above that only $\mathrm{Fe}^{\mathrm{II}} / \mathrm{L}$ high spin species are present during the reaction with $\mathrm{R}^{\cdot}$ at ambient temperature. The $\mathrm{Fe} / \mathrm{L} / \mathrm{L}$ low spin complex may result from the freezing process.

For comparison with the UV/Vis analysis, two more Moessbauer spectra were recorded. One with a typical setting of the polymerization experiment described by Simakova et. al. containing $\mathrm{Fe} \mathrm{e}^{\mathrm{II}} / \mathrm{L}-\mathrm{Cl}$ and ascorbic acid and the other one with $\mathrm{Fe}{ }^{\mathrm{III}} / \mathrm{L}-\mathrm{Cl}$ and an excess of ascorbic acid to check for a potential reduction. ${ }^{[1]}$ The obtained Moessbauer spectra showed no absorption (Figure A9B and C). Since Fe ${ }^{\mathrm{III}} / \mathrm{L}-\mathrm{Cl}$ is the only Moessbauer-silent species, this finding indicates that ascorbic acid provides a very low reducing potential during a polymerization and only traces of $\mathrm{Fe}^{\mathrm{III}}-\mathrm{Br} / \mathrm{L}$ are reduced to $\mathrm{Fe} / \mathrm{II} / \mathrm{L}$. This result is in agreement with the UV/Vis spectra, which show no change in the absorption spectrum upon adding ascorbic acid.

According to Scheme 5.1, small $\mathrm{Fe} / \mathrm{I} / \mathrm{L}$ concentrations are to be 
preferred for the ATRP pathway. Very small Fe $\mathrm{F}^{\mathrm{II}} / \mathrm{L}$ concentrations in combination with a controlled radical polymerization assume that the rate of the ATRP is faster than the rate for organometallic reactions. Moreover, the polymerization starting with $\mathrm{Fe}^{\mathrm{II}} / \mathrm{L}$ and a thermal radical initiator would provide no control over the polymerization. Although both reaction pathways, ATRP and OM, may occur, in principle, it is most likely that the reaction is dominated by the ATRP pathway. Therefore, it seems reasonable to assume that the mesohemin(MPEG500)2 catalyst provides control via ATRP.

\subsection{Rate coefficients from SP-PLP-EPR analysis}

Because of the mechanistic and kinetic complexity induced by the occurrence of simultaneous ATRP and OMRP with iron-mediated RDRP, the precise knowledge of the mechanism of the individual rate coefficients is necessary to gain an adequate understanding and to improve Fe-based RDRP systems. Since the ATRP reaction pathway for the $\mathrm{Fe}^{\mathrm{III}}-\mathrm{Br} / \mathrm{L}$ species is favored in the Fe-porphyrin-based RDRP, although the formation of organometallic Fe $\mathrm{F}^{\mathrm{III}}-\mathrm{R} / \mathrm{L}$ species is possible, the investigation of ATRP-related rate coefficients is more important. Especially the deactivation rate coefficient, $k_{\text {deact, }}$ plays a significant role for the control of the polymerization. Moreover, it is interesting to know the extent by which the water concentration may influence ATRP control.

The SP-PLP-EPR technique has been become a versatile tool to determine rate coefficients of radical polymerization. ${ }^{[62,169]}$ This technique offers the advantage of the direct highly time-resolved measurement of propagating radical concentration after instantaneous pulsed-laser-induced radical initiation. ${ }^{[62,170]}$ EPR may also allow the measurement of some metal compounds with unpaired electrons such as $\mathrm{Cu}^{\mathrm{II}}$ or with restrictions high-spin $\mathrm{Fe}^{\mathrm{III}} \cdot[66,126,170,171]$

The SP-PLP-EPR technique in aqueous solution has been applied for the first time in Fe-mediated ATRP. 


\subsubsection{Measurement of $\boldsymbol{k}_{\text {deact }}$ via SP-PLP-EPR}

This chapter deals with the measurement of the ATRP deactivation rate coefficient, $k_{\text {deact, }}$ within a wide range of $\mathrm{PEGMA} / \mathrm{H}_{2} \mathrm{O}$ mixtures with the above-described $\mathrm{Fe}^{\mathrm{III}}$ porphyrin complexes (Figure 5.1) via SP-PLPEPR. The SP-PLP-EPR experiments may be carried out such that ATRP deactivation kinetics is recorded without the interference by organometallic reactions, as will be shown below.

SP-PLP-EPR studies into $k_{\text {deact }}$ are easier to be performed in the case that deactivation rate is much faster than termination. As shown in chapter 3.2, the termination rate of PEGMA is relatively slow compared to radicals with a shorter side chain, e.g., of methyl methacrylate.

It is also advantageous that the sensitivity of EPR towards the detection of methacrylate-type radicals is better than, e.g., of styryl radicals. Moreover, methacrylate-type radicals provide less complicated kinetics due to the absence of backbiting and thus of midchain-radical formation. ${ }^{[118,119]}$

Illustrated in Scheme 5.2 is the procedure for measuring $k_{\text {deact. }}$ As with the Cu-mediated ATRP studies described in chapter 4.2.1, the experiment is started in the reverse ATRP fashion in which the catalyst is employed in the higher oxidation state, $\mathrm{Fe}^{\mathrm{II}} / \mathrm{L}-\mathrm{Br}$. The starting materials are marked red. Darocur 1173 (Darocur) acts as a watersoluble photoinitiator for producing primary radicals which rapidly react with monomer molecules, $\mathrm{M}$. The propagating radicals, $\mathrm{R}_{n}{ }^{\bullet}$, react with $\mathrm{Fe}{ }^{\mathrm{III}}-\mathrm{Br} / \mathrm{L}$ to generate deactivated alkyl halide, $\mathrm{Rn}-\mathrm{Br}$, and $\mathrm{Fe}{ }^{\mathrm{II}} / \mathrm{L}$.

The system under investigation contains $1.0 \mathrm{mM}$ of the $\mathrm{Fe}^{\mathrm{III}}$ porphyrin bromide complex, Fe ${ }^{\mathrm{II}} / \mathrm{L}-\mathrm{Br}$ (for the structure see Figure 5.1), and $20 \mathrm{mM}$ Darocur for PEGMA/ $\mathrm{H}_{2} \mathrm{O}$ mixtures ranging from 30 to $90 \mathrm{wt} \% \mathrm{H}_{2} \mathrm{O}$. The initial $\mathrm{Fe}$ III/L-Br concentration of $1 \mathrm{mM}$ was chosen to achieve a clear EPR spectrum with a measureable deactivation effect. Higher $\mathrm{Fe} \mathrm{III}^{\mathrm{II}} \mathrm{L}-\mathrm{Br}$ concentration would lead to faster deactivation, which may cause difficulties at the given time resolution of the EPR setup. Moreover, in order to avoid the reaction of $\mathrm{R}^{\bullet}$ with $\mathrm{Fe} \mathrm{e}^{\mathrm{II}} \mathrm{L}$ and thus the formation of organometallic species, the laser pulse intensity and the $\mathrm{Fe}$ III/L-Br concentration were carefully selected to generate only small amounts of $\mathrm{Fe}$ II/L. 


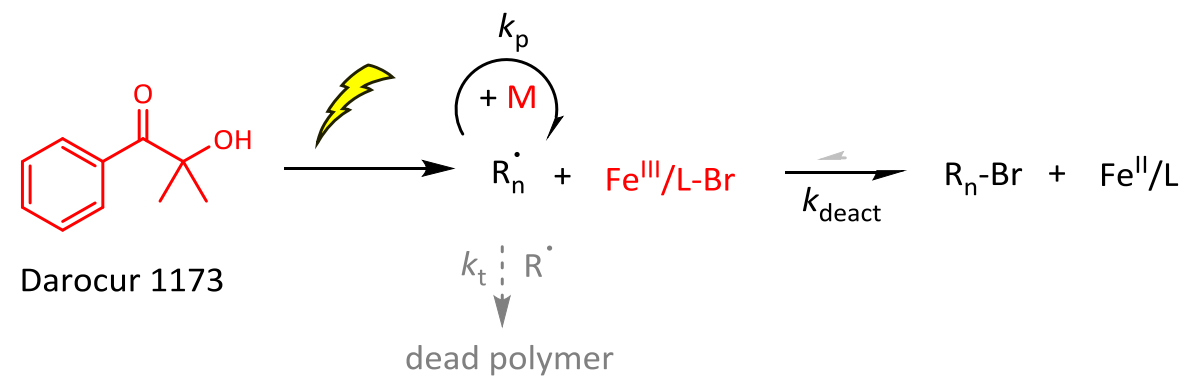

Scheme 5.2: SP-PLP-EPR measurement of $k_{\text {deact. }}$ The starting components, i.e., the photoinitiator Darocur 1173, monomer $\mathrm{M}$, and the $\mathrm{Fe}$ III/L-Br complex are marked red. The primary radicals are generated by a laser pulse which produces propagating radicals, $\mathrm{R}_{n}{ }_{\mathrm{n}}$, with a chain length $n$. $\mathrm{Fe}^{\mathrm{II}} / \mathrm{L}$ and $\mathrm{R}_{\mathrm{n}}-\mathrm{Br}$ are produced by deactivation.

As expected, the EPR spectrum of PEGMA radicals in the presence of $\mathrm{Fe}$ III/L-Br is identical to the one without any metal in the system (cf. Figure 3.9). The Fe $\mathrm{FII} / \mathrm{L}-\mathrm{Br}$ concentration cannot be detected via EPR due to a strong zero field splitting at the given temperatures. The Fe $\mathrm{FI}^{\mathrm{II}} / \mathrm{L}-\mathrm{Br}$ concentration may be detectable at very low temperatures below $20 \mathrm{~K}$, but due to the expansion of water in the EPR flat cell, the temperature cannot be below $273 \mathrm{~K}$. Thus, the catalyst concentration has been measured via UV/Vis spectroscopy. After applying 15 laser pulses, less than $10 \%$ of the $\mathrm{Fe}$ III/L-Br was converted. Consequently only minor amounts of $\mathrm{Fe} / \mathrm{II}$ are produced and the reverse reaction should not occur to a significant extent.

Shown in Figure 5.4 are the [PEGMA ${ }^{\bullet}$ ] versus time traces recorded at $20{ }^{\circ} \mathrm{C}$ for $30,50,70 \mathrm{wt} \% \mathrm{H}_{2} \mathrm{O} / \mathrm{PEGMA}$ with $1 \mathrm{mM}$ of $\mathrm{Fe} \mathrm{III}^{\mathrm{II}} / \mathrm{L}-\mathrm{Br}$ and without $\mathrm{Fe}^{\mathrm{III}} / \mathrm{L}-\mathrm{Br}$ in $50 \mathrm{wt} \% \mathrm{H}_{2} \mathrm{O} / \mathrm{PEGMA}$. In each case, an intense increase of PEGMA radicals occurs at $t=0$, when a single laser pulse is applied to the sample. The black line represents the radical decay in the absence of $\mathrm{Fe}$, where only radical-radical termination occurs. The colored lines represent the experiments with $\mathrm{Fe}$ III/L-Br. The decrease of $\left[\mathrm{PEGMA}^{*}\right.$ ] via the conventional termination occurs on an at least tenfold longer timescale than the deactivation in experiments with $\mathrm{Fe}^{\mathrm{III}} / \mathrm{L}-\mathrm{Br}$. 


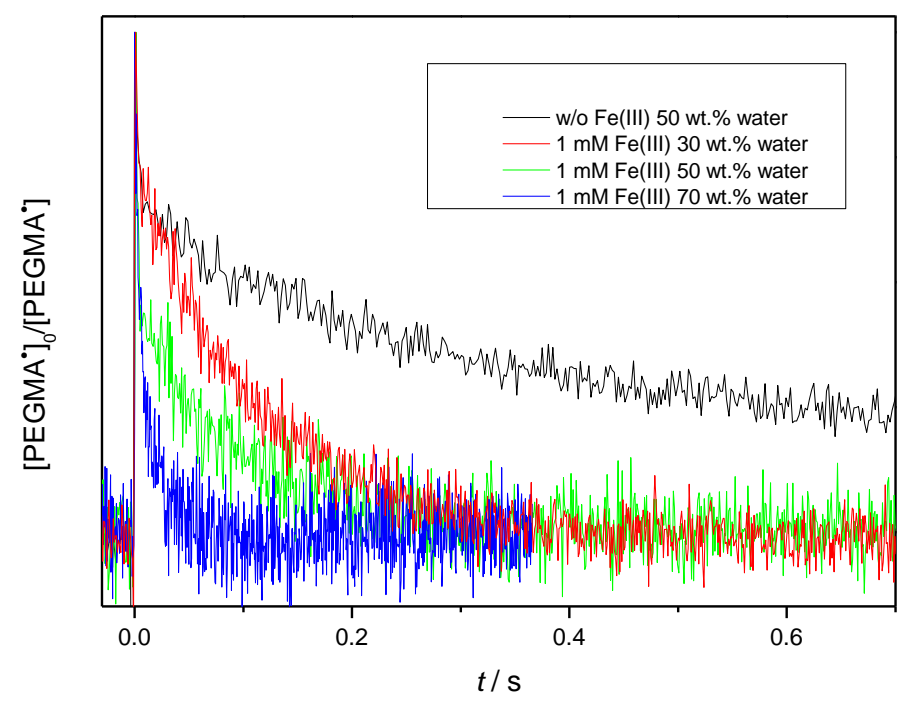

Figure 5.4: Normalized PEGMA ${ }^{\bullet}$ concentration vs time profiles at $20^{\circ} \mathrm{C}$ measured by SP-PLP-EPR with a single laser pulse being applied at $t=0$. The black line represents the radical decay by conventional radical-radical termination. The colored lines represent the radical decay via ATRP deactivation with $1 \mathrm{mM}$ mesohemin-(MPEG500)2 in mixtures with 30, 50 and $70 \mathrm{wt} \% \mathrm{H}_{2} \mathrm{O} / \mathrm{PEGMA}$, respectively.

Interestingly, the decrease in PEGMA ${ }^{\bullet}$ concentration in the presence of $\mathrm{Fe}$ is faster at higher water contents, although the $\mathrm{Fe}$ concentration is identical (1 mM). This observation indicates that ATRP deactivation by $\mathrm{Fe} \mathrm{III}^{\mathrm{II}} \mathrm{Br} / \mathrm{L}$ becomes faster toward higher water content.

Within successive experiments the radical decay becomes slower, due to $\mathrm{Fe}^{\mathrm{II}} / \mathrm{L}-\mathrm{Br}$ conversion to $\mathrm{Fe}^{\mathrm{II}} / \mathrm{L}$ and thus due to a lower catalyst concentration (see Figure A10). The slower decrease of radical concentration suggests that the trapping reaction of $\mathrm{R}^{\bullet}$ by $\mathrm{Fe}$ II/L may also be slower than the ATRP deactivation. As seen in Scheme 5.1, organometallic reactions may become significant at higher degrees of

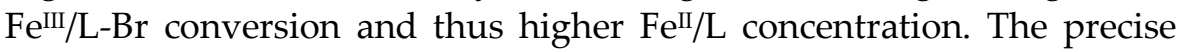
control of $\mathrm{Fe}$ III/L-Br conversion by the number of applied laser pulses contributes a particular advantage of the SP-PLP-EPR technique for measuring ATRP deactivation. 
The analysis of $k_{\text {deact }}$ is possible by two approaches. The first approach involves computational modeling via the program package PREDICI $^{\circledR}$ for fitting the experimental [PEGMA ${ }^{\bullet}$ ] vs time profiles. This approach requires an averaged $\mathrm{Fe} \mathrm{e}^{\mathrm{II}} / \mathrm{L}-\mathrm{Br}$ concentration and a calibration of EPR intensity with respect to absolute [PEGMA ${ }^{\bullet}$. The calibration of EPR intensity is performed via TEMPOL, as described in chapter 7.4.3. The modeling procedure further requires the precise knowledge of $k_{t^{1,1}}$ and of the associated composite-model parameters as well as of $k_{\mathrm{p}}$, such that $k_{\text {deact }}$ remains the only unknown parameter to be determined via the fitting of experimental radical concentration vs time data.

The second approach of the analysis of $k_{\text {deact }}$ benefits from the high ratio of deactivation over termination rate with the system under investigation. This approach is based on a pseudo first-order reaction of [PEGMA ${ }^{*}$ ] in the deactivation process after (5.1. ${ }^{[67]}$ Since deactivation is a first-order reaction with respect to $\left[\mathrm{R}^{\bullet}\right]$, whereas radical-radical termination is second order with respect to $\left[R^{\bullet}\right]$, termination plays a significant role only right after applying the laser pulse, when the radical concentration is high. At later times, the decay in radical concentration is dominated by deactivation. The radical concentration may be then fitted to a straight line: $\ln \left(\left[\mathrm{R}^{\bullet}\right]_{0} /\left[\mathrm{R}^{\bullet}\right]\right)$ vs time (Eq. (5.1). This method is particular useful for reactions with a low termination rate and high deactivation rate because no calibration for absolute radical concentration and no literature values for $k_{\mathrm{t}^{1,1}}$ and $k_{\mathrm{p}}$ are required.

$$
\frac{d\left(\left[\mathrm{R}^{\bullet}\right]_{0} /\left[\mathrm{R}^{\bullet}\right]\right)}{d t}=k_{\text {deact }} \cdot\left[\mathrm{Fe}^{\mathrm{III}} \mathrm{Br} / \mathrm{L}\right]
$$

Shown in Figure 5.5 are results for the two approaches. The plot on the left-hand side represents the PREDICI ${ }^{\circledR}$ procedure and the plot on the right-hand side shows the pseudo-first-order plot of $\ln \left(\left[\mathrm{R}^{\bullet}\right]_{0} /\left[\mathrm{R}^{\bullet}\right]\right)$ vs time. The PREDICI $^{\circledR}$ modeling in Figure $5.5 \mathrm{~A}$ yields $k_{\text {deact }}=1.2 \cdot 10^{5} \mathrm{~L} \mathrm{~mol}^{-1} \mathrm{~s}^{-1}$ in $50 \mathrm{wt} \% \mathrm{H}_{2} \mathrm{O} / \mathrm{PEGMA}$ at $20^{\circ} \mathrm{C}$.

Shown in Figure 5.5B is the plotted pseudo-first-order-approach of $\ln \left(\left[\mathrm{R}^{\bullet}\right]_{0} /\left[\mathrm{R}^{\bullet}\right]\right)$ vs time. The curvature in the early time regime of Figure $5.5 \mathrm{~B}$ indicates a significant contribution from radical-radical termination and has not been considered in the fitting process. The straight-line fit holds for later time regime when ATRP 

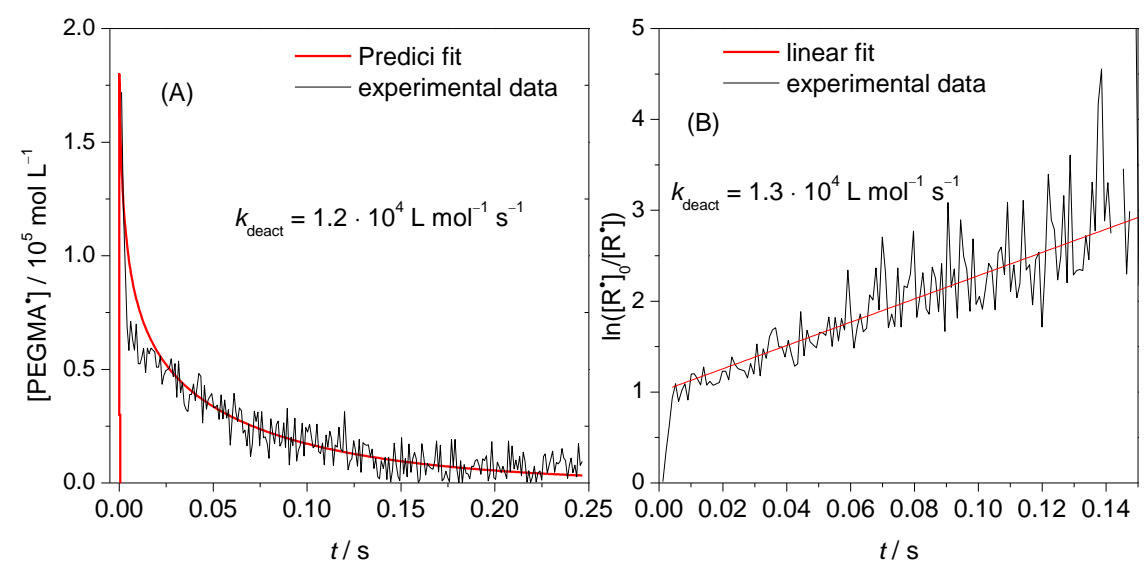

Figure 5.5: (A) Absolute PEGMA concentration vs time profile for mesohemin-(MPEG500) 2 in $50 \mathrm{wt} \% \mathrm{H}_{2} \mathrm{O} / \mathrm{PEGMA}$ at $20^{\circ} \mathrm{C}$. The determination of $k_{\text {deact }}$ was achieved via PREDICI ${ }^{\circledR}$ modeling. (B) $\ln \left(\left[\mathrm{R}^{\bullet}\right]_{0} /\left[\mathrm{R}^{\bullet}\right]\right)$ vs time trace for mesohemin-(MPEG500) 2 in $50 \mathrm{wt} \% \mathrm{H}_{2} \mathrm{O} / \mathrm{PEGMA}$ at $20^{\circ} \mathrm{C}$. The curvature in the early time regime indicates the significant contribution of radicalradical termination. A straight line has been fitted to the later time regime when ATRP deactivation controls the decay in radical concentration.

deactivation is the dominant pathway. The slope to the straight line provides the product $k_{\text {deact }} \cdot\left[\mathrm{Fe} \mathrm{FII}^{\mathrm{II}} / \mathrm{L}-\mathrm{Br}\right.$ ]. The $\mathrm{Fe} \mathrm{III}^{\mathrm{II}} / \mathrm{L}-\mathrm{Br}$ concentration has been measured via UV/Vis spectroscopy before and after applying the laser pulses. The Fe $\mathrm{III} / \mathrm{L}-\mathrm{Br}$ conversion was below $10 \%$ and the arithmetic mean value has been calculated from the measured concentrations. Combination of the so-obtained data yields $k_{\text {deact }}=1.3 \cdot 10^{5} \mathrm{~L} \mathrm{~mol}^{-1} \mathrm{~s}^{-1}$ in $50 \mathrm{wt} \% \mathrm{H}_{2} \mathrm{O} / \mathrm{PEGMA}$ at $20^{\circ} \mathrm{C}$. It is gratifying to note the $k_{\text {deact }}$ values from two approaches are in close agreement. The pseudo-first-order plot has been used as the preferred evaluation method in what follows.

Depicted in Figure 5.6 are the $k_{\text {deact }}$ values for mesohemin(MPEG500)2-mediated deactivation for 30, 50, 70, 80 and $90 \mathrm{wt} \%$ $\mathrm{H}_{2} \mathrm{O} / \mathrm{PEGMA}$ at $20^{\circ} \mathrm{C}$ obtained via the $\ln \left(\left[\mathrm{R}^{\bullet}\right]_{0} /\left[\mathrm{R}^{\bullet}\right]\right)$ vs time approach. The plot shows a strong increase in $k_{\text {deact }}$ between 50 and $90 \mathrm{wt} \% \mathrm{H}_{2} \mathrm{O}$ from $1.5 \cdot 10^{4} \mathrm{~L} \mathrm{~mol}^{-1} \mathrm{~s}^{-1}$ to $3.2 \cdot 10^{5} \mathrm{~L} \mathrm{~mol}^{-1} \mathrm{~s}^{-1}$. The smallest value for $k_{\text {deact }}=0.95 \cdot 10^{4} \mathrm{~L} \mathrm{~mol}^{-1} \mathrm{~s}^{-1}$ was determined with $30 \mathrm{wt} \% \mathrm{H}_{2} \mathrm{O}$, which is by about two orders of magnitude below $k_{\text {deact }}$ for a series of $\mathrm{Cu}$ - 
mediated systems. ${ }^{[36,66,126]}$

In contrast, $k_{\text {deact }}$ for $90 \mathrm{wt} \% \quad \mathrm{H}_{2} \mathrm{O}$ was estimated to be $3.2 \cdot 10^{5} \mathrm{~L} \mathrm{~mol}^{-1} \mathrm{~s}^{-1}$ which is more than one order of magnitude above the value for $30 \mathrm{wt} \% \mathrm{H}_{2} \mathrm{O}$ and is close to the reported value for the $\mathrm{Cu}-$ mediated ATRP of DMA with the ligand system 1,1,4,7,10,10hexamethyltriethylenetetramine (HMTETA): $k_{\text {deact }}=8 \cdot 10^{5} \mathrm{~L} \mathrm{~mol}^{-1} \mathrm{~s}^{-1} \cdot{ }^{[126]}$ The estimated $k_{\text {deact }}$ values in $90 \mathrm{wt} \% \mathrm{H}_{2} \mathrm{O}$ are also close to the reported values for the highly active tetrabutylammonium [ $\left.\mathrm{Fe}^{\mathrm{II}} \mathrm{Br}_{4}\right]$ catalyst with MMA in organic phase: being $k_{\text {deact }}=5.0 \cdot 10^{5} \mathrm{~L} \mathrm{~mol}^{-1} \mathrm{~s}^{-1}$ at $60^{\circ} \mathrm{C}$. ${ }^{68]} \mathrm{On}$ the other hand, the $k_{\text {deact }}$ value in $90 \mathrm{wt} \% \mathrm{H}_{2} \mathrm{O}$ lies one order of magnitude above the value reported for amine-bis(phenolates)ironmediated deactivation of $k_{\text {deact }}=2.7 \cdot 10^{4} \mathrm{~L} \mathrm{~mol}^{-1} \mathrm{~s}^{-1}$ at $60{ }^{\circ} \mathrm{C}$. [67]

As can be seen in Figure 5.6, the strongest increase of $k_{\text {deact }}$ occurs between 50 and $90 \mathrm{wt} \% \mathrm{H}_{2} \mathrm{O}$ in which range PEGMA polymerizations are mostly carried out. ${ }^{[1,33,52,110]}$ Since an efficient ATRP catalyst is associated with a fast deactivation and thus a high $k_{\text {deact, }}$ a higher water content is to be preferred for achieving higher ATRP control. It also can be stated that a certain amounts of water may be necessary for a successfully controlled polymerization. In Figure 5.6, the range of water concentrations in which ATRP of the system under investigation may be effectively controlled is marked by the black box.

In the iron-mediated RDRPs reported so far, e.g., with aminebis(phenolates), elevated temperatures are required to reach a favorable high deactivation rate. ${ }^{[67,143]}$ The smaller $k_{\text {deact }}$ values of these systems are compensated by a high $E_{\mathrm{A}}\left(k_{\text {deact }}\right)$ of about $35 \mathrm{~kJ} \mathrm{~mol}^{-1}$ which yields a sufficiently high deactivation rate and thus control at higher temperatures. ${ }^{[55,58,68,146]}$ In contrast to $\mathrm{FeBr}_{3}$ and to the aminebis(phenolates)iron systems, mesohemin-(MPEG500)2 benefits from the high $k_{\text {deact }}$ at higher water content even at $20^{\circ} \mathrm{C}$.

To discuss the increase in $k_{\text {deact }}$ and to make a prediction about $k_{\text {deact }}$ at water contents above $90 \mathrm{wt} \%$, it appears useful to compare the deactivation process with the termination of two radicals. Although the deactivation step is a chemical controlled process due to the halide transfer from the catalyst to the radical, the radical as well as the catalyst need to diffuse to each other. Because of the long-chain-PEGMA radical and the bulky catalyst, the diffusion behavior may be similar to the behavior of two long-chain radicals. During the 


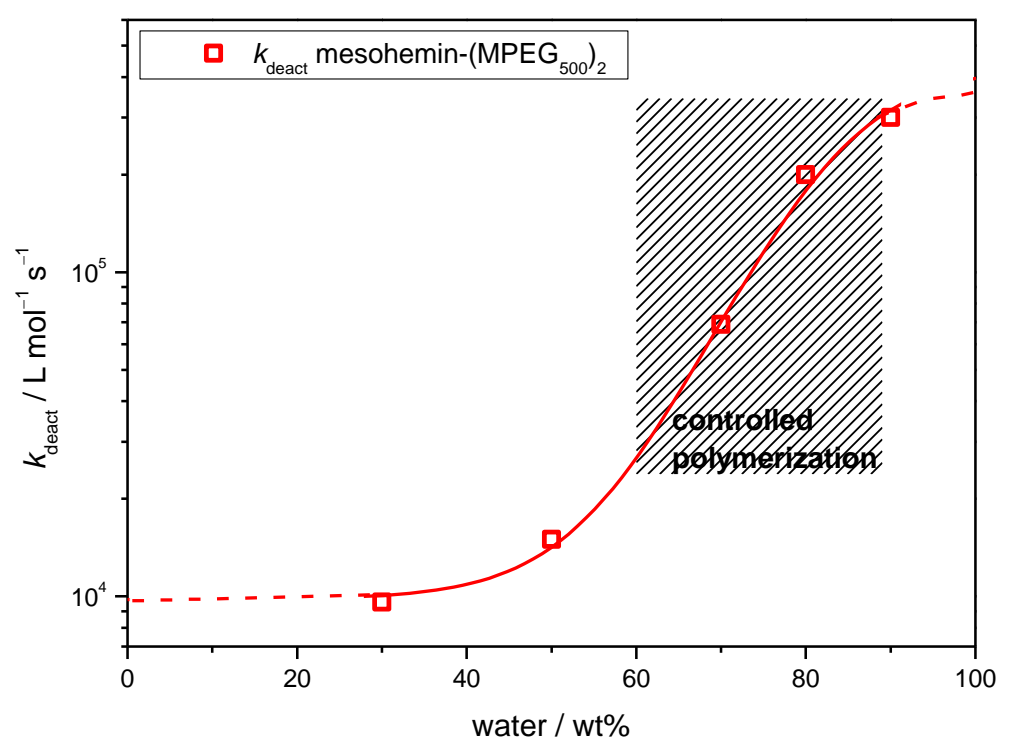

Figure 5.6: Variation of $k_{\text {deact }}$ with water content with PEGMA in mesohemin-(MPEG500)2 mediated ATRP at $20{ }^{\circ} \mathrm{C}$.

SP-PLP-EPR experiment, an average number of 200 monomer units are added to the radical functionality before deactivation by the $\mathrm{Fe}$ III/L-Br catalyst occurs. Therefore, it seems reasonable to compare $k_{\text {deact }}$ with the $k_{\mathrm{t}}{ }^{200,200}$, which may be calculated according to Equation 2.15 via the data presented in chapter 3.2.

Depicted in Figure 5.7 is the variation of the $k^{200,200}$ and of the measured $k_{\text {deact }}$ values as a function of water content. The $k_{\mathrm{t}}{ }^{200,200}$ values are by one order of magnitude above the $k_{\text {deact }}$ values. Moreover, the $k_{\mathrm{t}}{ }^{200,200}$ values exhibit a linear increase in the concentration range 30 to $70 \mathrm{wt} \% \mathrm{H}_{2} \mathrm{O}$, whereas the increase in $k_{\text {deact }}$ is best described with an Sshaped function. The dissimilarity of the variation of $k^{200,200}$ and $k_{\text {deact }}$ on water content demonstrates that $k_{\text {deact }}$ refers to no diffusion-controlled process.

It is unlikely that the increase in $k_{\text {deact }}$ continues in a pronounced fashion above $90 \mathrm{wt} \% \mathrm{H}_{2} \mathrm{O}$, as $k_{\text {deact }}$ would approach $k_{\mathrm{t}^{200,200}}$. The deactivation is a chemical controlled process, it may 


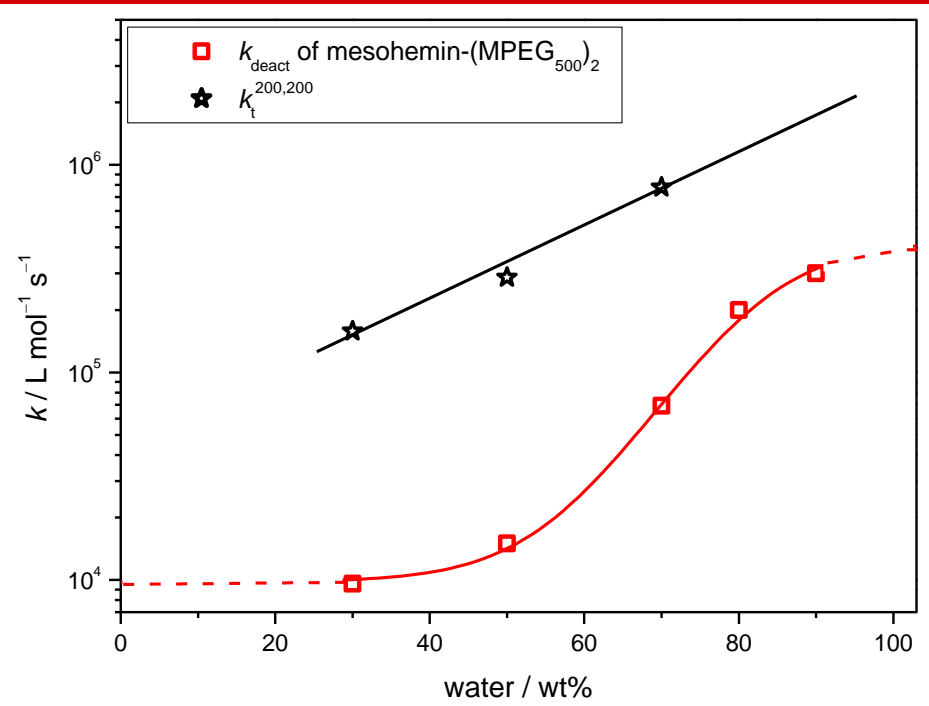

Figure 5.7: The variation on $k_{\text {deact }}$ and $k \mathrm{t}^{200,200}$ with the water content. The $k^{200,200}$ values are calculated via Equation 2.15 and the required parameter are used from Table 3.4 and Table 3.5.

be expected that $k_{\text {deact }}$ lies always below the diffusion controlled termination reaction of two large radicals. This assumption is also supported by the smaller increase in $k_{\text {deact }}$ between 80 and $90 \mathrm{wt} \% \mathrm{H}_{2} \mathrm{O}$.

Nevertheless, an increase of $k_{\text {deact }}$ with water content has not been reported so far, neither for $\mathrm{Cu}$-based ATRP, nor for Fe-based ATRP. For $\mathrm{Cu}$-mediated systems, measurements and computational calculations indicate that $k_{\text {deact }}$ is almost independent of the $\mathrm{H}_{2} \mathrm{O}$ content and a minor decrease of $k_{\text {deact }}$ has been observed in more polar solvents. ${ }^{[41]}$

In order to understand the variation of $k_{\text {deact }}$ with water content, the mechanism underlying the deactivation reaction needs to be considered. Even though deactivation is a concerted reaction step consisting of the transfer of bromide from the iron center to the alkyl radical and of a simultaneous reduction from $\mathrm{Fe}^{\mathrm{III}}$ to $\mathrm{Fe}^{\mathrm{II}}$, three factors have to be taken into account: the halide-iron bond strength, the redox potential of the $\mathrm{Fe}^{\mathrm{III}} / \mathrm{Fe}^{\mathrm{II}}$ couple in water and the structural change of the complex. Among these factors, the halide-iron bond strength seems to be the most important one. 
It is known from Cu-mediated ATRP that a stronger metal-halogen bond, e.g., in $\mathrm{Cu}^{\mathrm{II}}-\mathrm{Cl}$, results in a $k_{\text {deact }}$ which is by about one order of magnitude below the value of the associated Br species. ${ }^{[36]}$ Moreover, the $\mathrm{Cu}^{\mathrm{II}}$ complex is more stabilized in polar solvents. ${ }^{[41,42]}$ To explain the increase in $k_{\text {deact }}$ in case of the iron porphyrin system, ligand exchange reactions and $\mathrm{Fe}-\mathrm{Br}$ bond stability may offer an explanation.

Reported studies into the redox potential in different polar organic solvents showed that the reduction becomes easier in solvents with a high dielectric constant and that a weak coordinating axial ligand such as bromide also facilitates the reduction such as in the case of ATRP. ${ }^{[172-}$ 175] These studies also suggest that the axial ligand exchange is enhanced in more polar and coordinating solvents. ${ }^{[172,176,177]}$ Water provides both effects in having a high dielectric constant and in coordinating to the catalyst in a labile fashion to form a six-coordinated complex, thus weakening the metal-halide bond. The polyethylene glycol sidechain of PEGMA and of the porphyrin ligand may also coordinate axially in competition to water molecules. Polyethylene glycol exhibits a smaller dielectric constant corresponding to a weaker coordinating ability. This indicates that increasing the water content may favor water coordination, which results in lowering the metal-halide bond strength and thus increases $k_{\text {deact. }}$.

The geometry of the complex as the third aspect may have a smaller influence on $k_{\text {deact. }}$ Porphyrin structures are pre-organized ligands with a rigid planar structure. Only a minor change in the geometry during the transformation of $\mathrm{Fe}^{\mathrm{III}}$ to $\mathrm{Fe}^{\mathrm{II}}$ can is to be expected. The geometric change is restricted to the exchange of the axial ligand from a five-coordinated $\mathrm{Fe}^{\mathrm{III}}$ to a four-coordinate $\mathrm{Fe}^{\mathrm{II}}$. Potential solvent coordination would increase the coordination number. The planar porphyrin ligand structure will most likely be insensitive toward the reduction from $\mathrm{Fe}^{\mathrm{III}}$ to $\mathrm{Fe}^{\mathrm{II}}$.

To investigate the structural effect on $k_{\text {deact, }}$ two further derivatives of the complex were measured with $70 \mathrm{wt} \% \mathrm{H}_{2} \mathrm{O}$ analoguous to the procedure of the mesohemin-(MPEG500)2 catalyst. Shown in Figure 5.8A is the measured time resolved SP-PLP-EPR spectrum of PEGMA radicals with $1 \mathrm{mM}$ Fe ${ }^{\mathrm{III}}$-mesohemin-(MPEG500)-imidazole catalyst in $50 \mathrm{wt} \% \mathrm{H}_{2} \mathrm{O}$ at $20{ }^{\circ} \mathrm{C}$. Depicted in Figure $5.8 \mathrm{~B}$ is the associated pseudofirst-order plot of $\ln \left(\left[\mathrm{R}^{\bullet}\right]_{0} /\left[\mathrm{R}^{\bullet}\right]\right)$ vs time. 


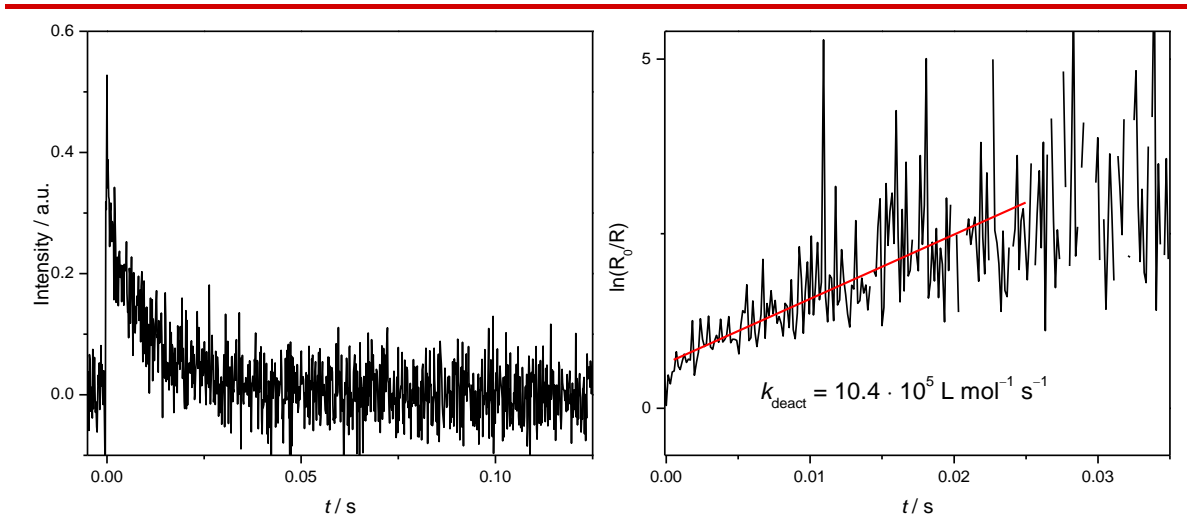

Figure 5.8: (A) EPR intensity vs time profile for mesohemin-(MPEG500)imidazole in $50 \mathrm{wt} \% \mathrm{H}_{2} \mathrm{O} / \mathrm{PEGMA}$ at $20^{\circ} \mathrm{C}$. (B) $\ln \left(\left[\mathrm{R}^{\bullet}\right]_{0} /\left[\mathrm{R}^{\bullet}\right]\right)$ vs time trace for mesohemin-(MPEG500)-imidazole in $50 \mathrm{wt} \% \mathrm{H}_{2} \mathrm{O} / \mathrm{PEGMA}$ at $20^{\circ} \mathrm{C}$. The curvature in the early time regime indicates the significant contribution of radical-radical termination. A straight line has been fitted to the later time regime when ATRP deactivation controls the decay in radical concentration.

Listed in Table 5.2 are the determined $k_{\text {deact }}$ values for mesoheminMPEG-imidazole and mesohemin-MPEG-thioether. In case of the mesohemin-MPEG-imidazole and the mesohemin-MPEG-thioether, one MPEG side arm is substituted by an amide side chain with an imidazole or thioether endgroup (see Figure 5.1). The mesohemin-(MPEG500)imidazole complex exhibits a higher $k_{\text {deact }}=11.2 \cdot 10^{4} \mathrm{~L} \cdot \mathrm{mol}^{-1} \cdot \mathrm{s}^{-1}$ than the mesohemin-(MPEG500)2, whereas $k_{\text {deact }}$ of the mesohemin-(MPEG500)thioether $k_{\text {deact }}=4.3 \cdot 10^{4} \mathrm{~L} \cdot \mathrm{mol}^{-1} \cdot \mathrm{s}^{-1}$ is slightly lower.

The coordinated side arms may influence the reactivity of the complex in a positive manner since the coordination of imidazole favors a low spin complex. Due to the smaller metal atom radius in low spin complexes and to the more symmetric electron distribution, the metal ion is better contained within the porphyrin plane in the low spin configuration. According to literature this may enhance the axial ligand exchange. ${ }^{[161]}$ It is not yet fully clear why the thioether complex shows a slightly smaller $k_{\text {deact. }}$

The stronger coordination ability of imidazole and thioether may stabilize the complex and make it more robust against the coordination 
of solvent and monomers with an acid functionality. For future applications it may be of interest that the strongly coordinated "protective" imidazole complex provides a high $k_{\text {deact }}$ that might be associated with a better control over polymerization.

Table 5.2: Deactivation rate coefficient, $k_{\text {deact, }}$ for mesohemin-(MPEG500)2, mesohemin-(MPEG)-imidazole and mesohemin-(MPEG)-thioether at $70 \mathrm{wt} \% \mathrm{H}_{2} \mathrm{O} / \mathrm{PEGMA}$ at $20{ }^{\circ} \mathrm{C}$.

\begin{tabular}{lc}
\hline Ligand in $70 \mathrm{wt}^{\circ} \mathrm{H}_{2} \mathrm{O} / \mathrm{PEGMA}$ & $k_{\text {deact }} / 10^{4} \mathrm{~L} \cdot \mathrm{mol}^{-1} \cdot \mathrm{s}^{-1}$ \\
\hline \hline Mesohemin-(MPEG500) 2 & $7.1 \pm 1.0$ \\
Mesohemin-(MPEG)-imidazole & $11.2 \pm 2.1$ \\
Mesohemin-(MPEG)-thioether & $4.3 \pm 1.5$ \\
\hline
\end{tabular}

\subsection{Rate coefficients via Stopped-Flow - UV/Vis spectroscopy}

The SP-PLP-EPR technique was used to measure $k_{\text {deact. }}$ Furthermore it is desirable to additionally determine the associated activation rate coefficient, $k_{\text {act, }}$ and thus the overall equilibrium constant, KATRP, at different water concentrations. The measurement of $k_{\text {act, }} k_{\text {deact }}$ and thus $K_{\text {ATRP }}$ may be achieved by using UV/Vis spectroscopy in conjunction with stopped-flow injection.

\subsubsection{Determination of $\boldsymbol{K}_{\text {model, }} \boldsymbol{k}_{\text {deact }}$ and $\boldsymbol{k}_{\text {add,Fe }}$}

This subchapter deals with the measurement of the activation and deactivation rate coefficients, and thus of the ATRP equilibrium constant for the monomer-free model system mesohemin-(MPEG500)2 catalyst at various solvent compositions. The rate coefficients are estimated via PREDICI ${ }^{\circledR}$. By an extended analysis of the experimental 
data, also the rate coefficient for the addition of radicals to the $\mathrm{Fe}^{\mathrm{II}} / \mathrm{L}$ complex may be estimated. The experiments were performed at solvent compositions of $\mathrm{H}_{2} \mathrm{O} /$ polyethylene glycol ( $\mathrm{Mn}_{\mathrm{n}} 500$, PEO) with water contents from 50 to $70 \mathrm{wt} \%$ at $20{ }^{\circ} \mathrm{C}$.

The conditions for measuring the ATRP-specific coefficients $k_{\text {act }}$ and $k_{\text {deact }}$ should be carefully selected to avoid the interference of OM reactions. Thus, according to Scheme 5.1, sub-stoichiometric amounts of $\mathrm{Fe}^{\mathrm{II}} / \mathrm{L}$ with respect to $\mathrm{R}-\mathrm{Br}$ are favorable to avoid significant contributions of OM reactions, whereas stoichiometric amounts of $\mathrm{Fe}^{\mathrm{II}} / \mathrm{L}$ and $\mathrm{R}-\mathrm{Br}$ may induce significant $\mathrm{OM}$ reactions.

The determination of $k_{\text {act }}$ and $k_{\text {deact, }}$ and thus $K_{\text {ATRP, }}$ with an excess of $\mathrm{R}-\mathrm{Br}$ with respect to $\mathrm{Fe}^{\mathrm{II}}$, is more feasible with the monomer-free model system. The ATRP activation-deactivation equilibrium for a monomerfree model system is referred to as $K_{\text {model }}$ in what follows.

The reaction scheme for a monomer-free Fe-mediated RDRP-type model system is illustrated in Scheme 5.3. The absence of monomer simplifies the reaction kinetics, as chain-length-dependent termination and concentration-dependent propagation are be excluded. The starting materials $\mathrm{Fe}^{\mathrm{II}} / \mathrm{L}$ and $\mathrm{R}-\mathrm{Br}$ are marked red. The reaction of $\mathrm{Fe} \mathrm{e}^{\mathrm{II}} / \mathrm{L}$ with, e.g., HEMA-Br acting as the alkyl halide initiator, $\mathrm{R}-\mathrm{Br}$, results in the

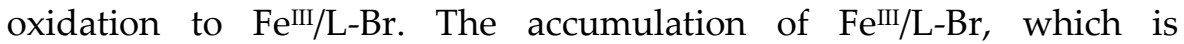
concurrent with termination of transient radicals according to Scheme 5.3 , is referred to as the persistent radical effect (PRE) and may be monitored via the $\mathrm{d}-\mathrm{d}$ transition of the $\mathrm{Fe}$ III/L-Br complex at $640 \mathrm{~nm}$ without interference of the OM species (cf. 5.1 and Figure A7).

The accumulation of $\mathrm{Fe}$ III/L-Br is expected to be particularly fast in case of the investigated mesohemin-(MPEG500)2-complex based on the results reported for polymerizations of PEGMA. ${ }^{[1]}$ Complete conversion of $\mathrm{Fe} / \mathrm{L}$ will occur in less than one minute. Therefore, the analysis of Kmodel for such fast reaction has been performed using stopped-flow injection in conjunction with $\mathrm{UV} / \mathrm{V}$ is spectroscopy to measure the change in absorption.

A stopped flow setup is built of a syringe driver which holds two syringes with the reactants, and a mixing chamber which allows for $\mathrm{UV} / \mathrm{Vis}$ monitoring. Temperature control is achieved by a cryostat. The stopped-flow injection technique allows for times being as low as a few milliseconds and high time resolution during the course of the experiment. The disadvantage of the stopped-flow technique is the 


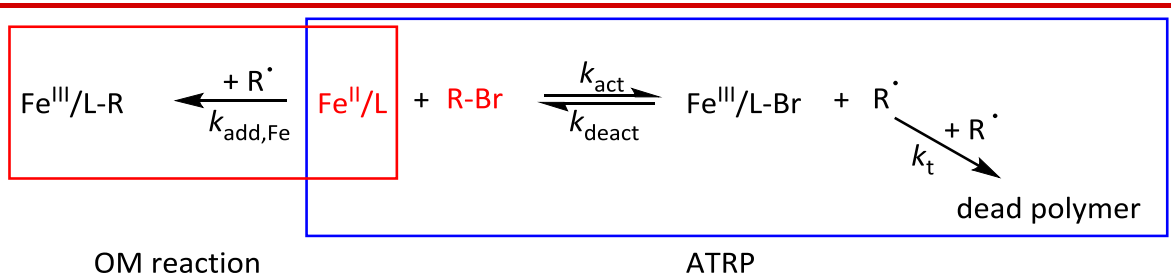

Scheme 5.3: Reaction scheme for the Fe-mediated RDRP-type reaction of the monomer-free model system; $\mathrm{R}-\mathrm{Br}$ refers to the dormant alkyl halide species, $\mathrm{R} \cdot$ to the radical species, $k_{\mathrm{t}}$ to the termination rate coefficient. $k_{\text {act }}$ and $k_{\text {deact }}$ are the ATRP rate coefficients for activation and deactivation, respectively. $k_{\text {add,Fe }}$ refers to the addition of a radical to the $\mathrm{Fe}^{\mathrm{II}} / \mathrm{L}$ complex via an OM reaction. The starting materials are marked red.

limitation to monomer-free model systems, as polymer would clog the low diameter tubing of the stopped-flow setup. Moreover, the higher viscosity of a polymerization system does not provide an efficient mixing.

To ensure efficient mixing even of the monomer-free model system, both mixing syringes were filled with identical solvent composition and identical amounts of added $\mathrm{NaBr}$ to prevent halide dissociation. As solvents, mixtures of 50 and $70 \mathrm{wt} \% \mathrm{H}_{2} \mathrm{O} / \mathrm{PEO}$ were used. $\mathrm{PEO}$ serves as a saturated analogue of PEGMA (cf. chapter 4). A typical stopped-flow experiment was carried out in the relevant solvent mixture with $0.9 \mathrm{mM}$ of the mesohemin-(MPEG500)2 catalyst with 0.50 equivalents of $\mathrm{Na}_{2} \mathrm{~S}_{2} \mathrm{O}_{4}$, in the first stopped flow syringe. $\mathrm{Na}_{2} \mathrm{~S}_{2} \mathrm{O}_{4}$ was directly added to the catalyst solution for in situ reduction without prior dissolution in water, to avoid the decomposition of $\left[\mathrm{SO}_{2}\right]^{-}$radicals. The second syringe contained $20 \mathrm{mM}$ of HEMA-Br.

Depicted in Figure 5.9 are the spectra for the reaction of $0.4 \mathrm{mM}$ mesohemin-(MPEG500) 2 catalyst with $10 \mathrm{mM}$ HEMA-Br in $50 \mathrm{wt} \%$ $\mathrm{H}_{2} \mathrm{O} / \mathrm{PEO}$ mixture at $20^{\circ} \mathrm{C}$, injected with an injection flow rate of $7 \mathrm{~mL} \cdot \mathrm{s}^{-1}$. The red line represents the $\mathrm{Fe} / \mathrm{II}$ spectrum at the beginning of the reaction (cf. chapter 5.1). The black line is associated with the

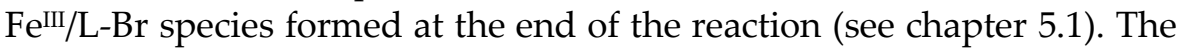
spectra are identical to the ones from the UV/Vis measurements without 


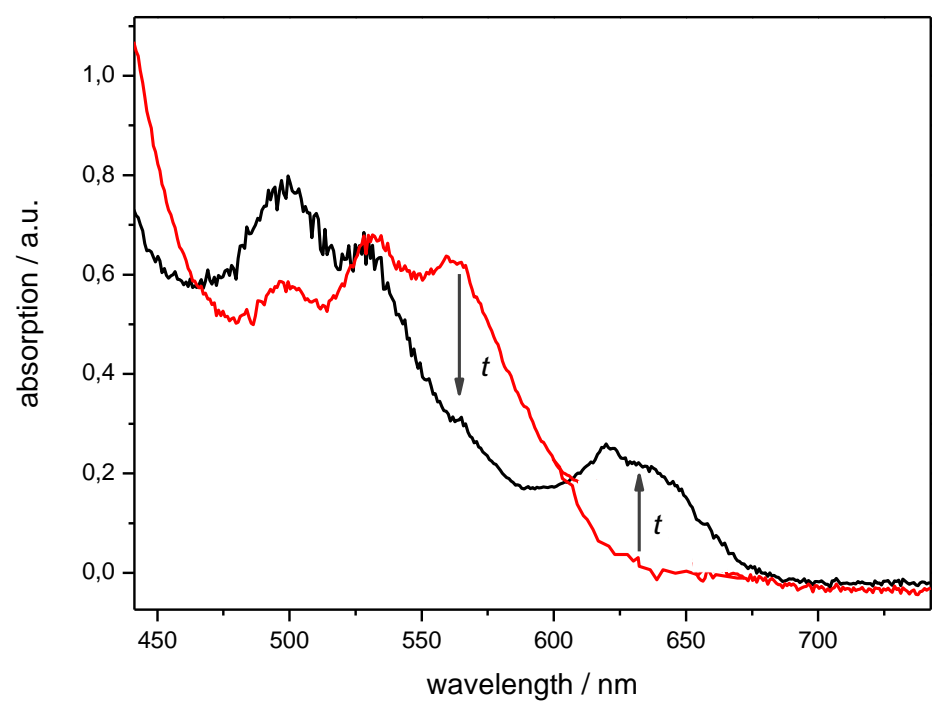

Figure 5.9: UV/Vis spectra via stopped-flow injection recorded for $0.4 \mathrm{mM}$ mesohemin-(MPEG500) 2 in $50 \mathrm{wt} \% \mathrm{H}_{2} \mathrm{O} / \mathrm{PEO}$ at $20{ }^{\circ} \mathrm{C}$. The red spectrum refers to the $\mathrm{Fe}^{\mathrm{II}}$ catalyst before the reaction with HEMA-Br. The black spectrum refers to the Fe $\mathrm{FII} / \mathrm{L}-\mathrm{Br}$ species at the end of the reaction with $10 \mathrm{mM}$ HEMA-Br. The arrows at 535 and $640 \mathrm{~nm}$ indicate the changes in absorption with the time. The absorbance at around $640 \mathrm{~nm}$ has been used to record the concentration time profiles.

stopped-flow injection (see Figure A7 and Figure 5.2). The $\mathrm{d}-\mathrm{d}$ absorbance at $640 \mathrm{~nm}$, which does not interfere with the absorption of Fe ${ }^{\mathrm{III}}-\mathrm{R}$ (see chapter 5.1 ) has been used to analyze the [Fe $\left.\mathrm{Fe}^{\mathrm{III}} / \mathrm{L}-\mathrm{Br}\right]$ vs time traces.

Shown in Figure 5.10 is a graph of the $\mathrm{Fe}$ III/L-Br concentration vs time trace for the reaction of $0.59 \mathrm{mM}$ Fe ${ }^{\mathrm{II}}-\mathrm{mesohemin}-(\mathrm{MPEG} 500)_{2}$ and $18 \mathrm{mM}$ HEMA-Br in $70 \mathrm{wt} \% \mathrm{H}_{2} \mathrm{O} / \mathrm{PEO}$ with an injection flowrate of $3 \mathrm{~mL} \cdot \mathrm{s}^{-1}$ at $20^{\circ} \mathrm{C}$. The experimental data (black line) have been fitted with PREDICI ${ }^{\circledR}$ (magenta line) as described below.

For fitting the experimental data, the reaction equations shown in Table 5.3 were implemented into the software package PREDICI ${ }^{\circledR}$. Due to the above-mentioned simplifications, the PREDICI ${ }^{\circledR}$ model consists of the 
four reactions: ATRP activation Eq 5.2 and deactivation Eq 5.3, radicalradical termination $\mathrm{Eq} 5.4$ and addition of radicals to the $\mathrm{Fe}^{\mathrm{II}} / \mathrm{L}$ complex Eq 5.5. The rate coefficient $k_{\mathrm{t}}$ is estimated via the diffusion limit as described in chapter 4.1.1.

The estimation of $k_{\text {act, }} k_{\text {deact }}$ and $k_{\text {add,Fe }}$ is based on three steps. Within the first two steps, it is assumed that the recorded [Fe ${ }^{I I I} / \mathrm{L}-\mathrm{Br}$ ] vs time trace in Figure 5.10 is predominantly controlled by $k_{\text {act }}$ and $k_{\text {deact, }}$ and that the reaction kinetics may be divided into two parts: the initial preequilibrium state and the equilibrium state towards the end of the reaction. ${ }^{[68]}$

First, the activation-deactivation equilibrium constant, Kmodel, was estimated via the F[Y]-function for the equilibrium state. ${ }^{[68]}$ The F[Y]function does however not consider the potential formation of $\mathrm{Fe} \mathrm{e}^{\mathrm{III}} / \mathrm{L}-\mathrm{R}$. The so-obtained $K_{\text {model }}$ values thus are systematically below the actual number. For the system under investigation, the initial discrepancy later turns out to be below a factor of 2 . The initial value derived via the F[Y]function for system in Figure 5.10 is $K_{\text {model }}=7 \cdot 10^{-5}$ and will be corrected via the modeling procedure within the subsequent evaluation steps. However, the first estimate of $K_{\text {model }}$ confirms the high activity of the mesohemin-(MPEG500)2 catalyst.

In the second step, $k_{\text {deact }}$ is estimated from the equilibrium state. Since $K_{\text {model }}=k_{\text {act }} / k_{\text {deact, }}$, the F[Y]-function provides a useful starting point for estimating $k_{\text {deact }}$ from the pre-equilibrium state of the $\left[\mathrm{Fe}^{\mathrm{III}} / \mathrm{L}-\mathrm{Br}\right]$ vs time traces. $k_{\text {act }}$ may be substituted by $K_{\text {model }} \cdot k_{\text {deact, }}$ such that $k_{\text {deact }}$ remains the only parameter to be fitted from the pre-equilibrium data. $k_{\text {deact }}$ was estimated to $3 \cdot 10^{5} \mathrm{~L} \mathrm{~mol}^{-1} \mathrm{~s}^{-1}$.

In the third step, after determination of $K_{\text {model }}$ and $k_{\text {deact, }}$ the experimental data may be used for an estimate of $k_{\text {add,Fe from the }}$ equilibrium state. Within the final modeling procedure of the [Fe $[\mathrm{II} / \mathrm{L}-\mathrm{Br}]$ vs time data, both $K_{\text {model }}$ (and thus $k_{\text {act }}$ ) and $k_{\text {deact }}$ will be refined along with the analysis of $k_{\text {add,Fe. }}$

According to Scheme 5.3, the ATRP mechanism is the dominant reaction pathway and the formation of $\mathrm{Fe} \mathrm{III}^{\mathrm{II}} \mathrm{L}-\mathrm{R}$ may be neglected in the pre-equilibrium state. If these reactions were entirely ATRP-controlled, $\mathrm{Fe}^{\mathrm{II}} / \mathrm{L}$ would be transformed almost entirely to $\mathrm{Fe} / \mathrm{III} / \mathrm{L}-\mathrm{Br}$, because of the

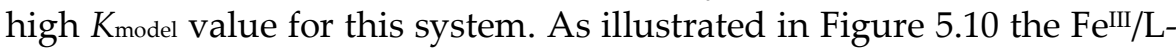
Br concentration reaches a maximum concentration of $0.50 \mathrm{mM}$, which differs from the overall Fe/L concentration of $0.59 \mathrm{mM}$. The discrepancy 
Table 5.3: Reaction scheme used for the PREDICI ${ }^{\circledR}$ modeling of the Fe $\mathrm{FII}^{\mathrm{II}} / \mathrm{L}-\mathrm{Br}$ concentration vs time traces.

\begin{tabular}{|l|c|}
\hline $\mathrm{Fe}^{\mathrm{II}} / \mathrm{L}+\mathrm{R}-\mathrm{Br} \stackrel{k_{\text {act }}}{\longrightarrow} \mathrm{Fe}^{\mathrm{III}} / \mathrm{L}-\mathrm{Br}+\mathrm{R} \cdot$ & $(5.2)$ \\
\hline $\mathrm{Fe}^{\mathrm{III}} / \mathrm{L}-\mathrm{Br}+\mathrm{R} \cdot \stackrel{k_{\text {deact }}}{\longrightarrow} \mathrm{Fe} / \mathrm{II}+\mathrm{R}-\mathrm{Br}$ & $(5.3)$ \\
\hline $\mathrm{R} \cdot+\mathrm{R} \cdot \stackrel{k_{\mathrm{t}}}{\longrightarrow} \mathrm{R}-\mathrm{R}$ & $(5.4)$ \\
\hline $\mathrm{Fe}^{\mathrm{II}} / \mathrm{L}+\mathrm{R} \cdot \stackrel{k_{\text {add }, \mathrm{Fe}}}{\longrightarrow} \mathrm{Fe} \mathrm{III}^{\mathrm{II}} / \mathrm{L}-\mathrm{R}$ & $(5.5)$ \\
\hline
\end{tabular}

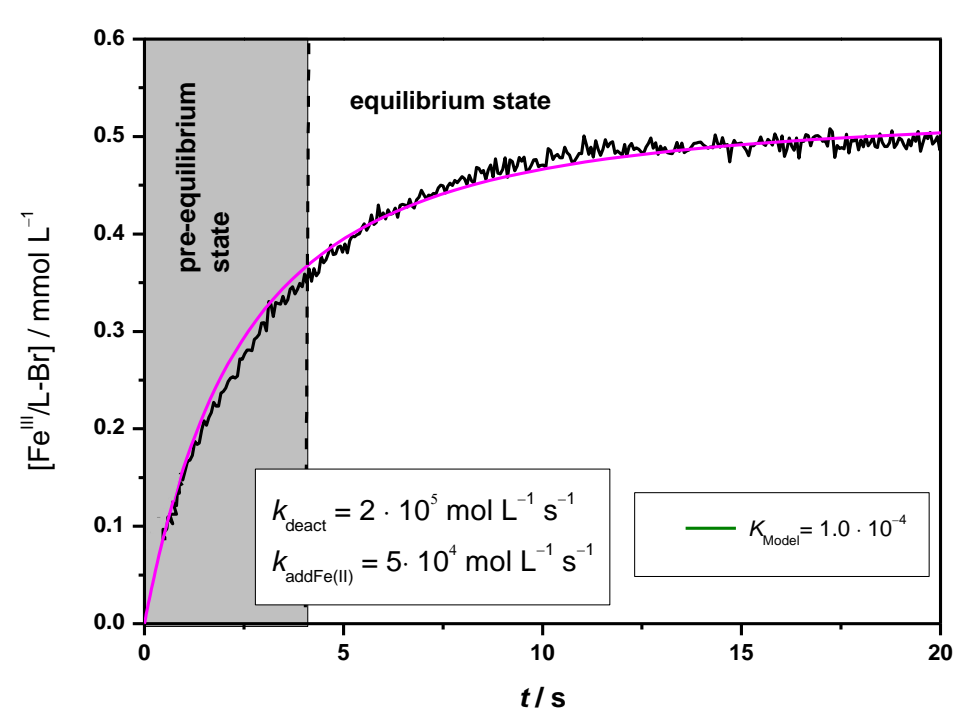

Figure 5.10: Recorded $\mathrm{Fe}$ III/L-Br concentration vs time profile via stoppedflow UV/Vis spectroscopy at $640 \mathrm{~nm}$ for the reaction of $0.59 \mathrm{mM}$ $\mathrm{Fe}^{\mathrm{II}}$-mesohemin-(MPEG500) ${ }_{2}$ complex with $18 \mathrm{mM}$ HEMA-Br in $70 \mathrm{wt} \% \mathrm{H}_{2} \mathrm{O} / \mathrm{PEO}$ at $20^{\circ} \mathrm{C}$. The black line represents the experimental data and the magenta line the PREDICI ${ }^{\circledR}$ fit. 
of ca. $20 \%$ is assigned to the formation of $\mathrm{Fe}$ III/L-R. This additional piece information about the relative amounts of Fe species may be used to estimate $k_{\text {add,Fe }}$ during the final modeling of the [Fe $\left.{ }^{\mathrm{II}} / \mathrm{L}-\mathrm{Br}\right]$ versus time trace.

A set of PREDICI ${ }^{\circledR}$ modelings were performed in which $k_{\text {add,Fe }}$ was estimated and $k_{\text {deact }}$ and $K$ model were kept constant. As illustrated in

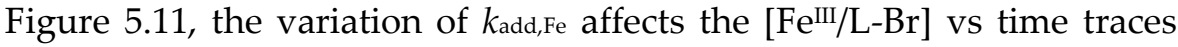
only in the equilibrium state and allows for the correct fit of this $\mathrm{Fe}^{\mathrm{III}} / \mathrm{L}-\mathrm{Br}$ concentration versus time trace under equilibrium conditions. After fitting $k_{\text {add,Fe, the value for }} K_{\text {model }}$ and $k_{\text {deact }}$ may be finally refined by fitting them to both reaction parts simultaneously while kadd,Fe is kept constant. $K_{\text {model }}$ and $k_{\text {deact }}$ are then determined to be $1 \cdot 10^{-4}$ and $2.1 \cdot 10^{5} \mathrm{~L} \mathrm{~mol}^{-1} \mathrm{~s}^{-1}$, respectively, at $70 \mathrm{wt} \%$ water concentration and $20^{\circ} \mathrm{C}$.

To illustrate the quality of the estimated values and of the fitting of the Fe $\mathrm{FI} / \mathrm{L}-\mathrm{Br}$ concentration vs time profiles, a set of PREDICI ${ }^{\circledR}$ simulations adopting various $K_{\text {model }}$ and $k_{\text {deact }}$ values were performed.

Shown in Figure 5.12A are simulated [Fe $\left.{ }^{\mathrm{III}} / \mathrm{L}-\mathrm{Br}\right]$ vs time traces for the experimental composition of $0.59 \mathrm{mM} \mathrm{Fe}{ }^{\mathrm{II}}$-mesohemin-(MPEG500) complex with $18 \mathrm{mM}$ HEMA-Br in $70 \mathrm{wt} \% \mathrm{H}_{2} \mathrm{O} / \mathrm{PEO}$ at $20^{\circ} \mathrm{C}$. $K_{\text {model }}$ has been varied between $0.5 \cdot 10^{-4}$ and $3.0 \cdot 10^{-4}$, whereas $k_{\text {deact }}$ and $k_{\text {add,Fe }}$ are kept constant at $2.0 \cdot 10^{5} \mathrm{~L} \mathrm{~mol}^{-1} \mathrm{~s}^{-1}$ and $5.0 \cdot 10^{4} \mathrm{~L} \mathrm{~mol}^{-1} \mathrm{~s}^{-1}$, respectively. Illustrated in Figure 5.12B are simulated [Fe $[\mathrm{III} / \mathrm{L}-\mathrm{Br}]$ vs time traces for the experimental composition with $k_{\text {deact }}$ being varied between $0.5 \cdot 10^{5}$ and $10.0 \cdot 10^{5} \mathrm{~L} \mathrm{~mol}^{-1} \mathrm{~s}^{-1}$, and $K_{\text {model }}$ and $k_{\text {add,Fe }}$ being kept constant at $1.0 \cdot 10^{-4}$ and $5.0 \cdot 10^{4} \mathrm{~L} \mathrm{~mol}^{-1} \mathrm{~s}^{-1}$, respectively.

As illustrated in Figure 5.12, the modeling process is very sensitive toward $K_{\text {model }}$ and $k_{\text {deact. }}$ A variation of $K_{\text {model }}$ by $20 \%$ from the optimum value results into strong deviations from the recorded $\mathrm{Fe} \mathrm{eI}^{\mathrm{II}} / \mathrm{L}-\mathrm{Br}$ concentration vs time trace. A similar precision is achieved for the modeling that has been carried out adopting several values for $k_{\text {deact. }}$ Although, the precision of the modelling process is very good, a higher error is adopted in Table 5.4, which takes the uncertainties due to calibration and mixing into account.

As illustrated by Figure 5.12, the modeled concentration vs time traces are influenced in different ways. With increasing $K_{\text {model }}$ the final $\mathrm{Fe} \mathrm{eII}^{\mathrm{II}} \mathrm{L}-\mathrm{Br}$ concentration is reached earlier and the concentration of the formed $\mathrm{Fe}^{\mathrm{III}} / \mathrm{L}-\mathrm{Br}$ reaches a higher level due to the more dominant 


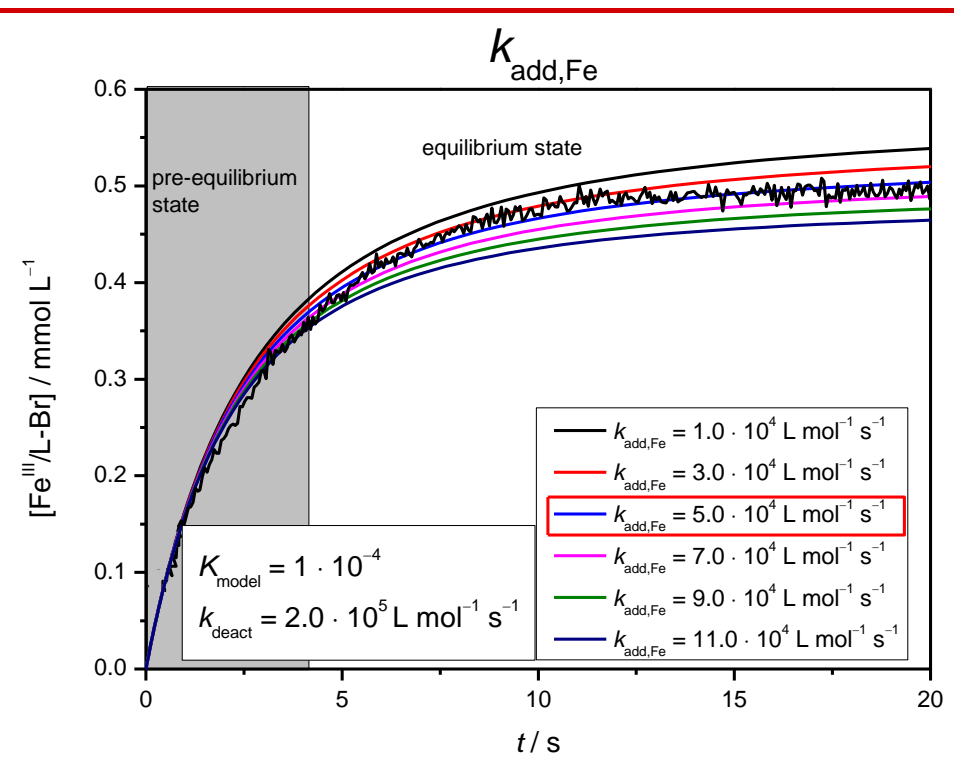

Figure 5.11: PREDICI ${ }^{\circledR}$ modeling of the $\left[\mathrm{Fe}^{\mathrm{III}} / \mathrm{L}-\mathrm{Br}\right]$ time profiles for different values of $k_{\text {add,Fe, }}$ whereas $k_{\text {deact }}$ and $K_{\text {model }}$ were kept constant. The concentrations of $\mathrm{Fe} / \mathrm{L}$ and HEMA-Br are identical to the ones in Figure 5.10 .

ATRP pathway. With increasing $k_{\text {deact, }}$ the final $\mathrm{Fe} \mathrm{III}^{\mathrm{II}} / \mathrm{L}-\mathrm{Br}$ concentration is also reached earlier, but the final concentration of $\left[\mathrm{Fe}^{\mathrm{III}} / \mathrm{L}-\mathrm{Br}\right]$ is less affected. Only minor variations of the combination of $K_{\text {model }}$ and $k_{\text {deact }}$ yield a matching fit to the experimental data.

Listed in Table 5.4 are the $K_{\text {model, }} k_{\text {deact }}$ and $k_{\text {add,Fe values estimated for }}$ mixtures with 50 and $70 \mathrm{wt} \% \mathrm{H}_{2} \mathrm{O} / \mathrm{PEO}$ at $20^{\circ} \mathrm{C}$. $k_{\text {deact }}$ increases with water content from $6.2 \cdot 10^{4} \mathrm{~L} \mathrm{~mol}^{-1} \mathrm{~s}^{-1}$ at $50 \mathrm{wt} \% \mathrm{H}_{2} \mathrm{O}$ to $2.1 \cdot 10^{5} \mathrm{~L} \mathrm{~mol}^{-1} \mathrm{~s}^{-1}$ at $70 \mathrm{wt} \% \mathrm{H}_{2} \mathrm{O}$. This effect is consistent with the measured $k_{\text {deact }}$ values from SP-PLP-EPR. Also the relative increase in $k_{\text {deact }}$ from $50 \mathrm{wt} \%$ to $70 \mathrm{wt} \% \mathrm{H}_{2} \mathrm{O}$, by almost a factor of 3.5 , is found in perfect agreement via both methods.

Absolute $k_{\text {deact }}$ values for the monomer-free model systems, $6.2 \cdot 10^{4} \mathrm{~L} \mathrm{~mol}^{-1} \mathrm{~s}^{-1}$ at $50 \mathrm{wt} \% \mathrm{H}_{2} \mathrm{O}$ and $2.1 \cdot 10^{5} \mathrm{~L} \mathrm{~mol}^{-1} \mathrm{~s}^{-1}$ at $70 \mathrm{wt} \% \mathrm{H}_{2} \mathrm{O}$ exceeds the associated numbers for the polymerization system, as obtained via SP-PLP-EPR, by a factor of 4 . Such a discrepancy between 

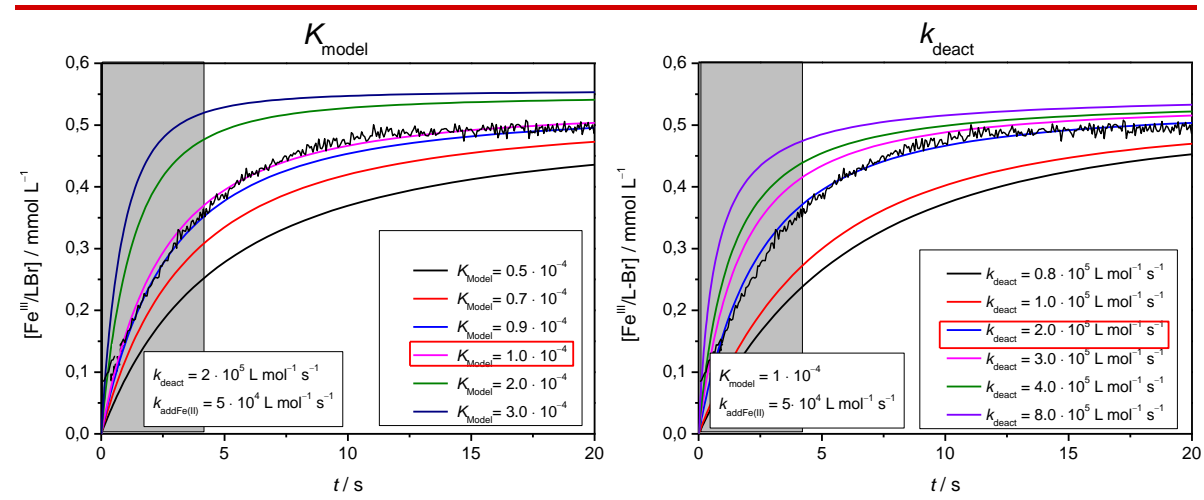

Figure 5.12: (A) PREDICI ${ }^{\circledR}$ simulation for the $\left[\mathrm{Fe}^{\mathrm{III}} / \mathrm{L}-\mathrm{Br}\right]$ time profiles with variation of $K_{\text {model, }}$ whereas $k_{\text {deact }}$ and $k_{\text {add,Fe }}$ were held constant. (B) PREDICI ${ }^{\circledR}$ simulation for the [Fe $\left.{ }^{I I I} / \mathrm{L}-\mathrm{Br}\right]$ time profiles with variation of $k_{\text {deact, }}$ whereas $K_{\text {model }}$ and $k_{\text {add,Fe }}$ were held constant. For both simulations concentrations of $\mathrm{Fe} / \mathrm{L} / \mathrm{L}$ and HEMA-Br are identical to the ones in Figure 5.10.

Table 5.4: Values for $K_{\text {model, }} k_{\text {deact }}$ and $k_{\text {add,Fe }}$ estimated for the mesohemin(MPEG500) 2 at $20^{\circ} \mathrm{C}$ via PREDICI ${ }^{\circledR}$ modeling.

\begin{tabular}{ccc}
\hline & $50 \mathrm{wt} \% \mathrm{H}_{2} \mathrm{O} / \mathrm{PEO}$ & $70 \mathrm{wt} \% \mathrm{H}_{2} \mathrm{O} / \mathrm{PEO}$ \\
\hline \hline$K_{\text {model }}$ & $(1.2 \pm 0.5) \cdot 10^{-4}$ & $(1.0 \pm 0.3) \cdot 10^{-4}$ \\
$k_{\text {deact }} / \mathrm{L} \mathrm{mol}^{-1} \mathrm{~s}^{-1}$ & $(6.2 \pm 1.7) \cdot 10^{4}$ & $(2.1 \pm 0.6) \cdot 10^{5}$ \\
$k_{\text {add,Fe }} / \mathrm{L} \mathrm{mol}^{-1} \mathrm{~s}^{-1}$ & $(1.3 \pm 0.9) \cdot 10^{4}$ & $(4.9 \pm 1.2) \cdot 10^{4}$ \\
\hline
\end{tabular}

model system and polymerization system is known from $\mathrm{Cu}$-mediated ATRP.[126] The higher $k_{\text {deact }}$ values for the model system are explained by the backstrain effect. ${ }^{[139]}$ As a consequence of the penultimate $\alpha$-methyl group on the polymeric backbone, a steric strain is induced that hinders the addition of bromide to the radical, and thus reduces $k_{\text {deact. }}$ In the model system, the methacrylate ATRP initiator has no penultimate unit to induce such steric strain.

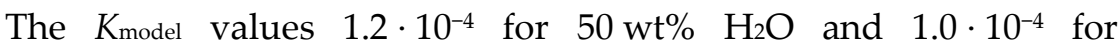


$70 \mathrm{wt} \% \mathrm{H}_{2} \mathrm{O}$ are almost the same. They are above the values reported for the other Fe-catalysts. The Kmodel value for $\mathrm{FeBr}_{2}$ in N-methyl-2pyrrolidone is at least by two orders of magnitude lower. ${ }^{[69]}$ Even the active Fe-amine-(bis)phenolates exhibit smaller $K_{\text {model }}$ values around $10^{-6} \cdot[57]$

The high activation-deactivation-equilibrium constants for the mesohemin-(MPEG500)2 catalyst are to be preferred in regenerative ATRP's, e.g., ARGET ATRP, due to the possibility of using Fe concentrations onto a ppm level. Moreover, the high activity and low Fe concentration is also favorable for the predominated ATRP pathway without interference by OM reactions.

The product of $K_{\text {model }}$ and $k_{\text {deact }}$ yields $k_{\text {act. }}$. The increase in $k_{\text {deact }}$ and a nearly constant $K_{\text {model }}$ indicate that the increase of $k_{\text {act }}$ is identical to the one of $k_{\text {deact. }}$ It has been reported for $\mathrm{Cu}$-mediated ATRP that $k_{\text {act }}$ increases with water content due to a better stabilization of the $\mathrm{Cu}^{\text {II }}$. $^{178]}$ For Fe-mediated ATRP, there seems to be an additional effect that increases $k_{\text {deact, }}$ i.e., a better axial ligand exchange in water, as discussed in the chapter 5.2.1.

Toward higher water content, $k_{\text {add,Fe }}$ increases from $1.3 \cdot 10^{4} \mathrm{~L} \mathrm{~mol}^{-1} \mathrm{~s}^{-1}$ at $50 \mathrm{wt} \%$ to $4.9 \cdot 10^{4} \mathrm{~L} \mathrm{~mol}^{-1} \mathrm{~s}^{-1} 70 \mathrm{wt} \% \mathrm{H}_{2} \mathrm{O}$. Despite

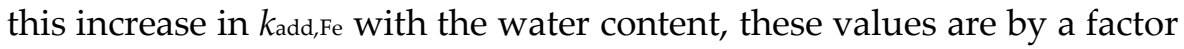
5 below the competing deactivation rate coefficients. $k_{\text {add, } \mathrm{Fe}}$ is not sufficiently large, to make the OM reactions competitive to ATRP techniques with the advantage of ATRP being further enhanced by using ppm levels of $\mathrm{Fe}^{\mathrm{II}}$ and regenerative concepts, e.g., ARGET ATRP.

Although $\mathrm{Na}_{2} \mathrm{~S}_{2} \mathrm{O}_{4}$ is an effective reducing agent for $\mathrm{Fe}$ III/L-Br, the very slow reduction of ascorbic acid may be favorable for highly active catalysts in an actual polymerization. For example, in the reported ARGET ATRP polymerization with the mesohemin-(MPEG500)2complex, in which ascorbic acid acts as the reducing agent, the resulting polymer provides narrow MMDs with a dispersity of 1.28.[1] Such dispersity would not be reached at a significant contribution of OM reactions.

As shown in chapter 5.1, the reduction of ascorbic acid during polymerization is very slow such that only trace amounts of $\mathrm{Fe}^{\mathrm{II}} / \mathrm{L}$ are produced. It may be assumed that the ratio of $\mathrm{Fe} \mathrm{III}^{\mathrm{II}} / \mathrm{L}-\mathrm{Br}$ to $\mathrm{Fe}^{\mathrm{II}} / \mathrm{L}$ is around 100:1. Based on the obtained $k_{\text {deact, }} k_{\text {act }}$ and $k_{\text {add,Fe }}$ values, the probability that radicals react in the ATRP pathway is 500 times larger 
than is the formation of the Fe $\mathrm{FII} / \mathrm{L}-\mathrm{R}$ species. The simultaneous increase of the ATRP-relevant parameters, $k_{\text {deact }}$ and $k_{\text {add,Fe, toward higher water }}$ content indicates that the polymerization is most likely controlled by ATRP.

The measurement of $k_{\text {deact, }} k_{\text {act }}$ and $k_{\text {add,Fe }}$ is very important for the understanding of the kinetics of Fe-mediated RDRP. It turned out that, despite the possibility of OM reactions, polymerizations are predominantly ATRP controlled with the mesohemin-(MPEG500)2 catalyst. This is particularly true, when an excess of $\mathrm{R}-\mathrm{Br}$ with respect to $\mathrm{Fe}^{\mathrm{II}} / \mathrm{L}$ is used. The same is holds for ARGET ATRPs, e.g., with ascorbic acid as a reducing agent, where only ppm levels of $\mathrm{Fe} / \mathrm{L}$ are produced.

Once the kinetics and mechanism of the reduction process is known, the set of rate coefficients from the present study allows for the simulation of the ATRP kinetics and polymer molar mass.

\subsection{Impact on polymerization}

The mechanistic and kinetic analysis suggests that the PEGMA ARGET ATRP with mesohemin-(MPEG500)2 operates exclusively via an ATRP mechanism. This situation is advantageous for polymerization since the formation of the stable Fe $\mathrm{F}^{\mathrm{II}} / \mathrm{L}-\mathrm{R}$ species is inhibited. Thus the polymerization may be faster and may provide higher chain-end functionality, which is advantageous for further modifications, e.g., for the synthesis of block copolymers.

Moreover, it has been shown that $k_{\text {deact }}$ increases toward higher water content and that $K_{\text {model }}$ is almost independent of water concentration. Since higher $k_{\text {deact }}$ is associated with better control, it is to be expected that a higher water concentration may be favorable for ATRP.

To check for the influence of water content on dispersity, a set of PEGMA ARGET ATRPs with ascorbic acid and mesohemin-(MPEG500)2 were carried out. Analogous to the procedure reported by Simakova et. al., the polymerization system contained $2 \mathrm{mM}$ Mesohemin-(MPEG500)2, $2 \mathrm{mM}$ ethyl $\alpha$-bromophenylacetate and $4 \mathrm{mM}$ ascorbic acid in various 
mixtures of $\mathrm{PEGMA} / \mathrm{H}_{2} \mathrm{O}$ at $25^{\circ} \mathrm{C} . .^{1]}$ The resulting polymer was analyzed via size exclusion chromatography (SEC).

Shown in the lower part of Figure 5.13 are the measured dispersities of the resulting PEGMA polymer. The upper part of Figure 5.13 correlates the dispersity with the ratio of $k_{\mathrm{p}}[\mathrm{M}] / k_{\text {deact }}\left[\mathrm{Fe} \mathrm{III}^{\mathrm{II}} / \mathrm{L}-\mathrm{Br}\right]$, i.e., the number of propagation steps prior to the deactivation step. The $k_{\text {deact }}$ and $k_{\mathrm{p}}$ values used for the estimates are reported in Chapter 5.2.1 and 3.1, respectively.

As shown in Figure 5.13, the dispersity decreases with water content from 1.85 in $70 \mathrm{wt} \%$ PEGMA toward 1.25 in $20 \mathrm{wt} \%$ PEGMA. This effect is consistent with the findings of an increasing $k_{\text {deact }}$ and a decreasing ratio of $k_{\mathrm{p}}[\mathrm{M}] / k_{\text {deact }}\left[\mathrm{Fe}^{\mathrm{III}} / \mathrm{L}-\mathrm{Br}\right]$. The ratio of $k_{\mathrm{p}}[\mathrm{M}] / k_{\text {deact }}\left[\mathrm{Fe}^{\mathrm{III}} / \mathrm{L}-\mathrm{Br}\right]$ is lowered from 80 at $30 \mathrm{wt} \% \mathrm{H}_{2} \mathrm{O}$ to about unity in $80 \mathrm{wt} \% \mathrm{H}_{2} \mathrm{O}$, which latter value indicates efficient control.

The findings show that an efficient control for an ARGET ATRP is achieved by the addition of at least $60 \mathrm{wt} \% \mathrm{H}_{2} \mathrm{O}$. The majority of PEGMA solution polymerization are performed in this concentration range because of the high viscosity and the swelling of the polymer.

The good control of polymerization at higher water content is achieved by the combination of a high $k_{\text {deact }}$ and the slow reducing rate of ascorbic acid, which yields an almost constant high $\mathrm{Fe}^{\mathrm{III}} / \mathrm{Br}$ concentration with only small traces of $\mathrm{Fe}^{\mathrm{II}} / \mathrm{L}$ being present in the solution.

Moreover, the mesohemin-(MPEG500)2 catalyst exhibits a high equilibrium constant of $1 \cdot 10^{-4}$ for the model system. It is known that the equilibrium constant of the model system is by one to two orders of magnitude above the equilibrium constant of the methacrylate polymerization system, the catalyst has also the potential of being used with the ATRP of acrylates - which usually provide a small KATRP than methacrylates - and should even sufficiently stable for ATRP of acidic monomers. In all these cases, ARGET ATRP with low levels of Fe $\mathrm{FI}^{\mathrm{II}}$ and with water concentration above $60 \mathrm{wt} \%$ should be best suited. 


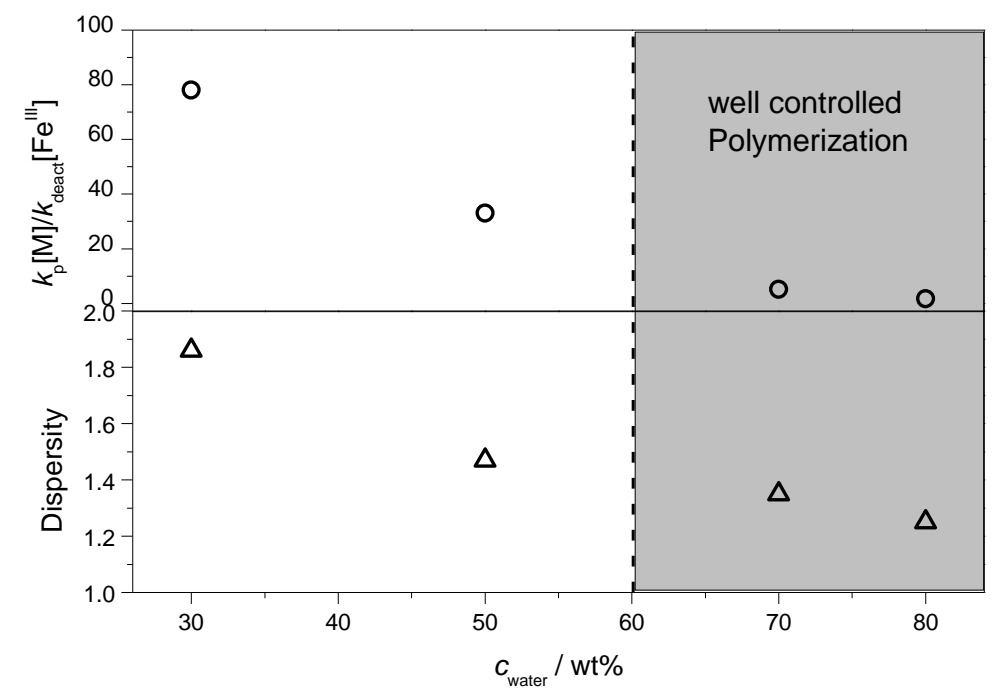

Figure 5.13: The upper part illustrates the ratio of $k_{\mathrm{p}}[\mathrm{M}] / k_{\text {deact }}\left[\mathrm{Fe} \mathrm{III}^{\mathrm{II}} / \mathrm{L}-\mathrm{Br}\right]$ as a function of the water content. The lower part shows the variation with water content of dispersity for mesohemin-(MPEG500)2 PEGMA ARGET ATRP. The polymerization system contained 2 mM mesohemin-(MPEG500)2, $2 \mathrm{mM}$ ethyl $\alpha$-bromophenylacetate and $4 \mathrm{mM}$ ascorbic acid in various mixtures of PEGMA/H2O at $25^{\circ} \mathrm{C}$. 
Iron-mediated ATRP in aqueous phase 


\section{6}

\section{Closing Remarks}

ATRP equilibrium constants, activation rate and deactivation rate coefficients were determined for $\mathrm{Cu}$ - and Fe-mediated ATRP in aqueous solution for monomer-free model systems, and polymerization systems with PEGMA.

For the $\mathrm{Cu}$-mediated ATRP with $\mathrm{CuBr} / 2,2$ '-bipyridine catalyst, it has been shown that KATRP increases by above three orders of magnitude in passing from bulk PEGMA solution to a pure water environment. The enhancement of KATRP is essentially due to the increase in $k_{\text {act, }}$ whereas $k_{\text {deact }}$ is independent of water content. A higher KATRP is associated with a faster polymerization. This faster polymerization rate in water, however, may be at the cost of a slight loss of control and of higher dispersity for the polymerization. This loss of control is induced by the halide dissociation of the $\mathrm{Cu}$ catalyst. Moreover the constant $k_{\text {deact }}$ does not counteract the higher radical concentration which is associated with a higher polymerization rate.

In highly diluted polymerization systems at $80 \mathrm{wt} \% \mathrm{H}_{2} \mathrm{O}$, KAtRP yields $2 \cdot 10^{-4}$. Such high KATRP value has so far only been reported for the very active $\mathrm{CuBr} / \mathrm{Me}_{6} \mathrm{TREN}$ catalyst in organic solvents. ${ }^{[60]}$ This enhancement of KATRP toward higher water content is a feature of the $\mathrm{Cu}$-mediated ATRP in aqueous solution, which allows for reducing the $\mathrm{Cu}$-catalyst concentration without compromising the polymerization 
rate.

A different behavior has found for the Fe-mediated ATRP of the mesohemin-(MPEG500)2 catalyst. In contrast to the Cu-mediated ATRP, $K_{\text {ATRP }}$ is almost independent of water content between 50 and $70 \mathrm{wt} \%$ $\mathrm{H}_{2} \mathrm{O}$. Nevertheless, this catalyst is the most active Fe-catalyst so far. KATRP for monomer-free model systems is with $1 \cdot 10^{-4}$ by almost one order of magnitude higher as the also very active [FeBr4 $]^{-}$catalyst and by almost two orders of magnitude as the Fe-amine-(bis)phenolates.

Besides the high $K_{\text {ATRP, }} k_{\text {deact }}$ increases strongly by one order of magnitude with water content to be $2 \cdot 10^{5} \mathrm{~L} \cdot \mathrm{mol}^{-1} \cdot \mathrm{s}^{-1}$ and is almost as large as the $k_{\text {deact }}$ of the $\left[\mathrm{FeBr}_{4}\right]^{-}$and of the Fe-amine-(bis)phenolate systems at temperatures above $60{ }^{\circ} \mathrm{C}$. As a consequence, the investigated $\mathrm{Fe} /$ mesohemin catalysts are very efficient even at low temperature to achieve well-controlled polymerizations.

It could be shown that the above-described findings with the water content for the $\mathrm{Cu}$ - and Fe-mediated ATRP have a different impact on the polymerization rate, the dispersity and the chain-end functionality. For a successful Cu-mediated ATRP, there is always the compromise between polymerization rate and efficient control. ATRP techniques with regenerative concepts, e.g., ARGET ATRP, may help to achieve a better control even at higher water content. In contrast to $\mathrm{Cu}$-mediated ATRP, the Fe-mediated ATRP strongly benefits from higher water content and it may be absolutely necessary to polymerize at higher water content.

Besides the described advantages of both ATRP systems in water, in future applications it has to be considered that on the one hand $\mathrm{Cu}$ ATRP in water may be accompanied by a loss of control. On the other hand, the good accessibility of different $\mathrm{Cu}$-ligands for a great variety of monomers may still be an advantage over the Fe-mediated ATRP at the moment. Moreover, most of the ligands for the $\mathrm{Cu}$-mediated ATRP are commercially available and cheap.

The Fe/heme systems are however difficult to synthesize and more expensive as the Cu-ligands. Nevertheless, these bio-inspired catalysts are the next generation of ATRP catalysts due to their bio-compatibility and very good polymerization behavior at ambient temperature and pressure. The mechanistic and kinetic analysis in this work for both systems provides an essential framework for further catalyst development. Especially the development of more efficient and cheaper 
Fe-catalyst with higher deactivation rate at lower water content and with slower organometallic reactions seems to be rewarding. 
Closing Remarks 


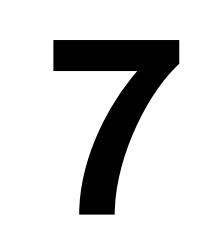

\section{Experimental}

\subsection{Chemicals}

Metal salts, solids and ligands. FeBr2 (ABCR, ultra dry, $99.995 \%$ metal basis), $\mathrm{FeBr}_{3}$ (ABCR, anhydrous, $99 \%$ ), $\mathrm{FeCl}_{2}$ (Aldrich, anhydrous, $99.998 \%$ metal basis), CuBr (Aldrich, 99.999\% metal basis), CuBr2 (Aldrich, $99.99 \%$ metal basis), copper(II) trifluoromethanesulfonate (Aldrich, $98 \%$ ), $\mathrm{NaBr}$ (Aldrich, $\geq 99 \%$ ), and 4-hydroxy-2,2,6,6tetramethylpiperidine 1-oxyl (TEMPOL, Aldrich, $97 \%$ ), 2,2'-Bipyridyl (bpy, Aldrich, $\geq 99 \%$ ), L-Ascorbic acid (AsAc, Aldrich, reagent grade), sodium dithionite (ABCR, technical grade, > 85\%), tris[2-(2methoxyethoxy)ethyl]amine (TDA-1, Aldrich, 95\%) were used as received. Fe ${ }^{\mathrm{III}} / \mathrm{Br}$-mesohemin-(MPEG500)2, Fe ${ }^{\mathrm{III}} / \mathrm{Br}-m e s o h e m i n-(\mathrm{MPEG} 500)-$ thioether, $\mathrm{Fe}^{\mathrm{III}} / \mathrm{Br}$-mesohemin-(MPEG500)-imidazole and $\mathrm{Fe}^{\mathrm{III}} / \mathrm{Cl}$ mesohemin-(MPEG500)2 were kindly provided by Antonina Simakova and Krzysztof Matyjaszewski at the Carnegie Mellon University of 
Pittsburgh. ${ }^{[1]}$

Initiators. 2-hydroxyethyl 2-bromoisobutyrate (HEMA-Br, Aldrich, $95 \%$ ), Ethyl $\alpha$-bromophenylacetat (EBrPA, ABCR, 97\%), methyl 2bromo-iso-butyrate (MBriB, Fluka, $\geq 99 \%$ ), ethyl $\alpha$-chlorophenylacetate (EClPA, Aldrich, $\quad 97 \%$ ), $\quad \alpha$-methyl-4-(methylmercapto-)- $\alpha$ morpholinopropiophenone (MMMP, Aldrich, 98\%), 2,2'-azobis[2-(2imidazolin-2-yl)propane] dihydrochloride (VA-44, Wako), 2,2'-azobis(4methoxy-2,4-dimethyl valeronitrile) (V-70, Wako) were used as received. 2,2'-Azobis(2-methylpropionitrile) (AIBN, Aldrich, $98 \%$ ) was recrystallized from cold ethanol (Aldrich, p.a.) and dried under vacuum prior to use.

Monomer and Solvents. Poly(ethylene glycol) dimethyl ether Mn 500 (PEO, Merck), poly(ethylene glycol) methyl ether methacrylate were purified by passing through a flash column with neutral aluminum oxide (Type CG-20, Aldrich). 1-Vinylpyrrolidin-2-one (NVP, Fluka, purum, $\geq 97 \%$ ) was purified by distillation under reduced pressure and strored at $-21^{\circ} \mathrm{C}$. Tetrahydrofuran (THF, Aldrich, for HPLC, inhibitor-free), n-dodecane (Aldrich, anhydrous, $\geq 99 \%$ ) were used as received. Ultrapure (type I) water (resistivity $18.2 \mathrm{M} \Omega \mathrm{cm}$ at $25^{\circ} \mathrm{C}$, total organic carbon < 5ppb) from a Millipore water purification system was used.

General information. Monomers, solvents and other liquid substances were degassed by several freeze-pump-thaw cycles. The solutions for all experiments were prepared under an argon atmosphere.

\subsection{PLP-SEC measurements ${ }^{3}$}

\subsubsection{Pulsed-Laser-Polymerization (PLP)}

Monomer, solvent and the photoinitiator Darocur 1173 were mixed,

${ }^{3}$ All PLP-SEC measurements were carried out by Stella Weber during her bachelor thesis. 
poured into a double-walled cylindrical cuvette (Starna, 65.14/Q/10, Spectrosil-fused quartz, path length $10 \mathrm{~mm}$ ) and degassed with argon for 5 minutes. The samples were tempered with a heat-transfer fluid (ethylene glycol:water $=4: 1$ ) using a thermostat (Haake K, Haake F3). After tempering the sample for $15 \mathrm{~min}$, the PLP experiment was performed with an ATLEX-I laser (ATL Lasertechnik $\mathrm{GmbH}$, pulse width: $20 \mathrm{~nm}$, maximum pulse energy: $7 \mathrm{~mJ}$, maximum pulse repetition rate: $1000 \mathrm{~Hz}$ ) operating on the XeF-line at $351 \mathrm{~nm}$. A further detailed setup is described elsewhere. ${ }^{[113]}$ PLP was performed at pulse repetition rate from 1 to $100 \mathrm{~Hz}$. After laser irradiation, the polymer/monomer mixture was given into a flask containing hydroquinone (HQ). Residual monomer was removed by dialysis with pre-wetted dialysis tubing (Spectra/Por 6, Spectrum Laboratories Inc., standard grade, regenerated cellulose, flat width of $18 \mathrm{~mm}, 11.5 \mathrm{~mm}$ in diameter with an MWCO of $2 \mathrm{kDa}$ or $1 \mathrm{kDa}$ ) closed with Spectra/Por closures (Spectrum Laboratories, Inc., polypropylene, sealing width of 12 or $23 \mathrm{~mm}$ )

\subsubsection{Size-Exclusion Chromatography (SEC)}

The SEC analysis of poly(PEGMA) was performed at $35^{\circ} \mathrm{C}$ with tetrahydrofurane as the eluent $\left(1 \mathrm{~mL} \cdot \mathrm{min}^{-1}\right.$ flow rate $)$ and with toluene as the flow-rate marker on an SEC system consisting of a Waters HPLC pump (Model 515), a JASCO As-2055-plus autosampler, three PSS SDV columns ( $5 \mu \mathrm{m}$ particle size; $10^{5}, 10^{3}$ and $10^{2} \AA$ pore sizes) and a Waters refractive index detector (Model 2410). The SEC was calibrated against narrowly distributed poly(MMA) and poly(Styrene) standards $(M=800$ to $2 \cdot 10^{6} \mathrm{~g} \cdot \mathrm{mol}^{-1}$, PSS). The MMDs of poly(PEGMA) were determined by the Mark-Houwink-constants from literature. ${ }^{[33]}$

\subsubsection{Density measurements}

The density of various PEGMA-water mixtures was measured between 22 and $60^{\circ} \mathrm{C}$. The density meter is based on the oscillating Utube principle and consists of a data acquisition unit (Anton Paar, DMA 60), a measuring unit (Anton Paar, DMA 602TP), and a high temperature cell (Anton Paar, DMA $602 \mathrm{H}$, Duran $^{\circledR} 50,-10 \leq \Theta \leq 150{ }^{\circ} \mathrm{C}$ ). 
The temperature inside the U-tube was monitored via a digital thermometer.

The density was calculated by the following equation:

$$
\rho=\frac{1}{\mathrm{~A}}\left(T^{2}-\mathrm{B}\right)
$$

Where $T$ is period, A and B are device specific constants of the oscillating U-tube and are calculated by the following equations.

$$
\begin{gathered}
\mathrm{A}=\frac{T_{\mathrm{H}_{2} \mathrm{O}}^{2}-T_{\text {Air }}^{2}}{\rho_{\mathrm{H}_{2} \mathrm{O}}-\rho_{\text {Air }}} \\
\mathrm{B}=T_{\text {Air }}^{2}-\left(\mathrm{A} \cdot \rho_{\text {Air }}\right)
\end{gathered}
$$

The density of water and air were taken from literature.[179]

\subsubsection{Viscosity measurements}

The viscosity was measured by an $\mathrm{AMVn}^{\mathrm{TM}}$ instrument (Anton Paar $\mathrm{GmbH}$ ) using Rheoplus ${ }^{\mathrm{TM}}$ (Anton Paar $\mathrm{GmbH}$ ) as the analysis software. The viscosimeter is a falling ball visocosimeter, which uses four different capillaries to cover a range between 0.3 and $20000 \mathrm{mPa}$.

\subsection{Spectroscopic measurements}

\subsubsection{Online FT-Vis/NIR spectroscopy}

Prior to the experiment, PEO or PEGMA and water were degassed by several freeze-pump-thaw cycles and stored under an argon atmosphere at $-33^{\circ} \mathrm{C}$. Each solvent mixture $(7 \mathrm{~mL})$ was separately prepared under argon. To the solvent mixture, $\mathrm{Cu}{ }^{\mathrm{I}} \mathrm{Br}, 2,2^{\prime}$-bipyridine and 500 to 1000 equivalents of $\mathrm{NaBr}$ were added to obtain a $7 \mathrm{mmol} \cdot \mathrm{L}^{-1}$

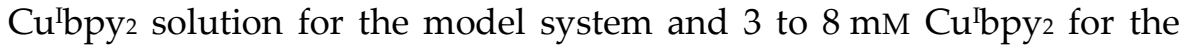


polymerization system. For the measurements at ambient pressure, $2 \mathrm{~mL}$ of the solution were filled into a quartz cuvette (117.100-QS, Hellma Analytics) of 5 and $10 \mathrm{~mm}$ optical path length, which was closed by a screw cap thus fixing a rubber/PTFE septum. The quartz cuvette was subsequently placed into the sample compartment of an FTVis/NIR spectrometer (IFS 66/S, Bruker). After starting spectral data collection, HEMA-Br was added through the septum via a microliter syringe to achieve initiator concentrations between 50 and $90 \mathrm{mmol} \cdot \mathrm{L}^{-1}$ for the model system or to match the $\mathrm{Cu}^{\mathrm{I} b p y}$ concentration in the polymerization system. The setup and procedure for the high-pressure measurements has been detailed elsewhere. ${ }^{[59,61,69]}$

The $\left[\mathrm{Cu}^{\mathrm{II}}(\mathrm{bpy})_{2} \mathrm{Br}\right]^{+}[\mathrm{Br}]^{-}$concentration was determined via the associated absorbance between $15500 \mathrm{~cm}^{-1}$ and $8000 \mathrm{~cm}^{-1}$. The spectra were recorded and evaluated using the software package Opus (Bruker Optic, version 7.0 and 6.0). The integration of the $d-d$ absorbance of $\mathrm{Cu}(\mathrm{II})$ complexes between 13300 and $11400 \mathrm{~cm}^{-1}$ was performed via Opus within the wavenumber range indicated by the dashed lines in Figure 1. The absorbance due to other components has been eliminated by subtraction of the absorbance integral at $t=0$, i.e., at zero $\mathrm{Cu}^{\mathrm{II}}$. The remaining absorption is entirely due the $\left[\mathrm{Cu}^{\mathrm{II}} \mathrm{Ln} \mathrm{X}\right]^{+}[\mathrm{X}]^{-}$complex. Each measurement of $K_{\text {model }}$ was repeated at least three times.

For calibration, three solutions were prepared of each $\mathrm{H}_{2} \mathrm{O} / \mathrm{PEO}$ or $\mathrm{H}_{2} \mathrm{O} /$ PEGMA mixture containing 1,3 and $6 \mathrm{mmol} \cdot \mathrm{L}^{-1}$ of $\left[\mathrm{Cu}^{\mathrm{II}}(\mathrm{bpy})_{2}\right]^{2+}(\mathrm{TfO})_{2}$, respectively, to which the same amount of $\mathrm{NaBr}$ as within the actual measurements was added.

The spectra were recorded and evaluated using the software package Opus (Bruker Optic, version 7.0 and 6.0).

\subsubsection{UV/Vis measurements}

The samples for the UV/Vis measurements (Cary 300, Agilent) were prepared under an argon atmosphere and were carried out in sealed quartz cells with 5 or $10 \mathrm{~mm}$ path length. The extinction coefficients at $640 \mathrm{~nm}$ for estimation of the catalyst concentration were determined with 3 different catalyst concentrations between 0.3 and $4.0 \mathrm{mM}$ for each solvent mixture. 


\subsubsection{Mössbauer}

The samples were prepared analogues to the UV/Vis measurements and were flash-frozen in liquid nitrogen after the desired reaction. The spectra were obtained with a ${ }^{57} \mathrm{Co}$ source embedded in a $\mathrm{Rh}$ matrix using an alternating constant acceleration Wissel Mössbauer spectrometer operated in the transmission mode and equipped with a closed-cylce helium cryostat (SHI 850, Janis). Isomer shifts are given relative to irion metal at ambient temperature. Symmetric Lorentzian doubles have been fitted to the zero-field spectra using the Mfit program. ${ }^{[180]}$

\subsection{SP-PLP-EPR measurements}

\subsubsection{Sample Preparation}

For measurement of the composite-model parameter, the purified monomer PEGMA and the ultrapure water were degassed by several freeze-pump-thaw cycles. The required monomer-solvent mixtures with ca. $20 \mathrm{mM}$ of the photoinitiator Darocur 1173 were prepared under an argon atmosphere in a glove box. The highly polar samples were filled in special EPR flat cells. For quantitative measurements, the volumes of all samples have to be the same. The EPR flat cells have been filled completely till the junction of the flat cell and the round neck.

For the measurement of the ATRP deactivation rate coefficient, $k_{\text {deact, }}$ the solvent mixtures of water and PEGMA were prepared analogous to the above-described procedure. Additionally, the ATRP catalysts under investigation: $\quad \mathrm{Cu}^{\mathrm{II}}$ (bpy)2 $\mathrm{Br}, \quad \mathrm{Fe}^{\mathrm{III}}$-mesohemin-(MPEG500)2, $\quad \mathrm{Fe}^{\mathrm{III}}-$ mesohemin-(MPEG)-imidazole and Fe ${ }^{\mathrm{III}}$-mesohemin-(MPEG)-thioether were been added in a concentration range between 1 to $3 \mathrm{mM}$. To prevent the halide dissociation an excess of ca. 500 equivalents of $\mathrm{NaBr}$ was added to the solution with high water content and 250 equivalents of $\mathrm{NaBr}$ for the measurements below $50 \mathrm{wt} \% \mathrm{H}_{2} \mathrm{O}$. 


\subsubsection{SP-PLP-EPR setup}

EPR spectra and $c_{R}(t)$-curves were recorded on a Bruker Elexsys $E$ 500 series CW EPR spectrometer consisting of a microwave brigde, microwave source, a detector, a cavity (ER 4122SHQE-LC, Version V1.1, Bruker), a console (spectrometer electronics) for electronic data processing and two tunable magnets. Temperature control was realized via an ER 4131VT unit (Bruker) by purging the sample cavity with nitrogen.

The sample was irradiated by a XeF laser (LPX 210 iCC, Lambda Physik) at $351 \mathrm{~nm}$ with about $80 \mathrm{~mJ} /$ pulse. The EPR spectrometer and the laser source were synchronized by a Quantum Composers 9314 pulse generator (Scientific Instruments).

The detailed setup is described and illustrated elsewhere. ${ }^{[62]}$

\subsubsection{SP-PLP-EPR experiment and calibration}

The basic principle of an SP-PLP-EPR experiment is to measure a pseudo-stationary EPR spectrum for the investigated type of monomer radical to find the appropriate magnetic field position for the time resolved EPR measurement. The pseudo-stationary PLP conditions are achieved by periodic laser pulsing with $20 \mathrm{~Hz}$. The time-resolved EPR spectra were measured at a magnetic field position with the maximum intensity. For an improved signal-to-noise quality, around 15 individual $\mathrm{CR}(t)$ traces were measured at time intervals up to $30 \mathrm{~s}$ and averaged. The EPR intensity has been converted into absolute radical concentration by a calibration against TEMPOL as detailed elsewhere. ${ }^{[62]}$ For the calibration, solvent mixtures of TEMPOL with following TEMPOL concentrations were used: $\quad 1 \cdot 10^{-4} \mathrm{~mol} \cdot \mathrm{L}^{-1}, \quad 1 \cdot 10^{-5} \mathrm{~mol} \cdot \mathrm{L}^{-1}$, $5 \cdot 10^{-5} \mathrm{~mol} \cdot \mathrm{L}^{-1}, 1 \cdot 10^{-6} \mathrm{~mol} \cdot \mathrm{L}^{-1}$ and $5 \cdot 10^{-6} \mathrm{~mol} \cdot \mathrm{L}^{-1}$.

The concentration of monomer has been measured via online Fourier transform (FT) Vis/NIR spectroscopy (IFS 66/S and IFS 88, Bruker) using a broadband mercury cadmium telluride (MCT) detecter. ${ }^{60,61]}$ The concentration of $\mathrm{Fe}^{\mathrm{III}}$ catalyst were measured via UV/Vis spectroscopy (Cary 300, Agilent). 


\subsection{Stopped-Flow injected measurements}

The samples for the stopped-flow injected UV/Vis measurements were prepared under an argon atmosphere and were stored in gas tight syringes. Before using the stopped-flow setup, the inner tubes and reaction cell were purged with nitrogen gas.

The stopped-flow experiments were performed with a two syringe setup. Each syringe contains a different reaction solution: one with the ATRP initiator and the other one with the catalyst. The content of the syringes were injected by a syringe driver (Bio-Logic $\mu$-SFM 20) into a ball mixer (Berger-Ball technology mixers) and then forwarded into the $\mathrm{UV} / \mathrm{Vis}$ cell (10 $\mathrm{mm}$ path length) for the measurement. The reaction temperature in the UV/vis cell was controlled by an external cryostat (Huber CC-75 cryostat). The detection of the absorption signal was realized via a diode array UV/Vis spectrometer (J\&M MCS-UVNIR500 diode array spectrometer, band width 190-1015 nm, resolution of about $1 \mathrm{~nm}$ ) between 400 and $800 \mathrm{~nm}$. A minimum integration time of $12 \mathrm{~ms}$ per spectrum was chosen. The whole setup was operated with the Biokine software, whereas data analysis was performed with the Specfit 32 global analysis software from Bio-Logic. All experiments were performed with different flowrates to check for potential mixing artefacts.

To archive efficient mixing in the monomer-free model system, both mixing syringes had the identical solvent composition with identical amounts of $\mathrm{NaBr}$. As solvents, mixtures of 50 and $70 \mathrm{wt} \% \mathrm{H}_{2} \mathrm{O} / \mathrm{PEO}$ were used. A typical stopped-flow experiment was carried out in the relevant solvent mixture with $0.9 \mathrm{mM}$ of the mesohemin-(MPEG500)2 catalyst with 0.50 equivalents of $\mathrm{Na}_{2} \mathrm{~S}_{2} \mathrm{O}_{4}$, in the first stopped flow syringe. $\mathrm{Na}_{2} \mathrm{~S}_{2} \mathrm{O}_{4}$ was directly added to the catalyst solution for in situ reduction without prior dissolving in water, to avoid the decomposition of $\left[\mathrm{SO}_{2}\right]^{-}$radicals. The second syringe contained ca. $20 \mathrm{mM}$ of HEMA-Br. 


\section{Light}

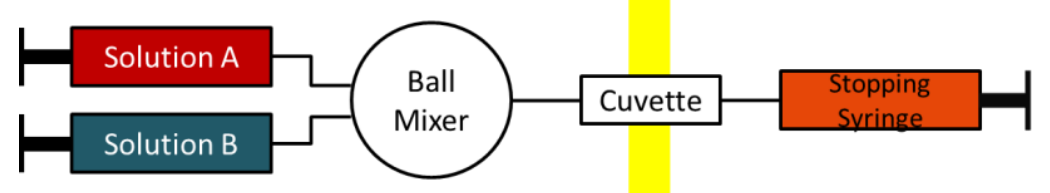

Diode Array UV/vis-

Spectrometer

Figure 7.1: Schematic setup for the stopped-flow injected UV/Vis spectroscopic measurements. 
Experimental

142 


\section{8}

\section{Appendix}

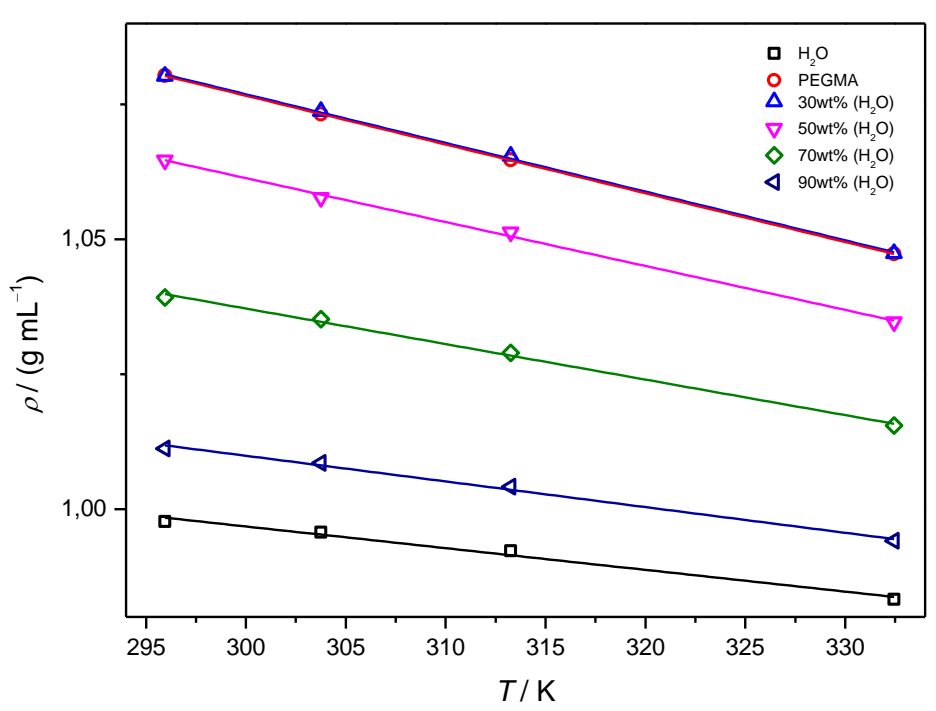

Figure A1: Density variation with the temperature variation of various PEGMA-water mixtures. 
Appendix

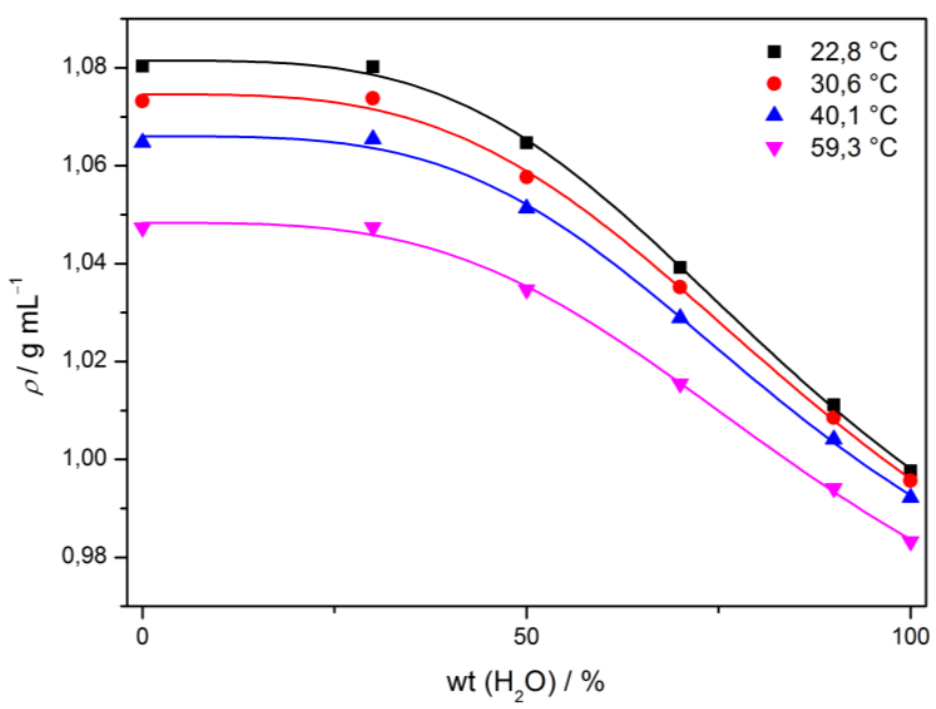

Figure A2: Density of PEGMA-water mixtures vs water content for various temperatures. 
Table A1: Viscosity for various PEGMA-water mixtures without $\mathrm{NaBr}$ and with $1 \mathrm{M} \mathrm{NaBr}$ at different temperatures.

\begin{tabular}{|c|c|c|c|}
\hline PEGMA / wt $\%$ & Temperature $/{ }^{\circ} \mathrm{C}$ & $\eta / \mathrm{mPa} \mathrm{s}$ & $\begin{array}{c}\eta / \mathrm{mPa} \text { s mit } \\
1 \mathrm{M} \mathrm{NaBr}\end{array}$ \\
\hline \multirow[t]{6}{*}{30} & 15 & 39.2 & 48.5 \\
\hline & 20 & 29.4 & 36.6 \\
\hline & 30 & 18.4 & 22.5 \\
\hline & 40 & 12.4 & 15.0 \\
\hline & 50 & 8.9 & 10.6 \\
\hline & 60 & 6.7 & 8.0 \\
\hline \multirow[t]{5}{*}{50} & 15 & 15.4 & 23.3 \\
\hline & 20 & 12.3 & 18.6 \\
\hline & 30 & 8.2 & 12.4 \\
\hline & 50 & 4.4 & 6.7 \\
\hline & 60 & 3.7 & 5.2 \\
\hline \multirow[t]{6}{*}{70} & 15 & 5.6 & 7.0 \\
\hline & 20 & 4.7 & 5.9 \\
\hline & 30 & 3.8 & 4.4 \\
\hline & 40 & 2.6 & 3.4 \\
\hline & 50 & 2.1 & 2.7 \\
\hline & 60 & 1.7 & 2.3 \\
\hline \multirow[t]{6}{*}{80} & 15 & 3.4 & 5.2 \\
\hline & 20 & 2.9 & 3.6 \\
\hline & 30 & 2.2 & 2.8 \\
\hline & 40 & 1.8 & 2.4 \\
\hline & 50 & 1.5 & 2.1 \\
\hline & 60 & 1.3 & 1.9 \\
\hline
\end{tabular}


Table A2: PLP conditions and propagation rate coefficient for the polymerization of PEGMA in water at ambient pressure and at $22{ }^{\circ} \mathrm{C}$.

\begin{tabular}{|c|c|c|c|c|c|c|}
\hline CPEGMA & CPEGMA & CInitiator & $v_{\text {rep }}$ & $M_{1} / M_{2}$ & $M_{2} / \mathrm{M}_{3}$ & $k_{\mathrm{p}}$ \\
\hline$w t \%$ & $\mathrm{~mol} \cdot \mathrm{L}^{-1}$ & $\mathrm{~mol} \cdot \mathrm{L}^{-1}$ & $\mathrm{~Hz}$ & & & $\begin{array}{l}\mathrm{L} \cdot \mathrm{mol}^{-1} \\
\mathrm{~s}^{-1}\end{array}$ \\
\hline \multirow[t]{24}{*}{100} & 2.07 & $5 \cdot 10^{-3}$ & 20 & 0.55 & 0.67 & 496 \\
\hline & & & 20 & 0.52 & 0.71 & 484 \\
\hline & & & 20 & 0.53 & 0.67 & 498 \\
\hline & & & 20 & 0.54 & 0.68 & 490 \\
\hline & & $2 \cdot 10^{-2}$ & 20 & 0.56 & 0.69 & 496 \\
\hline & & & 20 & 0.56 & 0.68 & 504 \\
\hline & & & 20 & 0.53 & 0.68 & 504 \\
\hline & & & 20 & 0.56 & 0.67 & 508 \\
\hline & & & 40 & 0.54 & 0.68 & 595 \\
\hline & & & 40 & 0.54 & 0.68 & 596 \\
\hline & & & 40 & 0.59 & 0.70 & 584 \\
\hline & & & 40 & 0.54 & 0.68 & 596 \\
\hline & & & 70 & 0.57 & 0.72 & 731 \\
\hline & & & 70 & 0.60 & 0.72 & 737 \\
\hline & & & 70 & 0.60 & 0.70 & 757 \\
\hline & & & 70 & 0.62 & 0.74 & 736 \\
\hline & & $5 \cdot 10^{-2}$ & 20 & 0.54 & 0.68 & 520 \\
\hline & & & 20 & 0.54 & 0.69 & 524 \\
\hline & & & 20 & 0.55 & 0.66 & 495 \\
\hline & & & 20 & 0.55 & 0.65 & 491 \\
\hline & & & 40 & 0.58 & 0.69 & 583 \\
\hline & & & 40 & 0.58 & 0.70 & 577 \\
\hline & & & 40 & 0.57 & 0.70 & 590 \\
\hline & & & 40 & 0.58 & 0.70 & 586 \\
\hline
\end{tabular}




\begin{tabular}{|c|c|c|c|c|c|c|}
\hline $\begin{array}{l}\text { CPEG } \\
\mathrm{MA}\end{array}$ & CPEGMA & CInitiator & $v_{\text {rep }}$ & $\begin{array}{l}M_{1} / \\
M_{2}\end{array}$ & $M_{2} / \mathrm{M}_{3}$ & $k_{\mathrm{p}}$ \\
\hline \multirow[t]{5}{*}{$w t \%$} & $\mathrm{~mol} \cdot \mathrm{L}^{-1}$ & $\mathrm{~mol} \cdot \mathrm{L}^{-1}$ & $\mathrm{~Hz}$ & & & $\underset{-1}{\mathrm{~L} \cdot \mathrm{mol}^{-1} \cdot \mathrm{s}}$ \\
\hline & & & 70 & 0.60 & 0.72 & 715 \\
\hline & & & 70 & 0.60 & 0.74 & 720 \\
\hline & & & 70 & 0.61 & 0.77 & 723 \\
\hline & & & 70 & 0.59 & 0.75 & 726 \\
\hline \multirow[t]{23}{*}{70} & 1.40 & $5 \cdot 10^{-3}$ & 10 & 0.56 & 0.59 & 801 \\
\hline & & & 10 & 0.56 & 0.58 & 812 \\
\hline & & & 15 & 0.54 & 0.67 & 872 \\
\hline & & & 15 & 0.55 & 0.67 & 867 \\
\hline & & & 20 & 0.59 & 0.64 & 896 \\
\hline & & & 20 & 0.56 & 0.67 & 907 \\
\hline & & & 20 & 0.56 & 0.66 & 904 \\
\hline & & & 20 & 0.57 & 0.65 & 905 \\
\hline & & & 40 & 0.57 & 0.70 & 1023 \\
\hline & & & 40 & 0.53 & 0.72 & 1023 \\
\hline & & & 40 & 0.61 & 0.67 & 1019 \\
\hline & & & 40 & 0.54 & 0.72 & 1025 \\
\hline & & $2 \cdot 10^{-2}$ & 20 & 0.54 & 0.65 & 979 \\
\hline & & & 20 & 0.56 & 0.66 & 987 \\
\hline & & & 20 & 0.56 & 0.67 & 955 \\
\hline & & & 20 & 0.53 & 0.68 & 949 \\
\hline & & & 40 & 0.57 & 0.70 & 1029 \\
\hline & & & 40 & 0.57 & 0.70 & 1059 \\
\hline & & & 40 & 0.59 & 0.68 & 1048 \\
\hline & & & 70 & 0.59 & 0.70 & 1329 \\
\hline & & & 70 & 0.62 & 0.70 & 1316 \\
\hline & & $5 \cdot 10^{-2}$ & 10 & 0.52 & 0.67 & 960 \\
\hline & & & 10 & 0.51 & 0.65 & 958 \\
\hline
\end{tabular}


Appendix

\begin{tabular}{|c|c|c|c|c|c|c|}
\hline $\begin{array}{l}\text { CPEG } \\
\text { MA }\end{array}$ & CPEGMA & CInitiator & $\nu_{\text {rep }}$ & $\begin{array}{l}M_{1} / \\
M_{2}\end{array}$ & $M_{2} / \mathrm{M}_{3}$ & $k_{\mathrm{p}}$ \\
\hline \multirow[t]{11}{*}{$w t \%$} & $\mathrm{~mol} \cdot \mathrm{L}^{-1}$ & $\mathrm{~mol} \cdot \mathrm{L}^{-1}$ & $\mathrm{~Hz}$ & & & $\underset{-1}{\mathrm{~L}} \cdot \mathrm{mol}^{-1} \cdot \mathrm{s}$ \\
\hline & & & 15 & 0.56 & 0.67 & 991 \\
\hline & & & 15 & 0.55 & 0.66 & 978 \\
\hline & & & 20 & 0.55 & 0.67 & 994 \\
\hline & & & 20 & 0.54 & 0.66 & 980 \\
\hline & & & 20 & 0.54 & 0.68 & 943 \\
\hline & & & 20 & 0.57 & 0.68 & 954 \\
\hline & & & 40 & 0.58 & 0.69 & 1102 \\
\hline & & & 40 & 0.59 & 0.68 & 1093 \\
\hline & & & 40 & 0.57 & 0.68 & 1103 \\
\hline & & & 40 & 0.59 & 0.69 & 1102 \\
\hline \multirow[t]{17}{*}{50} & 0.96 & $5 \cdot 10^{-3}$ & 15 & 0.55 & 0.66 & 1399 \\
\hline & & & 15 & 0.56 & 0.64 & 1384 \\
\hline & & & 20 & 0.54 & 0.68 & 1414 \\
\hline & & & 20 & 0.61 & 0.64 & 1424 \\
\hline & & $2 \cdot 10^{-2}$ & 15 & 0.53 & 0.67 & 1391 \\
\hline & & & 15 & 0.54 & 0.67 & 1397 \\
\hline & & & 20 & 0.57 & 0.67 & 1391 \\
\hline & & & 20 & 0.56 & 0.64 & 1405 \\
\hline & & & 20 & 0.54 & 0.67 & 1401 \\
\hline & & & 20 & 0.57 & 0.67 & 1424 \\
\hline & & & 40 & 0.58 & 0.68 & 1594 \\
\hline & & & 40 & 0.58 & 0.70 & 1554 \\
\hline & & & 40 & 0.60 & 0.67 & 1586 \\
\hline & & & 40 & 0.60 & 0.68 & 1572 \\
\hline & & $5 \cdot 10^{-3}$ & 20 & 0.57 & 0.66 & 1397 \\
\hline & & & 20 & 0.54 & 0.67 & 1399 \\
\hline & & & 20 & 0.53 & 0.68 & 1428 \\
\hline
\end{tabular}




\begin{tabular}{|c|c|c|c|c|c|c|}
\hline $\begin{array}{l}\text { CPEG } \\
\text { MA }\end{array}$ & CPEGMA & CInitiator & $v_{\text {rep }}$ & $\begin{array}{l}M_{1} / \\
M_{2}\end{array}$ & $M_{2} / \mathrm{M}_{3}$ & $k_{\mathrm{p}}$ \\
\hline \multirow[t]{6}{*}{$w t \%$} & $\mathrm{~mol} \cdot \mathrm{L}^{-1}$ & $\mathrm{~mol} \cdot \mathrm{L}^{-1}$ & $\mathrm{~Hz}$ & & & $\underset{-1}{\mathrm{~L}} \cdot \mathrm{mol}^{-1} \cdot \mathrm{s}$ \\
\hline & & & 20 & 0.56 & 0.67 & 1441 \\
\hline & & & 40 & 0.62 & 0.68 & 1567 \\
\hline & & & 40 & 0.58 & 0.67 & 1571 \\
\hline & & & 40 & 0.60 & 0.66 & 1598 \\
\hline & & & 40 & 0.61 & 0.65 & 1589 \\
\hline \multirow[t]{17}{*}{30} & 0.58 & $2 \cdot 10^{-2}$ & 15 & 0.58 & 0.64 & 1725 \\
\hline & & & 15 & 0.53 & 0.67 & 1703 \\
\hline & & & 15 & 0.53 & 0.67 & 1696 \\
\hline & & & 15 & 0.54 & 0.68 & 1709 \\
\hline & & & 20 & 0.56 & 0.68 & 1680 \\
\hline & & & 20 & 0.54 & 0.67 & 1736 \\
\hline & & & 20 & 0.56 & 0.67 & 1750 \\
\hline & & & 20 & 0.56 & 0.67 & 1753 \\
\hline & & & 40 & 0.61 & 0.69 & 2072 \\
\hline & & & 40 & 0.61 & 0.67 & 2143 \\
\hline & & $5 \cdot 10^{-2}$ & 15 & 0.60 & 0.66 & 1577 \\
\hline & & & 15 & 0.61 & 0.65 & 1579 \\
\hline & & & 15 & 0.58 & 0.65 & 1655 \\
\hline & & & 15 & 0.56 & 0.66 & 1665 \\
\hline & & & 20 & 0.55 & 0.68 & 1703 \\
\hline & & & 20 & 0.57 & 0.69 & 1725 \\
\hline & & & 20 & 0.56 & 0.69 & 1682 \\
\hline \multirow[t]{5}{*}{10} & 0.19 & $2 \cdot 10^{-2}$ & 15 & 0.62 & 0.69 & 2363 \\
\hline & & & 15 & 0.58 & 0.70 & 2362 \\
\hline & & & 15 & 0.59 & 0.72 & 2546 \\
\hline & & & 15 & 0.59 & 0.71 & 2420 \\
\hline & & & 20 & 0.61 & 0.71 & 2665 \\
\hline
\end{tabular}


Appendix

\begin{tabular}{|c|c|c|c|c|c|c|}
\hline $\begin{array}{l}\text { CPEG } \\
\mathrm{MA}\end{array}$ & CPEGMA & CInitiator & $v_{\text {rep }}$ & $\begin{array}{l}M_{1} / \\
M_{2}\end{array}$ & $M_{2} / \mathrm{M}_{3}$ & $k_{\mathrm{p}}$ \\
\hline \multirow[t]{10}{*}{$w t \%$} & $\mathrm{~mol} \cdot \mathrm{L}^{-1}$ & $\mathrm{~mol} \cdot \mathrm{L}^{-1}$ & $\mathrm{~Hz}$ & & & $\underset{-1}{\mathrm{~L}} \cdot \mathrm{mol}^{-1} \cdot \mathrm{s}$ \\
\hline & & & 20 & 0.65 & 0.67 & 2670 \\
\hline & & & 20 & 0.59 & 0.73 & 2671 \\
\hline & & & 20 & 0.59 & & 2813 \\
\hline & & $5 \cdot 10^{-2}$ & 15 & 0.59 & 0.72 & 2323 \\
\hline & & & 15 & 0.60 & 0.69 & 2339 \\
\hline & & & 20 & 0.58 & 0.71 & 2700 \\
\hline & & & 20 & 0.63 & 0.71 & 2761 \\
\hline & & & 20 & 0.60 & 0.69 & 2730 \\
\hline & & & 20 & 0.58 & 0.71 & 2737 \\
\hline \multirow[t]{11}{*}{5} & 0.10 & $2 \cdot 10^{-2}$ & 10 & 0.63 & 0.68 & 3180 \\
\hline & & & 10 & 0.63 & 0.71 & 3243 \\
\hline & & & 10 & 0.60 & 0.72 & 2908 \\
\hline & & & 10 & 0.64 & 0.70 & 2882 \\
\hline & & $5 \cdot 10^{-2}$ & 10 & 0.61 & 0.74 & 2890 \\
\hline & & & 10 & 0.60 & 0.71 & 2922 \\
\hline & & & 10 & 0.61 & 0.70 & 2901 \\
\hline & & & 15 & 0.61 & 0.73 & 3597 \\
\hline & & & 15 & 0.62 & 0.71 & 3512 \\
\hline & & & 15 & 0.63 & 0.70 & 3476 \\
\hline & & & 15 & 0.58 & 0.72 & 3457 \\
\hline
\end{tabular}


Table A3: PLP conditions and propagation rate coefficient for the polymerization of PEGMA in water at ambient pressure and at $30^{\circ} \mathrm{C}$.

\begin{tabular}{|c|c|c|c|c|c|c|}
\hline CPEGMA & CPEGMA & CInitiator & $\nu_{\text {rep }}$ & $M_{1} / M_{2}$ & $M_{2} / \mathrm{M}_{3}$ & $k_{\mathrm{p}}$ \\
\hline$w t \%$ & $\mathrm{~mol} \cdot \mathrm{L}^{-1}$ & $\mathrm{~mol} \cdot \mathrm{L}^{-1}$ & $\mathrm{~Hz}$ & & & $\begin{array}{l}\mathrm{L} \cdot \mathrm{mol}^{-1} \cdot \\
\mathrm{s}^{-1}\end{array}$ \\
\hline \multirow[t]{21}{*}{100} & 2.07 & $2 \cdot 10^{-2}$ & 10 & 0.54 & 0.66 & 551 \\
\hline & & & 10 & 0.52 & 0.68 & 553 \\
\hline & & & 10 & 0.53 & 0.67 & 559 \\
\hline & & & 10 & 0.52 & 0.67 & 558 \\
\hline & & & 20 & 0.56 & 0.67 & 581 \\
\hline & & & 20 & 0.57 & 0.67 & 590 \\
\hline & & & 20 & 0.56 & 0.69 & 581 \\
\hline & & & 20 & 0.58 & 0.69 & 588 \\
\hline & & & 40 & 0.57 & 0.70 & 661 \\
\hline & & & 40 & 0.59 & 0.67 & 679 \\
\hline & & & 40 & 0.61 & 0.66 & 658 \\
\hline & & & 40 & 0.62 & 0.67 & 663 \\
\hline & & $5 \cdot 10^{-2}$ & 10 & 0.54 & 0.67 & 547 \\
\hline & & & 10 & 0.52 & 0.68 & 546 \\
\hline & & & 10 & 0.54 & 0.67 & 544 \\
\hline & & & 10 & 0.53 & 0.67 & 550 \\
\hline & & & 20 & 0.57 & 0.67 & 589 \\
\hline & & & 20 & 0.58 & 0.66 & 596 \\
\hline & & & 20 & 0.55 & 0.68 & 583 \\
\hline & & & 20 & 0.57 & 0.68 & 581 \\
\hline & & & 40 & 0.58 & 0.69 & 674 \\
\hline \multirow[t]{3}{*}{50} & 0.96 & $2 \cdot 10^{-2}$ & 10 & 0.51 & 0.67 & 1685 \\
\hline & & & 10 & 0.50 & 0.69 & 1681 \\
\hline & & & 10 & 0.52 & 0.67 & 1711 \\
\hline
\end{tabular}


Appendix

\begin{tabular}{|c|c|c|c|c|c|c|}
\hline $\begin{array}{l}\text { CPEG } \\
\mathrm{MA}\end{array}$ & CPEGMA & CInitiator & $\nu_{\text {rep }}$ & $\begin{array}{l}M_{1} / \\
M_{2}\end{array}$ & $M_{2} / \mathrm{M}_{3}$ & $k_{\mathrm{p}}$ \\
\hline \multirow[t]{10}{*}{$w t \%$} & $\mathrm{~mol} \cdot \mathrm{L}^{-1}$ & $\mathrm{~mol} \cdot \mathrm{L}^{-1}$ & $\mathrm{~Hz}$ & & & $\underset{-1}{\mathrm{~L} \cdot \mathrm{mol}^{-1} \cdot \mathrm{s}}$ \\
\hline & & & 10 & 0.52 & 0.67 & 1709 \\
\hline & & & 20 & 0.67 & 0.74 & 1716 \\
\hline & & & 20 & 0.55 & 0.66 & 1748 \\
\hline & & & 20 & 0.56 & 0.67 & 1718 \\
\hline & & & 20 & 0.55 & 0.68 & 1722 \\
\hline & & & 40 & 0.59 & 0.66 & 1916 \\
\hline & & & 40 & 0.55 & 0.70 & 1920 \\
\hline & & & 40 & 0.58 & 0.69 & 1913 \\
\hline & & & 40 & 0.61 & 0.68 & 1924 \\
\hline \multirow[t]{12}{*}{50} & 0.96 & $5 \cdot 10^{-2}$ & 10 & 0.52 & 0.67 & 1702 \\
\hline & & & 10 & 0.53 & 0.65 & 1683 \\
\hline & & & 10 & 0.52 & 0.67 & 1667 \\
\hline & & & 10 & 0.51 & 0.67 & 1668 \\
\hline & & & 20 & 0.55 & 0.68 & 1738 \\
\hline & & & 20 & 0.54 & 0.68 & 1725 \\
\hline & & & 20 & 0.55 & 0.69 & 1682 \\
\hline & & & 20 & 0.54 & 0.67 & 1694 \\
\hline & & & 40 & 0.56 & 0.68 & 1900 \\
\hline & & & 40 & 0.56 & 0.69 & 1905 \\
\hline & & & 40 & 0.57 & 0.69 & 1866 \\
\hline & & & 40 & 0.57 & 0.66 & 1858 \\
\hline \multirow[t]{6}{*}{30} & 0.58 & $2 \cdot 10^{-2}$ & 10 & 0.55 & 0.69 & 2041 \\
\hline & & & 10 & 0.53 & 0.71 & 2082 \\
\hline & & & 10 & 0.54 & 0.67 & 2132 \\
\hline & & & 10 & 0.54 & 0.67 & 2037 \\
\hline & & & 20 & 0.56 & 0.68 & 2250 \\
\hline & & & 20 & 0.57 & 0.67 & 2193 \\
\hline
\end{tabular}




\begin{tabular}{|c|c|c|c|c|c|c|}
\hline $\begin{array}{l}\text { CPEG } \\
\text { MA }\end{array}$ & CPEGMA & CInitiator & $v_{\text {rep }}$ & $\begin{array}{l}M_{1} / \\
M_{2}\end{array}$ & $M_{2} / \mathrm{M}_{3}$ & $k_{\mathrm{p}}$ \\
\hline \multirow[t]{4}{*}{$w t \%$} & $\mathrm{~mol} \cdot \mathrm{L}^{-1}$ & $\mathrm{~mol} \cdot \mathrm{L}^{-1}$ & $\mathrm{~Hz}$ & & & $\underset{-1}{\mathrm{~L}} \cdot \mathrm{mol}^{-1} \cdot \mathrm{s}$ \\
\hline & & & 20 & 0.56 & 0.67 & 2231 \\
\hline & & & 20 & 0.55 & 0.68 & 2253 \\
\hline & & & 40 & 0.58 & 0.71 & 2545 \\
\hline \multirow[t]{12}{*}{30} & 0.58 & $5 \cdot 10^{-2}$ & 10 & 0.52 & 0.68 & 2013 \\
\hline & & & 10 & 0.52 & 0.68 & 2003 \\
\hline & & & 10 & 0.53 & 0.67 & 2037 \\
\hline & & & 10 & 0.53 & 0.69 & 2039 \\
\hline & & & 20 & 0.54 & 0.66 & 2177 \\
\hline & & & 20 & 0.58 & 0.65 & 2163 \\
\hline & & & 20 & 0.58 & 0.67 & 2225 \\
\hline & & & 20 & 0.55 & 0.69 & 2207 \\
\hline & & & 40 & 0.61 & 0.67 & 2531 \\
\hline & & & 40 & 0.60 & 0.67 & 2566 \\
\hline & & & 40 & 0.62 & 0.68 & 2537 \\
\hline & & & 40 & 0.57 & 0.69 & 2513 \\
\hline
\end{tabular}


Appendix

Table A4: PLP conditions and propagation rate coefficient for the polymerization of PEGMA in water at ambient pressure and at ${ }^{\circ} \mathrm{C}$

\begin{tabular}{|c|c|c|c|c|c|c|}
\hline CPEGMA & CPEGMA & CInitiator & $v_{\text {rep }}$ & $M_{1} / M_{2}$ & $M_{2} / \mathrm{M}_{3}$ & $k_{\mathrm{p}}$ \\
\hline$w t \%$ & $\mathrm{~mol} \cdot \mathrm{L}^{-1}$ & $\mathrm{~mol} \cdot \mathrm{L}^{-1}$ & $\mathrm{~Hz}$ & & & $\begin{array}{l}\mathrm{L} \cdot \mathrm{mol}^{-1} \cdot \\
\mathrm{s}^{-1}\end{array}$ \\
\hline \multirow[t]{22}{*}{100} & 2.07 & $2 \cdot 10^{-2}$ & 5 & 0.50 & 0.65 & 728 \\
\hline & & & 5 & 0.51 & 0.65 & 730 \\
\hline & & & 5 & 0.52 & 0.65 & 709 \\
\hline & & & 5 & 0.52 & 0.66 & 707 \\
\hline & & & 10 & - & 0.67 & 711 \\
\hline & & & 10 & 0.53 & 0.68 & 719 \\
\hline & & & 10 & 0.53 & 0.66 & 710 \\
\hline & & & 10 & 0.53 & 0.67 & 708 \\
\hline & & & 20 & 0.55 & 0.68 & 733 \\
\hline & & & 20 & 0.56 & 0.66 & 734 \\
\hline & & & 20 & 0.54 & 0.69 & 737 \\
\hline & & & 20 & 0.55 & 0.67 & 742 \\
\hline & & $5 \cdot 10^{-2}$ & 5 & 0.51 & 0.65 & 695 \\
\hline & & & 5 & 0.51 & 0.65 & 699 \\
\hline & & & 5 & 0.51 & 0.66 & 716 \\
\hline & & & 5 & 0.52 & 0.65 & 699 \\
\hline & & & 10 & 0.52 & 0.66 & 713 \\
\hline & & & 10 & 0.53 & 0.66 & 713 \\
\hline & & & 10 & 0.53 & 0.67 & 721 \\
\hline & & & 10 & 0.53 & 0.66 & 713 \\
\hline & & & 20 & 0.56 & - & 763 \\
\hline & & & 20 & 0.55 & 0.67 & 742 \\
\hline \multirow[t]{2}{*}{50} & 0.96 & $2 \cdot 10^{-2}$ & 5 & 0.50 & 0.63 & 2057 \\
\hline & & & 5 & 0.51 & 0.64 & 2058 \\
\hline
\end{tabular}




\begin{tabular}{|c|c|c|c|c|c|c|}
\hline $\begin{array}{l}\text { CPEG } \\
\text { MA }\end{array}$ & CPEGMA & CInitiator & $v_{\text {rep }}$ & $\begin{array}{l}M_{1} / \\
M_{2}\end{array}$ & $\mathrm{M}_{2} / \mathrm{M}_{3}$ & $k_{\mathrm{p}}$ \\
\hline \multirow[t]{11}{*}{$w t \%$} & $\mathrm{~mol} \cdot \mathrm{L}^{-1}$ & $\mathrm{~mol} \cdot \mathrm{L}^{-1}$ & $\mathrm{~Hz}$ & & & $\underset{-1}{\mathrm{~L}} \cdot \mathrm{mol}^{-1} \cdot \mathrm{s}$ \\
\hline & & & 5 & 0.50 & 0.65 & 2084 \\
\hline & & & 5 & 0.50 & 0.65 & 2071 \\
\hline & & & 10 & 0.51 & 0.70 & 2073 \\
\hline & & & 10 & 0.51 & 0.66 & 2062 \\
\hline & & & 10 & 0.53 & 0.66 & 2038 \\
\hline & & & 10 & 0.51 & 0.68 & 2034 \\
\hline & & & 20 & 0.56 & 0.67 & 2103 \\
\hline & & & 20 & 0.54 & 0.68 & 2099 \\
\hline & & & 20 & 0.54 & 0.68 & 2081 \\
\hline & & & 20 & 0.57 & 0.68 & 2082 \\
\hline \multirow[t]{11}{*}{50} & 0.96 & $5 \cdot 10^{-2}$ & 5 & 0.50 & 0.64 & 2009 \\
\hline & & & 5 & 0.50 & 0.65 & 1997 \\
\hline & & & 5 & 0.51 & 0.63 & 1980 \\
\hline & & & 10 & 0.52 & 0.69 & 2012 \\
\hline & & & 10 & 0.51 & 0.68 & 2023 \\
\hline & & & 10 & 0.52 & 0.67 & 1965 \\
\hline & & & 10 & 0.53 & 0.66 & 1952 \\
\hline & & & 20 & 0.55 & 0.69 & 2035 \\
\hline & & & 20 & 0.55 & 0.69 & 2044 \\
\hline & & & 20 & 0.56 & 0.67 & 2056 \\
\hline & & & 20 & 0.55 & 0.68 & 2066 \\
\hline \multirow[t]{6}{*}{30} & 0.58 & $2 \cdot 10^{-2}$ & 10 & 0.54 & 0.67 & 2495 \\
\hline & & & 10 & 0.52 & 0.69 & 2508 \\
\hline & & & 10 & 0.51 & 0.68 & 2495 \\
\hline & & & 10 & 0.53 & 0.68 & 2494 \\
\hline & & & 15 & 0.54 & 0.67 & 2539 \\
\hline & & & 15 & 0.53 & 0.67 & 2558 \\
\hline
\end{tabular}


Appendix

\begin{tabular}{|c|c|c|c|c|c|c|}
\hline $\begin{array}{l}\text { CPEG } \\
\text { MA }\end{array}$ & CPEGMA & CInitiator & $v_{\text {rep }}$ & $\begin{array}{l}M_{1} / \\
M_{2}\end{array}$ & $\mathrm{M}_{2} / \mathrm{M}_{3}$ & $k_{\mathrm{p}}$ \\
\hline \multirow[t]{7}{*}{$w t \%$} & $\mathrm{~mol} \cdot \mathrm{L}^{-1}$ & $\mathrm{~mol} \cdot \mathrm{L}^{-1}$ & $\mathrm{~Hz}$ & & & $\underset{-1}{\mathrm{~L} \cdot \mathrm{mol}^{-1} \cdot \mathrm{s}}$ \\
\hline & & & 15 & 0.54 & 0.67 & 2559 \\
\hline & & & 15 & 0.56 & 0.67 & 2570 \\
\hline & & & 20 & 0.55 & 0.68 & 2667 \\
\hline & & & 20 & 0.55 & 0.68 & 2678 \\
\hline & & & 20 & 0.57 & 0.67 & 2658 \\
\hline & & & 20 & 0.55 & 0.67 & 2624 \\
\hline \multirow[t]{12}{*}{30} & 0.58 & $5 \cdot 10^{-2}$ & 10 & 0.53 & 0.68 & 2470 \\
\hline & & & 10 & 0.53 & 0.68 & 2478 \\
\hline & & & 10 & 0.52 & 0.69 & 2442 \\
\hline & & & 10 & 0.55 & 0.66 & 2419 \\
\hline & & & 15 & 0.54 & 0.68 & 2503 \\
\hline & & & 15 & 0.55 & 0.67 & 2501 \\
\hline & & & 15 & 0.55 & 0.68 & 2458 \\
\hline & & & 15 & 0.55 & 0.67 & 2446 \\
\hline & & & 20 & 0.56 & 0.66 & 2530 \\
\hline & & & 20 & 0.56 & 0.67 & 2547 \\
\hline & & & 20 & 0.56 & 0.67 & 2530 \\
\hline & & & 20 & 0.56 & 0.67 & 2534 \\
\hline
\end{tabular}


Table A5: PLP conditions and propagation rate coefficient for the polymerization of PEGMA in water at ambient pressure and at $80^{\circ} \mathrm{C}$.

\begin{tabular}{|c|c|c|c|c|c|c|}
\hline CPEGMA & CPEGMA & CInitiator & $v_{\text {rep }}$ & $M_{1} / M_{2}$ & $M_{2} / \mathrm{M}_{3}$ & $k_{\mathrm{p}}$ \\
\hline$w t \%$ & $\mathrm{~mol} \cdot \mathrm{L}^{-1}$ & $\mathrm{~mol} \cdot \mathrm{L}^{-1}$ & $\mathrm{~Hz}$ & & & $\begin{array}{l}\mathrm{L} \cdot \mathrm{mol}^{-1} \cdot \\
\mathrm{s}^{-1}\end{array}$ \\
\hline \multirow[t]{24}{*}{100} & 2.07 & $2 \cdot 2 \cdot 10^{-2}$ & 10 & 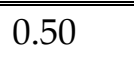 & $\begin{array}{c}0.65 \\
\end{array}$ & 1984 \\
\hline & & & 10 & 0.50 & 0.65 & 1979 \\
\hline & & & 10 & 0.51 & 0.64 & 2007 \\
\hline & & & 10 & 0.51 & 0.65 & 2001 \\
\hline & & & 15 & 0.50 & 0.64 & 2008 \\
\hline & & & 15 & 0.51 & 0.67 & 2019 \\
\hline & & & 15 & 0.52 & 0.67 & 1962 \\
\hline & & & 15 & 0.51 & 0.66 & 1951 \\
\hline & & & 20 & 0.53 & 0.66 & 1950 \\
\hline & & & 20 & 0.52 & 0.66 & 1970 \\
\hline & & & 20 & 0.50 & 0.68 & 1996 \\
\hline & & & 20 & 0.51 & 0.66 & 1974 \\
\hline & & $5 \cdot 10^{-2}$ & 10 & 0.50 & 0.65 & 1944 \\
\hline & & & 10 & 0.50 & 0.65 & 1960 \\
\hline & & & 10 & 0.50 & 0.65 & 1950 \\
\hline & & & 10 & 0.50 & 0.64 & 1980 \\
\hline & & & 15 & 0.51 & 0.66 & 2051 \\
\hline & & & 15 & 0.51 & 0.64 & 2063 \\
\hline & & & 15 & 0.51 & 0.65 & 2040 \\
\hline & & & 15 & 0.51 & 0.64 & 2034 \\
\hline & & & 20 & 0.52 & 0.66 & 2071 \\
\hline & & & 20 & 0.53 & 0.65 & 2092 \\
\hline & & & 20 & 0.51 & 0.67 & 1990 \\
\hline & & & 20 & 0.52 & 0.66 & 2026 \\
\hline
\end{tabular}


Appendix

\begin{tabular}{|c|c|c|c|c|c|c|}
\hline $\begin{array}{l}\text { CPEG } \\
\text { MA }\end{array}$ & CPEGMA & CInitiator & $\nu_{\text {rep }}$ & $\begin{array}{l}M_{1} / \\
M_{2}\end{array}$ & $M_{2} / \mathrm{M}_{3}$ & $k_{\mathrm{p}}$ \\
\hline$w t \%$ & $\mathrm{~mol} \cdot \mathrm{L}^{-1}$ & $\mathrm{~mol} \cdot \mathrm{L}^{-1}$ & $\mathrm{~Hz}$ & & & $\underset{-1}{\mathrm{~L} \cdot \mathrm{mol}^{-1} \cdot \mathrm{s}}$ \\
\hline \multirow[t]{12}{*}{50} & 0.96 & $2 \cdot 10^{-2}$ & 5 & 0.48 & 0.61 & 4910 \\
\hline & & & 5 & 0.48 & 0.61 & 4951 \\
\hline & & & 5 & 0.47 & 0.61 & 5006 \\
\hline & & & 5 & 0.47 & 0.61 & 5043 \\
\hline & & & 10 & 0.50 & 0.63 & 4972 \\
\hline & & & 10 & 0.49 & 0.62 & 4955 \\
\hline & & & 10 & 0.50 & 0.63 & 4964 \\
\hline & & & 10 & 0.49 & 0.64 & 4930 \\
\hline & & & 15 & 0.65 & 0.71 & 4837 \\
\hline & & & 15 & 0.66 & 0.70 & 4995 \\
\hline & & & 15 & 0.65 & 0.72 & 4945 \\
\hline & & & 15 & 0.65 & 0.72 & 4979 \\
\hline \multirow[t]{11}{*}{50} & 0.96 & $5 \cdot 10^{-2}$ & 5 & 0.48 & 0.65 & 4640 \\
\hline & & & 5 & 0.47 & 0.64 & 4661 \\
\hline & & & 5 & 0.49 & 0.62 & 4615 \\
\hline & & & 5 & 0.49 & 0.64 & 4598 \\
\hline & & & 10 & 0.49 & 0.66 & 4618 \\
\hline & & & 10 & 0.50 & 0.64 & 4526 \\
\hline & & & 10 & 0.50 & 0.65 & 4562 \\
\hline & & & 10 & 0.50 & 0.65 & 4556 \\
\hline & & & 15 & 0.51 & 0.66 & 4594 \\
\hline & & & 15 & 0.52 & 0.65 & 4564 \\
\hline & & & 15 & 0.51 & 0.65 & 4584 \\
\hline \multirow[t]{4}{*}{30} & 0.58 & $2 \cdot 10^{-2}$ & 5 & 0.48 & 0.62 & 6885 \\
\hline & & & 5 & 0.48 & 0.61 & 6879 \\
\hline & & & 5 & 0.48 & 0.61 & 6705 \\
\hline & & & 5 & 0.47 & 0.62 & 6662 \\
\hline
\end{tabular}




\begin{tabular}{|c|c|c|c|c|c|c|}
\hline $\begin{array}{l}\text { CPEG } \\
\text { MA }\end{array}$ & CPEGMA & CInitiator & $v_{\text {rep }}$ & $\begin{array}{l}M_{1} / \\
M_{2}\end{array}$ & $M_{2} / \mathrm{M}_{3}$ & $k_{\mathrm{p}}$ \\
\hline \multirow[t]{9}{*}{$w t \%$} & $\mathrm{~mol} \cdot \mathrm{L}^{-1}$ & $\mathrm{~mol} \cdot \mathrm{L}^{-1}$ & $\mathrm{~Hz}$ & & & $\underset{-1}{\mathrm{~L}} \cdot \mathrm{mol}^{-1} \cdot \mathrm{s}$ \\
\hline & & & 10 & 0.51 & 0.64 & 6983 \\
\hline & & & 10 & 0.51 & 0.65 & 6960 \\
\hline & & & 10 & 0.51 & 0.63 & 6969 \\
\hline & & & 10 & 0.50 & 0.65 & 6948 \\
\hline & & & 15 & 0.51 & 0.66 & 6942 \\
\hline & & & 15 & 0.51 & 0.67 & 6881 \\
\hline & & & 15 & 0.51 & 0.66 & 6892 \\
\hline & & & 15 & 0.52 & 0.66 & 6934 \\
\hline \multirow[t]{12}{*}{30} & 0.58 & $5 \cdot 10^{-2}$ & 5 & 0.49 & 0.62 & 6754 \\
\hline & & & 5 & 0.48 & 0.63 & 6733 \\
\hline & & & 5 & 0.47 & 0.64 & 6871 \\
\hline & & & 5 & 0.48 & 0.63 & 6910 \\
\hline & & & 10 & 0.50 & 0.65 & 6897 \\
\hline & & & 10 & 0.51 & 0.65 & 6867 \\
\hline & & & 10 & 0.50 & 0.65 & 6948 \\
\hline & & & 10 & 0.50 & 0.65 & 6772 \\
\hline & & & 15 & 0.52 & 0.65 & 6819 \\
\hline & & & 15 & 0.52 & 0.66 & 6901 \\
\hline & & & 15 & 0.51 & 0.66 & 6697 \\
\hline & & & 15 & 0.51 & 0.65 & 6722 \\
\hline
\end{tabular}




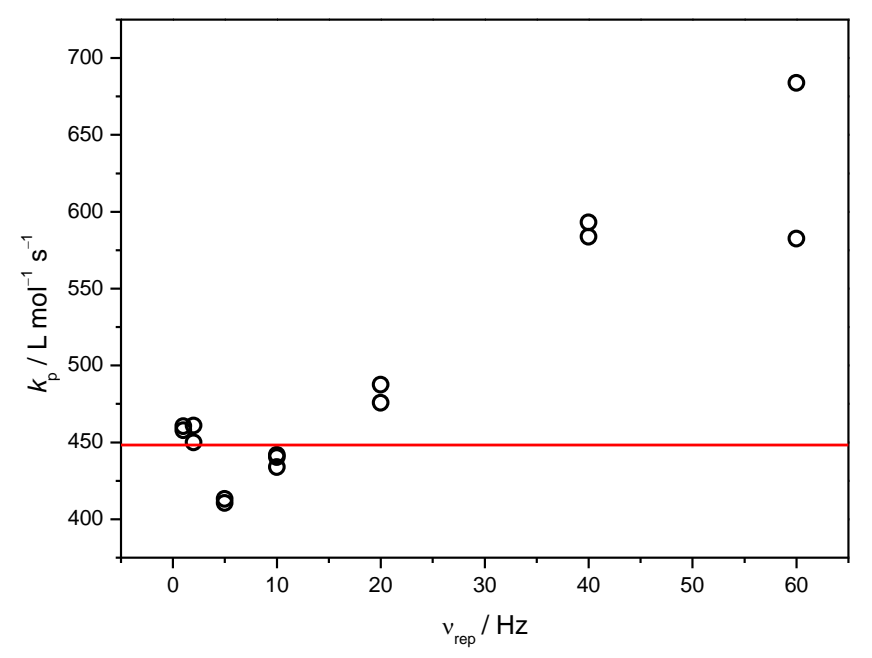

Figure A3: Variation on $k_{\mathrm{p}}$ with the laser pulse repetition rate, $v_{\text {rep, }}$ for PEGMA bulk at $20^{\circ} \mathrm{C}$. The red line refers to the arithmetic mean of $k_{\mathrm{p}}$ between 1 and $20 \mathrm{~Hz}$.

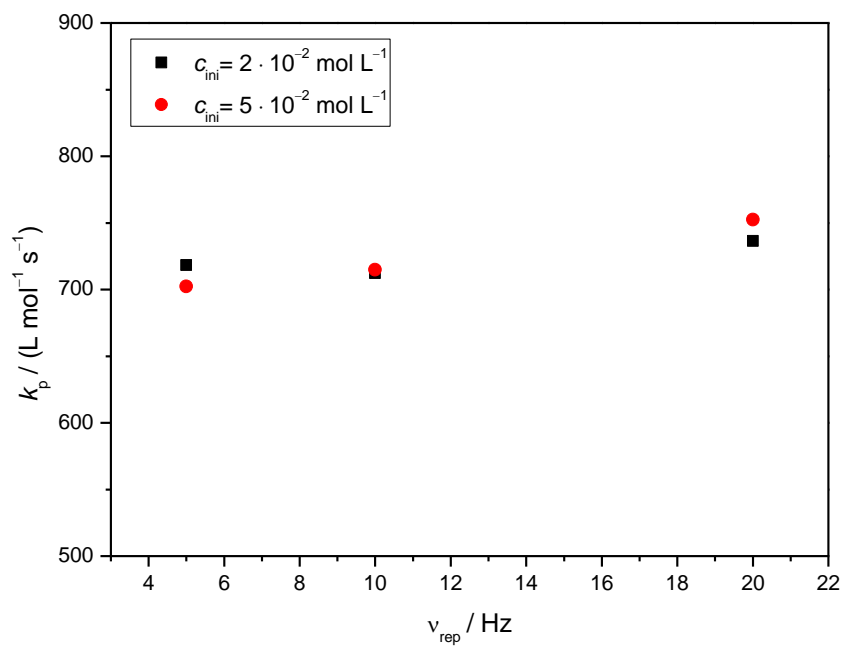

Figure A4: Variation on $k_{\mathrm{p}}$ with the initiator concentration in PEGMA bulk at $40{ }^{\circ} \mathrm{C}$. 


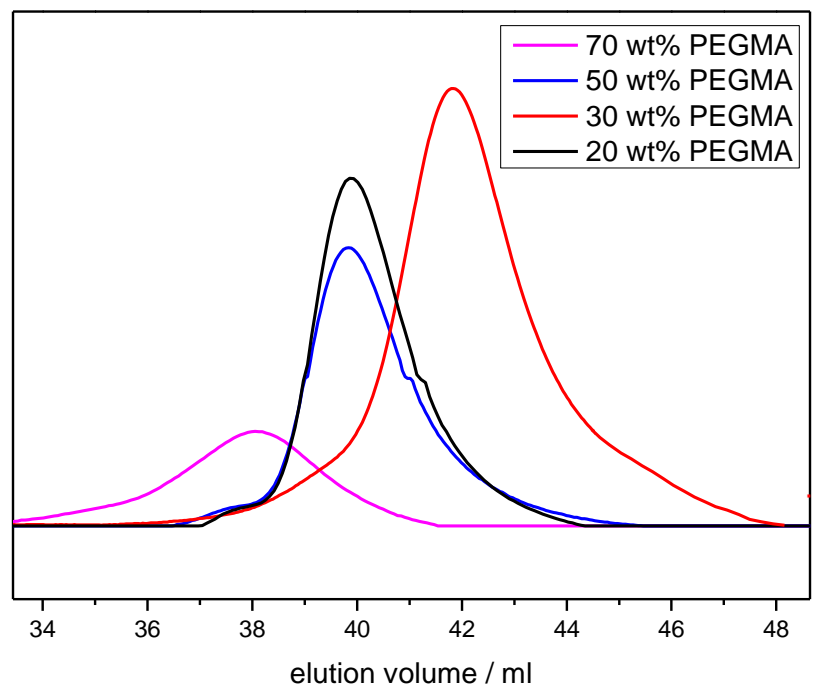

Figure A5: SEC spectra for different PEGMA polymerization with $\mathrm{CuBr} /-$ 2,2'-bipyridine at $20^{\circ} \mathrm{C}$. All polymerizations were carried out with an excess of 50 equivalents of $\mathrm{NaBr}$ with respect to the total $\mathrm{Cu}$-catalyst concentration. The concentration of the $\mathrm{Cu} / \mathrm{L}$ - and $\mathrm{Cu}{ }^{\mathrm{II}} / \mathrm{L}-\mathrm{Br}$ catalyst are shown in Table 4.6. 

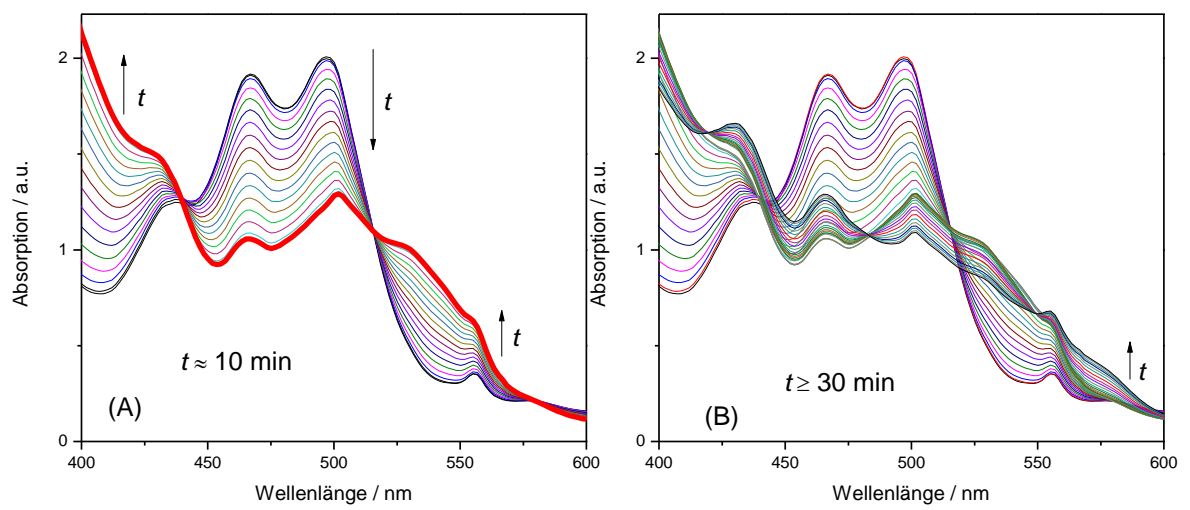

Figure A6: UV/Vis spectra for the PEGMA poylmerization with the Fe ${ }^{\mathrm{II}}$ mesohemin-(MPEG500)2 catalyst and with VA-44 in $50 \mathrm{wt} \% \mathrm{H}_{2} \mathrm{O}$ at $60{ }^{\circ} \mathrm{C}$. (A) Reaction of FeII/L with PEGMA radicals to the formation of the Fe ${ }^{\mathrm{III}} / \mathrm{L}-\mathrm{R}$ species in a time scale of $10 \mathrm{~min}$. The arrows indicate the direction of the absorbance change. The resulting Fe $\mathrm{III} / \mathrm{L}-\mathrm{R}$ species is marked red. (B) Shows the dissociation of the Fe $\mathrm{III} / \mathrm{L}-\mathrm{R}$ species during the continued polymerization after $30 \mathrm{~min}$. 


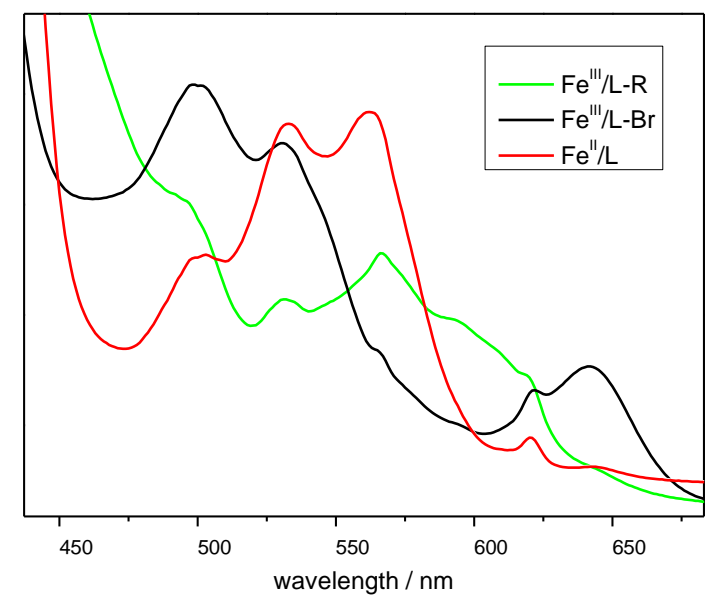

Figure A7: UV/Vis spectra of the participating mesohemin-(MPEG500)2 species in $\mathrm{PEO} / \mathrm{H}_{2} \mathrm{O}$ mixtures with $50 \mathrm{wt} \%$ water at $22{ }^{\circ} \mathrm{C}$. The black line indicates the initial Fe ${ }^{\mathrm{III}}-\mathrm{Br} / \mathrm{L}$ species which was reduced with $\mathrm{Na}_{2} \mathrm{~S}_{2} \mathrm{O}_{4}$ to yield the $\mathrm{Fe}^{\mathrm{II}} / \mathrm{L}$ spectrum (red line). The reaction of $\mathrm{Fe}$ initiator VA-44 at $65{ }^{\circ} \mathrm{C}$ lead to the FeII/L-R species (green line).

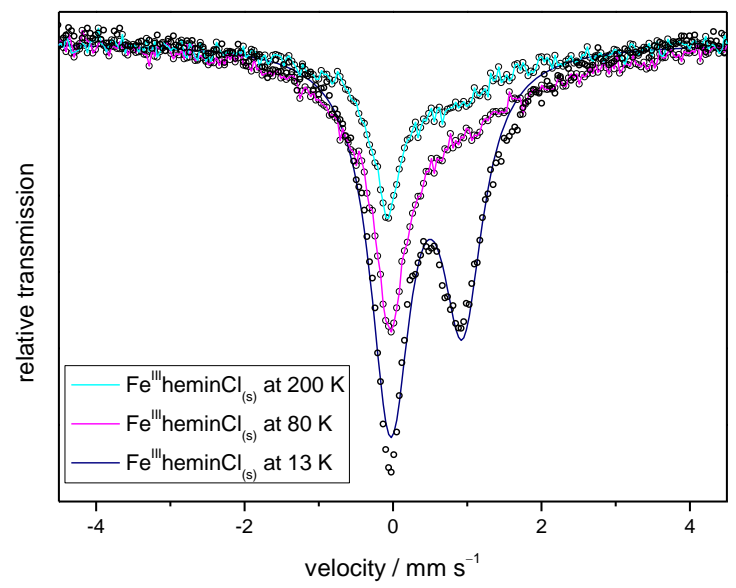

Figure A8: ${ }^{57} \mathrm{Fe}$ Mössbauer spectra recorded at various temperatures on a flash-frozen solution of $\mathrm{Fe}$ III/L-Cl in substance. The asymmetric peak shape is typical for Fe ${ }^{\mathrm{III}}$ complexes and is induced by intermediate spin relaxation. 

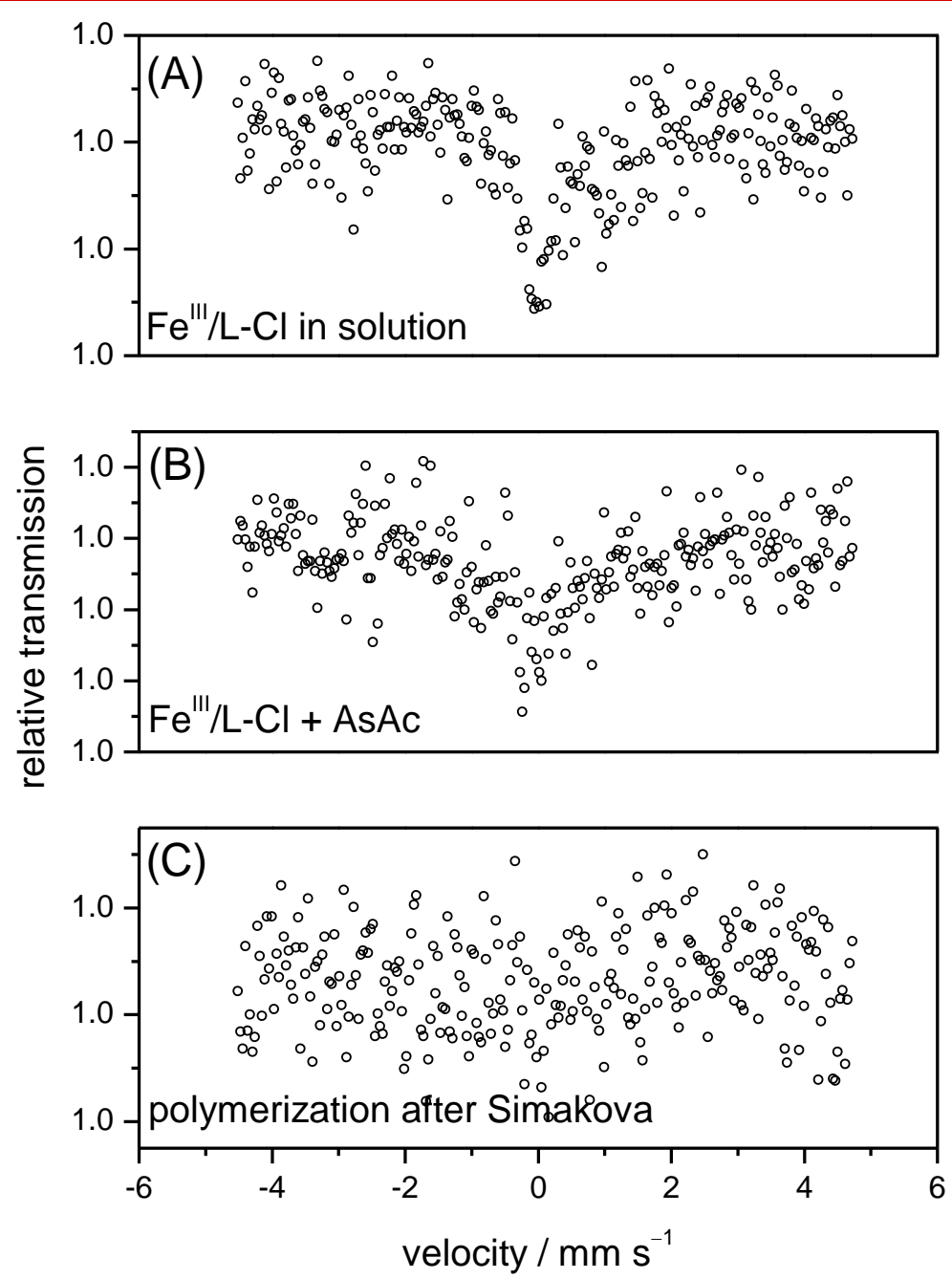

Figure A9: ${ }^{57} \mathrm{Fe}$ Mössbauer spectra recorded on a flash-frozen solution of $\mathrm{Fe}^{\mathrm{III}} / \mathrm{L}-\mathrm{Cl}$ after different reactions. (A) $\mathrm{Fe}$ III/L-Cl in PEGMA with $50 \mathrm{wt} \%$ water. (B) $\mathrm{Fe}$ III/L-Cl after the reaction with 5 equivalents ascorbic acid in a $50 \mathrm{wt} \%$ PEGMA-water mixture. (C) PEGMA polymerization in $50 \mathrm{wt} \%$ water after the procedure described by Simakova et al.[1] In all cases the $\mathrm{Fe}$ III/L-Cl species is Mössbauer silent and could not be detected due to intermediated spin relaxation. 


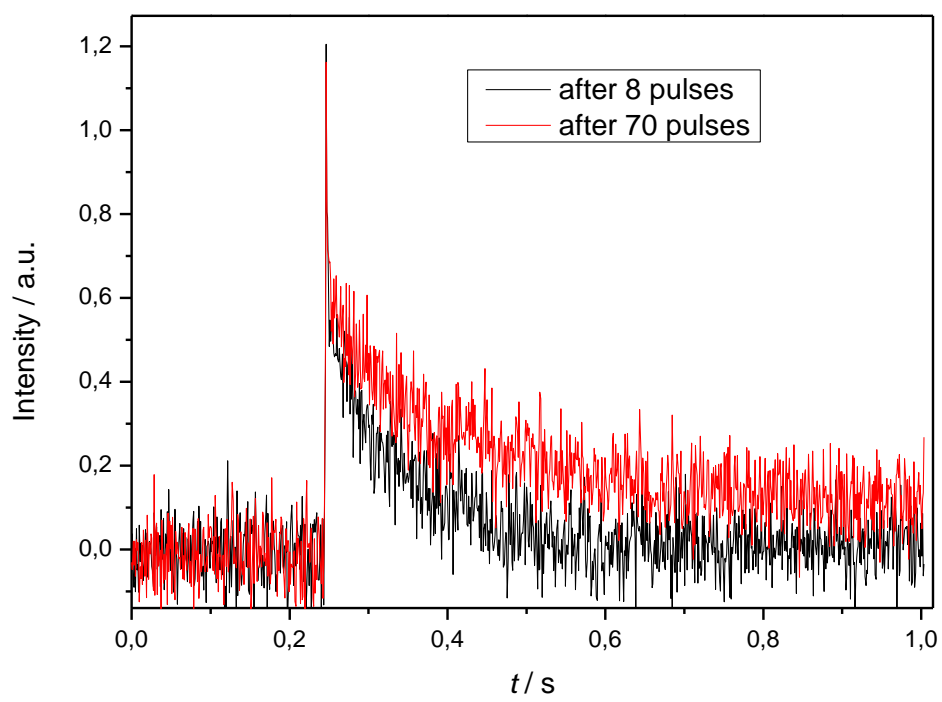

Figure A10: SP-PLP-EPR experiment with $1 \mathrm{mM}$ mesohemin-(MPEG500) 2 in $50 \mathrm{wt} \% \mathrm{H}_{2} \mathrm{O} / \mathrm{PEGMA}$ at $20^{\circ} \mathrm{C}$. PEGMA radical concentration vs time profiles measured by SP-PLP-EPR with a single laser pulse being applied at $t=0.23$. The black line represents the radical decay after 8 laser pulses applied. The red line represents the radical decay after 70 laser pulses being applied. Due to the consumption of $\mathrm{Fe}^{\mathrm{III}} / \mathrm{L}-\mathrm{Br}$ the decay in radical concentration decelerated. This finding suggests that the reaction of $\mathrm{Fe}^{\mathrm{II}} / \mathrm{L}$ with radicals is slower than the ATRP deactivation. 


\section{Abbreviations}

\begin{tabular}{|c|c|}
\hline A & absorbance \\
\hline$A_{0}$ & pre-exponential factor \\
\hline AIBN & 2,2'-azobis(2-methylpropionitrile) \\
\hline$\alpha_{\mathrm{s}}$ & $\begin{array}{l}\text { composite-model exponent for the short chain } \\
\text { regime }\end{array}$ \\
\hline$\alpha_{1}$ & $\begin{array}{l}\text { composite-model exponent for the short chain } \\
\text { regime }\end{array}$ \\
\hline AGET & Activator Generated by Electron Transfer \\
\hline ARGET & Activator ReGenerated by Electron Tranfer \\
\hline ATRA & atom-transfer radical addition \\
\hline ATRP & atom-transfer radical polymerization \\
\hline BDE & bond-dissociation energy \\
\hline bpy & 2,2'-bipyridine \\
\hline$c$ & concentration \\
\hline$c^{\prime}$ & $\begin{array}{l}\text { Y-intercept of the linearized } F[Y] \text {-function for the } \\
\text { non-equimolar case }\end{array}$ \\
\hline$c^{\prime \prime}$ & $\begin{array}{l}\text { Y-intercept of the linearizied } F[Y] \text {-function for the } \\
\text { equimolar case }\end{array}$ \\
\hline CCT & catalytic chain transfer \\
\hline CRP & controlled radical polymerization \\
\hline CRT & catalytic radical termination \\
\hline$d$ & optical pathway \\
\hline$\Delta \mathrm{V}^{\ddagger}$ & activation volume \\
\hline$\Delta_{\mathrm{r}} \mathrm{V}$ & reaction volume \\
\hline DMF & dimethylformamide \\
\hline$D P$ & degree of polymerization \\
\hline$E_{\mathrm{A}}$ & activation energy \\
\hline EBrPA & ethyl $\alpha$-bromophenylacetate \\
\hline EPR & electron paramagnetic resonance \\
\hline
\end{tabular}




\begin{tabular}{|c|c|}
\hline$\varepsilon$ & molar decadic extinction coefficient \\
\hline equiv & equivalents \\
\hline et al. & et alii \\
\hline$\eta(T, p)$ & $\begin{array}{l}\text { solvent viscosity at the given temperature and } \\
\text { pressure }\end{array}$ \\
\hline$\eta$ & solvent viscosity \\
\hline$f$ & initiator efficiency \\
\hline FT & Fourier transform \\
\hline GC & gas chromatography \\
\hline$h$ & Planck constant \\
\hline HEMA-Br & 2-hydroxyethyl 2-bromoisobutyrate \\
\hline HEMA & 2-hydroxyethyl methacrylate \\
\hline HMTETA & 1,1,4,7,10,10-hexamethyltriethylenetramine \\
\hline$i$ & chain length \\
\hline$i_{\mathrm{c}}$ & crossover chain length \\
\hline$k_{\text {act }}$ & rate coefficient for the activation \\
\hline$k_{\mathrm{B}}$ & Boltzmann constant \\
\hline KATRP & ATRP equilibrium constant \\
\hline$k_{\text {deact }}$ & rate coefficient for ATRP deactivation \\
\hline Kmodel & $\begin{array}{l}\text { ATRP equilibrium constant in case of model } \\
\text { systems }\end{array}$ \\
\hline$k_{\mathrm{p}}$ & propagation rate coefficient \\
\hline$k_{\mathrm{t}}$ & termination rate coefficient \\
\hline$k_{t, \mathrm{com}}$ & rate coefficient of the termination by combination \\
\hline$k_{\mathrm{t}, \mathrm{dis}}$ & $\begin{array}{l}\text { rate coefficient of the termination by } \\
\text { disproportionation }\end{array}$ \\
\hline$k \mathrm{t}^{\mathrm{i}, \mathrm{i}}$ & $\begin{array}{l}\text { termination rate coefficient for monomers with } \\
\text { chain-length } i, i\end{array}$ \\
\hline$k_{\mathrm{t}^{1,1}}$ & $\begin{array}{l}\text { termination rate coefficient for monomers with } \\
\text { chain-length unity }\end{array}$ \\
\hline LMCT & ligand to metal charge transfer \\
\hline M & monomer molecule \\
\hline MA & methyl acrylate \\
\hline
\end{tabular}




\begin{tabular}{|c|c|c|}
\hline MBriB & \multicolumn{2}{|l|}{ methyl 2-bromoisobutyrate } \\
\hline $\mathrm{MBrP}$ & \multicolumn{2}{|l|}{ methyl 2-bromopropionate } \\
\hline MCT & \multicolumn{2}{|l|}{ mercury cadmium telluride } \\
\hline Me6TREN & \multicolumn{2}{|c|}{ tris(2-dimethylaminoethyl)amine } \\
\hline $\mathrm{MeCN}$ & \multicolumn{2}{|l|}{ acetonitrile } \\
\hline MFA & \multicolumn{2}{|l|}{ modified fluoralkoxy } \\
\hline MMA & \multicolumn{2}{|l|}{ methyl methacrylate } \\
\hline$M_{\mathrm{n}}$ & \multicolumn{2}{|l|}{ number-average molar mass } \\
\hline$M_{\mathrm{w}}$ & \multicolumn{2}{|l|}{ weight-average molar mass } \\
\hline NIR & \multicolumn{2}{|l|}{ near-infrared } \\
\hline NMP & \multicolumn{2}{|l|}{$N$-methyl-2-pyrrolidone } \\
\hline NMR & \multicolumn{2}{|l|}{ nuclear magnetic resonance } \\
\hline OMRP & \multicolumn{2}{|c|}{ organometallic-mediated radical polymerization } \\
\hline $\mathrm{OM}$ & \multicolumn{2}{|l|}{ organometallic } \\
\hline OSET & \multicolumn{2}{|l|}{ outer sphere electron transfer } \\
\hline$p$ & \multicolumn{2}{|l|}{ pressure } \\
\hline$P D I$ & \multicolumn{2}{|l|}{ dispersity } \\
\hline PE & \multicolumn{2}{|l|}{ polyethylene } \\
\hline PEGMA & \multicolumn{2}{|c|}{ poly (ethylene glycol) methyl ether methacrylate } \\
\hline PEEGMA & \multicolumn{2}{|c|}{ poly (ethylene glycol) ethyl ether methacrylate } \\
\hline $\mathrm{PEBr}$ & \multicolumn{2}{|l|}{ 1-Phenylethyl bromide } \\
\hline PEO & \multicolumn{2}{|c|}{ poly (ethylene glycol) dimethyl ether } \\
\hline PID & \multicolumn{2}{|c|}{ proportional-integral-derivative controller } \\
\hline PLP & \multicolumn{2}{|c|}{ pulse-laser-induced polymerization } \\
\hline PMDETA & \multirow{2}{*}{\multicolumn{2}{|c|}{$\begin{array}{l}N, N, N^{\prime}, N^{\prime \prime}, N^{\prime \prime} \text {-pentame-thyldiethylenetria } \\
\text { polymer generated by combination }\end{array}$}} \\
\hline $\mathrm{P}_{n+m}$ & & \\
\hline $\mathrm{P}_{n}=$ & $\begin{array}{l}\text { unsaturated polymer } \\
\text { disproportionation }\end{array}$ & generated \\
\hline $\mathrm{P}_{m} \mathrm{H}$ & $\begin{array}{l}\text { saturated polymer } \\
\text { disproportionation }\end{array}$ & generated \\
\hline PRE & persisten radical effect & \\
\hline PS & polystyrene & \\
\hline
\end{tabular}


$R$

RAFT

RDRP

RI

$\mathrm{R}_{n} \cdot$

$R_{\mathrm{P}}$

SEC

SP

$T$

TEMPOL

UV

Vis

wt $\%$ ideal gas constant

reversible addition-fragmentation chain-transfer reversible deactivation radical polymerization refractive index

radical consisting of $n$ monomer units polymerization rate size-exclusion chromatography single pulse temperature 4-hydroxy-2,2,6,6-tetramethylpiperidine 1-oxyl ultraviolet visible weight percent 


\section{Literature}

[1] Simakova, A., Mackenzie, M., Averick, S. E., Park, S., Matyjaszewski, K. Angew. Chem. Int. Ed. Engl. 2013, 52, 12148.

[2] Lechner, M. D., Gehrke, K., Nordmeier, E. H. Makromolekulare Chemie; Springer Berlin Heidelberg, 2014.

[3] Elias, H.-G. Industrielle Polymere und Synthesen; Wiley-VCH, 2001.

[4] Szwarc, M. J. Polym. Sci. Part A Polym. Chem. 1998, 36, ix.

[5] Poli, R., Allan, L. E. N., Shaver, M. P. Prog. Polym. Sci. 2014, 39, 1827.

[6] Matyjaszewski, K., Xia, J. Chem. Rev. 2001, 101, 2921.

[7] Kamigaito, M., Ando, T., Sawamoto, M. Chem. Rev. 2001, 101, 3689.

[8] di Lena, F., Matyjaszewski, K. Prog. Polym. Sci. 2010, 35, 959.

[9] Braunecker, W. A., Matyjaszewski, K. Prog. Polym. Sci. 2007, 32, 93.

[10] Ouchi, M., Terashima, T., Sawamoto, M. Chem. Rev. 2009, 109, 4963.

[11] Chiefari, J., Chong, Y. K. B., Ercole, F., Krstina, J., Jeffery, J., Le, T. P. T., Mayadunne, R. T. A., Meijs, G. F., Moad, C. L., Moad, G., Rizzardo, E., Thang, S. H. Macromolecules 1998, 31, 5559.

[12] Moad, G., Rizzardo, E., Thang, S. H. Acc. Chem. Res. 2008, 41, 1133.

[13] Moad, G., Chong, Y. K., Postma, A., Rizzardo, E., Thang, S. H. Polymer (Guildf). 2005, 46, 8458.

[14] Moad, G., Rizzardo, A. E., Thang, S. H. Aust. J. Chem. 2005, 58, 379.

[15] Vana, P. Macromol. Symp. 2007, 248, 71.

[16] Perrier, S., Takolpuckdee, P. J. Polym. Sci. Part A Polym. Chem. 2005, 43, 5347.

[17] Hawker, C. J., Bosman, A. W., Harth, E. Chem. Rev. 2001, 101, 3661.

[18] Georges, M. K., Veregin, R. P. N., Kazmaier, P. M., Hamer, G. K. 
Macromolecules 1993, 26, 2987.

[19] Poli, R. Chem. - A Eur. J. 2015, 21, 6988.

[20] Tsarevsky, N. V., Matyjaszewski, K. Chem. Rev. 2007, 107, 2270.

[21] Ulasan, M., Yavuz, E., Bagriacik, E. U., Cengeloglu, Y., Yavuz, M. S. J. Biomed. Mater. Res. Part A 2015, 103, 243.

[22] Adali-kaya, Z., Tse Sum Bui, B., Falcimaigne-Cordin, A., Haupt, K. Angew. Chemie Int. Ed. 2015, 127, 5281.

[23] Destarac, M. Macromol. React. Eng. 2010, 4, 165.

[24] Guimard, N. K., Oehlenschlaeger, K. K., Zhou, J., Hilf, S., Schmidt, F. G., Barner-kowollik, C. Macromol. Chem. Phys. 2012, 213, 131.

[25] Wang, J., Matyjaszewski, K. J. Am. Chem. Soc. 1995, 117, 5614.

[26] Kato, M., Kamigaito, M., Sawamoto, M., Higashimuras, T. Macromolecules 1996, 28, 1721.

[27] Kharasch, M. S., Jensen, E. V, Urry, W. H. Science (80-. ). 1945, 102, 128.

[28] Minisci, F. Acc. Chem. Res. 1975, 8, 165.

[29] Gossage, R. A., van de Kuil, L., van Koten, G. Am. Chem. Soc. 1998, 31, 423.

[30] Matyjaszewski, K. Macromolecules 2012, 45, 4015.

[31] Coullerez, G., Carlmark, A., Malmström, E., Jonsson, M. J. Am. Chem. Soc. 2004, 108, 10.

[32] Bergenudd, H., Coullerez, G., Jonsson, M., Malmström, E. Macromolecules 2009, 42, 3302.

[33] Simakova, A., Averick, S. E., Konkolewicz, D., Matyjaszewski, K. Macromolecules 2012, 45, 6371.

[34] Magenau, A. J. D., Strandwitz, N. C., Gennaro, A., Matyjaszewski, K. Science 2011, 332, 81.

[35] Matyjaszewski, K., Tsarevsky, N. V, Braunecker, W. A., Dong, H., Huang, J., Jakubowski, W., Kwak, Y., Nicolay, R., Tang, W. Macromolecules 2007, 7795.

[36] Tang, W., Kwak, Y., Braunecker, W., Tsarevsky, N. V, Coote, M. L., Matyjaszewski, K. J. Am. Chem. Soc. 2008, 130, 10702.

[37] Tang, W., Matyjaszewski, K. Macromolecules 2006, 39, 4953. 
[38] Tsarevsky, N. V., Pintauer, T., Matyjaszewski, K. Macromolecules 2004, 37, 9768.

[39] Pintauer, T., Matyjaszewski, K. Coord. Chem. Rev. 2005, 249, 1155.

[40] Pintauer, T., Braunecker, W., Collange, E., Poli, R., Matyjaszewski, K. Macromolecules 2004, 37, 2679.

[41] Horn, M., Matyjaszewski, K. Macromolecules 2013, 46, 3350.

[42] Braunecker, W. a., Tsarevsky, N. V., Gennaro, A., Matyjaszewski, K. Macromolecules 2009, 42, 6348.

[43] Bortolamei, N., Isse, A. a, Magenau, A. J. D., Gennaro, A., Matyjaszewski, K. Angew. Chem. Int. Ed. Engl. 2011, 50, 11391.

[44] Wang, Y., Zhong, M., Zhu, W., Peng, C.-H., Zhang, Y., Konkolewicz, D., Bortolamei, N., Isse, A. a., Gennaro, A., Matyjaszewski, K. Macromolecules 2013, 46, 3793.

[45] Tang, W., Tsarevsky, N. V, Matyjaszewski, K. J. Am. Chem. Soc. 2006, 128, 1598.

[46] Tsarevsky, N., Braunecker, W. Macromolecules 2006, 39, 6817.

[47] Konkolewicz, D., Krys, P., Góis, J. R., Mendonca, P. V., Mingjiang, Z., Wang, Y., Gennaro, A., Isse, A. A., Fantin, M., Matyjaszewski, K. Macromolecules 2014, 47, 560 .

[48] Poli, R., Shaver, M. P. Chem. Eur. J. 2014, 20, 17530.

[49] Xue, Z., He, D., Xie, X. Polym. Chem. 2015, 6, 1660.

[50] Sigg, S. J., Seidi, F., Renggli, K., Silva, T. B., Kali, G., Bruns, N. Macromol. Rapid Commun. 2011, 32, 1710.

[51] Yang, D., He, D., Liao, Y., Xue, Z., Zhou, X., Xie, X. J. Polym. Sci. Part A Polym. Chem. 2014, 52, 1020.

[52] He, W., Zhang, L., Miao, J., Cheng, Z., Zhu, X. Macromol. Rapid Commun. 2012, 33, 1067.

[53] Silva, T. B., Spulber, M., Kocik, M. K., Seidi, F., Charan, H., Rother, M., Sigg, S. J., Renggli, K., Kali, G., Bruns, N. Biomacromolecules 2013, 14, 2703.

[54] Ng, Y.-H., di Lena, F., Chai, C. L. L. Chem. Commun. 2011, 47, 6464.

[55] Allan, L. E. N., Macdonald, J. P., Reckling, A. M., Kozak, C. M., Shaver, M. P. Macromol. Rapid Commun. 2012, 33, 414.

[56] Poli, R. Angew. Chemie Int. Ed. 2006, 45, 5058. 
[57] Schroeder, H., Buback, M., Shaver, M. P. Macromolecules 2015, 48, 6114.

[58] Schroeder, H., Lake, B. R. M., Demeshko, S., Shaver, M. P., Buback, M. 2015.

[59] Buback, M., Morick, J. Macromol. Chem. Phys. 2010, 211, 2154.

[60] Morick, J., Buback, M., Matyjaszewski, K. Macromol. Chem. Phys. 2012, 213, 2287.

[61] Morick, J., Buback, M., Matyjaszewski, K. J. Chem. Phys. 2011, 212, 2423.

[62] Kattner, H., Buback, M. Macromol. Symp. 2013, 333, 11.

[63] Barth, J., Buback, M., Hesse, P., Sergeeva, T. Macromol. Rapid Commun. 2009, 30, 1969.

[64] Arita, T., Buback, M., Janssen, O., Vana, P. Macromol. Rapid Commun. 2004, 1376.

[65] Yamada, B., Westmoreland, D. G., Kobatake, S., Konosu, O. Prog. Polym. Sci. 1999, 24, 565.

[66] Soerensen, N., Barth, J., Buback, M., Morick, J., Schroeder, H., Matyjaszewski, K. Macromolecules 2012, 45, 3797.

[67] Schroeder, H., Buback, M. Macromolecules 2015, 48, 6108.

[68] Schroeder, H., Buback, J., Demeshko, S., Matyjaszewski, K., Meyer, F., Buback, M. Macromolecules 2015, 48, 1981.

[69] Schroeder, H., Yalalov, D., Buback, M., Matyjaszewski, K. Macromol. Chem. Phys. 2012, 213, 2019.

[70] Schroeder, H., Buback, M., Matyjaszewski, K. Chem. Phys. 2014, 215, 44.

[71] Schrooten, J., Lacík, I., Stach, M., Hesse, P., Buback, M. Macromol. Chem. Phys. 2013, 214, 2283.

[72] Lacík, I., Učňová, L., Kukučková, S., Buback, M., Hesse, P., Beuermann, S. Macromolecules 2009, 42, 7753.

[73] Stach, M., Lacík, I., Chorvat, D., Buback, M., Hesse, P., Hutchinson, R. A., Tang, L. Macromolecules 2008, 41, 5174.

[74] Buback, M., Hesse, P., Lacík, I. Macromol. Rapid Commun. 2007, 28, 2049.

[75] Beuermann, S., Buback, M., Hesse, P., Kukučková, S., Lacík, I. Macromol. Symp. 2007, 248, 41.

[76] Lacík, I., Beuermann, S., Buback, M. Macromol. Chem. Phys. 2004, 205, 
1080.

[77] Beuermann, S., Nelke, D. Macromol. Chem. Phys. 2003, 204, 460.

[78] Heuts, J. P. A., Gilbert, R. G., Radom, L. Macromolecules 1995, 28, 8771.

[79] Beuermann, S. Macromolecules 2002, 9300.

[80] Smith, G. B., Heuts, J. P. a., Russell, G. T. Macromol. Symp. 2005, 226, 133.

[81] di Lena, F., Matyjaszewski, K. Prog. Polym. Sci. 2010, 35, 959.

[82] Morick, J. Kinetik von Atom-Transfer Radikalischen Polymerisationen bis zu hohen Drücken, Georg-August-Universtität Göttingen, 2012.

[83] Yamamoto, S., Pietrasik, J., Matyjaszewski, K. J. Polym. Sci. Part A Polym. Chem. 2007, 194.

[84] Lutz, J.-F. J. Polym. Sci. Part A Polym. Chem. 2008, 46, 3459.

[85] Luzon, M., Boyer, C., Peinado, C., Corrales, T., Whittaker, M., Tao, L., Davis, T. P. J. Polym. Sci. Part A Polym. Chem. 2010, 48, 2783.

[86] Lutz, J.-F., Stiller, S., Hoth, A., Kaufner, L., Pison, U., Cartier, R. Biomacromolecules 2006, 7, 3132.

[87] Ryan, S. M., Wang, X., Mantovani, G., Sayers, C. T., Haddleton, D. M., Braydon, D. J. J. Control. Release 2009, 135, 51.

[88] Tuncel, a. Polymer (Guildf). 2000, 41, 1257.

[89] Börner, H. G., Schlaad, H. Soft Matter 2007, 3, 394.

[90] Wright, P. S. J Dent Res 1980, 614.

[91] Reiter, J., Michálek, J., Vondrák, J., Chmelíková, D., Přádný, M., Mička, Z. J. Power Sources 2006, 158, 509.

[92] Konkolewicz, D., Magenau, A. J. D., Averick, S. E., Simakova, A., He, H., Matyjaszewski, K. Macromolecules 2012, 45, 4461.

[93] Cheng, Z., Zhu, X., Fu, G. D., Kang, E. T., Neoh, K. G. Macromolecules 2005, 38,7187 .

[94] Olaj, O. F., Bitai, I., Hinkelmann, F. Makromol. Chemie 1987, 288, 1689.

[95] Olaj, O. F., Bitai, I. Die Angew. Makromol. Chemie 1987, 155, 177.

[96] Buback, M., Gilbert, R. G., Driscolie, K. F. O., Russello, G. T., Schweerg, J. 2006, 3280, 3267.

[97] Beuermann, S., Buback, M., Davis, T. P., Gilbert, R. G., Hutchinson, R. A., 
Kajiwara, A., Klumperman, B., Russell, G. T. Macromol. Chem. Phys. 2000, $201,1355$.

[98] Gilbert, R. G., Hutchinson, R. A. Macromol. Chem. Phys. 2003, 204, 1338.

[99] Buback, M., Kurz, C. Macromol. Chem. Phys. 1998, 199, 2301.

[100] Beuermann, S., Buback, M., Davis, T. I., Gilbert, R. G., Hutchinson, R. A., Olaj, F. O., Russell, G. T., Schweer, J., van Herk, A. M. Macromol. Chem. Phys. 1997, 1545.

[101] Buback, M., Kurz, C. H., Schmaltz, C. Macromol. Chem. Phys. 1998, 199, 1721.

[102] Wang, Y., Schroeder, H., Morick, J., Buback, M., Matyjaszewski, K. 604.

[103] Thickett, S. C., Gilbert, R. G. Polymer (Guildf). 2004, 45, 6993.

[104] LacI, I., Beuermann, S., Buback, M. Macromolecules 2003, 36, 9355.

[105] Beuermann, S., Buback, M., Lacík, I. Macromolecules 2001, 34, 6224.

[106] Beuermann, S., Buback, M., Hesse, P., Kukučková, S., Lacık, I. Macromol. Symp. 2007, 248, 23.

[107] Stach, M., Lacık, I., Kasak, P., Chorvat, D., Saunders, A. J., Santanakrishnan, S., Hutchinson, R. A. Macromol. Chem. Phys. 2010, 580.

[108] Robinson, K., Khan, M. Macromolecules 2001, 34, 3155.

[109] Siegmann, R., Jelicic, A., Beuermann, S. Macromol. Chem. Phys. 2010, 211, 546.

[110] Miao, J., He, W., Zhang, L., Wang, Y., Cheng, Z., Zhu, X. J. Polym. Sci. Part A Polym. Chem. 2012, 50, 2194.

[111] Oh, J., Min, K., Matyjaszewski, K. Macromolecules 2006, 39, 3161.

[112] Beuermann, S., Paquet, D. A., McMinn, J. H., Hutchinson, R. A. Macromolecules 1996, 29, 4206.

[113] Drawe, P., Buback, M. Macromol. Theory Simulations 2015.

[114] Beuermann, S., Buback, M., Hesse, P., Lacík, I. Macromolecules 2006, 39, 184.

[115] Buback, M., Mähling, F.-O. J. Supercrit. Fluids 1995, 8, 119.

[116] van Herk, A. M. J. Chem. Educ. 1995, 72, 138.

[117] Buback, M., Müller, E., Russell, G. T. J. Phys. Chem. A 2006, 110, 3222. 
[118] Barth, J., Buback, M. Macromol. Rapid Commun. 2009, 30, 1805.

[119] Barth, J., Buback, M., Hesse, P., Sergeeva, T. Macromolecules 2009, 42, 481.

[120] Kamachi, M. J. Polym. Sci. Part A Polym. Chem. 2002, 40, 269.

[121] Barth, J., Siegmann, R., Beuermann, S., Russell, G. T., Buback, M. Macromol. Chem. Phys. 2012, 213, 19.

[122] Barth, J., Buback, M. Macromolecules 2011, 44, 1292.

[123] Friedman, B., Shaughnessy, B. O. Macromolecules 1993, 26, 5726.

[124] Fröhlich, M. G., Vana, P., Zifferer, G. Macromol. Theory Simulations 2007, 16,610 .

[125] Fröhlich, M. G., Vana, P., Zifferer, G. J. Chem. Phys. 2011, 127, 164906.

[126] Sörensen, N. Kinetics and Mechanism of Cu-Catalyzed Atom Transfer Radical Polymerization, Georg-August University Goettingen, 2015.

[127] Barner-Kowollik, C., Russell, G. T. Prog. Polym. Sci. 2009, 34, 1211.

[128] Barth, J., Buback, M., Russell, G. T., Smolne, S. Macromol. Chem. Phys. 2011, 212, 1366.

[129] Kattner, H., Buback, M. Macromolecules 2015, 48, 309.

[130] Kattner, H., Buback, M. Macromolecules 2015, 48, 7410.

[131] Kattner, H., Buback, M. Macromol. Chem. Phys. 2014, 215, 1180.

[132] Nanda, A. K., Matyjaszewski, K. Macromolecules 2003, 36, 599.

[133] Wang, X.-S., Armes, S. P. Macromolecules 2000, 33, 6640.

[134] Zhang, Q., Wilson, P., Li, Z., McHale, R., Godfrey, J., Anastasaki, A., Waldron, C., Haddleton, D. M. J. Am. Chem. Soc. 2013, 135, 7355.

[135] Anastasaki, A., Haddleton, A. J., Zhang, Q., Simula, A., Droesbeke, M., Wilson, P., Haddleton, D. M. Macromol. Rapid Commun. 2014, 1.

[136] Fischer, H., Kothe, T., Marque, S., Martschke, R. J. Chem. Soc. Perkin Transcr. 2 1998, 1553.

[137] Perrier, S., Haddleton, D. Macromol. Symp. 2002, 272, 261.

[138] Wang, Y., Kwak, Y., Buback, J., Buback, M., Matyjaszewski, K. ACS Macro Lett. 2012, 1, 1367.

[139] Brown, H. C., Berneis, H. L. J. Am. Chem. Soc. 1953, 75, 10. 
[140] Matyjaszewski, K., Patten, T. E., Xia, J. J. Am. Chem. Soc. 1997, 119, 674.

[141] Enthaler, S., Junge, K., Beller, M. Angew. Chem. Int. Ed. Engl. 2008, 47, 3317.

[142] Ferro, R., Milione, S., Caruso, T., Grassi, A. J. Mol. Catal. A Chem. 2009, 307, 128.

[143] Schroeder, H., Matyjaszewski, K., Buback, M. Macromolecules 2015, 48, 4431.

[144] Bergenudd, H., Jonsson, M., Malmström, E. J. Mol. Catal. A Chem. 2011, 346, 20.

[145] Pizarro, G. C., Marambio, O. G., Jeria-orell, M., Flores, M. E., Rivas, B. L. J. Appl. Polym. Sci. 2010, 118, 3649.

[146] Wang, Y., Matyjaszewski, K. Macromolecules 2010, 43, 4003.

[147] Xue, Z., Noh, S. K., Lyoo, W. S. J. Polym. Sci. Part A Polym. Chem. 2008, 2922.

[148] Moineau, G., Dubois, P., Jerome, R., Senninger, T., Teyssie, P. Macromolecules 1998, 9297, 545.

[149] Hou, C., Qu, R., Ji, C., Wang, C., Wang, C. Polym. Int. 2006, 55, 326.

[150] Saikia, P. J., Hazarika, A. K., Shashi, D. B. Polym. Bull. 2013, 70, 1483.

[151] Teodorescu, M., Gaynor, S. G., Matyjaszewski, K. Macromolecules 2000, 33, 2335.

[152] Poli, R. Chem. Eur. J. 2015, 21, 6988.

[153] Pound, G., Eksteen, Z., Pfukwa, R., Mckenzie, J. M., Lange, R. F. M., Klumperman, B. 2008, 46, 6575.

[154] He, W., Cheng, L., Zhang, L., Liu, Z., Cheng, Z., Zhu, X. ACS Appl. Mater. Interfaces 2013, 5, 9663.

[155] Sigg, S. J., Seidi, F., Renggli, K., Silva, T. B., Kali, G., Bruns, N. Macromol. Rapid Commun. 2011, 32, 1710.

[156] Wade, R. S., Castro, C. E. J. Am. Chem. Soc. 1973, 226.

[157] Brault, D., Neta, P. J. Am. Chem. Soc. 1981, 103, 2705.

[158] Brault, D., Bizet, C., Morliere, P., Rougee, M., Land, E. J., Santus, R., Swallow, A. J. J. Am. Chem. Soc. 1980, 1015, 1015.

[159] Guilard, R., Boisselier-Cocolios, B., Tabard, A., Cocolios, P., Simonet, B., 
Kadish, K. M. Inorg. Chem. 1985, 24, 2509.

[160] Lexa, D., Savqant, J., Wang, D. L. Organ 1986, 5, 1428.

[161] The Handbook of Porphyrin Science; Kadish, K. M.; Smith, K. M.; Guilard, R., Eds.; World Scientific Publishing Co. Pte. Ltd, 2012.

[162] Donohoe, R. J., Atamian, M., Bocian, D. F. J. Am. Chem. Soc. 1987, 109, 5593.

[163] Chang, C. K., Sotiriou, C. J. Heterocycl. Chem. 1985, 22, 1739.

[164] Tabard, A., Cocolios, P., Lagrange, G., Gerardin, R., Hubsch, J., Lecomte, C., Zarembowitch, J., Guilard, R. Inorg. Chem. 1988, 27, 110.

[165] König, E., Ritter, G., Kanellakopulos, B. Inorganica Chim. Acta 1982, 59, 285.

[166] Moss, T. H., Bearden, A. J., Caughey, W. S. J. Chem. Phys. 1969, 51, 2624.

[167] Scheidt, R. W., Reed, C. A. Chem. Rev. 1981, 81, 543.

[168] Ali, E., Sanyal, B., Oppeneer, P. M. J. Phys. Chem. B 2012, 116, 5849.

[169] Buback, M., Schroeder, H., Kattner, H. Macromolecules 2016.

[170] Schroeder, H., Buback, M. Macromolecules 2014, 47, 6645.

[171] Wang, Y., Soerensen, N., Zhong, M., Schroeder, H., Buback, M., Matyjaszewski, K. Macromolecules 2013, 46, 683.

[172] Bottomley, L. A., Kadish, K. M. Inorg. Chem. 1981, 20, 1348.

[173] Nappa, M., Valentine, J. S. J. Am. Chem. Soc. 1978, 100, 5075.

[174] Constant, L. A., Davis, D. G. Anal. Chem. 1975, 47, 2253.

[175] Kadish, K. M., Morrison, M. M., Constant, L. A., Dickens, L., Davis, D. G. J. Am. Chem. Soc. 1975, 8387, 8387.

[176] Kadish, K. M., Bottomley, L. A. J. Am. Chem. Soc. 1977, 99, 2380.

[177] Koerner, R., Wright, J. L., Ding, X. D., Nesset, M. J. M., Aubrecht, K., Watson, R. a, Barber, R. A., Mink, L. M., Tipton, A. R., Norvell, C. J., Skidmore, K., Simonis, U., Walker, F. A. Inorg. Chem. 1998, 37, 733.

[178] Horn, M., Matyjaszewski, K. Macromolecules 2013, 46, 3350.

[179] Weast, R. C. CRC-Handbook of Chemistry and Physics; CRC-Press: Florida, USA.

[180] Bill, E. Mfit. Max-Planck Institute for Chemical Energy Conversion, 2008. 


\section{Danksagung}

Mein besonderer Dank gilt Herrn Prof. Dr. M. Buback für das interessante Thema und die herausfordernde Themenstellung dieser Arbeit. Seine Unterstützung und zahlreichen Diskussion waren für mich besonders wertvoll. Weiterhin möchte ich Prof. Dr. P. Vana für die Übernahme des Korreferats danken.

Außerdem bedanke ich mich bei Herrn Prof. Dr. Franc Meyer, Prof. Dr. Burkhard Geil, PD Dr. Thomas Zeuch, Dr. Florian Ehlers für die Teilnahme am Prüfungskomitee.

Ein herzlicher Dank gebührt Prof. Dr. Krzystof Matyjaszewski und Antonia Simakova für die thematische Kooperation und Bereitstellung der Eisenkatalysatoren.

Ebenso bedanke ich mich bei Stella Weber, die mit riesigem Fleiß alle PLP-SEC Messungen durchgeführt hat und dabei immer gut gelaunt und hoch motiviert war.

Ein herzlicher Dank geht auch an Prof. Dr. Franc Meyer für die Möglichkeit der Stopped-Flow Messungen in seinem Arbeitskreis. Außerdem danke ich Dr. Serhiy Demeshko für die Mössbauer Messungen und fachliche Beratung und Diskussion.

Herrn Hans-Peter Vögele danke ich für zahlreiche lustige Anekdoten und den vielen Hilfestellungen in Bezug zur Hochdruckpolymerisation und FT-NIR Spektroskopie.

Besonderer Dank gilt Hendrik Schröder, Patrick Drawe, Hendrik Kattner, Dennis Hübner und Alexander Groschopp für die Korrektur und hilfreichen Anmerkungen für diese Dissertation sowie die Diskussionsbereitschaft während der ganzen Promotion. Außerdem bedanke ich mich bei meinen ehemaligen und aktuellen Bürokollegen 
Nicolai Sörensen, Jens Schrooten, Arne Wolpers, Nils Wittenberg, Sonja Schmidt und Martin Kassel für die zahlreichen Diskussion um die Promotion und um die Dinge des Alltags.

Außerdem möchte ich mich beim ganzen Arbeitskreis für die freundliche und lockere Atmosphäre, in der ich mich sehr wohl gefühlt habe, bedanken.

Ein ganz besonderer Dank gebührt meiner Mutter, die mich immer unterstützt hat und mir in ganz besonders schweren Zeiten geholfen und beigestanden hat. Genauso möchte ich auch meinem Vater danken, der diesen Moment leider nicht mehr miterleben kann. Er hat immer daran geglaubt, dass ich alles erreichen kann, was ich mir vornehme und er hat mir beigebracht nie aufzugeben. Ebenso bin ich meinen lieben Großeltern dankbar für die kleinen und großen Hilfen während des ganzen Studiums.

Einen ganz besonderer Dank gilt meiner Freundin Anne, die mich gerade in der kritischen Phase besonders unterstützt und mir immer wieder unerschütterlich Mut zugesprochen hat. Bei unserem kleinen Krümmelchen bedanke ich mich, dass es mir gerade am Ende der Promotion noch einmal einen riesigen Motivationsschub gegeben hat. 


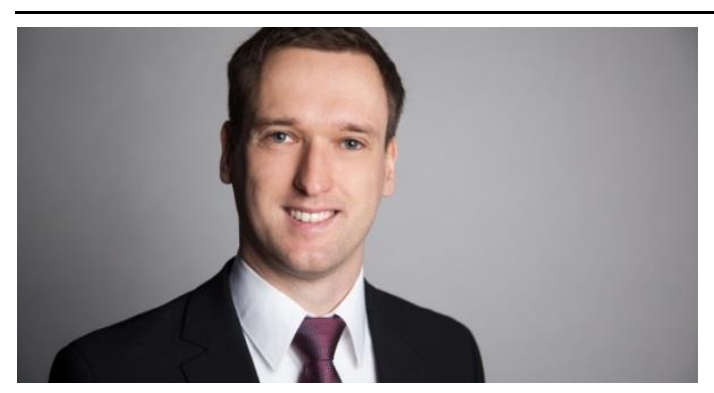

\section{About the Author}

Sebastian Smolne, ${ }^{*}$ November 1, 1986 in Ludwigslust, Germany

\section{Curriculum Vitae}

$12 / 2012-05 / 2016$

$10 / 2010-10 / 2012$

$10 / 2007-10 / 2012$

08/ $1999-07 / 2006$
Promotion an der Universität Göttingen bei Prof. Michael Buback

Titel: $\mathrm{Cu}$ - and Fe-mediated Atomtransfer Radical Polymerization in Aqueous Solution

Masterstudium Chemie an der Universität Göttingen

Bachelorstudium Chemie an der Universität Göttingen

Abitur am Bernhard-RiemannGymnasium Scharnebeck

\section{Publikationen}

2015

Smolne S., Buback M., Kinetic Investigations of Cu-Mediated ATRP in Aqueous Solution, Macromolecular Chemistry and Physics, 2015. 